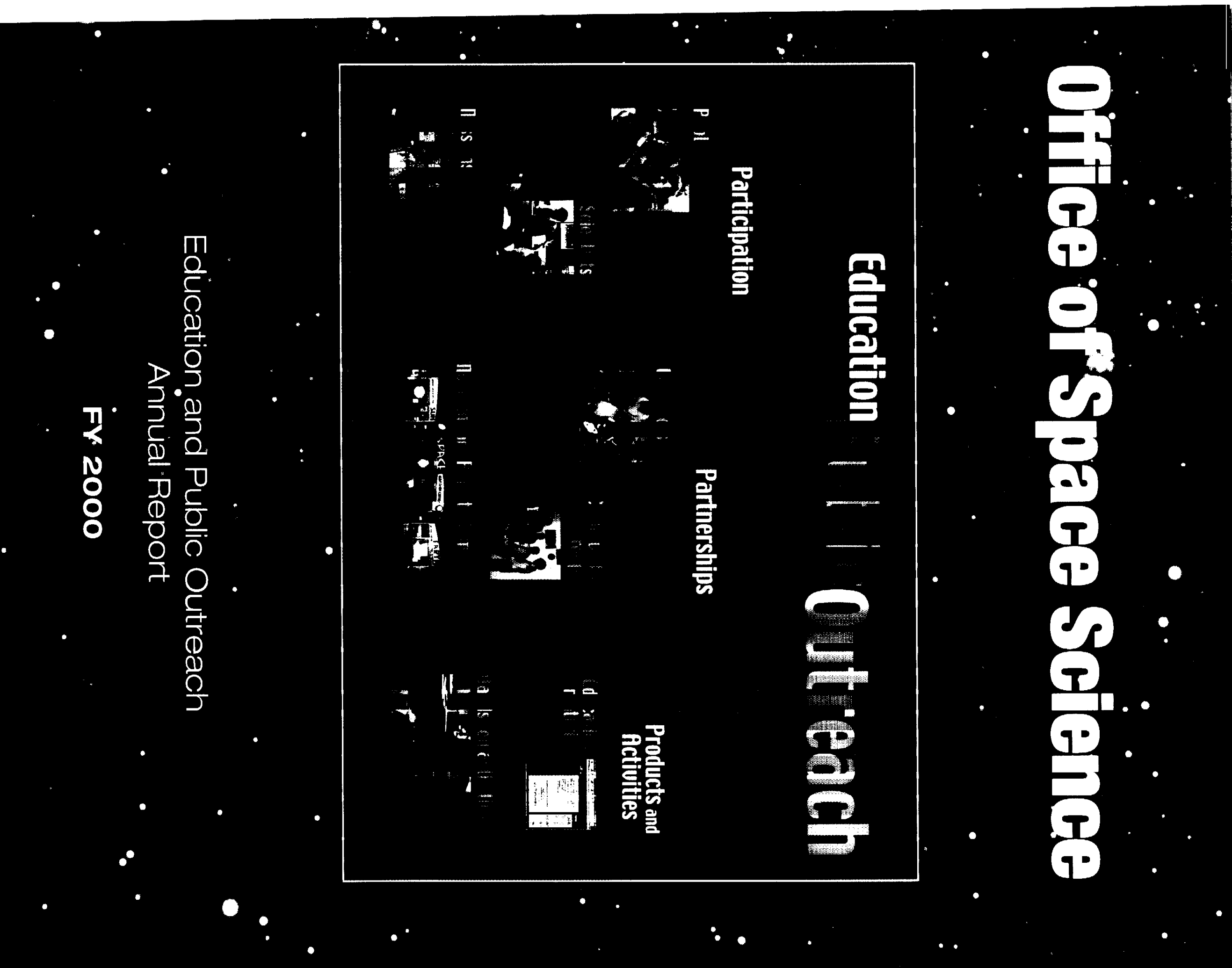


Cover illustration courtesy of the Space Telescope Science Institute. 
“The most important result of NASA's Space SCIENCE PROGRAM IS THE SENSE OF WONDER AND IMAGINATION IT INSPIRES IN AMERICA's YOUTH."

\author{
EDWARD J. WeILER, \\ NASA Associate Administrator for Space Science
}





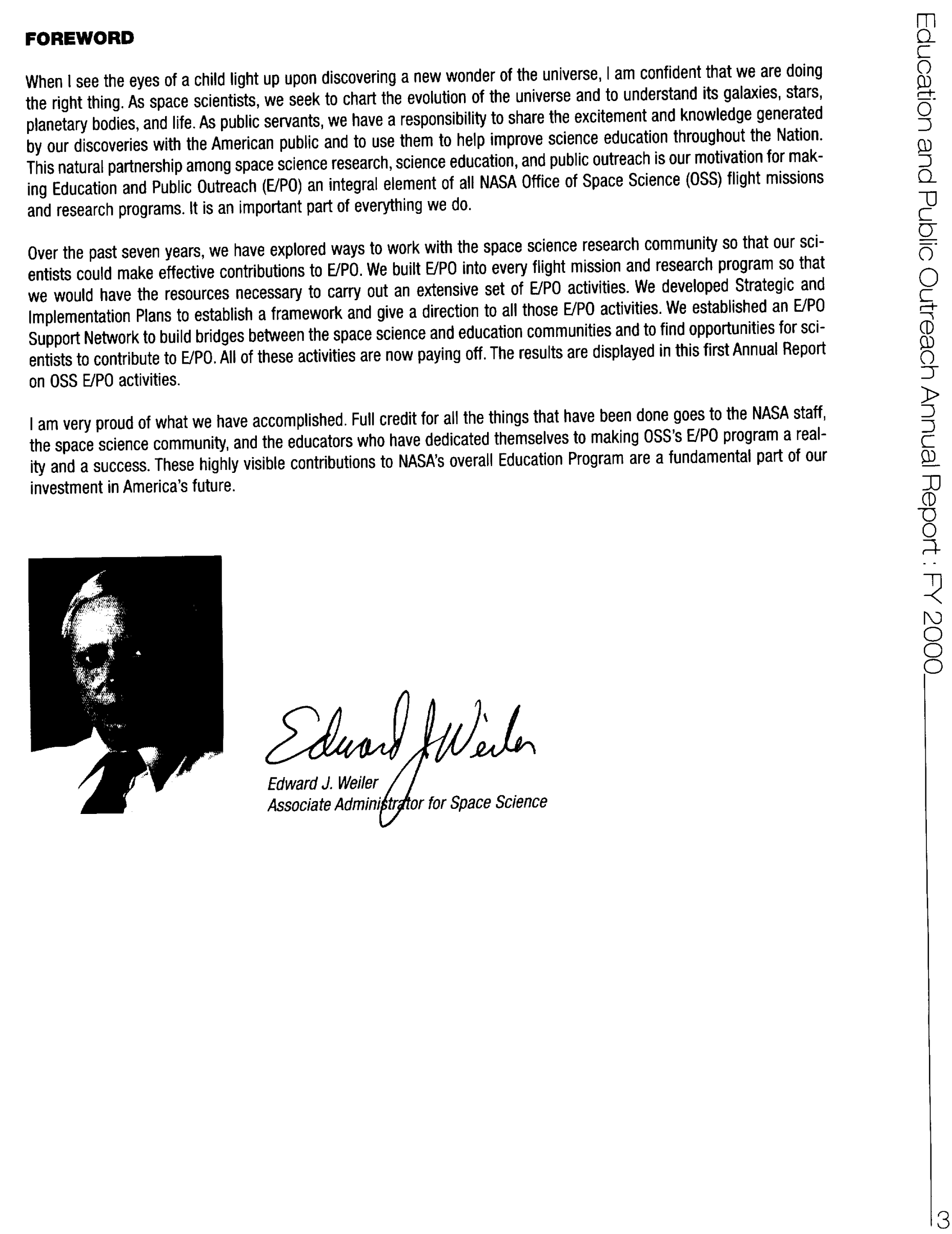



“The EDUCATION MisSion of OSS IS to ENGAGE ITS COMMUNITY OF RESEARCH SCIENTISTS, MANAGERS, ENGINEERS, AND SUPPORT STAFF ACROSS THE COUNTRY IN EDUCATION AND PUBLIC OUTREACH ACTIVITIES." 

This first Annual Report on NASA Space Science Education and Public Outreach (E/PO) activities is a major milestone in a quest that began seven years ago to create a major E/PO Program within the NASA Space Science Enterprise.

OSS has always had a strong commitment to education, although the focus of this effort has traditionally been on graduate and post-graduate training. Seven years ago, for a variety of reasons, we extended this commitment to pre-college education and to contributing to the broad public understanding of science, mathematics, and technology. When we set off on this new course, there were a small number of individual, isolated efforts underway within OSS, largely focused on individual space scientists going into classrooms and affecting very small numbers of teachers and students. Today, a significant national program is underway, with hundreds of activities now in place involving partnerships with dozens of educational organizations across the country and collectively reaching millions of people. It has taken much hard work by a large number of dedicated individuals in both the space science and education communities to get from there to here. The change has been truly remarkable.

In a very real sense, this first Annual Report signifies the coming of age of the OSS E/PO Program. It summarizes nearly 400 educational products and activities that took place in Federal Fiscal Year 2000 as a result of the OSS E/PO program. We have undoubtedly omitted many other excellent products and activities that were not reported to us. We hope to obtain a more comprehensive picture in the future. These products and activities are the outcome of the hard work and dedication of the study teams that developed the OSS E/PO Strategic and Implementation Plans, the space scientists involved in planning and carrying out the E/PO components of OSS missions and research programs, the OSS E/PO Support Network members who have given selflessly to assisting others in developing high quality E/PO projects, the educators who have worked so enthusiastically with the space science community, and the NASA managers who continue to place a high priority on E/PO activities. It sets a standard and a baseline against which to measure the even greater achievements expected from the OSS E/PO program in future years.
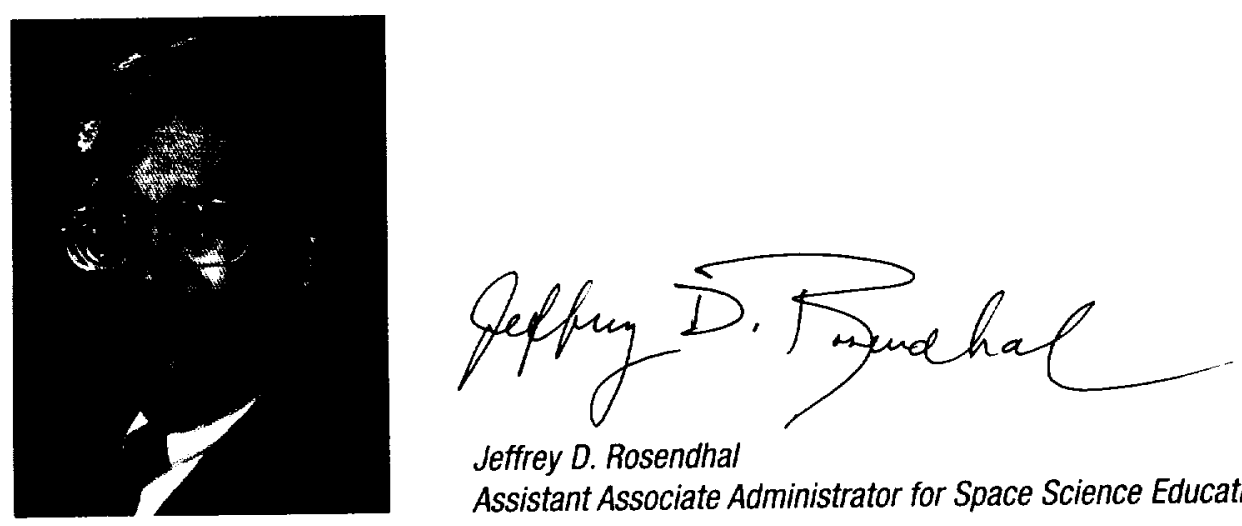

Jeffrey D. Rosendhal

Assistant Associate Administrator for Space Science Education and Public Outreach 



\section{EXECUTIYE SUMMARY}

This Annual Report is a summary of nearly 400 Education and Public Outreach (E/P0) products and activities developed or carried out in FY2000 under NASA's Office of Space Science (OSS) E/PO program. It includes products and activities developed by OSS missions and research programs, innovative space science concepts developed under the Initiative to Develop Education through Astronomy and Space Science (IDEAS) Program, projects initiated under the Minority University Education and Research Partnership Initiative in Space Science, and a number of additional comprehensive or special purpose programs managed by OSS at NASA Headquarters. Taking into account the fact that many of the activities reported involve multiple events that took place in a variety of venues, the total number of E/PO events reported for FY2000 is over 1,500 , with events having taken place in all 50 States, the District of Columbia, one U.S. Territory (Guam), and four foreign nations (Australia, Canada, Mexico, and Peru).

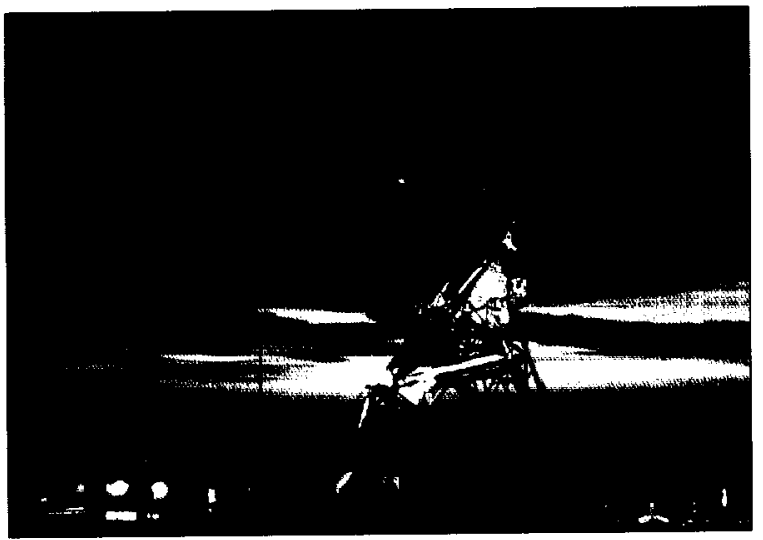

The Goldstone Apple Valley Radio Telescope (GAVRT) is being used by middle and high school students in 13 states to monitor radio-wave emissions from Jupiter's atmosphere and radiation belts as an aid in interpreting measurements to be made by the Cassini spacecraft.

Public recognition of OSS E/PO activities in FY2000 was substantial, with over 20 awards or other forms of public recognition for educational excellence received. Web sites such as the Chandra X-ray Observatory's Gateway to the Universe of X-Ray Astronomy!, the Sun-Earth Connection Forum's Solar Max 2000, the ACE mission's Cosmic and Heliospheric Learning Center, the University of California at Berkeley's Science Education Gateway (SEGway), and the SIRTF Multi-Wavelength Messier Gallery received 17 such awards. The IMAGE mission's Blackout! video earned two Crystal Awards of Excellence for Video, and the Hubble Space Telescope Heritage Photo Gallery was awarded the Sixteenth Annual Infinity Award for Applied Photography by the International Center of Photography (ICP). Individuals who were recognized for specific contributions to education included Marilyn Lindstrom of NASA Johnson Space
Center, who was awarded the NASA Exceptional Service Medal for her K-12 education efforts in Astromaterials and Solar System Exploration, and Dr. Sten Odenwald, an employee of Raytheon ITS at NASA Goddard Space Flight Center, who received the American Astronomical Society Solar Physics Division's annual award for Popular Writing.

In FY2000, OSS provided materials, technical expertise, and other resources for use in exhibits, planetarium shows, bulletin boards, and education projects at 110 science centers, museums, and planetariums in 39 States, the District of Columbia, and Guam. Among the more visible outcomes from these contributions were three major museum exhibitions featuring OSS missions that began national tours. The Space Weather Center exhibit was displayed at the Denver Museum of Nature and Science, the Discovery Center in Red Bluff, California, and the Maryland Science Center in Baltimore. MarsQuest premiered at the McWane Center in Birmingham, Alabama, and the Hubble Space Telescope: New Views of the Universe exhibit premiered at Chicago's Adler Planetarium and Science Museum before moving on to Space Center Houston in Texas. A smaller version of the Hubble exhibit began its tour in Saginaw, Michigan. The development of major new programs and the creation of new exhibit galleries and planetariums were initiated under OSS sponsorship at science centers across the country, including Chicago's Adler Planetarium and Astronomy Museum; the Ft. Lauderdale Museum of Discovery and Science; Discovery Place in Charlotte, South Carolina; and the Museum of Coastal Carolina (MOCC) in Ocean isle Beach, North Carolina. The New Millennium Program's Space Place provided outreach activities to over a hundred museums, planetariums, and libraries in rural areas of the country, drawing in audiences traditionally not reached by NASA.

Providing opportunities for true and meaningful participation in space science activities by individuals from groups that are currently underserved and underutilized in science and technology is a critical concern for OSS. The Minority University Education and Research Partnership Initiative in Space Science Program, initiated in partnership with the Office of Equal Opportunity Programs, brought 15 minority institutions, including 6 Historically Black Colleges and Universities (HBCU's), 3 HispanicServing Institutions (HSI's), and 3 Tribal Colleges and Universities (TCU's), into new projects aimed at developing space science academic and/or research programs on their campuses. These projects include such aspects as active participation of minority institution students in NASA space science missions, integration of space science materials into undergraduate courses and pre-college outreach programs, development of new space science courses and degree programs, and establishment of new space science faculty positions. 


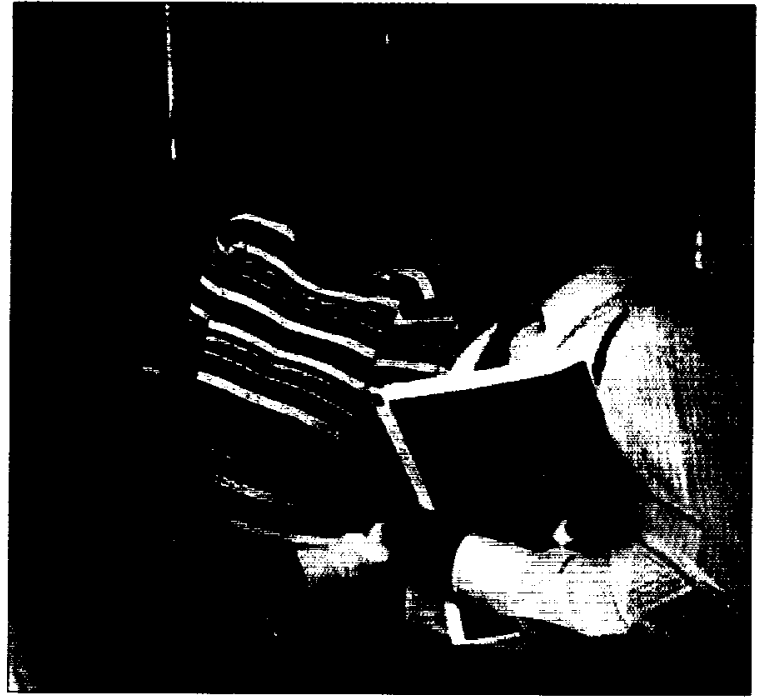

A teacher with Spanish-speaking students gets tips on using solar storms to meet State learning goals at the DePaul Space Science for lllinois Teachers summer workshop.

Over 120 educational products developed by the OSS E/PO program are summarized in this report. The majority of these products are targeted at the middle and high school levels, where Earth and Space Science have the largest impact in the curricula. Taking into account the fact that most of the products are accessible to a range of audiences and grade levels, approximately a quarter of the products can be used for elementary school education, and approximately a third of the products can be used in higher education, including community colleges and adult/continuing education programs. Over two-thirds of the products are also useful to the general public. Ready access to many of these resources is provided by the new Web-based NASA Space Science Education Resource Directory at http://teachspacescience.stsci.edu. We believe that the development of this Directory has provided a major service to both the space science and education communities.

The Report also summarizes nearly 200 0SS-sponsored programs that involved direct interactions of the OSS community with teachers, students, and the public. Nearly two-thirds of these programs supported classroom education through some 75 programs for teachers conducted at over 130 different venues, over 40 programs for students conducted at more than 450 venues, and a number of efforts directed at systemic reform. The remaining third of these programs were aimed at improving the public understanding of space science or at encouraging greater participation of the science community in E/PO activities.

An important key to carrying out such a vast portfolio of E/PO activities was establishing E/PO partnerships with over 200 institutions and organizations outside of NASA. In addition, OSS had substantial presence at some 50 conferences for educators or scientists, with exhibits, workshops, materials, and knowledgeable staff available to discuss space science E/PO issues with conference attendees.

During the next several years, attention will be turned to improving the systems that have already been created and completing a number of major activities now underway. Voyage, an accurate, one ten-billionth scale model solar system will be placed on the National Mall in Washington, DC, in fall 2001. Cosmic Horizons: Our Place in Space and Time, a 5,000-square-foot traveling exhibition about our scientific understanding of the structure and evolution of the universe, is scheduled to open in 2002 at Boston's Museum of Science. Two new Passport to Knowledge programs, Live From a Black Hole and Live From the Edge of Space and Time, will be developed and produced, and the total solar eclipse on June 21, 2001 will be Webcast live to visitors at science centers around the Nation and to people using their home computers.

The Resource Directory will be continually expanded with new products and with the incorporation of new capabilities, including the capability for users to provide reviews of the resources being offered. More effective mechanisms for delivering space science discoveries and results to science centers and planetariums will be devised and piloted. Ever greater emphasis will be placed on working at the State and regional levels, on improving the participation of underserved and underutilized groups in space science activities, and on finding new ways for the space science community to participate in E/PO.

This report represents a snapshot of the accomplishments of the past year. Many OSS missions and research programs are just beginning their education and public outreach programs. This is just a preview of the even larger numbers of activities that will happen in the years to come. 


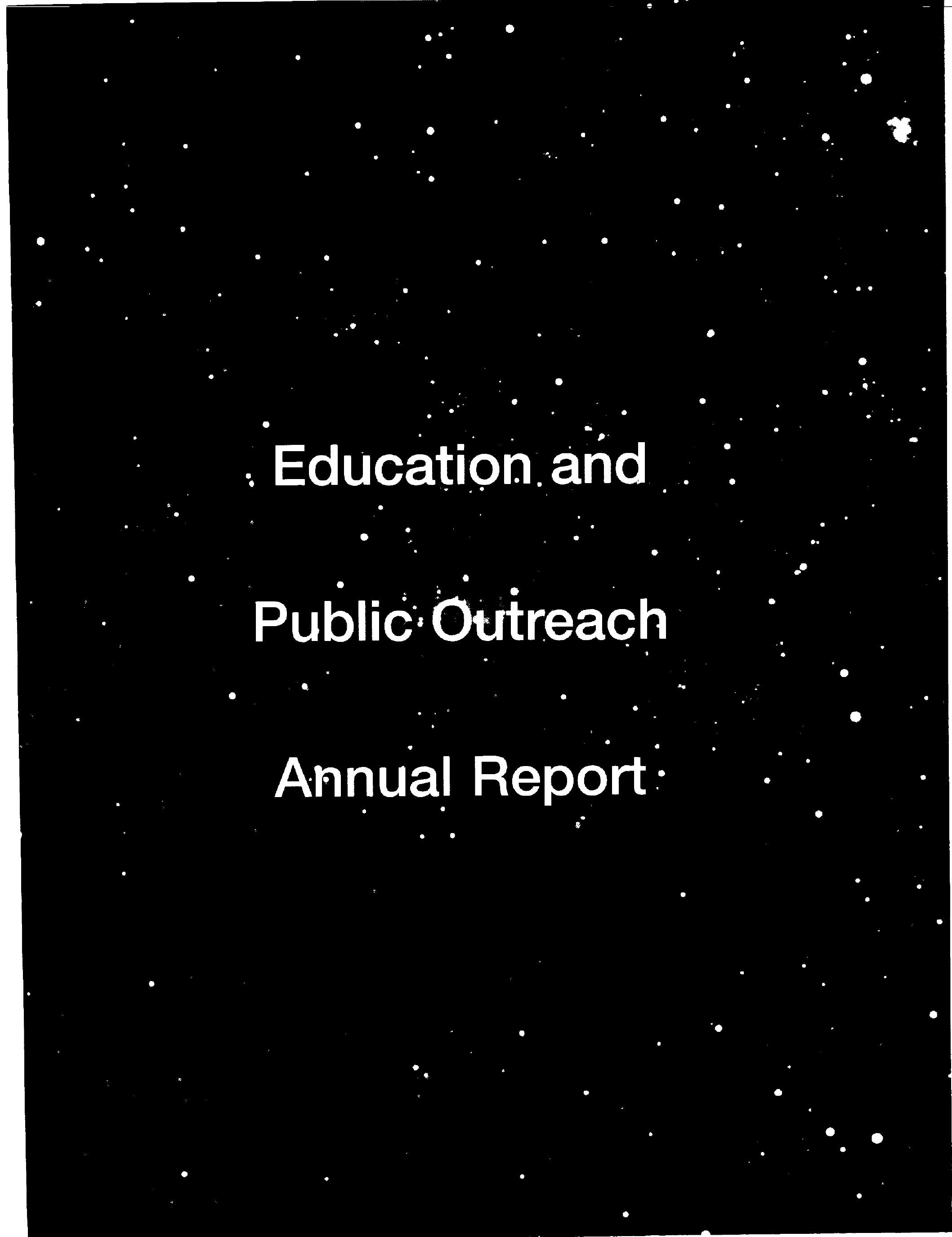



"It will be the total effect of a broad ensemble of high-leverage activities carried out over a long period of time which can make a difference."

The OSS EIPO Implementation Plan

\section{INTRODUCTION}

This Annual Report is a summary of the hundreds of Education and Public Outreach (E/P0) programs carried out in Federal Fiscal Year (FY 2000 under the sponsorship of NASA's Office of Space Science (0SS). Examples of the activities covered include award-winning educational Web sites, major exhibitions in museums and science centers, partnerships with minority universities, an online directory of space science educational resources, research projects that allow students and teachers to participate in NASA space science missions, live Webcasts of total solar eclipses, and public television broadcasts on major space science research areas.

In total, nearly $400 \mathrm{E} / \mathrm{PO}$ products and activities are summarized in this report. Appendix A provides a full description of each product or activity. Included are:

I over 120 educational products, the majority of which were targeted at middle and high school education;

I nearly 200 educational programs and events, targeted at supporting classroom education, improving the public understanding of space science, or encouraging greater participation of the science community in E/PO activities; and

I a variety of projects providing support to science centers and planetariums, emphasizing targeted outreach, or addressing special needs.
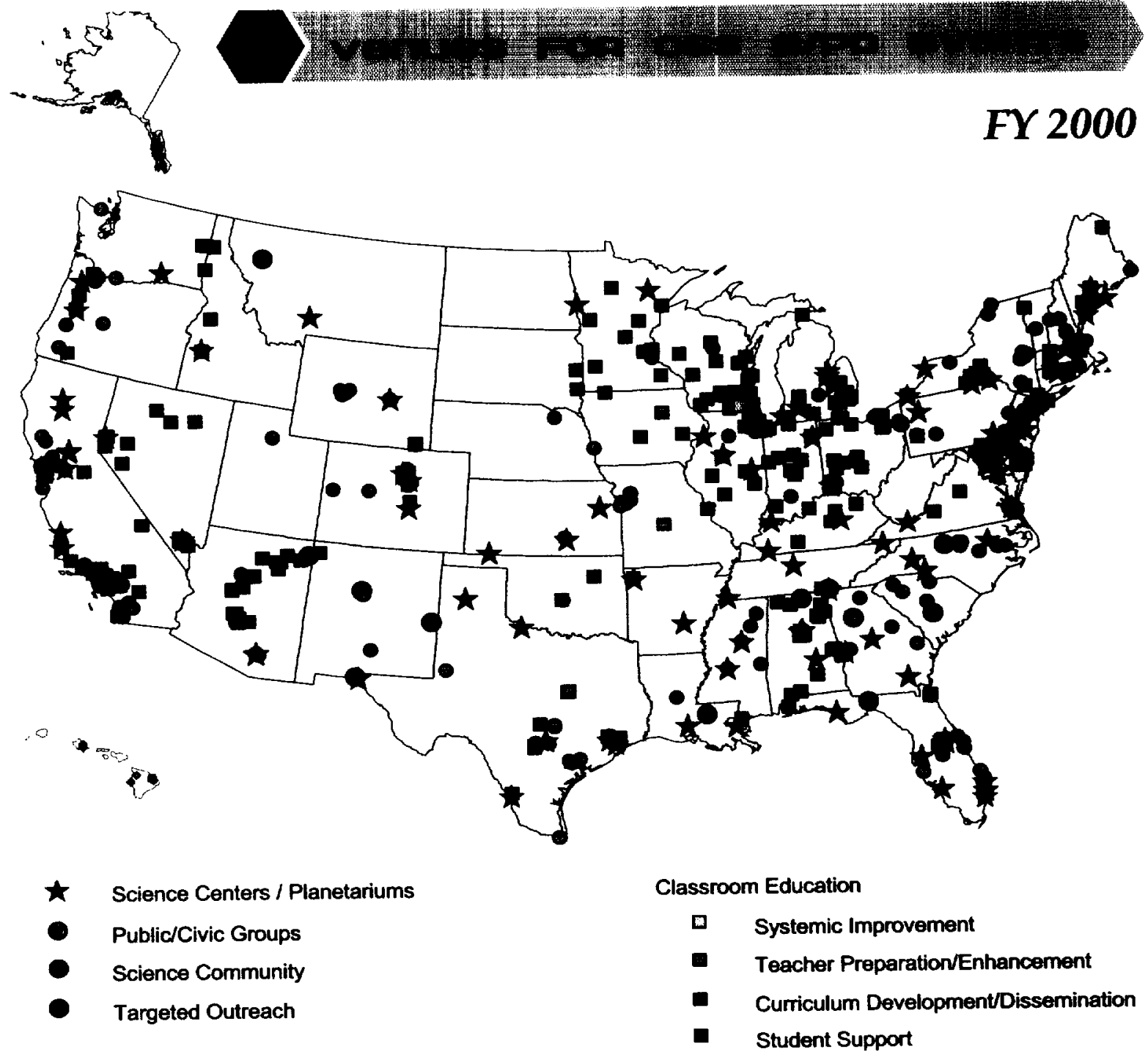

The venues, at which over 1,500 E/PO events took place under OSS sponsorship in FY 2000 , encompassed all 50 states, the District of Columbia, and one U.S. Territory. 
The vast majority of these products and activities were developed using resources built into OSS missions and research programs. Every OSS mission and research program is expected to devote a portion of its resources to E/PO activities, and to embed those E/PO activities into its overall program. This approach has created a highly diversified portfolio of E/PO activities being carried out in conjunction with science and mission development activities in locations across the country. Adding to this portfolio are innovative space science E/PO programs developed under the Initiative to Develop Education through Astronomy and Space Science (IDEAS) Program, projects initiated under the Minority University Education and Research Partnership Initiative in Space Science, and a number of additional special programs managed by OSS at NASA Headquarters. Appendix B provides a roster of E/PO points of contact for each of these missions and programs.

Many of the activities reported involved multiple events that took place in a variety of venues. Taking this into account, the total number of E/PO events reported for $F Y$ 2000 is over 1,500 , with events having taken place in all 50 States, the District of Columbia, one U.S. Territory (Guam), and four foreign nations (Australia, Canada, Mexico, and Peru).

The OSS E/PO Program is one component of NASA's overall education strategy. It contributes to meeting the mandates of the NASA Strategic Plan to "involve the education community in our endeavors to inspire America's students, create learning opportunities, enlighten inquisitive minds," and to "communicate widely the content, relevancy, and excitement of NASA's missions and discoveries to inspire and to increase understanding and the broad application of science and technology." It is based upon the unique science performed by OSS-the results from its missions and research programs-and the unique capabilities of the space science community.

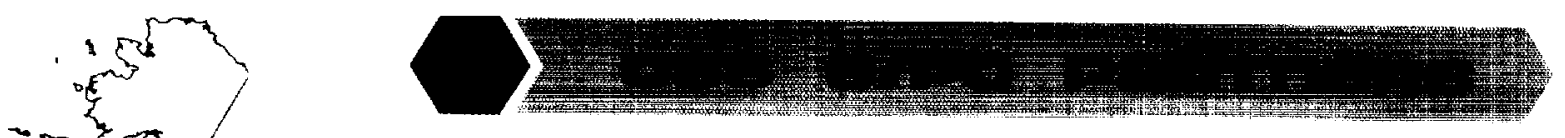

FY 2000

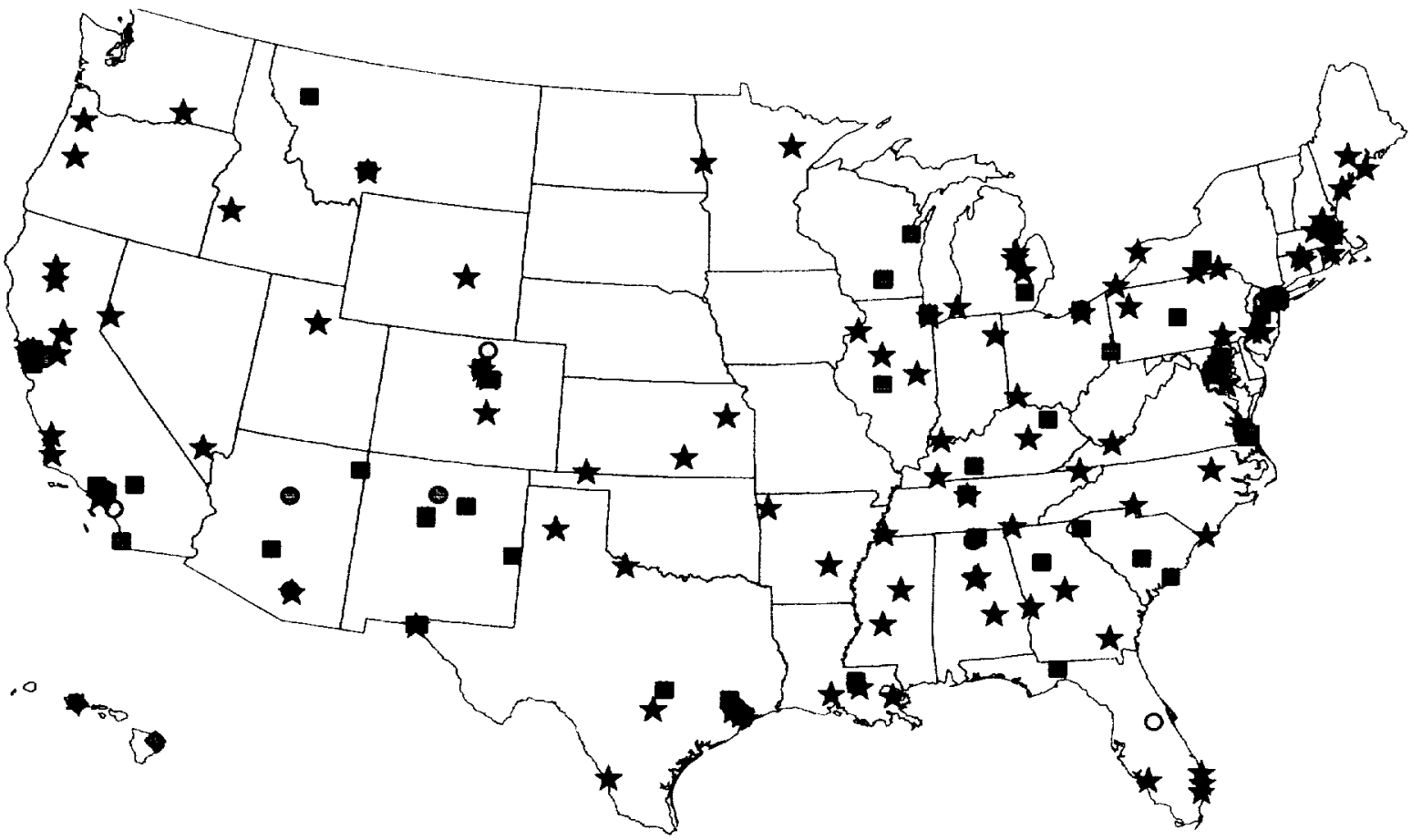

\ Science Centers, Museums, and Planetariums

O Science Organizations: NASA-Affiliated

- Science Organizations: Non-NASA

- Commericel, Non-Profit, and Mass Media Orgs
Educational Institutions and Organizations: K-12

- Educational Institutions and Organizations: Higher Ed

- Orgs Promoting Minority Participation in Science

Over 200 institutions and organizations partnered with OSS to carry out E/PO activities in FY 2000. 
OSS has made a major commitment to actively engage its community of space scientists in NASA's education efforts. In their daily work, space scientists strive toward answering fundamental questions about the nature of our universe: How did the universe begin and evolve? Where did we come from? Where are we going? Are we alone? These are questions that inspire the imagination. As discoveries leading toward answers are made, the OSS science community is committed to sharing them with the educational community and with the public. By sharing with teachers and students the excitement of new discoveries and the stories of how those discoveries were made, OSS hopes to enhance the quality of science, mathematics, and technology education across the Nation. By bringing to the public the knowledge gained from new discoveries, OSS hopes to increase the public's understanding of science and technology. By exposing students across America to the excitement of space science early and often, OSS hopes to contribute to creating a 21st century scientific and technical workforce that will continue America's leadership in science and technology.

The OSS approach is based on building partnerships with the education community and other organizations engaged in education to create activities that meet the needs of educators and that use multiplier effects to reach as large an audience as possible. In FY 2000, over 200 such partnerships contributed to producing OSS-sponsored E/PO activities. A full list of these partners appears as Appendix C. Included among them are 110 science centers, museums, and planetariums; 31 organizations and institutions dedicated to $\mathrm{K}-12$ education; 50 institutions of higher education, including 23 minority institutions; 14 research laboratories or observatories; 7 minority-serving organizations; and 11 commercial, non-profit, or mass media organizations. The types of high-leverage activities emphasized include becoming involved in systemic initiatives, working with universities on teacher training, arranging for widespread distribution of curriculum materials and other products, and working with public institutions such as science museums and planetariums that attract large audiences.

Conferences provide an effective means of contact with organizations and individuals engaged in space science E/PO activities. In FY 2000, OSS had substantial presence at approximately 50 such conferences with exhibits, workshops, materials, and knowledgeable staff available to discuss space science E/PO issues with conference attendees. These conferences included nearly 30 national or regional conferences of educators, four conferences of organizations promoting minority participation in science, and a dozen science conferences at which OSS encouraged scientists to more actively participate in E/PO activities. A list of these conferences appears as Appendix D.

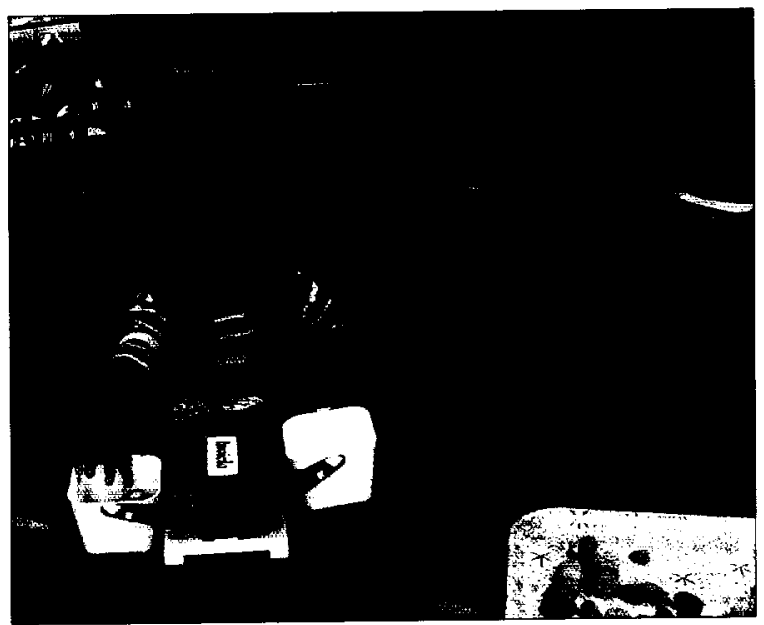

Kindergarten students in Cincinnati experiment with making impact craters, thanks to OAl Broker/Facilitator Workshops that introduced their teachers to hands-on activities found in NASA classroom activity guides.

OSS has established an E/PO Support Network to help coordinate and integrate all of the E/PO projects now underway, to build effective bridges between the science and education communities, and to help identify effective opportunities for scientists to participate in E/PO. The major elements of this network are the Education Forums and the Broker/Facilitators. The Forums are charged with coordinating the E/PO efforts of space science missions and helping to make their discoveries and results readily available to the education community. The Broker/ Facilitators are charged with encouraging the involvement of space scientists in education through creating partnerships with educators to carry out high-leverage E/PO activities. Each Forum is responsible for supporting missions within one of the four OSS research themes: the Astronomical Search for Origins and Planetary Systems (ASO), Solar System Exploration (SSE), Structure and Evolution of the Universe (SEU), and the Sun-Earth Connection (SEC). Each Broker/Facilitator is responsible for serving space scientists and educators within a specific geographical region.

In this report, the work of Support Network members in carrying out E/PO projects is specifically mentioned only for those projects in which they played a visible, leadership role. For the many other projects in which they played the background role of catalyzing, coordinating, and facilitating the E/PO activities of others-as well as coordinating the reporting of those activities for this report-the work of Support Network members is not explicitly mentioned, but is implicitly assumed and greatly appreciated.

Because the OSS E/PO Program emphasizes high leverage activities and extensive partnerships undertaken in a decentralized way, any attempt to compile information on all of the OSS E/PO activities is bound to be incomplete. The information contained here was compiled from data 


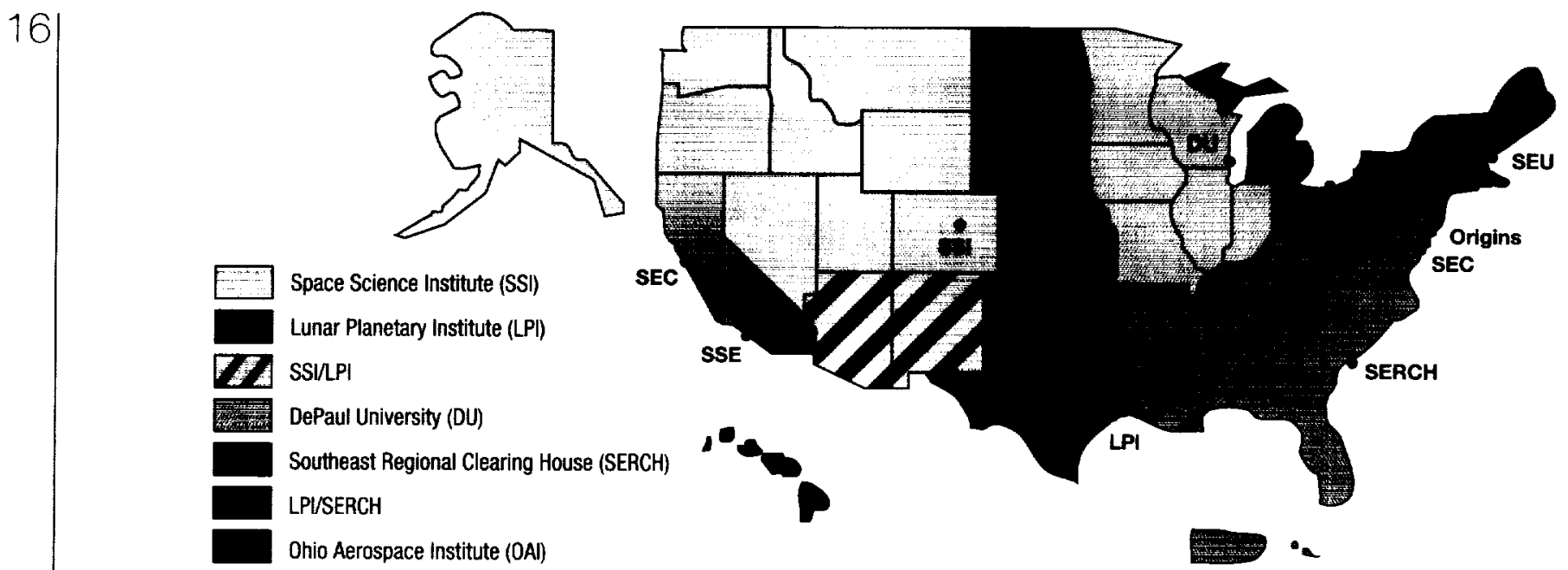

The OSS E/PO Support Network consists of Forums that coordinate the E/PO activities of space science missions and Broker/Facilitators that develop partnerships between scientists and educators. Colors indicate regions served by each Broker/Facilitator.

entered into the OSS E/PO Tracking and Reporting System by the individuals carrying out each E/PO activity. This Annual Report should therefore be regarded as a representative-rather than comprehensive-compilation of OSS E/PO activities. The statistical information reported should be regarded as minimum-rather than actualvalues for the quantities reported. It is expected that future reports will present a more comprehensive picture.

The sections of this report that follow begin by providing information on the types of public recognition that the OSS E/PO Program is now starting to receive. They then go on to give statistical summaries and to describe examples of activities taken from each of the following categories:
I Science Center Shows/Exhibits. Planetarium shows and museum or science center exhibits and events.

I Targeted Outreach. Projects that provide substantial targeted outreach to underserved/underutilized groups.

- Educational Products. Products designed for use in classrooms, for enhancing the public understanding of science, and/or for special interest groups.

I Educational Programs/Events. Programs/events primarily intended to enhance formal classroom education or the public understanding of science.

The examples cited represent just a few highlights from the rich portfolio of activities laid out in full in the appendices. The main body of the report concludes with a brief look at future plans for the OSS E/PO Program. Appendices and indices then provide comprehensive details on all OSS $E / P 0$ products and activities that were reported for $F Y$ 2000. 


\section{AWARD-WINNING PROJECTS}

Public recognition of OSS E/PO activities in FY 2000 has been substantial, with over 20 awards or other forms of public recognition for educational excellence received. Web sites providing information on NASA space science missions and educational resources based on that information received 17 such awards; videos and photo galleries received three awards; and one award was received for excellence in popular science writing.

Leading the list of award-winning Web sites was the Chandra X-ray Observatory's Gateway to the Universe of $X$-Ray Astronomy! site, http://www.chandra.harvard.edu/, which won the San Francisco Exploratorium's Ten Cool Sites Award, the Britannica.com "The Best Web Sites" Award, and the Griffith Observatory's Star Award. The Chandra Web site was also recognized as a Net-Mom Approved Site, an Internet Brothers Presents Elite Site, and a USA Today Hot Site.

The Solar Max 2000 Web site, http://sunearth.gsfc. nasa.gov/max/index.html, developed by the Sun-Earth Connection Forum, was awarded a cyber teddy and was highlighted in USA Today's technology section as a Hot Site. It was included in Science magazine on the NetWatch page under HotPicks, and it was highlighted as a Space Site of the Week by Space Careers. Solar Max 2000 is listed in the Yahoo! News Section under Space Weather and was cited in the online journals, Current Web Contents and Copernicus Interactive.

Other award-winning Web sites included the ACE-sponsored Cosmic and Heliospheric Learning Center, $h$ ttp://helios.gsfc.nasa.gov, which was named as one of the Eisenhower National Clearinghouse's Digital Dozen Web sites; the University of California at Berkeley's Science Education Gateway (SEGway) site http:// cse.ssl.berkeley.edu/segway/, which was highly rated by Schoolzone's panel of 400 expert teachers in the United Kingdom; and the SIRTF Multi-Wavelength Messier Gallery Web site, which won the Griffith Observatory Star Award for excellence in science education on the Internet, was recognized by Science magazine as one of their HotPicks, and received Schoolzone's Five-Star Award.

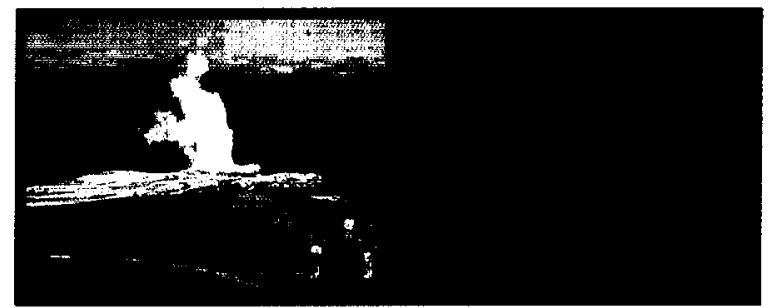

Visible and infrared light views of Old Faithful help introduce SIRTF Web site visitors to the idea of obsenving Earth and astronomical objects at different wavelengths.

Leading the list of award-winning videos and photographs was the Blackout' video developed by the IMAGE mission to illustrate the phenomenal eruptions of our Sun and their effects upon Earth. Competing in a field of more than 3,200 entries, Blackout! earned Crystal Awards of Excellence for Video in both the Education and the Animation/Special Effects categories. The film $A$ Star's Life, originally produced by the Hubble Space Telescope mission as part of their New Views of the Universe museum exhibit, was selected for screening at the Second International Vancouver Effects and Animation Festival. In photography, the outstanding images compiled by the Hubble Heritage program team were awarded the Sixteenth Annual Infinity Award for Applied Photography by the International Center of Photography (ICP) in New York City.

Outstanding individual efforts in education were also recognized in FY 2000. Marilyn Lindstrom of NASA Johnson Space Center was awarded one of NASA's highest honors, the NASA Exceptional Service Medal, for her sustained superb efforts to enhance $\mathrm{K}-12$ education in Astromaterials and Solar System Exploration. Her recent work has involved the Destination Moon planetarium show and Astromaterials/Astrobiology curriculum writing. Dr. Sten Odenwald, an employee of Raytheon ITS at NASA Goddard Space Flight Center, received the American Astronomical Society Solar Physics Division's annual award for Popular Writing in recognition of his popular articles on the Sun and its effects on Earth's environment. 
"We are rapidly approaching the day when the primary discriminator between the 'haves' and the 'have-nots' will be between those who understand technology and those who do not."

Daniel S. Goldin, NASA Administrator

\section{SCIENCE CENTER SHOWS/EXHIBITS}

Science centers, museums, and planetariums provide an important opportunity for using the results of NASA space science missions to improve the public understanding of science and technology. In FY 2000, OSS provided materials, technical expertise, and other resources for use in exhibits, planetarium shows, bulletin boards, and education projects at 110 science centers, museums, and planetariums in 39 States, the District of Columbia, and the U.S. Territory of Guam. Examples of some of the more visible outcomes from these contributions, including several major traveling exhibitions featuring NASA space science missions, major development projects at a number of the Nation's science centers, and the unique Space Place outreach program, are described below.

The Space Weather Center exhibition is a 700-square-foot exhibition developed through a partnership led by the Space Science Institute that included several of NASA's Sun-Earth Connection missions and research programs, the National Science Foundation, and a number of commercial vendors. The exhibition shows visitors how space weather phenomena-disturbances in the Sun's atmosphere that affect Earth's environment-play a role in their everyday lives. The Space Weather Center incorporates a number of interactive displays together with graphics of the Sun and aurorae and near real-time data from NASA missions currently studying the Sun and near-Earth space environment. Museums that rent or purchase the exhibition join the Space Weather Museum Network (SWMN) and receive educational and public relation materials, access to public talks by space weather scientists, and opportunities for networking with other SWMN museum sites. The Space Weather Center Exhibition opened at the Denver Museum of Nature and Science in April 2000, moved to the Discovery Center in Red Bluff, California, in July, and ended the fiscal year by opening at the Maryland Science Center in Baltimore in September.

The 5,000-square-foot traveling exhibition, Hubble Space Telescope: New Views of the Universe, opened in June 2000 at the Adler Planetarium and Astronomy Museum in Chicago. Developed in a collaboration of the Space Telescope Science Institute and the Smithsonian Institution Traveling Exhibition Service, the exhibition invites visitors to explore the cosmos through the eyes of Hubble Space Telescope. Using activities, video, artifacts, and vivid
Hubble images, they learn about the telescope's history, design, and purpose, as well as gain a greater understanding of planets, stars, galaxies, and the universe. A large format poster book has been released to accompany the exhibition, and each venue hosting the exhibition also receives a discovery trunk filled with educational materials for classroom visitors. A smaller, 2,000-square-foot version of the exhibition opened in September 2000 at the Castle Museum in Saginaw, Michigan, and will be available for smaller venues unable to accommodate the larger-sized exhibition.

On September 30, 2000, MarsQuest, a 4,500-square-foot, traveling exhibition developed by the Space Science Institute, opened at the McWane Center in Birmingham, Alabama. MarsQuest is organized around three important locations on Mars: 1) Olympus Mons, the largest volcano in the solar system; 2) Valles Marineris, a canyon as long as the United States is wide; and 3) Ares Vallis, the Pathfinder landing site. Each area makes comparisons between Mars and Earth, giving visitors a real sense of the Martian environment. MarsQuest visitors encounter more than 20 interactive experiences, four life-size models, and dramatic artwork of Martian landscapes. Visitors can send commands to maneuver a rover over a simulated Martian landscape, among many other engaging hands-on opportunities. Additional components of the MarsQuest program include a 30-minute planetarium show from Loch Ness Productions narrated by actor Patrick Stewart, best known as Captain Picard of the TV program Star Trek: The Next Generation, and a MarsQuest Education Program that provides onsite full-day workshops for museum staff and teachers.

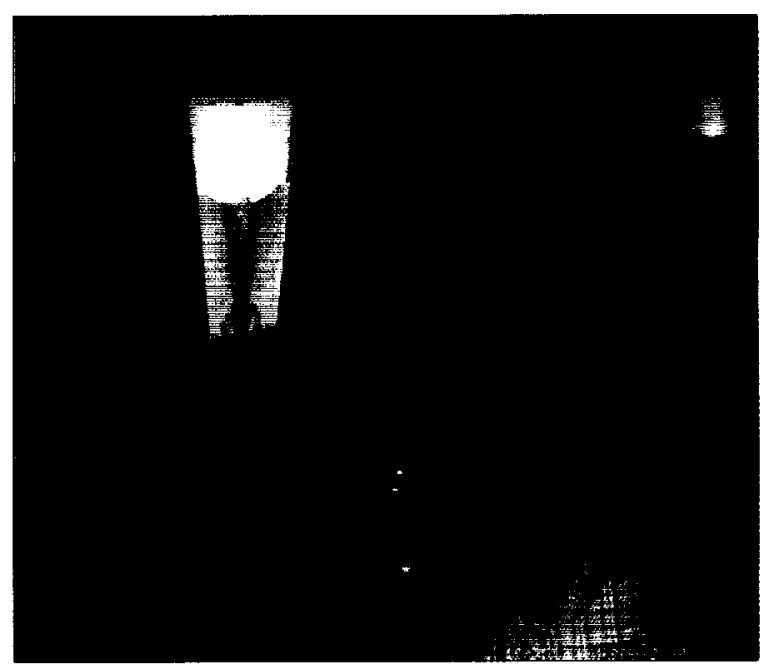

A young visitor to the Space Science Institute's MarsQuest exhibit learns about volcanoes.

A major development project at the Adler Planetarium and Astronomy Museum in Chicago to establish a new Center for Space Science Education under OSS sponsorship began in FY 2000. The purpose of this Center is to present 
a broad program of astronomy and space science education to students, teachers, and the general public in the midwestern region of the country. Educational products and programs are being developed and tested through partnerships with Chicago area schools and the Illinois State Board of Education and then distributed more widely. New technological capabilities are being developed for use in delivering educational programming into the schools and homes of endusers throughout the Midwest and the rest of the Nation. Major public programs on astronomy and space science are being developed for presentation to the Adler Planetarium's 500,000 visitors per year. The existing infrastructure and extensive links between the education and space science research communities in the Chicago area provide a unique venue for science researchers to become effectively involved in education and public outreach.

In FY 2000, 0SS also initiated support for major development projects in a number of science centers located in areas previously not well served by space science educational resources. For example, with this support, the Ft. Lauderdale Museum of Discovery and Science began renovation of its Space Base gallery to update exhibits and textual information to reflect current scientific information and to provide a focus on current NASA space science missions. Discovery Place in Charlotte, North Carolina, initiated plans to install a new planetarium instrument in its recently acquired Museum of Coastal Carolina (MOCC) in Ocean Isle Beach, North Carolina. Discovery Place also began work on the planning and design of Nova Nautics, a hands-on curriculum for grades $6-8$ in space mission design. With support from the Office of Human Resources and Education, development also began on new space science exhibits, planetarium shows, and education programs at the Franklin Institute Science Museum in Philadelphia, Pennsylvania, the Bishop Museum in Honolulu, Hawaii, the Mauna Kea Astronomy Educational Center in Hilo, Hawaii, and the Chabot Space and Science Center in Oakland, California. OSS is working closely with the Office of Human Resources and Education to ensure a NASA space science focus in all of these programs.

Drawing in audiences traditionally not reached by NASA is also a special focus of the New Millennium Program's Space Place. Space Place uses an anchor Web site at http://spaceplace.nasa.gov/to deliver interlinked outreach activities to partners that include the Boys and Girls Clubs of America, the YWCA, and over a hundred museums, planetariums, and libraries in rural areas of the country. Monthly columns for children run in regional newspapers and magazines across the country, and articles are also printed in such specialty publications as Weekly Reader and Technology Teacher. Hands-on activities like art competitions tied to mission launches and a card game (with real strategy), showcase the technology-driven missions of NASA's New Millennium Program, including the Deep Space 1 and Space Technology 5 space science technology missions.

Through science center, museum, and planetarium projects such as these, OSS hopes to build alliances that will bring the excitement of space science to audiences in all parts of the country. Further information on these and other such projects may be found in Appendix A. 
"Meeting the future needs of a society based on science and technology will require the involvement of individuals from groups who, at the current time, are not as effectively utilized as they should be in science and technology."

The OSS E/PO Implementation Plan

\section{TARGETED OUTREACH}

Targeted outreach projects are those that emphasize true and meaningful participation in OSS activities by individuals from groups that are currently underserved and underutilized in science and technology. These projects are motivated by the recognition that meeting the future needs of a society based on science and technology requires the involvement of all Americans.

Minority institutions of higher education play a vitally important role in training underrepresented minorities in the sciences and technical fields; however, at present, very few minority institutions have active space science programs on their campuses. To correct this deficit, OSS has made a commitment to developing the capabilities of students, faculty, and managers at minority institutions so that they can compete for space science opportunities and funding on the same basis as everyone else.

On January $31,2000,0 S S$, in partnership with the Office of Equal Opportunity Programs, issued a pioneering NASA Research Announcement (NRA) entitled the "Minority University Education and Research Partnership Initiative in Space Science." This NRA was carefully developed through extensive visits, meetings, and discussions with representatives of minority institutions to ascertain the most effective strategies for achieving common goals. It set the long-term goals of enhancing minority college (two-year and four-year) and university participation in space science through a variety of mechanisms, and, more generally, increasing the understanding of science, technology, and the role of research in contemporary society by a broad and diverse segment of the American population. A key element of the strategy for accomplishing these goals was facilitating and fostering the development of links among OSS, the space science research community, and minority institutions through the establishment of exchange programs and long-term partnerships.

The response from the minority university community was enthusiastic and overwhelming, with 60 proposals received. On September $1,2000,15$ of these proposals, including 6 HBCU's, 3 HSI's, 3 TCU's, and 3 other minority institutions, were selected for funding. Descriptions of some representative programs from among those selected follow.

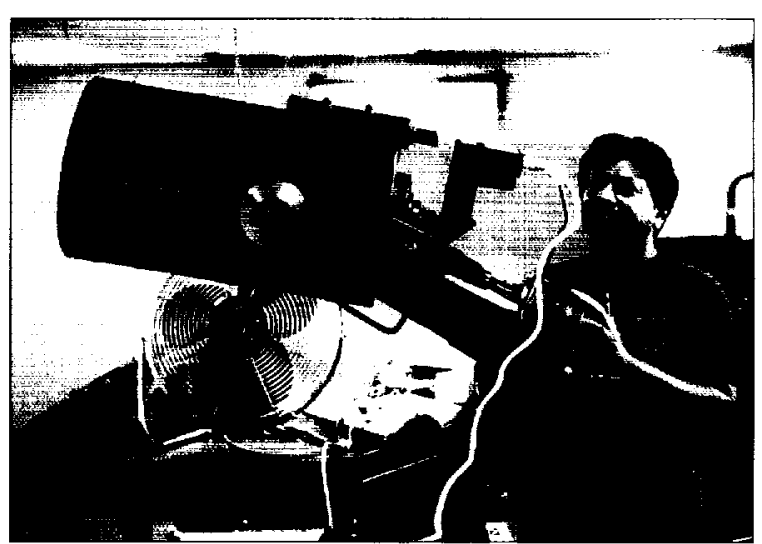

A student at South Carolina State University, a Historically Black University, learns the intricacies of nebular analysis by using a CCD camera attached to a 12 -inch reflecting telescope.

A prime example of the type of research collaborations this initiative sought to develop is found in the proposal from Southern University and A\&M College in Baton Rouge, Louisiana, entitled "Partnerships in Astronomy and Astrophysics Education and Research at Southern University." This project will bring Southern University students and faculty into active participation in two NASA space science missions. In collaboration with Louisiana State University, Southern University faculty and students will carry out hardware development activities on campus at Southern for the Minute-of-Arc Resolution Gamma-Ray Imaging Experiment (MARGIE) balloon project, currently undergoing concept studies as part of NASA's Ultra-Long Duration Balloon flight program. In collaboration with the Smithsonian Astrophysical Observatory's (SAO) Ultraviolet Coronagraph Spectrometer (UVCS) on the Solar and Heliospheric Observatory ( $\mathrm{SOHO})$, SAO scientists will establish a solar corona lecture series at Southern, provide research opportunities at SAO for Southern students, and develop associated Internet and mentoring support for the Southern students.

Comprehensive space science education projects, such as the "Connecting Sun City with Sun-Earth Connections" proposal submitted by the University of Texas at El Paso (UTEP), were also sought under this initiative. UTEP will leverage El Paso's reputation as "Sun City" to bring the science from NASA's Sun-Earth Connection theme into classes at UTEP and the EI Paso schools, as well as other educational activities. Their coordinated and integrated interdisciplinary approach will start with having UTEP faculty from all of the science departments integrate Sun-Earth Connection science into undergraduate courses in their respective disciplines. The results will then be used for visits to El Paso high schools, special events, a oneweek summer science camp at UTEP for high school students, a one-week summer institute at UTEP for teachers with a focus on the Texas Essential Knowledge and Skills, and school-year follow-up. Educational resources for this project will be provided by the Sun-Earth Connection 
Education Forum at the University of California at Berkeley, NASA Goddard Space Flight Center, the Space Telescope Science Institute, and the El Paso Science Museum.

The "Stars on Earth" proposal from Southwestern Indian Polytechnic Institute (SIPI) and the "New Opportunities through Minority Initiatives in Space Science" proposal from the University of Hawaii at Hilo (UHH) bring space science involvement to communities of Native Americans and Native Hawailans, respectively. The SIPI program will infuse space science knowledge into their already successful Upward Bound program in a manner specifically designed to improve the educational attitudes of Native American students and their teachers about science, mathematics, and technology. In addition, through a collaboration with the University of New Mexico, SIPI will establish a Meteorite Identification Laboratory on campus at SIPI and involve SIPI faculty and students in research collaborations on Mars surface science and landing site identification. The UHH program collaborates with the Kamehameha Schools (a private school system for Native Hawaiians) and the Hawaii Department of Education to develop K-12 curriculum connecting space science with Pacific sky lore and traditional Hawaiian knowledge. In addition, UHH will develop new undergraduate courses and cooperative research and training projects with the Mauna Kea Observatories aimed at preparing students for either entering graduate school in astronomy or for entering technical careers at major observatories.
OSS also participates in developing space science research and education capabilities at minority institutions under the Office of Equal Opportunity Programs' University Research Centers (URC) program. The primary space science project in the URC program is the Center for Automated Space Science (CASS) at Tennessee State University (TSU). CASS has developed a set of automated telescopes sited at their Washington Camp Observatory in southern Arizona but operated remotely from the TSU campus in Nashville. In November 1999, CASS made international news with the first reported direct detection of a planet orbiting a star other than our own Sun. Using the CASS automated photometric telescopes, astronomer Greg Henry detected a transit-a drop in starlight brightness caused by a planet passing in front of its parent star-of the Sun-like star HD 209458. Analysis of these observations allowed the firstever determination of the mass, radius, and density of a planet orbiting another star. This achievement, which was recognized by President William Clinton during his address at the 26th National Conference On Blacks In Higher Education, is a prime example of the successes that OSS has had in developing the space science capabilities of minority institutions to the point that they indeed can "compete for space science opportunities and funding on the same basis as everyone else."

Further information on these and other targeted outreach projects, including descriptions of all 15 projects selected under the Minority University Partnership Initiative, may be found in Appendix A. 
"Wow, this is terrific! I can find exciting, current, and accurate space science lessons and activities for my students so easily."

Susan Higley, 1999 Maryland Teacher of the Year

\section{EDUCATIONAL PRODUCTS}

Developing and disseminating educational products with a space science content is one of the most important services that OSS provides to the education community. Over 120 such products are summarized in this report. The majority of these products are targeted at the middle and high school levels, where Earth and Space Science have the largest impact in the curricula. Taking into account the fact that most of the products are accessible to a range of audiences and grade levels, approximately one-quarter of the products can be used for elementary school education, and approximately one-third of the products can be used in higher education, including community colleges and adult/continuing education programs. Over two-thirds of the products are also useful to the general public.
All of the products address topics within the space science subject area, but many of the products also include topics in other areas. Physical science topics are included in more than half of the products, and Earth science topics are included in over a third of them. Mathematics, technology, and life sciences topics are also included in some of the products. The types of materials found in each product include classroom activities, lesson plans, educator's guides, background information, and image sets.

The formats in which the products are available have a profound effect on the size of the audience to which they can be distributed. For this reason, the vast majority of the products are available as Web sites or as PDF files that can be easily downloaded and printed. Less than 20 percent of the products are restricted to hard-copy formats such as CD-ROMs, books, lithographs, videos, posters, or kits.

Making these products readily accessible to educators and to scientists was a major OSS goal that was realized at the close of FY 2000 with the initial public release of the NASA Space Science Education Resource Directory. Developed in a collaboration led by NASA's Sun-Earth Connection Forum at the University of California, Berkeley, and Origins Forum at the Space Telescope Science Institute, the Resource Directory contained more than 100 educational

\section{GRADE LEVEL/AUDIENCE FOR OSS E/PO PRODUCTS}

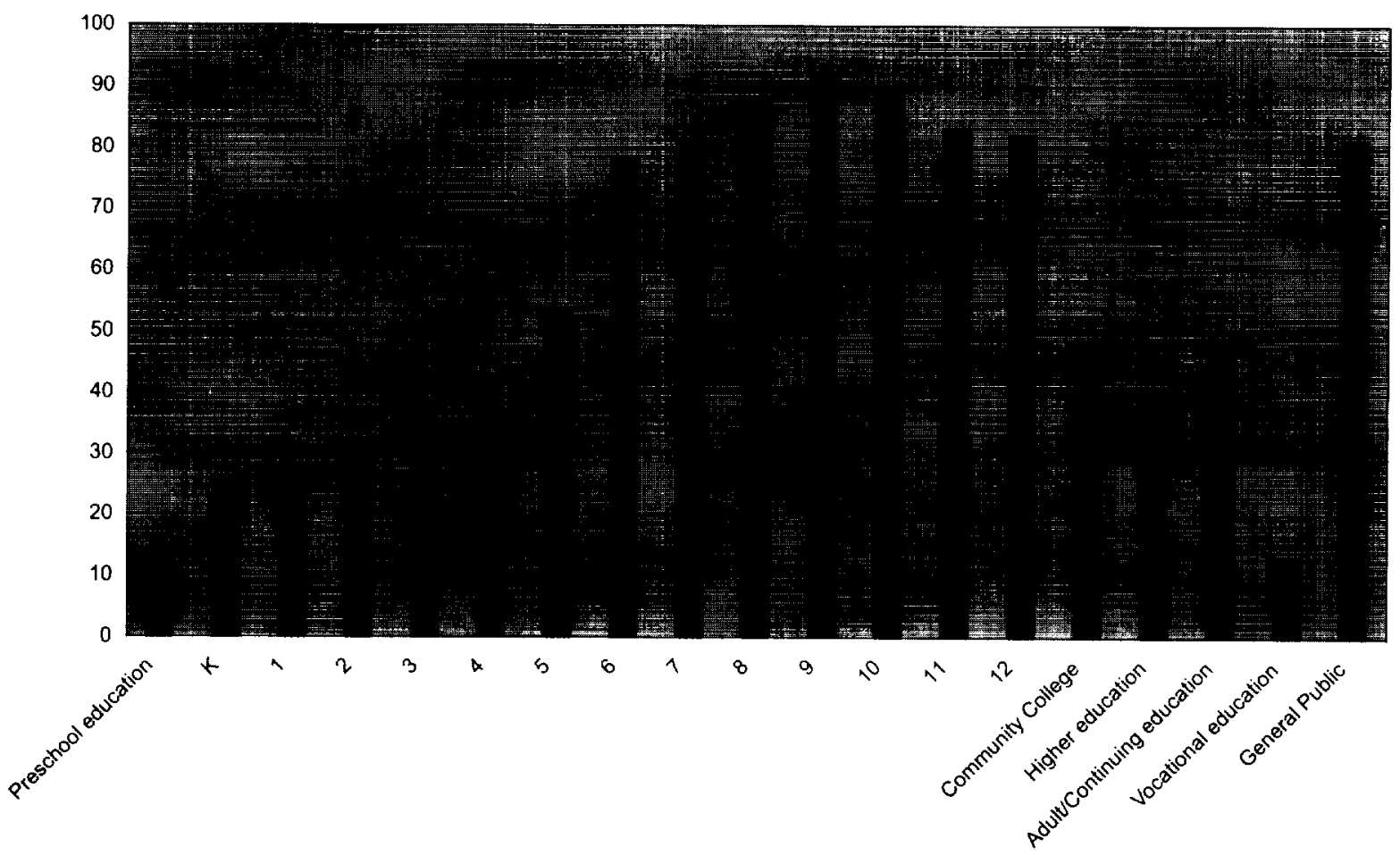

As shown in this histogram, the majority of OSS E/PO products are targeted at the middle and high school levels, where space science has its largest impact on the curricula. The histogram counts every grade level and audience for which each product is acceptable, so there is significant duplicate counting of the 124 products included in the histogram. 
resources at the time of its initial release. To ensure that all resources in the Resource Directory could be easily obtained by educators who want them, the listings in the initial release were limited to only those resources that were available electronically over the Internet. The Resource Directory therefore contains slightly more than 80 percent of the products described in this Annual Report.

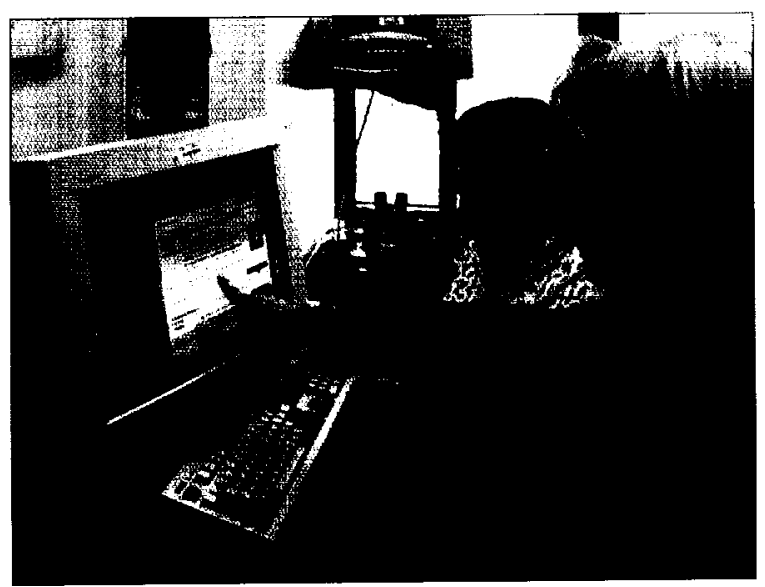

Teachers using the NASA Space Science Education Resource Directory can easily locate and download materials for use in their classrooms.
To maximize its utility, the Resource Directory was developed in close consultation with the U.S. Department of Education's Gateway to Educational Materials (GEM) and with focus groups of teachers. The resulting directory is compatible with and linked to national educational databases that are familiar to and widely used by teachers. Educators seeking materials can easily search the Resource Directory by keywords, browse the directory by topics, or conduct advanced searches using any combination of keywords, grade levels, formats, and subjects. Future versions of the Resource Directory will extend the content to multimedia products and print materials that are readily available in large quantities at moderate cost. Additional electronically accessible materials will also be added on an ongoing basis.

Descriptions and pertinent information about all of the OSS-sponsored educational products produced in FY 2000 can be found in Appendix A. Information on obtaining those products that are currently available for widespread distribution can be found in the Resource Directory at http://teachspacescience.stsci.edu 
"The most precious resource of all is the people who participate in the space science program."

The OSS E/PO Strategic Plan

\section{EDUCATIONAL PROGRAMS/EVENTS}

Direct interactions of the OSS community of scientists, managers, engineers, and support staff with teachers, students, and the public is a fundamentally important part of the OSS E/PO strategy. In FY 2000 , nearly 200 OSS-sponsored programs involved such interactions. Nearly two-thirds of these programs supported classroom education through some 75 programs for teachers conducted at over 130 different venues, over 40 programs for students conducted at more than 450 venues, and a number of efforts directed at systemic reform. The remaining third of these programs were aimed at improving the public understanding of space science or at encouraging greater participation of the science community in E/PO activities. Examples of some of these programs follow.

Teacher workshops were conducted at major national educators' conferences such as the National Science Teachers Association (NSTA) and the National Council of Teachers of Mathematics (NCTM). These workshops brought the excitement of NASA space science missions and discoveries to teachers through a variety of topics that ranged from the Cassini Mission's Saturn in Your Backyard and Kitchen to the High Energy Astrophysics Data Center's Imagine the Universe!
The Solar System Educators Program (SSEP) involved thousands of teachers across the Nation in the excitement of space exploration by working through a team of 77 volunteer educators recruited and trained at NASA Jet Propulsion Laboratory (JPL) by Space Explorers, Inc., in partnership with the Virginia Space Grant Consortium. During a four-day Institute at JPL, the volunteer educators met scientists, project managers, and other mission personnel and were provided with hands-on demonstrations, lectures, tours, and many opportunities to immerse themselves in JPL's robotic missions to the Solar System. Each educator then returned to his or her home town and held a minimum of three workshops, reaching a total of 100 teachers who would then pass this information along to their students.

The DePaul University Broker/Facilitator worked extensively with teachers and science supervisors at the State level in Illinois and at the city level in Chicago. Their Space Science for Illinois Teachers (SSIT) summer program, funded partially by the Illinois Board of Higher Education, immersed 28 Illinois teachers and science supervisors in an intensive professional development program that featured a one-week trip to NASA Goddard Space Flight Center and one week at DePaul. The teachers developed instructional strategies for integrating content presented by Goddard scientists into their classrooms, and service components for sharing with other teachers. The Chicago Teachers' Advisory group assembled by DePaul helped create partnerships to develop ways to bring space science to the schoolchildren of Chicago. Advisory meetings occurred quarterly and attracted a broad group of teachers representative of the Chicago Public School System.

\section{FY 2000 OSS E/PO PROGRAMS}

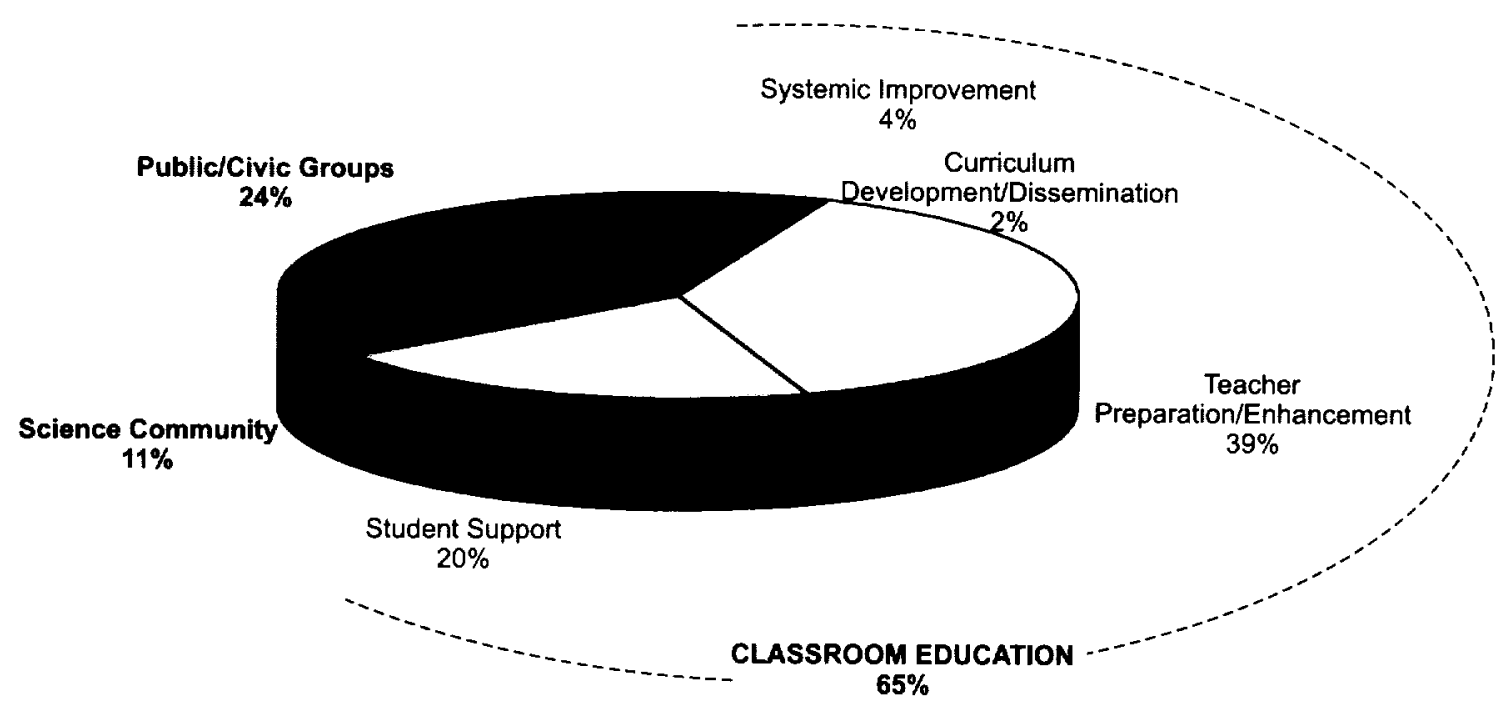

OSS E/PO programs support both classroom education and outreach, with a heavy emphasis on teacher training and enhancement. 
Direct interactions with students took place in a variety of formats and venues. In many cases, NASA scientists and educators came into classrooms or community settings to talk about a specific NASA space science mission or topic. Collectively, many thousands of students were reached through such programs.

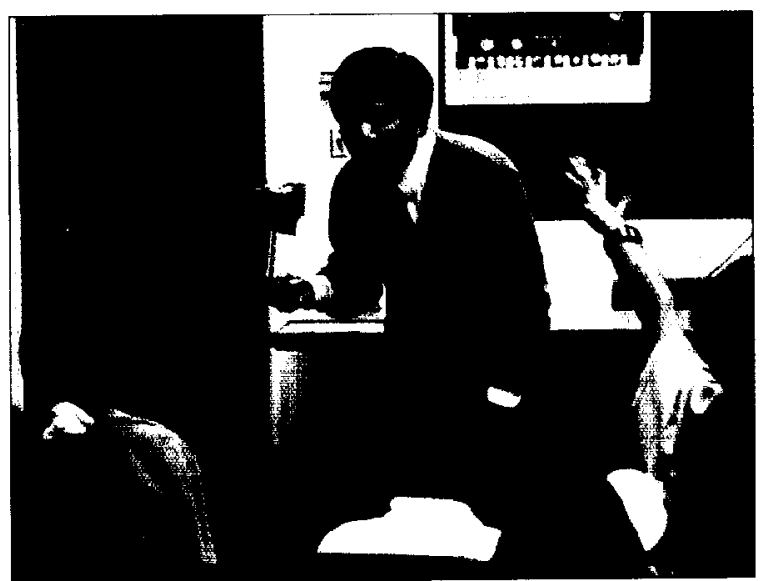

The excitement of space science missions comes directly to the community, as members of the Pasadena, California Boys and Girls Club learn about the Deep Space 1 mission directly from the New Millennium Program Manager.

Students became directly involved in research work through activities such as the Goldstone Apple Valley Radio Telescope (GAVRT) project. In a partnership between JPL and the Lewis Center for Educational Research, 6th to 12th grade students working over the Internet from their classrooms assume command of a decommissioned 34-meter NASA antenna from the Deep Space Network to make radio astronomy observations of Jupiter. The data they collect and analyze is submitted to JPL for inclusion in observational databases.

Conferences and other public events were used during FY 2000 to reach both the science community and the general public. Activities directed at the science community were aimed at increasing scientists' familiarity with OSS E/PO efforts and current educational practices, and at encouraging their increased participation in E/PO activities. Twenty-two such programs and activities were held at a variety of venues. Many of these programs took the form of presentations or exhibits at science meetings such as the American Association for the Advancement of Science, the American Astronomical Society, and the American Geophysical Union.

A variety of media and venues were used to reach the general public and increase the understanding of space science. The venues included open houses at research facilities, public lectures, exhibits at fairs and shopping centers, and mass media broadcasts. Some examples of particularly innovative activities include the award winning Earth and Sky daily radio series, the Explore! public library program, the Solar System Ambassadors outreach program, and the Passport to Knowledge video series.

Earth and Sky was a series of twelve 90-second radio interviews on planetary science topics from JPL, heard by millions of listeners on over 950 commercial and public stations throughout the United States.

The Explore! program was developed by the LPI Broker/ Facilitator to facilitate distribution of basic space science information and related NASA materials, utilizing the highly leveraged public library systems. Libraries have long provided essential learning resources that strengthen and perpetuate formal and informal education. Through libraries, NASA materials can be utilized, organized, and distributed nationwide to a broad spectrum of the populace. To date, librarians in all 56 parishes in Louisiana, in the city of Houston, and elsewhere in Texas have been trained on the use of space science related materials. Expansion of this program to additional areas is planned in the future.

The Solar System Ambassadors program uses motivated volunteers to organize and conduct public events that communicate exciting discoveries and plans in Solar System research, exploration, and technology through non-traditional forums such as community service clubs, libraries, museums, planetariums, star parties, and mall displays. In FY 2000, ambassadors conducted approximately 600 events that directly reached more than half a million people in communities across the United States.

Public television is the venue for the Passport to Knowledge (P2K) series of videos produced by Geoff Haines-Stiles Productions, Inc. In FY 2000, a new hourIong space science vide0, Live From The Sun 2000: To The Max, highlighting the solar maximum that occurred in late summer 2000, was broadcast. The P2K programs aired over more than 250 participating PBS stations and NASATV, and included both real-time and asynchronous interactions via the Internet with NASA and other researchers. Also during FY 2000, four previous NASAsupported P2K projects-Live from Mars, Live from the Hubble Space Telescope, Live from the Sun, and Live from the Stratosphere-underwent comprehensive reformatting to create Passport to the Solar System, a Space and Earth science module formatted for in-class use. All P2K programs are accompanied by hands-on and online classroom activities, and are consistent with and support the National Science Education Standards/AAAS Project 2061 Benchmarks.

Further information on these and hundreds of other educational programs and activities carried out by OSS in FY 2000 may be found in Appendix A. 


\section{SUMMARY AND fUTURE PLANS}

In the seven years since the OSS E/PO program began, enormous progress has been made. The policy of requiring every space science mission and program to engage in E/PO activities has generated hundreds of projects taking place in every corner of the Nation. The Support Network of Educational Forums and Regional Broker/Facilitators has grown from being only a concept on paper to becoming an extremely active and productive body. The partnerships formed with educational institutions and organizations, science centers and planetariums, minority communities, and research institutions have leveraged OSS E/PO resources far beyond what was even imaginable seven years ago.

A number of major activities now underway will be completed over the next few years. Voyage, an accurate, one ten-billionth scale model solar system, is being prepared by the Challenger Center for Space Science Education in Alexandria, Virginia, for placement on the National Mall in Washington, DC, in the fall of 2001. Cosmic Horizons: Our Place in Space and Time, a 5000-square-foot traveling exhibition that helps museum-goers explore the extraordinary recent breakthroughs and current mysteries in our scientific understanding of the structure and evolution of the universe, is scheduled to open in 2002 through a partnership of NASA's Structure and Evolution of the Universe Forum and Boston's Museum of Science.

The Resource Directory will be continually expanded with new products and with the incorporation of new capabilities, including the capability for users to provide reviews of the resources being offered. More effective mechanisms for delivering space science discoveries and results to science centers and planetariums will be devised and piloted. Ever greater emphasis will be placed on working at the State and regional levels and on improving the participation of underserved and underutilized groups in space science activities.

We will continue to use public television and the Internet to extend our public outreach. Two new Passport to Knowledge programs will be developed and produced. The first program, Live From a Black Hole, will be based on discoveries made by the Chandra $X$-Ray Observatory. The second program, Live From the Edge of Space and Time, will be based on the upcoming Microwave Anisotropy Probe mission's studies of the large scale structure of the universe. The Internet will be used to deliver a live, inter- active Webcast of the June 21, 2001, total solar eclipse to visitors at science centers around the Nation and to people using their home computers. San Francisco's Exploratorium and NASA's Sun-Earth Connection Forum are arranging links with southern Africa where a team on the ground will attempt to view the Moon eclipsing the Sun, and with the International Space Station, where a team of astronauts will attempt to view the shadow of the Moon racing across the surface of the Earth.

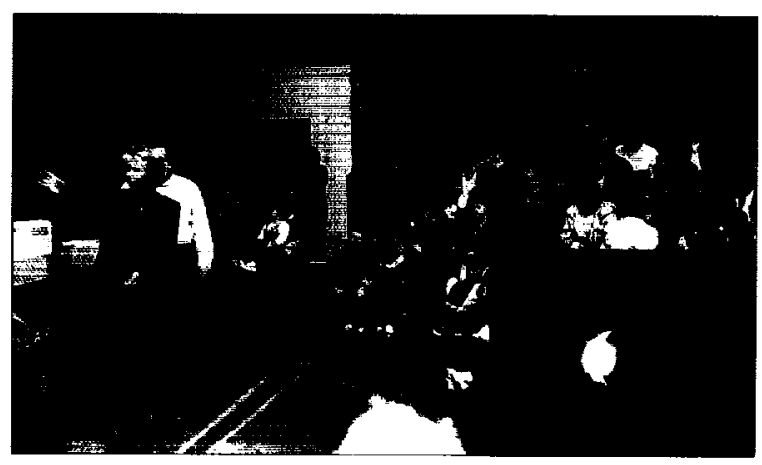

A live Web cast from Aruba allowed science center visitors and home computer users to witness the excitement of a total solar eclipse, courtesy of the Exploratorium and the NASA Sun-Earth Connection Education Forum.

New alliances to extend the reach of the OSS E/PO program will continue to be sought and built. Efforts have already begun with organizations such as the Girl Scouts of the USA and National 4-H Council, as well as with professional societies of minority scientists. These activities will continue to mature over the next several years. New activities to evaluate the effectiveness and impact of our E/PO programs will be initiated. Processes for working closely with the space science community will continue to be streamlined, and new avenues for space scientists to participate effectively in E/PO will continue to be developed.

OSS is pleased to be an integral part of NASA's efforts to enhance the quality of science, mathematics, and technology education across the Nation and to increase the public's understanding of science and technology. The projects underway, the partnerships that have been built, and the willingness of the space science and education communities to work together on E/PO activities are testimonies to the mutual recognition by all involved of the importance of these endeavors. We are already making a difference. We plan to do even better in the future. 
This directory provides detailed information on each of the OSS E/PO products and programs produced or carried out in FY 2000. 
National Aeronautics and Space Administration : Office of Space Science. 


\section{Science Centers}

\section{Science Center Exhibits}

\section{Cosmic Horizons: Our Place in Space and Time}

\begin{abstract}
Msn/Prg: $\quad$ SEU Forum
Theme(s): $\quad$ SEU

Description: Cosmic Horizons: Our Place in Space and Time is a 5,000square-foot traveling exhibition to help museum-goers explore the extraordinary recent breakthroughs and current mysteries in our scientific understanding of the structure and evolution of the universe. Cosmic Horizons aims to foster an ongoing "cosmic conversation" among museum audiences, scientists, educators, and students about what we know about the universe, how we know it, and what it means. A coordinated set of programmatic activities and resources for adult and family audiences, materials for teachers and students, and onsite workshops will be developed in partnership with Boston's Museum of Science to maximize the impact of this space-science education endeavor.

$\begin{array}{ll}\text { Lead: } & \text { SEU Forum, Smithsonian Astrophysical Observatory, } \\ & \text { Cambridge, MA } 02138 \\ \text { Partner(s): } & \text { Boston Museum of Science, Boston, MA } 02114\end{array}$
\end{abstract}

\section{Hubble Space Telescope National Visitor Center}

$\begin{array}{ll}\text { Msn/Prg: } & \text { HST } \\ \text { Theme(s): } & \text { ASO }\end{array}$

Description: The Hubble Space Telescope National Visitor Center is located at the Maryland Science Center in Baltimore. The permanent exhibit is part of the OuterSpacePlace exhibit-a 4,000-square-foot handson/minds-on experience featuring new discoveries from the Hubble Space Telescope and other Maryland-based space science resources, including The Johns Hopkins University and FUSE spacecraft.

$\begin{array}{ll}\text { Lead: } & \text { Office of Public Outreach, Space Telescope Science } \\ & \text { Institute, Baltimore, MD } 21218 \\ \text { Venue(s): } & \text { Maryland Science Center, Baltimore, MD } 21230\end{array}$

\section{Hubble Space Telescope: New Views of the Universe}

Msn/Prg: $\quad$ ASO Forum, HST

Theme(s): $\quad$ ASO

Description: Hubble Space Telescope: New Views of the Universe is a 5,000-square-foot traveling exhibition highlighting the technology and exciting discoveries of the Hubble Space Telescope. The exhibition was developed in collaboration with the Smithsonian Institution Traveling Exhibition Service (SITES). A smaller version for venues with more limited facilities is also on tour.
Lead: $\quad$ Office of Public Outreach, Space Telescope Science Institute, Baltimore, MD 21218

Partner(s): $\quad$ Smithsonian Institution Travelling Exhibition Service (SITES), Washington, DC 20560

Venue(s): $\quad$ Adler Planetarium and Astronomy Museum, Chicago, IL 60605

Space Center Houston, Houston, TX 77258-0653

The Castle Museum, Saginaw, Ml 48602

\section{MarsQuest}

$\begin{array}{ll}\text { Msn/Prg: } & \text { SSI B/F, OHRE } \\ \text { Theme(s): } & \text { SSE }\end{array}$

Description: The Space Science Institute's MarsQuest project is a 4,500square-foot, $\$ 3$ million, traveling exhibition that premiered at the McWane Center in Birmingham, Alabama, on September 30, 2000. The University of Alabama at Birmingham joined McWane to make Birmingham the first stop on a nine-city, three-year tour that will enable millions of Americans to share in the excitement of the scientific exploration of Mars and learn more about their own planet in the process. MarsQuest is organized around three intriguing locations on Mars: 1) Olympus Mons, the largest volcano in our solar system; 2) Valles Marineris, a canyon as long as the United States is wide; and 3) Ares Vallis, the Pathfinder landing site. Each area makes comparisons between Mars and Earth, giving visitors a real sense of the Martian environment. MarsQuest visitors encounter more than 20 interactive experiences, four life-size models, and dramatic artwork of Martian landscapes. Visitors can send commands to maneuver a rover over a simulated Martian landscape, among many other engaging hands-on opportunities. Additional components of the MarsQuest program include a 30-minute planetarium show from Loch Ness Productions narrated by actor Patrick Stewart, best known as Captain Picard of the TV program "Star Trek, The Next Generation." The MarsQuest Education Program implements onsite fullday workshops for museum staff and teachers that empower them to make use of the MarsQuest exhibit to share the thrill of scientific discovery with students and the public. Workshop facilitators are Dr. Cheri Morrow of the Space Science Institute, Sheri Klug of the Mars K-12 Education Program at Arizona State University, and Dr. Steve Lee of the University of Colorado's Laboratory for Atmospheric and Space Physics. About 20 scientists have participated in the design, development, and implementation of the MarsQuest project. Scientists' contributions have included ideas and perspectives for the conceptual design and specific interactions, access, and processing of the best Mars imagery for the murals and the HDTV presentation, editing panel text and the planetarium show script for science accuracy and currency, and contributing public lectures at museum sites as well as presentations in educator workshops. The Space Science Institute developed the MarsQuest exhibition with major funding from the National Science Foundation and the National Aeronautics and Space Administration. Additional support was provided by Mitsubishi Digital Electronics America, Inc., Hewlett-Packaro Company, and CBS. For more information on the MarsQuest exhibit, please see http://www.spacescience.org/ For the latest MarsQuest itinerary, please see $h t t p: / / w w w . a s t c . o r g$ 


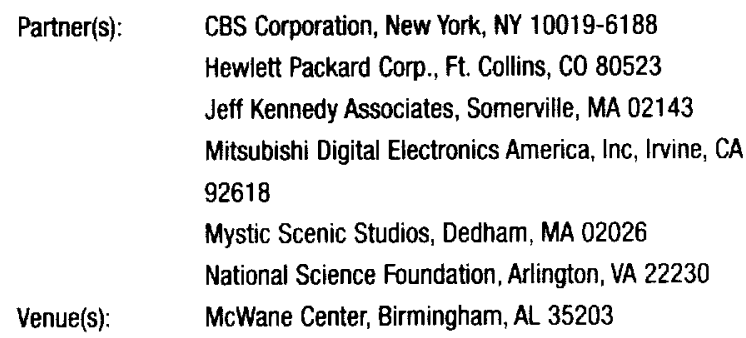

\section{NEAR Asteroids in the Atrium Maryland Science Center}

$$
\text { Msn/Prg: NEAR }
$$$$
\text { Theme(s): } \quad \text { SSE }
$$

Description: NEAR permanent exhibit, model, asteroid, posters, displays, and video in both the main museum where Asteroids in the Atrium is hanging in the main atrium with the display and video components, and also a smaller exhibit in Spacelink with model, videos, and hand-outs. Live event on NASA-TV highlighted in SpaceLink and with JHU/APL representative Marc Clayton on hand to answer questions. February 12 and 13, 2000: NEAR pre-orbit activities in SpaceLink. February 14: APL representative spoke during live event.

$$
\begin{array}{ll}
\text { Lead: } & \text { NEAR E/P0 Team, Johns Hopkins University Applied } \\
& \text { Physics Laboratory, Laurel, MD 20723-6099 } \\
\text { Venue(s): } & \text { Maryland Science Center, Baltimore, MD 21230 } \\
& \text { (Participants: 380219 local) }
\end{array}
$$

\section{Space Weather Center} $\begin{array}{ll}\text { Msn/Prg: } & \text { SEC Forum, SSI B/F, ACE, HESSI, IMAGE, ISTP, SOHO } \\ \text { Theme(s): } & \text { SEC }\end{array}$

Description: The Space Weather Center Exhibit is a 700-square-foot traveling exhibit developed by a partnership that included the Space Science Institute, the Sun-Earth missions and programs at NASA Goddard Space Flight Center (GSFC), and Condit Exhibits, Inc. The exhibit shows visitors how space weather phenomena-disturbances in the Sun's atmosphere that affect Earth's environment-play a role in their everyday lives. The Space Weather Center incorporates engaging interactives and stunning graphics of the Sun and aurorae, as well as near real-time data from NASA missions currently studying the Sun and near-Earth space environment. Many scientists contributed to the development of the Space Weather Center in partnership with educators and exhibit designers. Scientists' roles included reviewing conceptual design and panel text, accessing and processing data for use in exhibit graphics and the update-able CD-ROM display, and presenting in teacher workshops. Museums who rent or purchase the exhibit join the Space Weather Museum Network (SWMN) and receive educational and public relation materials, access to public talks by space weather scientists, and opportunities for networking with other SWMN museum sites. The Space Science Institute has also developed a Space Weather Center Web site (http://www.spacescience.org/SWOP/1.html) along with educator workshops for both museum staff and secondary teachers. In addition, GSFC has developed a Web site and teacher workshops. For more information on the exhibit, please see http://www.spacescience.org/SWOP/Exhibits/ Mini_Exhibit/1.html and http://www-istp.gsfc.nasa.gov/ exhibit/

\author{
Lead: $\quad$ SSI, Space Science Institute, Boulder, CO 80303 \\ Partner(s): $\quad$ Condit Exhibits, Denver, CO 80223 \\ NASA Goddard Space Flight Center, Greenbelt, MD \\ 20771 \\ SUNBEAMS, NASA Goddard Space Flight Center, \\ Greenbelt, MD 20771 \\ Venue(s): Denver Museum of Nature and Science, Denver, CO \\ 80205 \\ Discovery Center, Red Bluff, CA 96080 \\ Discovery Museum, Sacramento, CA 95821 \\ (Participants: 180000 local) \\ Maryland Science Center, Baltimore, MD 21230 \\ (Participants: 190000 local; 2 events)
}

\section{Voyago - A Scale Model Solar System for the National Mall}

$\begin{array}{ll}\text { Msn/Prg: } & \text { OSS } \\ \text { Theme(s): } & \text { SSE }\end{array}$

Description: Voyage is an accurate, one ten-billionth scale model solar system to be placed on the Capitol Mall in Washington, DC, along a 600meter path from the National Air and Space Museum to the Smithsonian Castle on Jefferson Drive. The model will consist of 13 units, one each for the nine planets, the Sun, small bodies (comets/asteroids), and two anchor units. Visitors will be placed within the model, and be able to experience the relative sizes of the model worlds in relation to the distances between them. Through the use of Voyage storyboards, they will see such things as canyons on Mars as long as the continental United States, storm systems on Jupiter twice the size of Earth, and astronauts on the surface of the Moon. The content is guided by National Science Education Standards, and makes use of extensive studies conducted on visitor and student pre-knowledge and misconceptions about Earth and the solar system. Installation on the Mall is expected in fall 2001.

Lead: $\quad$ Dr. Jeff Goldstein, Challenger Center for Space Science Education, Alexandria, VA 22314

Partner(s): $\quad$ Smithsonian Institution, Washington, DC 20560

Venue(s): $\quad$ National Capitol Mall, Washington, DC 20560

\section{Planetarium Shows}

\section{Beyond the Edge of the Universe}

$\begin{array}{ll}\text { Msn/Prg: } & \text { CXO, CGRO, RXTE } \\ \text { Theme(s): } & \text { SEU }\end{array}$

Description: Gorgeous new images from the Chandra Telescope reveal the edge of the universe. This program explores questions about the fate of the universe, and updates the audience on what scientists have learned from the images.

Lead: SEU Forum, Smithsonian Astrophysical Observatory, Cambridge, MA 02138 


\section{Destination Moon}

Msn/Prg: Sample Curation

Theme(s): $\quad$ SSE

Description: Destination Moon is a planetarium show that opened July 20, 1999 at the Houston Museum of Natural Science. It depicts the successes of Apollo, knowledge learned from returned samples and robotic missions, and excitement of future human lunar exploration. It was produced by a collaboration of HMNS, NASA JSC, LPI and Rice University. It is available in both high tech Sky Vision and simple versions from Sky Skan.

Lead: $\quad$ Sample Curation E/PO Team, NASA Johnson Space Center, Houston, TX 77058

Partner(s): $\quad$ Houston Museum of Natural Science, Houston, TX 77030

Lunar and Planetary Institute, Houston, TX 77058

Rice University, Houston, TX 77005

Venue(s): $\quad$ Houston Museum of Natural Science, Houston, TX 77030

Exploring the Solar System at Fiske Planetarium

Msn/Prg: IDEAS

Theme(s): $\quad$ SSE

Description: The team developed a new show in collaboration with several local teachers, their students, and educators. Much of the script development was done by University of Colorado astronomy graduate students interested in public education and outreach. In addition, classroom activities were developed that teachers can use to build a unit on astronomy and space science. These activities are all available on the Web.

$\begin{array}{ll}\text { Lead: } & \text { Dr. Catharine Garmany, University of Colorado, } \\ & \text { Boulder, CO 80309 } \\ \text { Partner(s): } & \text { Fiske Planetarium, Boulder, CO } 80309 \\ \text { Venue(s): } & \text { Fiske Planetarium, Boulder, C0 80309-0408 } \\ & \text { (Participants: } 2654 \text { local) }\end{array}$

\section{Materials/Support}

\section{Adler Planetarium}

Msn/Prg: SSE Forum

Theme(s): $\quad$ SSE

Description: Provide video, images, content review, and technical support for Adler Planetarium's new Solar System Gallery and new Star Rider planetarium show.

Lead:

SSE Forum, NASA Jet Propulsion Laboratory, Pasadena, CA 91109
Venue(s): Adler Planetarium and Astronomy Museum, Chicago, IL 60605

\section{Bishop Museum/Mauna Kea Education Conter}

Msn/Prg: $\quad$ OHRE

Description: Funding to date has resulted in the development of a number of new hands-on exhibits in the Bishop Museum. Additionally, two planetarium programs, one on astronomy and space science and another on the subject of exploration, have been developed. Work is now underway to plan for a hands-on science and technology center to be associated with the Mauna Kea Observatory and to be located at the University of Hawaii at Hilo.

Lead: $\quad$ Pat Duarte, Bishop Museum, Honolulu, HI $96817-$

$$
2704
$$

Partner(s): $\quad$ Mauna Kea Astronomy Educational Center, Hilo, HI 96720

Venue(s): $\quad$ Bishop Museum, Honolulu, HI 96817-2704 Mauna Kea Astronomy Educational Center, Hilo, HI 96720

\section{Center for Space Sclence Education at the Adler Planetarium and Astronomy Museum}

Msn/Prg: $\quad$ OSS

Description: The Adler Planetarium and Astronomy Museum in Chicago is establishing a Center for Space Science Education. The purpose of this Center is to present a broad program of astronomy and space science education to students, teachers, and the general public in the midwestern region of the country. Educational products and programs will be developed and tested through partnerships with Chicago area schools and the Illinois State Board of Education and then distributed more widely. New technological capabilities will be used for delivering educational programming into the schools and homes of end-users throughout the Midwest and the rest of the Nation. Major public programs on astronomy and space science will be presented to the Adler Planetarium's 500,000 visitors per year. The existing infrastructure and extensive links between the education and space science research communities in the Chicago area will provide a unique venue for science researchers to become effectively involved in education and public outreach.

Lead: $\quad$ Dr. Paul Knappenberger, Jr., Adler Planetarium and Astronomy Museum, Chicago, IL 60605

Venue(s): Adler Planetarium and Astronomy Museum, Chicago, IL 60605

\section{Chabot Space and Sclence Center}

$$
\text { Msn/Prg: } \quad \text { SOFIA, OSS, OHRE }
$$

Theme(s): $\quad$ ASO

Description: The Chabot Space and Science Center (CSSC) is a new science and technology center in the hills above Oakland, California. CSSC is dedicated to astronomy, featuring the largest planetarium in Northern 


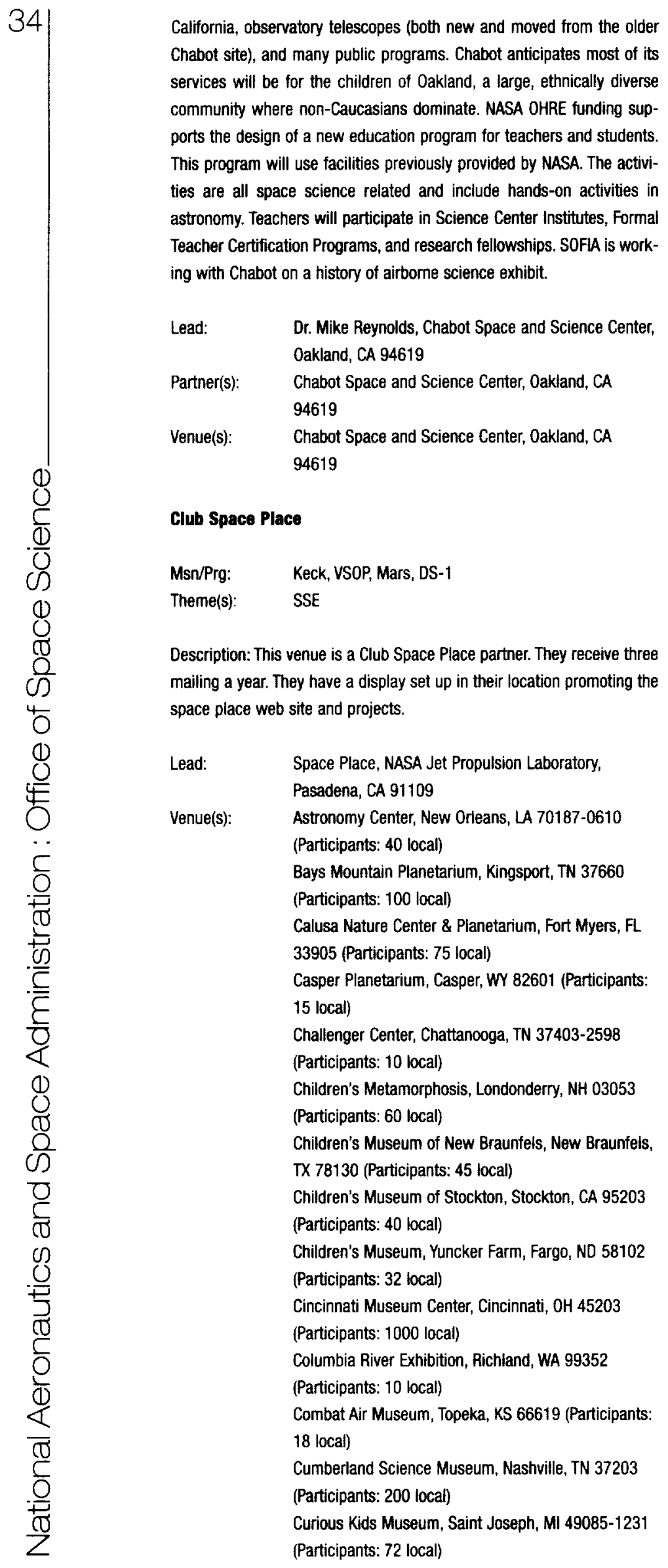

Delta College Planetarium, Bay City, M| 48708

(Participants: 40 local)

Discovery Museum, Sacramento, CA 95821

(Participants: 30 local)

El Paso Independent School District, El Paso, TX

79925-1008 (Participants: 34 local)

Erie Historical Museum and Planetarium, Erie, PA

16507 (Participants: 2 local)

Evergreen Airventure, McMinnville, OA 97128

(Participants: 29 local)

Family Museum, Bettendorf, IA 52722 (Participants:

125 local)

Fiske Planetarium, Boulder, CO 80309-0408

(Participants: 40 local)

Golden Pond Planetarium, Golden Pond, KY 42211

(Participants: 1500 local)

Griffith Observatory, Los Angeles, CA 90027-1255

(Participants: 71000 local)

Hands-on Science Central, Fort Wayne, IN 46805

(Participants: 340 local)

Hummel Planetarium, Richmond, KY 40475

(Participants: 35 local)

Junior Museum of Bay County, Florida, Panama City,

FL 32405 (Participants: 35 local)

Kansas Aviation Museum, Wichita, KS 67210

(Participants: 25 local)

Koch Science Center and Planetarium, Evansville, IN

47713-1037 (Participants: 60 local)

Lafayette Planetarium, Lafayette, LA 70503

(Participants: 60 local)

Laredo Children's Museum, Laredo, TX 78040

(Participants: 10 local)

Lida G. Sharpe Planetarium, Memphis, TN 38111-

3399 (Participants: 600 local)

Longway Planetarium, Flint, MI 48503 (Participants:

80 local)

Maryland Science Center, Baltimore, MD 21230

(Participants: 30 local)

Mid-America Air Museum, Liberal, KS 67905-2199

(Participants: 10 local)

Museum of Art \& Science, Macon, GA 31210-4806

(Participants: 75 local)

Museum of the Rockies, Bozeman, MT 59717

(Participants: 124 local)

National Soaring Museum, Elmira, NY 14903-9204

(Participants: 63 local)

New England Air Museum, Windsor Locks, CT 06096

(Participants: 43 local)

Niagara Aerospace Museum, Niagra Falls, NY 14304

(Participants: 20 local)

North Museum of Natural History and Science,

Lancaster, PA 17603 (Participants: 25 local)

Northern Stars Planetarium, Fairfield, ME 04937

Owl Head Transportation, Owl Head, ME 04854

(Participants: 10 local)

Red River Valley Museum, Vernon, TX 76385-2004

(Participants: 10 local) 
Roberson Museum \& Science Center, Binghamton, NY 13901 (Participants' 300 local)

The Children's Museum, Rocky Mount, NC 278013754 (Participants: 20 local)

Russell C. Davis Planetarium, Jackson, MS 39201 -

4115 (Participants: 50 local)

Santa Maria Museum of Flight, Santa Maria, CA

93455 (Participants: 10 local)

Science Center of West Virginia, Bluefield, WN 24701

(Participants: 12 local)

South Florida Science Museum, West Palm Beach, FL 33405 (Participants: 100 local)

Southern Forest World, Waycross, GA 31503

(Participants: 12 local)

Southern Museum of Flight, Birmingham, AL 35206

(Participants: 35 local)

Southworth Planetarium, Portland, ME 04104-9300

(Participants: 30 local)

Staerkel Planetarium, Champaign, IL 61821-1899

(Participants: 38 local)

Storer Planetarium, Prince Frederick, MD 20678

(Participants: 25 local)

The Air Victory Museum, Medford, NJ 08055

(Participants: 10 local)

The Planetarium, North Las Vegas, NV 89030-4296

(Participants: 12 local)

Turkey Run State Park and Planetarium, Marshall, IN

47589 (Participants: 880 local)

Turtle Bay Museums, Redding, CA 96099-2360

(Participants: 140 local)

University of Guam Planetarium, Mangilao, Guam

96923 (Participants: 13 local)

Venango Arts, Science, and Industry Museum, Oil City,

PA 16301 (Participants: 11 local)

Wallace Planetarium, Fitchburg, MA 01420

(Participants: 14 local)

Warhawk Air Museum, Boise, ID 83703 (Participants:

10 local)

Willamette Science and Technology Center, Eugene,

OR 97401 (Participants: 25 local)

\section{Design a Space Science Mission with Nova Nautics}

Msn/Prg: $\quad$ SERCH B/F, OSS

Description: OSS is supporting acquisition of a new planetarium instrument to be installed in the Museum of Coastal Carolina (MOCC) in Ocean Isle Beach, North Carolina, and the planning, designing, and delivering of Nova Nautics, a hands-on curriculum for grades $6-8$ in space mission design. Discovery Place, a major regional science center located in Charlotte, North Carolina, will oversee both of these projects in partnership with MOCC. MOCC is the only natural history museum in the southern coastal area of North Carolina. Recently acquired by Discovery Place, MOCC is a primary source of science education for 17 counties in the region, serving many economically disadvantaged students. Once completed, the proposed planetarium will be used to present daily programs on space science topics to school groups and the general public, and thus become the first space science education complex in the region. The Nova Nautics curriculum will allow students to design, test, analyze, and manage a space mission from initial concept to its end. Mission scenarios will be linked to the four NASA space science themes. The curriculum is linked to the National Science Education Standards for grades 5-8 and will be for be designed to fit a variety of educational formats ranging from traditional after-school programs to week-long camps.

Lead: $\quad$ Doug Baldwin, Discovery Place, Chariotte, NC 28202

Partner(s): $\quad$ Museum of Coastal Carolina, Ocean Isle Beach, NC 28469

Venue(s): $\quad$ Discovery Place, Charlotte, NC 28202

\section{Franklin Institurte}

Msn/Prg: $\quad$ OHRE

Description: Project will result in a new 5,000-square-foot exhibit on astronomy and space exploration called Journey Through Space. A set of hands-on interactive experiences will be included.

Lead: $\quad$ Polly McKenna-Cress, Franklin Institute Science Museum, Philadelphia, PA 19103

Venue(s): $\quad$ Franklin Institute Science Museum, Philadelphia, PA 19103

\section{Great Lakes Planotarium Association (GLPA) Space Science Advisory Committee}

Msn/Prg: $\quad$ ASO Forum, SEC Forum, SEU Forum, SSE Forum, DePaul B/F, OAI B/F

Description: The committee was formed to assist the NASA Office of Space Science to more effectively address the needs of small and medium planetariums in the Midwest, and to help planetarians make more effective use of existing NASA resources. It consists of seven GLPA members representing a diverse group of planetariums, and eight members of the OSS Education Support Network. During the first year of its existence, the group developed a grants program for planetariums, connected GLPA to a team of planetary scientists which led to the inclusion of GLPA in a Discovery mission proposal, and provided feedback on a variety of OSS education resources and projects.

Lead: DePaul Broker/Facilitator, DePaul University, Chicago, IL 60614

Partner(s): Great Lakes Planetarium Association, Shaker Heights, $\mathrm{OH} 44120$

\section{Griffith Observatory}

Msn/Prg: NEAR

Theme(s): $\quad$ SSE

Description: NEAR materials were supplied by Kerri Beisser, JHU/APL $E / P 0$, to enhance the program that they were putting together for a pro- 
gram on asteroids. They received a copy of the NEAR video, flyover videos, fact sheets, and lithos.

Lead: $\quad$ NEAR E/PO Team, Johns Hopkins University Applied Physics Laboratory, Laurel, MD 20723-6099

Venue(s): $\quad$ Griffith Observatory, Los Angeles, CA 90027-1255

Hubble Nows Early Access Program

Msn/Prg: $\quad$ HST

Theme(s): $\quad$ ASO

Description: Planetarium- and museum-based astronomy educators are often contacted by local news media to comment on recent discoveries by NASA space missions. In this program we offer private early access to upcoming press releases from the Space Telescope Science Institute's news operation. All applicants are screened for appropriateness and sign an agreement to honor embargo dates. Interested planetarium/museum professionals may contact John Stoke for more information: stoke@stsci.edu or 410-338-4394.

Lead

Office of Public Outreach, Space Telescope Science Institute, Baltimore, MD 21218

\section{Hubble Space Telescope 10th Anniversary Slide Set and Script \\ Msn/Prg: $\quad$ HST \\ Theme(s): $\quad$ ASO}

Description: A set of $4035 \mathrm{~mm}$ color slides with caption booklet, offered to USA-based museums and planetariums at no cost in celebration of the 10th Anniversary of the deployment of the Hubble Space Telescope. The purpose of the slide set is to allow community-based astronomy educators and interpreters present the Hubble story to their own local audiences. The images were culled and narratives were written by experts on both the hardware and science sides of the Hubble program at Goddard Space Flight Center and at the Space Telescope Science Institute.

Lead: $\quad$ Office of Public Outreach, Space Telescope Science Institute, Baltimore, MD 21218

\section{Hubble Space Telescope 10th Anniversary Video}

Msn/Prg: HST

Theme(s): $\quad$ ASO

Description: A seven-minute VHS video commemorating the 10th Anniversary of the Hubble Space Telescope, produced by the Astronomy Visualization Lab, Office of Public Outreach, Space Telescope Science Institute. This tape was offered at no charge to museums, science centers, and planetariums in the USA. Several venues borrowed the video on professional Betacam tape for transfer to optical media to play in their exhibition halls.

Lead: $\quad$ Office of Public Outreach, Space Telescope Science Institute, Baltimore, MD 21218

\section{International Planetarlum Society}

Msn/Prg: SSE Forum

Theme(s): $\quad$ SSE

Description: The International Planetarium Society is the largest group of planetarium professionals in the world, representing small, medium, and large planetariums. JPL provides a small number of high-resolution slides and video of planetary mission results for replication and distribution to IPS membership at their cost. This high-leverage activity makes the materials available in a timely fashion to potentially 2,400 planetaria worldwide, many that do not yet have the capability to download large files.

Lead: $\quad$ SSE Forum, NASA Jet Propulsion Laboratory, Pasadena, CA 91109

Venue(s): International Planetarium Society

\section{Loulslana Mature Center Planetarium}

$\begin{array}{ll}\text { Msn/Prg: } & \text { NEAR } \\ \text { Theme(s): } & \text { SSE }\end{array}$

Description: Kerri Beisser and Linda Butler, JHU/APL E/PO, distributed materials and began a partnership with Assistant Planetarium Curator to showcase NEAR at the Louisiana Nature Center Planetarium, New Orleans, Louisiana.

Lead: $\quad$ NEAR E/PO Team, Johns Hopkins University Applied Physics Laboratory, Laurel, MD 20723-6099

Venue(s): Louisiana Nature Center Planetarium, New Orleans, LA 70127

\section{MASA Johnson Space Center Astroblology Institute Education and Exhiblts}

Msn/Prg: NAI

Theme(s): $\quad$ ASO

Description: Johnson (JSC) provides assistance with exhibit materials and information for a variety of museums and science centers. The Mars meteorite display samples have been used at many public and scientific forums. Our goal is to make planetary materials and scientific information, especially in the form of graphics, available to scientists or public groups. These products will help us share the direction of current research at JSC NAI with the public.

Lead: $\quad$ Astrobiology Institute E/P0 Team, NASA Ames Research Center, Moffett Field, CA 94035

\section{MASA Space Science Education and Outreach Resources for} Planetariums

Msn/Prg: $\quad$ DePaul B/F

Description: The invited presentation gave planetarians from the Great Lakes Planetarium Association (GLPA) an overview of NASA space sci- 
ence resources available to planetarians, and opportunities for partnerships with NASA missions, scientists, and educators. It focused primarily on the needs of small planetariums. The presentation spawned discussions with GLPA members that then led to the formation of the GLPA OSS Advisory Committee. A summary of the presentation was published in the Proceedings of the 35th Annual GLPA Conference.

Lead: DePaul Broker/Facilitator, DePaul University, Chicago, IL 60614

Venue(s): $\quad$ Great Lakes Planetarium Association Annual Meeting Kalamazoo, MI 49007 (Participants: 120 local)

\section{NASA Space Science Education Partnership}

MSn/Prg: $\quad$ SERCH B/F, OSS

Description: As part of a major renovation project being undertaken by the Museum of Discovery and Science in Fort Lauderdale, Florida, NASA's Office of Space Science is supporting renovation of the Space Base exhibit gallery and adjacent space. The current Space Base Gallery, which introduces visitors to the technology of flight, space flight and space exploration, has not been updated since it first opened in 1992. The NASA funding will enable the museum to update exhibits and textual information to reflect current scientific information and to provide a current NASA mission focus. The primary subject matter will be (a) How we learn about outer space, (b) Planet Earth's place in the universe, and (c) The universe and us. Exhibit stations will encourage exploration through a variety of learning modalities, including cooperative play, open-ended experimentation, building, sorting, classification, and motor skills. Each exhibit station will explore a particular concept that builds upon concepts learned at other exhibit stations, thus providing a cumulative learning experience.

Lead: $\quad$ Dr. Paul Siboroski, Museum of Discovery and Science, Ft. Lauderdale, FL 33312-1707

Venue(s): $\quad$ Museum of Discovery and Science, Ft. Lauderdale, FL 33312-1707

\section{National Air and Space Museum}

Msn/Prg: $\quad$ SOFIA

Theme(s): $\quad$ ASO

Description: The National Air and Space Museum (NASM) staff, headed by Dr. R. Craddock, plans to provide a SOFIA one-hundredth scale model, information, and other items for the revision/remodeling of the NASM exhibit on airborne astronomy in the planetary science hall. The exhibit now features the Kuiper Airborne Observatory, SOFIA's predecessor. The new exhibit should be in place by the end of calendar year 2000 .

$\begin{array}{ll}\text { Lead: } & \text { SOFIA E/PO Team, NASA Ames Research Center, } \\ & \text { Moffett Field, CA 94035 } \\ \text { Venue(s): } & \text { National Air and Space Museum, Washington, DC } \\ & 20560-0321\end{array}$

\section{National Air and Space Museum}

Msn/Prg: SSE Forum

Theme(s): $\quad$ SSE

Description: Refresh Planets Gallery with new backlit planetary images in the Tools section, What's New section, and gallery icon exhibit.

Lead: $\quad$ SSE Forum, NASA Jet Propulsion Laboratory, Pasadena, CA 91109

Venue(s): $\quad$ National Air and Space Museum, Washington, DC 20560-0321

\section{MEAR Show $@$ Rainwater Planetarium}

Msn/Prg: NEAR

Theme(s): $\quad$ SSE

Description: Kerri Beisser, JHU/APL E/PO, gave James Hill slides and videos and materials for planetarium shows at Rainwater Planetarium in French Camp, Mississippi.

Lead: $\quad$ NEAR E/PO Team, Johns Hopkins University Applied Physics Laboratory, Laurel, MD 20723-6099

Venue(s): $\quad$ Rainwater Planetarium and Observatory, French Camp, MS 39745

OSS Booth at Great Lakes Planetarium Association (GLPA)

Msn/Prg: DePaul B/F

Description: The Office of Space Science booth in the CyberSpace room of the Adler Planetarium allowed GLPA members to learn about NASA resources and opportunities, discuss planetarium-related issues with members of the OSS Education Support Network, and explore and provide feedback to the developers of the NASA Space Science Resource Directory and Space Science Informal Access on internet-connected computer terminals.

Lead: DePaul Broker/Facilitator, DePaul University, Chicago, IL 60614

Venue(s): $\quad$ Annual Meeting of the Great Lakes Planetarium Association, Chicago, IL 60605 (Participants: 120 local)

\section{OSS Exhiblt at Association of Science-Technology Centers} (ASTC)

Msn/Prg: $\quad$ SEC Forum, OSS

Theme(s): $\quad$ SEC

Description: NASA OSS, led by Ann Marie Trotta, participated in the NASA exhibit that was visited by at least 200 visitors out of 1,900 registered attendees. SECEF staff supported the exhibit, space science sessions, and showcase, and networked with many museums and science centers. 
Venue(s): $\quad$ Association of Science-Technology Centers (ASTC), October 1999, Tampa, FL 33617

\section{Planotarium Leaming and Teaching Opportunitles (PLATO) \\ Msn/Prg: DePaul B/F}

Description: DePaul is funding the Planetarium Learning and Teaching Opportunities (PLATO) Grants Program to promote space science education through 15 grants of up to $\$ 1,000$ for innovative planetarium-based projects that engage school children, teachers, and the public in space science learning experiences. The PLATO program was announced at the 36th Annual GLPA Conference at the Adler Planetarium in Chicago.

Lead: DePaul Broker/Facilitator, DePaul University, Chicago, IL 60614

Partner(s): $\quad$ Great Lakes Planetarium Association, Shaker Heights $\mathrm{OH} 44120$

\section{Space Place Museum Partners}

Msn/Prg: $\quad$ Galileo, DS-1

Theme(s): $\quad$ SSE

Description: Two times a year, participating museums are sent new posters, postcards, and mission stickers to put up on a bulletin board they set up and maintain. This bulletin board has borders surrounding the display that are supplied by JPL with the first shipment. The borders promote the Space Place Web site.

Lead: $\quad$ Space Place, NASA Jet Propulsion Laboratory, Pasadena, CA 91109

Venue(s): $\quad$ Arkansas Air Museum, Fayetteville, AR 72701 (Participants: 20 local)

Art and Science Center of Southeast Arkansas, Pine Bluff, AR 71601-4903 (Participants: 32 local)

Children's Museum, Boca Raton, FL 33432

(Participants: $\mathbf{5 0}$ local)

Don Harrington District Center, Amarillo, TX 79106

(Participants: 60 local)

Estrella Squadron Warbird, Atascadero, CA 93422

(Participants: 5 local)

Fleischmann Planetarium, Reno, NV 89557

(Participants: 50 local)

Gayle Planetarium, Montgomery, AL 36106

(Participants: 30 local)

John May Museum Center, Colorado Springs, CO

80926 (Participants: 20 local)

Lakeview Museum of Arts \& Science, Peoria, IL

61614-5985 (Participants: 50 local)

Lutz Children's Museum, Manchester, CT 06040

(Participants: 30 local)

McClellan Aviation Museum, North Highlands, CA

95660 (Participants: 25 local)

Omnisphere Theater, Columbus, GA 31901

(Participants: 10 local)
Paulucci Space Theater, Hibbing, MN 55746-3357

(Participants: 8 local)

Pima Air and Space Museum, Tucson, AZ 85719

(Participants: 240 local)

West Museum of Flight, Hawthorne, CA 90250

(Participants: 2 local)

YMCA of the U.S.A., New York, NY 10118

\section{STEREO Presentation at Maryland Sclence Center}

Msn/Prg: $\quad$ STEREO

Description: Kerri Beisser and Linda Butter of JHU/APL- E/PO provided 200 STEREO posters and 3-D glasses to the Maryland Science Center Education Department. Lee Billingsley will use them as part of an informal presentation called Explainers, which deals with the overall concept of 3-D images, as we hold several events for press, public, and educators in late September/early October 2000 . These events are centered around the opening of the new 3-D IMAX theater. Posters and glasses will be used as giveaways following the presentations. Posters remaining after these events will be used for our ongoing informal presentations throughout the year.

Lead: $\quad$ STEREO E/PO Team, Johns Hopkins University Applied Physics Laboratory, Laurel, MD 20723-6099

Venue(s): Maryland Science Center, Baltimore, MD 21230

\section{VlowSPACE-Broadband Exhibltion Multimedia}

$\begin{array}{ll}\text { Msn/Prg: } & \text { HST, Keck } \\ \text { Theme(s): } & \text { ASO }\end{array}$

Description: An ongoing series of computer-based multimedia presentations, produced by the Space Telescope Science Institute's Office of Public Outreach. ViewSPACE is intended for use in museum, science center, and planetarium exhibit halls. The presentations combine high-resolution images, minimaliy intrusive text, mesmerizing space music, and digital music clips to deliver a quiet, inspiring experience of celestial beauty and wonder. ViewSPACE draws from all realms of astronomy to put Hubble images into context. Interested parties should contact John Stoke at the Space Telescope Science Institute in Baltimore: 410 338-4394, stoke@stsci.edu

Lead: $\quad$ Office of Public Outreach, Space Telescope Science Institute, Baltimore, MD 21218

Venue(s): $\quad$ KSC Visitor Complex, Kennedy Space Center, FL 32899

Maryland Science Center, Baltimore, MD 21230 (Participants: 100000 local) 
Targeted Outreach

\section{Minority Institution Inittative in Space Science}

\section{A Space Sclence Curriculum at Hampton University: Development of a Minor, Faculty Enhancement, and K-14 Outreach}

Msn/Prg: OSS, OEOP

Theme(s): $\quad$ ASO, SEC, SSE

Description: Hampton University will conduct a comprehensive and systematic program that will expand its existing base of space science experience from within the Hampton Center for Atmospheric Sciences (CAS) to encompass other Hampton University faculty, education students, community colleges, and local schools. An undergraduate academic program that focuses on the atmospheres of solar system bodies, and on the connections of the Sun with those bodies will be designed and implemented. As part of this program, a minor in atmospheric and space sciences will be developed within the Hampton University Physics Department. The Physics Department faculty will establish a space science course at a local community college and mentor a community college faculty member to assume responsibility for teaching that course. They will also implement a K-12 outreach program by training Hampton University education students to make space science presentations at local schools.

Lead: $\quad$ Dr. Scott Bailey, Hampton University, Hampton, VA 23668

Partner(s): $\quad$ University of Colorado, Boulder, CO 80309

Venue(s): $\quad$ Hampton University, Hampton, VA 23668

\section{An Urban Outreach Program in Space Sclence}

\section{Msn/Prg: $\quad$ OSS, OEOP}

Theme(s): $\quad$ ASO, SSE

Description: Through partnerships with NASA Johnson Space Center (JSC), the Houston Museum of Natural Science, Texas Southern University, and Houston-area schools and community groups, the University of Houston-Downtown (UH-D) will bring space science content to a variety of educational activities at all levels. Undergraduate students from UH-D and Texas Southern will receive research internships from the JSC Earth Science and Solar System Division, culminating in abstracts to be presented by the students at the annual Lunar and Planetary Science Conference. Student Ambassadors from minority-serving high schools and universities will be trained by NASA and university scientists to give space science demonstrations and short classes to museum visitors, school classrooms and clubs, and community-based youth organizations. Inservice teacher workshops on the origin and evolution of life and on the solar system will be offered by UH-D, Texas Southern, and JSC.

Lead: $\quad$ Dr. Penny Morris-Smith, University of HoustonDowntown, Houston, TX 77002
Partner(s):

Houston Museum of Natural Science, Houston, TX 77030

Interfaith Ministries for Greater Houston, Houston, TX

77002

Klein Independent School District, Klein, TX 77379-

3299

NASA Johnson Space Center, Houston, TX 77058

Raul Yzaguirre School for Success, Houston, TX

77002

Society of Hispanic Professional Engineers, Houston, TX 77259-0091

Society of Mexican American Engineers and

Scientists, Houston, TX 77259

Texas Southern University, Houston, TX 77004

Venue(s): $\quad$ University of Houston-Downtown, Houston, TX 77002

\section{Astronomy and Astrophysics Course Development at Salish Kootenal College}

Msn/Prg: $\quad$ OSS, OEOP

Description: Salish Kootenai College (SKC) will address a fundamental need for space science course development at SKC by developing four new space science courses. Two of these courses will be introductory astronomy courses for non-science majors, one for on-campus students and one for distance education delivery. The other two courses are a course in stellar astronomy and astrophysics and a course in galactic astronomy and astrophysics, both designed to help prepare SKC students to transfer to a baccalaureate degree program in astronomy or astrophysics elsewhere, and to better prepare them to participate in astrophysics research with the Principal Investigator.

$\begin{array}{ll}\text { Lead: } & \text { Dr. Timothy Olson, Salish Kootenai College, Pablo, MT } \\ & 59855 \\ \text { Venue(s): } & \text { Salish Kootenai College, Pablo, MT } 59855\end{array}$

Collision Processes In Astrophysical Plasmas

Msn/Prg: OSS, OEOP

Description: Florida A\&M University will develop new opportunities in space science in conjunction with an anticipated new Ph.D. program in physics. In collaboration with the Smithsonian Astrophysical Observatory, the Physics Department will establish a new graduate course in Atomic and Molecular Astrophysics. In collaboration with the Lawrence Livermore National Laboratory (LLNL), they will develop theoretical tools for modeling $x$-ray line formation by charge exchange, identify $x$-ray lines that can serve as diagnostics for these processes, and test the predicted spectra against laboratory measurements. They will also study electron impact processes for collisions with atomic and molecular ions.

Lead: $\quad$ Dr. Charles Weatherford, Florida A\&M University Tallahassee, FL 32307

Partner(s): $\quad$ Lawrence Livermore National Laboratory, Livermore, CA 94551-9900

Venue(s): $\quad$ Florida A\&M University, Tallahassee, FL 32307 


\section{Connecting Sun City with Sun-Earth Connections}

Msn/Prg: OSS, OEOP

Theme(s): $\quad$ SEC

Description: The University of Texas at El Paso (UTEP) will leverage EI Paso's reputation as "Sun City" to bring the science from NASA's SunEarth Connection theme into classes at UTEP and the EI Paso schools, and into other educational activities. Their coordinated and integrated interdisciplinary approach begins by having UTEP faculty from all of the science departments integrate Sun-Earth Connection science into undergraduate courses in their respective disciplines. The results will then be used for visits to El Paso high schools, special events, a one-week summer science camp at UTEP for high school students, a one-week summer institute at UTEP for teachers with a focus on the Texas Essential Knowiedge and Skills, and school year follow-up. Educational resources for this project will be provided by the Sun-Earth Connection Education Forum at the University of California at Berkeley and NASA Goddard Space Flight Center, and by the Space Telescope Science Institute.

Lead: $\quad$ Dr. Ramon Lopez, University of Texas at El Paso, Paso, TX 79968-0515

Partner(s): $\quad$ El Paso Science Museum, El Paso, TX 79901

SEC Forum, Berkeley, CA 94720

SEC Forum, Greenbelt, MD 20771

Space Telescope Science Institute, Baltimore, MD 21218

Venue(s): $\quad$ University of Texas at El Paso, El Paso, TX 799680515

\section{Enhancement of Space Science Research at South Carolina State University (SCSU)}

Msn/Prg: $\quad$ OSS, OEOP

Theme(s): $\quad$ SEU

Description: South Carolina State University (SCSU) will develop an extensive research and education partnership with a diverse range of institutions and locales, and they will bolster their astrophysics program by adding a second tenure-track astrophysicist to be supported by SCSU after grant period. The research projects will include providing thermophysical properties measurements of microgram superconducting materials that the Lawrence Livermore National Laboratory (LLNL) is developing for astrophysical $x$-ray detectors, and providing test observations of emission line objects in support of LLNL development of an Imaging Fourier Transform Spectrometer. SCSU will also expand its existing research on emission-line objects through new collaborations with NASA Goddard Space Flight Center and Clemson University, and gain access to Southern Hemisphere observations by joining a new collaboration between LLNL and the Boyden Observatory in South Africa. The education projects will include developing 9th-12th grade curriculum materials in galactic and extragalactic astronomy and cosmology, and providing inservice teacher workshops in collaboration with Case Western University, NASA's Southeastern Regional Clearinghouse (SERCH) Broker/Facilitator, and NASA's Classroom of the Future. They will use recruitment and scholarships to create a minority student pipeline in physics and astronomy from the University of the Virgin Islands and two- year colleges in South Carolina to SCSU and then on to Clemson for graduate work. In addition, they will establish an advanced research program in which minority students previously trained in existing SCSU summer programs will go on to conduct research at major astrophysical facilities.

Lead: $\quad$ Dr. Donald Watter, South Carolina State University, Orangeburg, SC 29117

Partner(s): $\quad$ Case Western Reserve University, Cleveland, $\mathrm{OH}$ 44106

Center for Educational Technologies, Wheeling, WW 26003

Clemson University, Clemson, SC 29634

Lawrence Livermore National Laboratory, Livermore, CA $94551-9900$

NASA Goddard Space Flight Center, Greenbelt, MD 20771

National Optical Astronomy Observatory, Tucson, AZ 85729-6732

SERCH Broker/Facilitator, Charleston, SC 29424

University of the Orange Free State, Bloemfontein, South Africa

University of the Virgin Islands, St. Thomas, U.S. Virgin Islands 00802

Venue(s): $\quad$ South Carolina State University, Orangeburg, SC 29117

\section{Internet-Based Education and Research with Robotic Telescopes for Native American and Hispanic Students}

Msn/Prg: $\quad$ OSS, OEOP

Description: Diné College, its partners in the South-West internet Program for Enhancement of Minority Education (SWIPEME), and its research collaborators at the Lawrence Livermore National Laboratory and the Space Telescope Science Institute will establish a common virtual educational and research environment using state-of-the-art computer and Internet technologies coupled with space observatory and robotic telescope data to deliver space science education and research programs to largely rural populations of Native American and Hispanic students in the Southwest. They will develop and disseminate a distributed curriculum in space science that is integrated into the programs of all SWIPEME campuses so that students at each member institution will be able to complete (or transfer to) a four-year physics and astronomy degree with a space science focus, and they will optimize the space sciences curriculum for the Internet in order to reach rural campuses where personnel are not available for direct implementation. In addition, faculty and students at all participating institutions will participate in a variety of collaborative space science research activities utilizing high bandwidth Internet connections and remotely-located collaborators.

Lead: $\quad$ Dr. Steven Semkin, Diné College, Shiprock, NM 86556 
Partner(s)

University of New Mexico, Albuquerque, NM 87131

New Mexico Highlands University, Las Vegas, NM

87701

University of California, Berkeley, CA 94720

Los Alamos National Laboratory, Los Alamos, NM

87545

Venue(s):

Diné College, Shiprock, NM 86556

MASA-HBCU Partnership to Enhance Minority Education and Research Participation in the Space Sciences

Msn/Prg: OSS, OEOP

Theme(s): $\quad$ SEC, SEU

Description: The Norfolk State University (NSU) Nuclear and Particle Physics Group will partner with the Laboratory for High Energy Astrophysics of NASA Goddard Space Flight Center to participate in the BESS, ISOMAX, ACCESS, and OWL particle astrophysics missions. The NSU contributions will include numerical simulations, analysis of digital data, development of new detector technologies, and development of data acquisition systems. This partnership is a first step toward the eventual creation of an astronomy option within the NSU Bachelor of Science curriculum and a graduate program involving the current NSU Nuclear and Particle Physics Group in particle astrophysics education and research. NSU will develop new courses in Observational Astronomy for high school teachers, and in Techniques for High Energy Astrophysics Detectors and Introduction to Astrophysics for undergraduate science majors. They will also offer summer research internships for local high school teachers and conduct an outreach program centered at the NSU planetarium that will include traveling activities, a bimonthly publication, Web site, public lectures, and cosmic ray detector chambers for use at high schools.

Lead:

Dr. Carlos Salgado, Norfolk State University, Norfolk, VA 23504

Partner(s): Chesapeake Public Schools, Chesapeake, VA 23322 NASA Goddard Space Flight Center, Greenbelt, MD 20771

Norfolk Public Schools, Norfolk, VA 23504

Portsmouth City Public Schools, Portsmouth, VA

23707-1205

Virginia Beach City Public Schools, Virginia Beach, VA 23456-0038

Venue(s):

Norfolk State University, Norfoik, VA 23504

\section{New Mexico Connections: Connecting People, Places, and} Research

$\begin{array}{ll}\text { Msn/Prg: } & \text { OSS, OEOP } \\ \text { Theme(s): } & \text { SEC, SEU }\end{array}$

Description: Eastern New Mexico University (ENMU) will build linkages through Pennsylvania State University with the Cosmic Ray Energetics and Mass (CREAM) balloon project. The Principal Investigator will extend his participation in CREAM from summers-only to one full year of project development work at Penn State, while involving a New Mexico teacher and ENMU undergraduate students in the research at Penn State during summers and at ENMU during academic years. ENMU will also develop and deliver three one-credit-hour courses for local $K-12$ teachers to increase their knowledge of space science and its relation to the history, culture, and facilities in New Mexico, and they will sponsor "NASA nights" at ENMU for students, parents, and teachers to engage in special learning opportunities.

$\begin{array}{ll}\text { Lead: } & \text { Dr. Scott Nutter, Eastern New Mexico University, } \\ & \text { Portales, NM } 88130 \\ \text { Partner(s): } & \text { Pennsylvania State University, State College, PA } \\ & 16803 \\ \text { Venue(s): } & \text { Eastern New Mexico University, Portales, NM 88130 }\end{array}$

New Opportunities through Minority Initiatives in Space Science

Msn/Prg: $\quad$ OSS, OEOP

Description: The University of Hawaii at Hilo $(\mathrm{UH}-\mathrm{H})$ will forge a unique partnership with the major observatories that sit at their doorstep and with a local school system that serves Native Hawaiian students. Utilizing the resources of the Mauna Kea observatories, $\mathrm{UH}-\mathrm{H}$ will develop two new undergraduate courses and laboratories: a lower division course designed to introduce prospective astronomers and observatory technicians to the basics of observational astronomy, and an upper division course in astronomical instrumentation. Through these courses and through cooperative research and training projects with the Mauna Kea Observatories, $\mathrm{UH}-\mathrm{H}$ expects to prepare the students for either entering graduate school in astronomy or for entering technical careers at major observatories. UH-H will also collaborate with the Kamehameha Schools (a private school system for Native Hawaiians) and the Hawaii Department of Education to develop K-12 curriculum connecting space science with Pacific sky lore and traditional Hawaiian knowledge.

$\begin{array}{ll}\text { Lead: } & \text { Dr. Richard Crowe, University of Hawaii at Hilo, Hilo, } \\ & \text { HI 96720-4091 } \\ \text { Partner(s): } & \text { Gemini Observatory, Hilo, HI } 96720 \\ & \text { Kamehameha Schools, Hilo, HI 96720 } \\ & \text { NASA Infrared Telescope Facility (IRTF), Honolulu, HI } \\ & 96822 \\ \text { Venue(s): } & \text { University of Hawaii at Hilo, Hilo, HI 96720-4091 }\end{array}$

\section{New York City Space Science Research Alliance}

Msn/Prg: $\quad$ OSS, OEOP

Description: Medgar Evers College will initiate a comprehensive approach to developing undergraduate degree and research programs at multiple campuses in the City University of New York (CUNY) system. They will establish a space science major within the CUNY BS degree program through cross-enrollment in space science courses to be offered by each participating college, at the American Museum of Natural History and at NASA's Goddard Institute for Space Studies. They will establish a multicampus space science research center in New York City, and use it to create a pipeline of space science research activities ranging from high school through community college, four-year college, and graduate school. 
Lead: Dr. Leon Johnson, Medgar Evers College, Brooklyn, NY 11225

Partner(s): $\quad$ American Museum of Natural History, New York, NY 10024

City College of New York, New York, NY 10031

College of Staten Island, Staten Island, NY 10314

Goddard Institute for Space Studies, New York, NY

10025

LaGuardia Community College, Long Island, NY 11101

Long Island University, Brooklyn, NY 11201

Minority University Space Interdisciplinary Network,

NASA Goddard Space Flight Center, Greenbelt, MD

20771

NASA Goddard Space Flight Center, Greenbelt, MD

20771

New York City Louis Stokes Alliance for Minority

Participation, New York, NY 10031

Queensborough Community College, Bayside, NY

11364

South Carolina State University, Orangeburg, SC

29117

Venue(s): $\quad$ Medgar Evers College, Brooklyn, NY 11225

Partnerships In Astronomy and Astrophysics Education and Research at Southern UnIversity

Msn/Prg: OSS, OEOP

Theme(s): $\quad$ SEC, SEU

Description: This project leverages the innovative joint Southern University at Baton Rouge and Louisiana State University (LSU) astrophysics program, under which the Principal Investigator holds an appointment at both universities, to bring Southern University students and faculty into active participation in two NASA space science flight projects. In collaboration with LSU, Southern University faculty and students will carry out hardware development activities on campus at Southern for the Minute-of-Arc Resolution Gamma-ray Imaging Experiment (MARGIE) balloon project. In a collaboration with the Smithsonian Astrophysical Observatory's (SAO) Ultraviolet Coronagraph Spectrometer (UVCS) on the Solar and Heliospheric Observatory ( $\mathrm{SOHO}$ ), SAO scientists will establish a solar corona lecture series at Southern, provide research opportunities at SAO for Southern University students, and develop associated Internet and mentoring support for the students.

Lead: $\quad$ Dr. J. Gregory Stacy, Southern University and A\&M College, Baton Rouge, LA 70813

Partner(s): $\quad$ Highland Road Park Observatory, Baton Rouge, LA 70810

Louisiana State University, Baton Rouge, LA 70803-

4001

Smithsonian Astrophysical Observatory, Cambridge, MA 02138

Venue(s): $\quad$ Southern University and A\&M College, Baton Rouge, LA 70813

\section{Space Sclence Education and Sun-Earth Connection}

Msn/Prg: $\quad$ OSS, OEOP

Theme(s): $\quad$ SEC, SSE

Description: Alabama A\&M University (AAMU) will initiate a new BS degree program in physics and applied physics with space science as the major concentration area. They will develop four new AAMU advanced physics courses in the lower atmosphere, upper atmosphere, solar system, and orbital mechanics, to be taught by existing AAMU faculty and scientists from NASA Marshall Space Flight Center. AAMU students will also cross-enroll in additional space science courses at the University of Alabama at Huntsville. In collaboration with NASA Goddard Space Flight Center, NASA Marshall Space Flight Center, the University of Alabama at Huntsville, and the Lawrence Livermore National Laboratory, AAMU will develop a research program in the short-term and long-term effects of solar variability on the terrestrial environment. All AAMU students enrolled in the new degree program will be required to complete a one-semester research project in this area.

$\begin{array}{ll}\text { Lead: } & \text { Dr. Arjun Tan, Alabama A\&M University, Normal, AL } \\ & 35762 \\ \text { Partner(s): } & \text { Lawrence Livermore National Laboratory, Livermore, } \\ & \text { CA } 94551-9900 \\ & \text { NASA Goddard Space Flight Center, Greenbelt, MD } \\ & 20771 \\ & \text { NASA Marshall Space Flight Center, Marshall Space } \\ & \text { Flight Center, AL 35812 } \\ & \text { University of Alabama at Huntsville, Huntsville, AL } \\ & 35899 \\ \text { Venue(s): } & \text { Alabama A\&M University, Normal, AL } 35762\end{array}$

Stars on Earth

Msn/Prg: OSS

Theme(s): $\quad$ SSE

Description: In partnership with the U.S. Department of Education Upward Bound program and the University of New Mexico, Southwestern indian Polytechnic Institute (SIPI) will conduct a unique program that infuses space science knowledge into the successful Upward Bound format in a manner specifically designed to improve the educational attitudes of Native American students and their teachers about science, mathematics, and technology. Activities will include an intensive summer residential program, Saturday academies, and year-round academic support and research activities for high school students, parents, and teachers. In addition, through a collaboration with Dr. Horton Newsome of the University of New Mexico Institute for Meteoritics, SIPI will establish a meteorite identification laboratory on campus at SIPI and involve SIPI faculty and students in research collaborations on Mars surface science and landing site identification.

Lead:

Catherine Abeita, Southwestern Indian Polytechnic Institute, Albuquerque, NM 87184

Partner(s): $\quad$ University of New Mexico, Albuquerque, NM 87131

Venue(s): $\quad$ Soutthwestern Indian Polytechnic Institute,

Albuquerque, NM 87184 
York College Observatory Educational Outreach Service to the College and the Public School Community

Msn/Prg: $\quad$ OSS, OEOP

Theme(s): $\quad$ SEU, SSE

Description: York College will improve its science education infrastructure by linking the newly funded York College Observatory with the NASA Jet Propulsion Laboratory Telescopes in Education program, the Microwave Anisotropy Probe (MAP) mission educational outreach programs, the Department of Astrophysical Sciences at Princeton University, York College faculty, and master teachers from the NYC Public Schools. With Princeton, they will establish an undergraduate research program in variable stars and itinerant solar system bodies using All-Sky Automated Search program data. They will improve their physics curricula by incorporating astronomy into all levels of the undergraduate physics major and into the physics programs for secondary school teachers. They will improve general education and pre-service teacher training courses by incorporating NASA-developed materials, Web sites, and linkages into such courses. They will improve secondary school science education by reactivating and developing for accreditation a Secondary High School Physics Education Program, by establishing an after-school series of space science theme institutes for pre-service and in-service teachers, and by creating a model demonstration class in physics for inner city high schools. To ensure continuity, they will hire a new astronomy faculty member and convert that position to a tenure-track position at the conclusion of the grant period.

Lead: $\quad$ Dr. Martin Spergel, York College, Jamaica, NY 11451 Partner(s): $\quad$ American Museum of Natural History, New York, NY 10024

NASA Jet Propulsion Laboratory, Pasadena, CA 91109 Princeton University, Princeton, NJ 08544-1001

Venue(s): $\quad$ York College, Jamaica, NY 11451

\section{University Research Centers}

Center for Automated Space Sclence (CASS)

Msn/Prg: $\quad$ OSS, OEOP

Theme(s): $\quad$ ASO, SEC, SEU

Description: CASS operates and is expanding a completely automated astronomical observatory in the mountains of southern Arizona for highprecision photometry, CCD imaging, and high-resolution spectroscopy. These telescopes make astronomical observations less expensive and more flexible through automated operations. They will provide supporting observations for a wide variety of space-based observing plattorms as well as important data on magnetic activity in cool stars. One ongoing program measures long-term luminosity changes in Sun-like stars in a way that will be useful for understanding Sun-induced changes in Earth's climate. Another program uses the automatic telescopes in a search for extra-solar planets.
Lead:

Dr. Michael Busby, Tennessee State University, Nashville, TN 37403

Partner(s): $\quad$ South Carolina State University, Orangeburg, SC 29117

Western Kentucky University, Bowling Green, KY 42101

Venue(s): $\quad$ Tennessee State University, Nashville, TN 37403

\section{Other Activities}

\section{An Astronomy Outreach Program for Mavajo and Hopl Middle Schools \\ Msn/Prg: $\quad$ IDEAS}

Description: The goals are to use astronomy to get Navajo and Hopi children excited about astronomy, science, and education in general, and to help teachers of Navajo and Hopi students learn about astronomy and astronomy activities so that they can better incorporate astronomy into their classrooms.

Lead: $\quad$ Dr. Amanda Bosh, Lowell Observatory, Flagstaff, AZ 86001

Venue(s): $\quad$ Chinle Middle School, Chinle, AZ 86503

Cottonwood Day School, Cottonwood, AZ 86326

Hopi Day School, Phoenix, AZ 85018

Hopi Polacca Day School, Polacca, AZ 86042

Second Mesa Day School, Second Mesa, AZ 86043

Tonalea Day School, Scottsdale, AZ 85257

Tse' Bit' Ai Middle School, Shiprock, NM 87420

\section{Minority University-Space Interdisciplinary Metwork (MU-SPIM) Break-0ut Session}

$\begin{array}{ll}\text { Msn/Prg: } & \text { MESSENGER } \\ \text { Theme(s): } & \text { SSE }\end{array}$

Description: September 14, 2000: Stephanie Stockman, panel participant, has developed a flight programs break-out session at Joint Minority University-Space Interdisciplinary Network (MU-SPIN) and NASA Minority University Research and Education Division (MURED) Conference, Atlanta, Georgia, for university students and professors.

$\begin{array}{ll}\text { Lead: } & \text { Messenger E/PO Team, NASA Goddard Space Flight } \\ & \text { Center, Greenbelt, MD 20771 } \\ \text { Partner(s): } & \text { Minority University Space Interdisciplinary Network, } \\ & \text { NASA Goddard Space Flight Center, Greenbelt, MD } \\ & 20771 \\ \text { Venue(s): } & \text { Minority University-Space Interdisciplinary Network } \\ & \text { (MU-SPIN) Conference, September 2000, Atlanta, GA } \\ & 30308 \text { (Participants: } 50 \text { local) }\end{array}$




\section{Minority University-Space Interdisciplinary Network (MU-SPIN) Workshop}

Msn/Prg: SEC Forum, Ulysses, ACE, HESSI, IMAGE, TRACE, ISTP, SOHO, Wind, Voyager, Deep Impact, Genesis

Theme(s): SEC

Description: MU-SPIN Workshops were developed to provide information and networking opportunities for college professors and school district representatives pertaining to funding, collaborations, and professional development.

$\begin{array}{ll}\text { Lead: } & \text { SEC Forum, NASA Goddard Space Flight Center, } \\ & \text { Greenbelt, MD 20771 } \\ \text { Partner(s): } & \text { Minority University Space Interdisciplinary Network, } \\ & \text { NASA Goddard Space Flight Center, Greenbelt, MD } \\ & 20771 \\ & \text { SUNBEAMS, NASA Goddard Space Flight Center, } \\ & \text { Greenbelt, MD 20771 } \\ \text { Venue(s): } & \text { Atlanta, GA 30308 (Participants: 250 local) } \\ & \text { Morgan State University, Baltimore, MD 21251 } \\ & \text { (Participants: } 25 \text { local) } \\ & \text { South Carolina State University, Orangeburg, SC } \\ & \text { 29117 (Participants: } 55 \text { local) } \\ \text { University of Texas at El Paso, El Paso, TX 79968- } & \text { 0515 (Participants: 40 local) }\end{array}$

National Conference of Black Physics Students

Msn/Prg: $\quad$ OSS

Description: The conterence provides an outlet for schools and companies to recruit talented Black students while at the same time provides a forum in which mentors and industrial contacts are brought together with students. We, the conference committee, have taken special care to make sure that this year's conference addresses many of the social issues that Black students face in physics as well as the pragmatic issues of getting jobs or moving on to the next phase of education. NASA provided information about student programs and careers at NASA, especially in the area of Space Science.

Lead: $\quad$ OSS, NASA Headquarters, Washington, DC 20546

Partner(s): $\quad$ National Conference of Black Physics Students

Venue(s): National Conference of Black Physics Students, Berkeley, CA 94720

OSS Exhiblt at National Council of La Raza

Msn/Prg: $\quad$ SEC Forum, OSS

Theme(s): $\quad$ SEC

Description: The NASA Office of Equal Opportunity Programs sponsored this Hispanic outreach conference and recruited staff from almost all Enterprises/Field Centers to staff a 40-foot $\times 60$-foot exhibit. SECEF was invited to coordinate a Space Science booth that was staffed by space scientists and education specialists primarily from GSFC and JPL. SERCH, an OSS broker/facilitator, was also present. More than 1,500 visitors stopped by the Space Science booth.

$\begin{array}{ll}\text { Lead: } & \text { SEC Forum, NASA Goddard Space Flight Center, } \\ & \text { Greenbelt, MD } 20771 \\ \text { Venue(s): } & \text { National Council of La Raza, Houston, TX } 77010\end{array}$

\section{OSS Outreach at National Society of Black Physicists (NSBP)}

Msn/Prg: $\quad$ SEC Forum, OSS

Description: This year the National Society of Black Physicists (NSBP) had a joint meeting with the National Conference of Black Physics Students at North Carolina A\&T State University. NASA Goddard Equal Opportunity Programs Office had a recruitment table at the conference. Dr. Beth Brown, an NRC fellow and an astrophysicist, presented talks and also staffed the booth.

Lead: $\quad$ OSS, NASA Headquarters, Washington, DC 20546

Partner(s): $\quad$ National Society of Black Physicists

Venue(s): $\quad$ National Society of Black Physicists, Greenboro, NC 27411

\section{Outer Planets/Solar Probe Project: From the Sun to the Star Nations}

Msn/Prg: $\quad$ SIRTF, NAl, Keck, Solar Probe, Ulysses, Cassini/Huygens Probe, Galileo, Voyager, Deep Impact, Stardust, Mars, OP/SP, Europa Orbiter Pluto/Kuiper Express, DS-1, DSMS

Theme(s): $\quad$ SSE

Description: From the Sun to the Star Nations brings together expertise in the areas of science, science education, intercultural communications, and traditional star knowledge to devise ways to present space exploration and star knowledge side by side in a balanced and respectful look at science and cultural issues. By working in several venues--the traditional community, the schools, and the Tribal College structure-this approach provides greater access to science and technology for Native American youth, while contributing to the preservation of living traditiona) knowledge. We facilitate learning experiences, school-to-work internships, and Web-based instruction, and cultivate an ongoing relationship with elders in the community. We facilitate community access to computers and the Internet. We encourage efforts to recover and preserve traditional knowledge in ongoing oral traditions.

Lead: $\quad$ OP/SP E/P0 Team, NASA Jet Propulsion Laboratory, Pasadena, CA 91109

Venue(s): $\quad$ Flagstaff School District, Flagstaff, AZ 86004 (Participants: 10 local) Hopi Public Schools, AZ86039 (Participants: 250 local) Northern Arizona University, Flagstaff, AZ 86011 (Participants: 499 local; 4 events) Pinon Community School, Pinon, AZ 86510 (Participants: 175 local) Pinon School District, Pinon, AZ 86510 (Participants: 552 local) 
Tuba City School District, Tuba City, AZ 86045

(Participants: 344 local)

\section{Educational Products}

\section{A Teachers' Guide to the Universe}

$\begin{array}{ll}\text { Subject(s): } & \text { Mathematics, Space Science } \\ \text { Format(s): } & \text { Web Site } \\ \text { Audience: } & \text { Grades } 9-12 \\ \text { Msn/Prg: } & \text { MAP } \\ \text { Theme(s): } & \text { SEU }\end{array}$

Description: This Web page was designed for high school teachers or educators of the same level who are interested in teaching astronomy and cosmology to their students. The lesson plans were designed over several months in collaboration with Professor David Spergel of the Department of Astrophysics of Princeton University and Dr. Margaret Fels, Center for Teaching and Learning at Princeton University, to enrich high school classrooms with astronomy lesson plans according to guidelines suggested by the Core Curriculum Content Standards of the State of New Jersey and by the National Science Education Standards.

Lead:

$$
\begin{aligned}
& \text { MAP E/PO Team, Adler Planetarium and Astronomy } \\
& \text { Museum, Chicago, IL } 60605
\end{aligned}
$$

\section{ACE Brochure}

Subject(s):

Earth Science, Physical Science, Space Science, Technology

Format(s): Pamphlet

Audience: $\quad$ Grades 9-12, AdultContinuing Education, Community College, General Public

Msn/Prg: $\quad$ ACE

Theme(s): $\quad$ SEC, SEU

Description: 24-page, full-color booklet explaining the Advanced Composition Explorer (ACE) mission and ACE science. Includes information on composition, solar activity, cosmic rays, and space weather.

Lead:

ACE E/PO Team, NASA Goddard Space Flight Center, Greenbelt, MD 20771

\section{ACE Science Fact Sheot}

$\begin{array}{ll}\text { Subject(s): } & \begin{array}{l}\text { Earth Science, Physical Science, Space Science, } \\ \text { Technology }\end{array} \\ & \text { Pamphlet } \\ \text { Format(s): } & \begin{array}{l}\text { Grades 9-12, Adult/Continuing Education, Community } \\ \text { Audience: }\end{array} \\ & \text { College, General Public, Higher Education } \\ \text { Msn/Prg: } & \text { ACE } \\ \text { Theme(s): } & \text { SEC, SEU }\end{array}$

Description: 1-page, double-sided, full-color fact sheet explaining the Advanced Composition Explorer (ACE) mission and ACE science. Includes information on cosmic rays and energetic particles.

Lead: ACE E/PO Team, NASA Goddard Space Flight Center, Greenbelt, MD 20771

\section{Aerogel Brochure}

$\begin{array}{ll}\text { Subject(s): } & \text { Space Science } \\ \text { Format(s): } & \text { Pamphlet, PDF } \\ \text { Audience: } & \text { General Public } \\ \text { Msn/Prg: } & \text { Stardust } \\ \text { Theme(s): } & \text { SSE }\end{array}$

Description: This resource was developed for the general public. It is a top-level overview of aerogel and its use on the STARDUST mission.

Lead: $\quad$ Stardust E/PO Team, NASA Jet Propulsion Laboratory, Pasadena, CA 91109

\section{Amazing Space Web Site}

$\begin{array}{ll}\text { Subject(s): } & \text { Physical Science, Space Science } \\ \text { Format(s): } & \text { Web Site } \\ \text { Audience: } & \text { Grades K-12, General Public } \\ \text { Msn/Prg: } & \text { HST } \\ \text { Theme(s): } & \text { ASO }\end{array}$

Description: "Amazing Space" is a set of Web-based interactive activities primarily designed for classroom use, but made available for all to enjoy All lessons include spectacular images taken by the Hubble Space Telescope and high-quality graphics, videos, and animation designed to enhance student understanding and interest. Extensive Teacher Pages are provided with each module.

Lead: $\quad$ Amazing Space Team, Space Telescope Science Institute, Baltimore, MD 21218

\section{AstroCappella}

$\begin{array}{ll}\text { Subject(s): } & \text { Physical Science, Space Science } \\ \text { Format(s): } & \text { CD, Pamphlet, Web Site } \\ \text { Audience: } & \text { Grades K-12, Community College, General Public, } \\ & \text { Higher Education } \\ \text { Msn/Prg: } & \text { HEASARC } \\ \text { Theme(s): } & \text { SEU }\end{array}$

Description: AstroCappella combines the love of music with the love of astronomy. The Audio CD contains six songs dealing with radio astronomy, the Doppler shift, Hubble Space Telescope, $x$-ray astronomy, the Sun, and nearby stars. An activity booklet with the lyrics for the songs and a gtossary of terms accompany the audio CD. The AstroCappella Web site features both the AstroCappella songs and activities, as well as additional background information about the songs' topics. 


46 Lead: $\begin{array}{ll}\text { HEASARC E/PO Team, NASA Goddard Space Flight } \\ \text { Center, Greenbelt, MD } 20771\end{array}$

Astronaut Challenge

$\begin{array}{ll}\text { Subject(s): } & \text { Space Science } \\ \text { Format(s): } & \text { Web Site } \\ \text { Audience: } & \text { Grades 6-8, General Public } \\ \text { Msn/Prg: } & \text { HST } \\ \text { Theme(s): } & \text { ASO }\end{array}$

Description: This interactive online computer lesson is filled with video clips and up-to-the-minute information from NASA and the Space Telescope Science Institute. Your students, using critical thinking and reading skills, search for word and picture clues to sequence the events in the 1997 Second Servicing Mission of the Hubble Space Telescope.

Lead: $\quad$ Amazing Space Team, Space Telescope Science Institute, Baltimore, MD 21218

\section{Bringing Images from Space to Earth}

$\begin{array}{ll}\text { Subject(s): } & \text { Earth Science, Physical Science, Space Science } \\ \text { Format(s): } & \text { Pamphlet, Web Site } \\ \text { Audience: } & \text { Grades 6-12, General Public } \\ \text { Msn/Prg: } & \text { DSMS } \\ \text { Theme(s): } & \text { SSE }\end{array}$

Description: Flyers describing the process of a spacecraft acquiring an image of a planet or moon and how that becomes a photograph we can see.

Lead:

DSMS E/PO Team, NASA Jet Propulsion Laboratory, Pasadena, CA 91109

\section{Bulld a Dobsonian Tolescope Activity}

$\begin{array}{ll}\text { Subject(s): } & \text { Space Science, Technology } \\ \text { Format(s): } & \text { Book, Web Site } \\ \text { Audience: } & \text { Grades 6-12, Adult/Continuing Education, Community } \\ & \text { College, General Public, Higher Education, Vocational } \\ & \text { Education } \\ \text { Msn/Prg: } & \text { OSS, OHRE } \\ \text { Theme(s): } & \text { SSE }\end{array}$

Description: This Web site contains complete instructions for constructing a Sidewalk (Dobsonian) telescope using an eight-inch diameter or teninch diameter purchased objective mirror. You will need to purchase one objective (primary) mirror and one diagonal, flat (secondary) mirror, in order to build the telescope. Mirrors may be purchased from mail-order telescope supply houses. Coulter Optical is an excellent, dependable source for good-quality, inexpensive mirrors, so we have included their address in the Sources section. What we describe as a Sidewalk Telescope, or Dobsonian Telescope, is a simple Newtonian reflecting telescope in a sturdy, wooden alt-azimuth mount or rocker. The telescope consists of a concave objective (or primary) mirror, which is usually mounted in the bottom of the tube. This objective gathers light from the object under observation and brings the light to a focus, forming an image of the object in what is called the focal plane or image plane, at the upper end of the tube

$$
\begin{array}{ll}
\text { Lead: } & \text { Telescopes in Education, NASA Jet Propulsion } \\
& \text { Laboratory, Pasadena, CA } 91109
\end{array}
$$

\section{Cassini Mission to Saturn Color Fact Sheet}

$\begin{array}{ll}\text { Subject(s): } & \text { Physical Science, Space Science } \\ \text { Format(s): } & \text { PDF } \\ \text { Audience: } & \text { Grades 7-12, Adult/Continuing Education, Community } \\ & \text { College, General Public, Higher Education } \\ \text { Msn/Prg: } & \text { Cassini/Huygens Probe } \\ \text { Theme(s): } & \text { SSE }\end{array}$

Description: This is a Cassini/Huygens mission fact sheet with Titan's orbit around Saturn, the mission's interplanetary trajectory and the Cassini spacecraft image with labeled parts. The fact sheet can be ordered hardcopy or downloaded as a PDF file.

Lead:

Cassini E/PO Team, NASA Jet Propulsion Laboratory, Pasadena, CA 91109

\section{Cassinl Mission to Saturn Spanish Fact Sheet}

$\begin{array}{ll}\text { Subject(s): } & \text { Physical Science, Space Science } \\ \text { Format(s): } & \text { PDF } \\ \text { Audience: } & \text { Grades 7-12, Adult/Continuing Education, Community } \\ & \text { College, General Public, Higher Education } \\ \text { Msn/Prg: } & \text { Cassini/Huygens Probe } \\ \text { Theme(s): } & \text { SSE }\end{array}$

Description: This is a Cassini/Huygens mission fact sheet. It has Titan's orbit around Saturn, the mission's interplanetary trajectory, and the Cassini spacecraft image with labeled parts. The fact sheet can be ordered from Cassini Outreach in hardcopy or downloaded from the Cassini Web site as a PDF file.

Lead: Cassini E/P0 Team, NASA Jet Propulsion Laboratory,
Pasadena, CA 91109

\section{Cassinl/Huygens Mission to Saturn and Ttan}

$\begin{array}{ll}\text { Subject(s): } & \begin{array}{l}\text { Earth Science, Physical Science, Space Science, } \\ \text { Technology }\end{array} \\ \text { Format(s): } & \begin{array}{l}\text { Slide/Slide set } \\ \text { Grades 5-12, Adult/Continuing Education, Community }\end{array} \\ \text { Audience: } & \text { College, General Public, Higher Education, Vocational } \\ & \text { Education } \\ \text { Msn/Prg: } & \text { Cassini/Huygens Probe } \\ \text { Theme(s): } & \text { SSE }\end{array}$

Description: 20 color slides with fact sheet depicting Cassini/Huygens Mission to Saturn and Titan. It has images of Saturn and a descent profile of Huygens and Cassini mural. To view online, go to http://www.jpl,nasa.gov/cassini/lmages/slides 
Lead:

Cassini E/PO Team, NASA Jet Propulsion Laboratory, Pasadena, CA 91109

\section{Cassini/Huygens Spacecraft 1/37 Scale Model}

Subject(s): $\quad$ Earth Science, Physical Science, Space Science

Format(s): $\quad$ Kit, Model, PDF, Web Site

Audience: $\quad$ Grades 9-12, Adult/Continuing Education, Community College, General Public, Vocational Education

Msn/Prg: $\quad$ Cassini/Huygens Probe

Theme(s): $\quad$ SSE

Description: This is a 1/37 scale model of the Cassini/Huygens Spacecraft. This activity requires only scissors and glue to create, and is for an experienced modeler.

Lead: $\quad$ Cassini E/PO Team, NASA Jet Propulsion Laboratory, Pasadena, CA 91109

\section{Chandra 101: Overview for Teachers and Students}

$\begin{array}{ll}\text { Subject(s): } & \text { Space Science } \\ \text { Format(s): } & \text { Web Site } \\ \text { Audience: } & \text { Grades 8-12, Adult/Continuing Education, Community } \\ & \text { College, General Public, Higher Education } \\ \text { Msn/Prg: } & \text { CXO } \\ \text { Theme(s): } & \text { SEU }\end{array}$

Description: Chandra 101 provides basic information about topics pertaining to the Chandra X-Ray Observatory. Quality site offering clear information and detailed links for those who wish to investigate further.

Lead: $\quad$ CXO E/PO Team, Harvard-Smithsonian Center for Astrophysics, Cambridge, MA 02138

\section{Chandra Coloring and Activity Book}

Subject(s):

Space Science

Format(s):

Web Site

Audience:

Grades 4-8, General Public

Msn/Prg:

CXO

Theme(s):

SEU

Description: This fun and exciting 24-page coloring and activity book includes general information on $x$-ray astronomy, Chandra, and the STS93 mission. It is intended for parents to use with their children. It also looks at the sources Chandra investigates: black holes, supernovae, galaxy clusters, and even a mystery object. Each image is accompanied by a summary of information. Activities include a maze, word search, connect-the-dots, and word jumble.

Lead:

CXO E/PO Team, Harvard-Smithsonian Center for Astrophysics, Cambridge, MA 02138

\section{Chandra Photo Album}

Subject(s): $\quad$ Physical Science, Space Science

Format(s): Photograph, Web Site

Audience: $\quad$ Grades 6-12, Adult/Continuing Education, Community

College, General Public, Higher Education

Msn/Prg: $\quad$ CXO

Theme(s): $\quad$ SEU

Description: A collection of images taken by the Chandra $X$-ray Observatory, including image descriptions and comparison with optical images. Includes Cycle 1 science images, Chandra's Ffirst images, images by category, chronological listing, and a sky map. Printable handouts of images with captions.

Lead:

CXO E/PO Team, Harvard-Smithsonian Center for Astrophysics, Cambridge, MA 02138

\section{Colliding Galaxies}

$\begin{array}{ll}\text { Subject(s): } & \text { Space Science } \\ \text { Format(s): } & \text { Lithograph, PDF } \\ \text { Audience: } & \text { Adult/Continuing Education, General Public, Preschool } \\ & \text { Education } \\ \text { Msn/Prg: } & \text { HST } \\ \text { Theme(s): } & \text { SEU }\end{array}$

Description: Picture and brief description of the antennae colliding galaxies.

Lead:

HST E/PO Team, Space Telescope Science Institute, Baltimore, MD 21218

\section{Comets}

Subject(s): $\quad$ Space Science

Format(s): Web Site

Audience: Grades 5-8, General Public

Msn/Prg: $\quad$ HST

Theme(s): $\quad$ ASO

Description: Comets identifies the possible ingredients that could make up a comet. Students mix different combinations of elements and compounds found in a comet's nucleus to make different-looking comets. They learn that these ingredients create different types of comet tails. An assessment activity using real images of comets asks students to name the type of tail shown. Students also explore myths, legends, and facts connected to the appearance of comets throughout history.

Lead: $\quad$ Amazing Space Team, Space Telescope Science Institute, Baltimore, MD 21218 
Comets: A Multimedia Presentation for Schools

$\begin{array}{ll}\text { Subject(s): } & \text { Space Science } \\ \text { Format(s): } & \text { Slide/Slide set, Web Site } \\ \text { Audience: } & \text { General Public } \\ \text { Msn/Prg: } & \text { IDEAS } \\ \text { Theme(s): } & \text { ASO }\end{array}$

Description: The presentation covers three topics, Cosmic Fossils, Comet Hyakutake and Comet Hale-Bopp. Sample topics of the presentation are the nature and structure of comets, Oort Cloud, comet tails, orbits, spectra, and electromagnetic radiation. The presentation can be either viewed via the World Wide Web or downloaded as a PowerPoint slide show.

Lead: $\quad$ Dr. J. Mukherjee, Florida Space Grant Consortium, Kennedy Space Center, FL 32899

\section{Cosmic and Heliospheric Learning Center}

Subject(s): $\quad$ Earth Science, Physical Science, Space Science, Technology

Format(s): Web Site

Audience: Grades 9-12, Adult/Continuing Education, Community College, General Public, Higher Education

Msn/Prg: $\quad$ ACE

Theme(s): $\quad$ SEC, SEU

Description: Tutorial on heliospheric and cosmic ray science. A collection of resources covering astrophysics basics, space weather, solar activity, related news and activities, glossary, history, and "Ask a Physicist" service with hundreds of $Q \& A$.

Lead: ACE E/PO Team, NASA Goddard Space Flight Center, Greenbelt, MD 20771

Cosmic Survey: What Are Your Ideas About the Unlverse?

$\begin{array}{ll}\text { Subject(s): } & \text { Space Science } \\ \text { Format(s): } & \text { PDF, Web Site } \\ \text { Audience: } & \text { Grades 6-12, Adult/Continuing Education, Community } \\ & \text { College, General Public, Higher Education } \\ \text { Msn/Prg: } & \text { SEU Forum } \\ \text { Theme(s): } & \text { SEU }\end{array}$

Description: Lesson plan and activity composed of a three-part questionnaire that launches students on discussions about where objects in space are located, and when they were formed-an introduction to the concepts of structure and evolution of the universe.

Lead: $\quad$ SEU Forum, Smithsonian Astrophysical Observatory, Cambridge, MA 02138

\section{Deep Impact Fact Sheet}

Subject(s):

Earth Science, Mathematics, Physical Science, Space Science

Format(s): $\quad$ Pamphlet, PDF

Audience: $\quad$ Grades 6-12, Adult/Continuing Education, Community College, General Public, Higher Education, Vocational Education

Msn/Prg: $\quad$ Deep Impact

Theme(s): $\quad$ SSE

Description: An overview of the Deep Impact Mission is provided on a fact sheet of two pages. The science abjectives, implementation, and description of the spacecraft and impactor are discussed. This fact sheet is appropriate for middle school through adult audiences.

Lead: $\quad$ Office of Public Outreach, NASA Jet Propulsion Laboratory, Pasadena, CA 91109

\section{Deep Space Network Brochure}

$\begin{array}{ll}\text { Subject(s): } & \text { Space Science, Technology } \\ \text { Format(s): } & \text { Pamphlet, Web Site } \\ \text { Audience: } & \text { Adult/Continuing Education, Community College, } \\ & \text { General Public, Higher Education, Vocational } \\ & \text { Education } \\ \text { Msn/Prg: } & \text { DSMS } \\ \text { Theme(s): } & \text { SSE }\end{array}$

Description: This brochure describes the capabilities of NASA's Deep Space Network, which provides the means of communicating with robotic spacecraft expioring the solar system. For general audiences. Includes some technical information.

Lead: DSMS E/PO Team, NASA Jet Propulsion Laboratory, Pasadena, CA 91109

\section{Deep Space Network Communications}

$\begin{array}{ll}\text { Subject(s): } & \text { Earth Science, Physical Science, Space Science } \\ \text { Format(s): } & \text { Lithograph, PDF } \\ \text { Audience: } & \text { Grades 6-12, General Public } \\ \text { Msn/Prg: } & \text { DSMS } \\ \text { Theme(s): } & \text { SSE }\end{array}$

Description: Lithograph describing the role of the Deep Space Network in receiving the data from robotic spacecraft exploring the solar system.

Lead: DSMS E/PO Team, NASA Jet Propulsion Laboratory, Pasadena, CA 91109 


\section{Deep Space Network-Radlo Astronomy}

$\begin{array}{ll}\text { Subject(s): } & \text { Earth Science, Physical Science, Space Science } \\ \text { Format(s): } & \text { Lithograph, PDF } \\ \text { Audience: } & \text { Grades 6-12, General Public } \\ \text { Msn/Prg: } & \text { DSMS } \\ \text { Theme(s): } & \text { SSE }\end{array}$

Description: This resource is a lithograph describing how radio astronomy can reveal new information about planets, galaxies, and other phenomenon which are not apparent through visible wavelengths.

Lead:

$$
\begin{aligned}
& \text { DSMS E/PO Team, NASA Jet Propulsion Laboratory, } \\
& \text { Pasadena, CA } 91109
\end{aligned}
$$

\section{Destination Mars}

$\begin{array}{ll}\text { Subject(s): } & \text { Earth Science, Space Science, Life Science } \\ \text { Format(s): } & \text { Book, PDF } \\ \text { Audience: } & \text { Grades 5-12, Adult/Continuing Education, Community } \\ & \text { College, General Public, Higher Education } \\ \text { Msn/Prg: } & \text { Sample Curation } \\ \text { Theme(s): } & \text { SSE }\end{array}$

Description: This resource is an activity packet. It is a set of 6 hands-on lessons relating to Mars. It focuses on geology + water + life, but also includes math and social studies lessons. Lessons range from 5 th grade all the way to college level. A video is also available.

Lead: $\quad$ Sample Curation E/PO Team, NASA Johnson Space Center, Houston, TX 77058

\section{Differential Rotation of the Sun}

$\begin{array}{ll}\text { Subject(s): } & \text { Physical Science, Space Science } \\ \text { Format(s): } & \text { Web Site } \\ \text { Audience: } & \text { Grades 9-12 } \\ \text { Msn/Prg: } & \text { SOHO } \\ \text { Theme(s): } & \text { SEC }\end{array}$

Description: A lesson using $\mathrm{SOHO}$ data to illustrate the differential rotation of the Sun.

Lead:

$$
\begin{aligned}
& \text { SOHO E/PO Team, NASA Goddard Space Flight Center, } \\
& \text { Greenbelt, MD } 20771
\end{aligned}
$$

\section{Do You See What I See? A Lesson About Astronomical Imaging}

$\begin{array}{ll}\text { Subject(s): } & \text { Physical Science, Space Science } \\ \text { Format(s): } & \text { Web Site } \\ \text { Audience: } & \text { Grades 6-10 } \\ \text { Msn/Prg: } & \text { Yohkoh } \\ \text { Theme(s): } & \text { SEC }\end{array}$

Description: Build your own inexpensive, color, filter wheel and use it to study an image of the Crab Nebula. Discover why scientists use different filters to study astronomical images. View several images of the Sun as seen through different solar filters. Lead: $\quad$ Yohkoh E/PO Team, Lockheed Martin Solar and
Astrophysics Lab, Palo Alto, CA 94304

\section{Eagle Nebula}

$\begin{array}{ll}\text { Subject(s): } & \text { Space Science } \\ \text { Format(s): } & \text { Lithograph, PDF } \\ \text { Audience: } & \text { Grades K-12, Adult/Continuing Education, General } \\ & \text { Public, Preschool Education } \\ \text { Msn/Prg: } & \text { HST } \\ \text { Theme(s): } & \text { ASO }\end{array}$

Description: Pictures and brief description of the Eagle Nebula. Lead: HST E/PO Team, Space Telescope Science Institute,
Baltimore, MD 21218

$\begin{array}{ll}\text { Electromagnetic Radiation on Trial } \\ \text { Subject(s): } & \text { Physical Science } \\ \text { Format(s): } & \text { Web Site } \\ \text { Audience: } & \text { Grades } 9-12 \\ \text { Msn/Prg: } & \text { EUVE } \\ \text { Theme(s): } & \text { SEU }\end{array}$

Description: Students are introduced to the properties of electromagnetic radiation in a variety of ways. For example, students can create a "Quipu" - a method used by the ancient Incas. Students also are encouraged to use an electronic bulletin board to communicate with each other, posting insights, ideas, evidence, and questions on electromagnetic radiation. As part of this activity, students also put the different types of the electromagnetic radiation "on trial," selecting the judge, prosecutor, defense counsel, and jury, and learning about electromagnetic energy by arguing the pros and cons of each wavelength.

Lead:

EUVE E/PO Team, University of California, Berkeley, CA 94720

\section{Europa Geology Interactive Jigsaw Puzzle}

$\begin{array}{ll}\text { Subject(s): } & \text { Earth Science, Space Science } \\ \text { Format(s): } & \text { Web Site } \\ \text { Audience: } & \text { Grades 6-12, Community College, Higher Education } \\ \text { Msn/Prg: } & \text { Galileo } \\ \text { Theme(s): } & \text { SSE }\end{array}$

Description: This is a Galileo mission interactive online activity that allows teachers and students to reconstruct and understand geologic history processes, using an image from Jupiter's moon, Europa. Europa is thought to have an ocean beneath its icy crust.

Lead: $\quad$ Galileo E/PO Team, NASA Jet Propulsion Laboratory, Pasadena, CA 91109 


\section{Europa: Another Water World}

$\begin{array}{ll}\text { Subject(s): } & \text { Earth Science, Space Science } \\ \text { Format(s): } & \text { PDF } \\ \text { Audience: } & \text { Grades 6-12, Community College, General Public, } \\ & \text { Higher Education } \\ \text { Msn/Prg: } & \text { Galileo } \\ \text { Theme(s): } & \text { SSE }\end{array}$

Description: Europa: Another Water World is display artwork that has been reformatted into PDF format. Comparing Europa to Earth's size and oceans, it tells the story of the Galileo spacecraft's exploration of Europa in the late 1990's, and explains why scientists believe there may be an acean of water underneath Europa's icy crust. This resource can be downloaded from the Resource Directory.

Lead: $\quad$ Galileo E/P0 Team, NASA Jet Propulsion Laboratory, Pasadena, CA 91109

\section{Europa-Juplter's lcy Moon}

$\begin{array}{ll}\text { Subject(s): } & \text { Earth Science, Space Science } \\ \text { Format(s): } & \text { Poster/Wallsheet } \\ \text { Audience: } & \text { Grades K-12, Community College, General Public, } \\ & \text { Higher Education, Vocational Education } \\ \text { Msn/Prg: } & \text { Galileo } \\ \text { Theme(s): } & \text { SSE }\end{array}$

Description: This is a poster with facts, activities, and resources on the back. JPL Number is JPL-784 2/99.

Lead: Galileo E/PO Team, NASA Jet Propulsion Laboratory, Pasadena, CA 91109

\section{EWWE Satellite Data Flow Demonstration}

$\begin{array}{ll}\text { Subject(s): } & \text { Space Science, Technology } \\ \text { Format(s): } & \text { Web Site } \\ \text { Audience: } & \text { Grades 4-8 } \\ \text { Msn/Prg: } & \text { EUVE } \\ \text { Theme(s): } & \text { SEU }\end{array}$

Description: This is a hands-on demonstration of the communication path between the Extreme Uitraviolet Explorer (EUVE) satellite and a scientist on Earth. The module includes a Java applet animation of the satellite data flow and background information on the various communication links. The purpose of this lesson plan is to show students how the data are sent and received by making them active participants in the chain of events. This demonstration also allows students to get a feel for the dynamic of satellite communications and orbital motion around Earth.

Lead:

EUVE E/PO Team, University of California, Berkeley, CA 94720

\section{Exploring Mars}

$\begin{array}{ll}\text { Subject(s): } & \text { Earth Science, Mathematics, Physical Science, Space } \\ & \text { Science } \\ \text { Format(s): } & \text { Book, PDF, Web Site } \\ \text { Audience: } & \text { Grades 4-10 } \\ \text { Msn/Prg: } & \text { Mars } \\ \text { Theme(s): } & \text { SSE }\end{array}$

Description: This is an educator's resource guide that has activities for elementary, middle, and high school students. By offering teachers five distinct activities that do not depend on one another, "Exploring Mars" is perfect for teachers wanting short, focused activities. The design of this module enables teachers to do one, some, or all of the activities to give their students a powerful introduction to Mars, planets, astronomy, and space exploration.

Lead: Mars E'PO Team, NASA Jet Propulsion Laboratory, Pasadena, CA 91109

\section{Exploring Meteorite Mysteries Teacher's Guide}

Subject(s):

Format(s):

Audience:

Msn/Prg:

Theme(s):

\author{
Earth Science, Physical Science, Space Science \\ Book, PDF, Specimens \\ Grades 11-12, Community College, Higher Education \\ Sample Curation \\ SSE
}

Description: This program allows educators to borrow meteorite samples and provides a teacher's guide with activities and a slide set to support lessons on the earliest history of the solar system and meteorite impacts on Earth. The lessons in the Teacher's Guide range in grade level from 5th to 12 th grade. These educational materials may be borrowed as a package, and the guide and/or slides are also available separately. These products are available through Spacelink or the JSC Web site. The teacher's guide can be downloaded from the JSC outreach Web site, or is available as hard copy.

Lead: $\quad$ Sample Curation E/PO Team, NASA Johnson Space Center, Houston, TX 77058

\section{Exploring the Moon Teacher's Guide}

Subject(s): $\quad$ Earth Science, Space Science, Technology

Format(s): $\quad$ Book, PDF, Specimens, Web Site

Audience: $\quad$ Grades 5-12, Community College, Higher Education

Msn/Prg: $\quad$ Sample Curation

Theme(s): $\quad$ SSE

Description: This program allows educators to borrow lunar samples and provides a teacher's guide with activities and slide set to support lessons on lunar exploration, geology, and history. These educational materials are loaned as a package, and the guide and slides are also available separately. This product is the Teacher's Guide, it can be downloaded or can be ordered in hard copy from Spacelink. 
Lead:

Dr. G. Jeffrey Taylor, University of Hawaii, Honolulu, HI 96822

\section{Eye on the Sky}

$\begin{array}{ll}\text { Subject(s): } & \text { Earth Science } \\ \text { Format(s): } & \text { Web Site } \\ \text { Audience: } & \text { Grades 1-3, General Public } \\ \text { Msn/Prg: } & \text { OHRE } \\ \text { Theme(s): } & \text { SEC }\end{array}$

Description: This animated interactive journal allows students in grades $\mathrm{K}-3$ to record weather data that they have observed first-hand. Using language that supports and reinforces early literacy skills, students identify seasons, categorize weather and cloud types, and measure temperature. The journal provides a writing section where students reflect on their observations. An illustrated summary page captures all student input and can be printed to include in individual student journals or for use in whole class weather activities.

Lead

Center for Science Education, Space Sciences Laboratory, University of California, Berkeley, CA 94720

\section{From Galileo to Hubble: Why a Telescope in Space?}

$\begin{array}{ll}\text { Subject(s): } & \text { Space Science } \\ \text { Format(s): } & \text { Web Site } \\ \text { Audience: } & \text { Grades 4-12, General Public } \\ \text { Msn/Prg: } & \text { HST } \\ \text { Theme(s): } & \text { ASO }\end{array}$

Description: Learn about a brief history of telescopes from the time of Galileo to the present Hubble Space Telescope.

Lead: $\quad$ Amazing Space Team, Space Telescope Science Institute, Baltimore, MD 21218

\section{Galaxies Galore, Games, and More}

$\begin{array}{ll}\text { Subject(s): } & \text { Space Science } \\ \text { Format(s): } & \text { Web Site } \\ \text { Audience: } & \text { Grades 1-5, General Public } \\ \text { Msn/Prg: } & \text { HST } \\ \text { Theme(s): } & \text { SEU }\end{array}$

Description: Galaxies Galore, Games, and More is a learning module designed to allow elementary students to use their observational skills, recognize patterns, and learn how galaxies are classified. In these lessons students will learn the parts of galaxies and will be able to identify the three main types: spiral, elliptical, and irregular. Students will become acquainted with the structure of their home galaxy, the Milky Way.

Lead:

Amazing Space Team, Space Telescope Science Institute, Baltimore, MD 21218

\section{Galaxy Centaurus A}

$\begin{array}{ll}\text { Subject(s): } & \text { Space Science } \\ \text { Format(s): } & \text { Lithograph, PDF } \\ \text { Audience: } & \text { Grades K-12, Adult/Continuing Education, General } \\ & \text { Public, Preschool Education } \\ \text { Msn/Prg: } & \text { HST } \\ \text { Theme(s): } & \text { SEU }\end{array}$

Description: Pictures and brief details about the Galaxy Centaurus $A$, which contains a black hole.

Lead:

HST E/PO Team, Space Telescope Science Institute, Baltimore, MD 21218

\section{Gallieo Public Web SHe}
Subject(s): $\quad$ Earth Science, Physical Science, Space Science, Technology
Format(s): Web Site
Audience: $\quad$ Grades 6-12, Adult/Continuing Education, Community College, General Public, Higher Education
Msn/Prg: Galileo
Theme(s): SSE

Description: The Web site for the Galileo Mission. This site has current information and images for Jupiter and its moons. There are also educational resources, such as activities, puzzles, models, and fact sheets.

Lead: Galileo E/PO Team, NASA Jet Propulsion Laboratory, Pasadena, CA 91109

\section{Galileo Spacecraft 1/45 Scale Model}

$\begin{array}{ll}\text { Subject(s): } & \text { Earth Science, Space Science } \\ \text { Format(s): } & \text { Kit, Model, POF } \\ \text { Audience: } & \text { Grades 9-12, Adult/Continuing Education, General } \\ & \text { Public, Vocational Education } \\ \text { Msn/Prg: } & \text { Galileo } \\ \text { Theme(s): } & \text { SSE }\end{array}$

Description: The Galileo spacecraft, currently orbiting the planet Jupiter, is one of the most complex robatic spacecraft ever flown. This $1 / 45$ scale model is a construction project requiring great care and several hours of time, but once completed, the builder will be quite familiar with the spacecraft and its components. Requires printer, heavy white paper, scissors, tape, and art knife. Please see instructions at http:// www.jpl.nasa.gov/galileo/model/instructions.html

Lead Galileo E/PO Team, NASA Jet Propulsion Laboratory, Pasadena, CA 91109 


\section{Gamma-ray Bursts Booklet}

$\begin{array}{ll}\text { Subject(s): } & \text { Mathematics, Physical Science, Space Science } \\ \text { Format(s): } & \text { Pamphlet, PDF, Web Site } \\ \text { Audience: } & \text { Grades 9-12 } \\ \text { Msn/Prg: } & \text { HEASARC } \\ \text { Theme(s): } & \text { SEU }\end{array}$

Description: An information/activity booklet which accompanies the Gamma-ray Bursts poster. This booklet describes the history and science of gamma-ray bursts, concentrating on the story of their discovery, subsequent investigations, our current knowledge, and how the entire electromagnetic spectrum is used to investigate them. It also describes what we don't know about gamma-ray bursts. The booklet includes nine activities.

Lead: $\quad$ HEASARC E/PO Team, NASA Goddard Space Flight Center, Greenbelt, MD 20771

\section{Gamma-ray Bursts Poster \\ Subject(s): $\quad$ Physical Science, Space Science \\ Format(s): Poster/Wallsheet \\ Audience: $\quad$ Grades 9-12, Adult/Continuing Education, Community College, General Public, Higher Education \\ Msn/Prg: $\quad$ HEASARC \\ Theme(s): $\quad$ SEU}

Description: A poster illustrating the power of gamma-ray bursts, comparing them to Earth-based and cosmic power sources.

Lead: $\quad$ HEASARC ESO Team, NASA Goddard Space Flight Center, Greenbelt, MD 20771

\section{Get the Picture}

$\begin{array}{ll}\text { Subject(s): } & \text { Mathematics, Physical Science, Space Science } \\ \text { Format(s): } & \text { Web Site } \\ \text { Audience: } & \text { Grades } 6-10 \\ \text { Msn/Prg: } & \text { HEASARC } \\ \text { Theme(s): } & \text { SEU }\end{array}$

Description: The activities found in this lesson provide students with a hands-on experience which will simulate the process of downloading actual data from a High-Energy Satellite, and allow students to translate these data into colored or shaded pixels. This lesson was written in accordance with the National Teacher Training Institute (NTT) format, which focuses on the utilization of instructional television in the classroom.

Lead:

HEASARC E/PO Team, NASA Goddard Space Flight Center, Greenbelt, MO 20771

\section{Goldstone Apple Valley Radio Telescope (GAYRT) Pamphlet}

$\begin{array}{ll}\text { Subject(s): } & \text { Earth Science, Physical Science, Space Science } \\ \text { Format(s): } & \text { Pamphlet } \\ \text { Audience: } & \text { Grades 6-12, General Public } \\ \text { Msn/Prg: } & \text { DSMS } \\ \text { Theme(s): } & \text { SSE }\end{array}$

Description: GAVRT is a project where students can learn real science by collecting and analyzing data obtained from a $34 \mathrm{~m}$ radio telescope using radio astronomy. This is a classroom activity linked through the Internet. Teacher training and support is provided. Descriptive brochure is available. Brochure is free; project support is not free.

Lead: $\quad$ DSMS E/PO Team, NASA Jet Propulsion Laboratory, Pasadena, CA 91109

\section{Hellx Nebula}

Space Science

Format(s):

Lithograph, PDF

Audience:

Grades K-12, Adult/Continuing Education, General Public, Preschool Education

Msn/Prg: $\quad$ HST

Theme(s): $\quad$ ASO

Description: Picture, overlay, and brief description of the Helix Nebula.

Lead: $\quad$ HST E/PO Team, Space Telescope Science Institute, Baltimore, MD 21218

\section{How Astronomers Use Spectra to Learn About the Sun and Other Stars}

Subject(s): $\quad$ Earth Science, Physical Science, Space Science

Format(s): $\quad$ Pamphlet, Web Site

Audience: $\quad$ Grades 6-12, General Public

Msn/Prg: $\quad$ Solar and Heliospheric Sciences

Theme(s): $\quad$ SEC

Description: Booklet describing uses of spectroscopy in astranamy; includes activity, student worksheet, and education standards.

\section{How Big Is That Star?}

$\begin{array}{ll}\text { Subject(s): } & \text { Mathematics, Physical Science, Space Science } \\ \text { Format(s): } & \text { Web Site } \\ \text { Audience: } & \text { Grades 6-8 } \\ \text { Msn/Prg: } & \text { HEASARC } \\ \text { Theme(s): } & \text { SEU }\end{array}$

Description: A lesson plan in which students will be able to explain the relationship between density, mass, and radius for a list of stars, understand how a binary star system's orbit can cause observed changes in the brightness of a star, and determine diameters of stars in such systems by analyzing data and manipulating equations. 


\section{Hubble Deep Field Academy}

$\begin{array}{ll}\text { Subject(s): } & \text { Space Science } \\ \text { Format(s): } & \text { Web Site } \\ \text { Audience: } & \text { Grades 6-8, General Public } \\ \text { Msn/Prg: } & \text { HST } \\ \text { Theme(s): } & \text { ASO }\end{array}$

Description: Join Professor WifPic in examining the Hubble Deep Field image and simulate the process astronomers have gone through to count, classify, and identify objects in the image as well as estimate their distances from Earth.

Lead:

$$
\text { Amazing Space Team, Space Telescope Science }
$$$$
\text { Institute, Baltimore, MD } 21218
$$

\section{Hubble Deep Field Poster}

$\begin{array}{ll}\text { Subject(s): } & \text { Space Science } \\ \text { Format(s): } & \text { PDF, Poster Wallsheet } \\ \text { Audience: } & \text { Grades 6-12, General Public } \\ \text { Msn/Prg: } & \text { HST } \\ \text { Theme(s): } & \text { ASO }\end{array}$

Description: This image from NASA's Hubble Space Telescope shows hundreds of galaxies in an area of the sky as small as President Roosevelt's eye on a dime held at arm's length. Never before seen galaxies are visible in this "deepest-ever" view of the universe, called the "Hubble Deep Field."

Lead: $\quad$ Amazing Space Team, Space Telescope Science Institute, Baltimore, MD 21218

Hubble Space Telescope

$\begin{array}{ll}\text { Subject(s): } & \text { Space Science } \\ \text { Format(s): } & \text { Lithograph, PDF } \\ \text { Audience: } & \text { Grades K-12, Adult/Continuing Education, General } \\ & \text { Public } \\ \text { Msn/Prg: } & \text { HST } \\ \text { Theme(s): } & \text { ASO }\end{array}$

Description: Picture, diagram, and brief details about the Hubble Space Telescope.

Lead:

HST E/PO Team, Space Telescope Science Institute, Baltimore, MD 21218

\section{Hubble's Galaxy Gallery}

$\begin{array}{ll}\text { Subject(s): } & \text { Space Science } \\ \text { Format(s): } & \text { Lithograph, PDF } \\ \text { Audience: } & \text { Grades K-12, Adult/Continuing Education, General } \\ & \text { Public, Preschool Education } \\ \text { Msn/Prg: } & \text { HST } \\ \text { Theme(s): } & \text { ASO }\end{array}$

Description: Picture and brief description of the Hubble Deep Field.

Lead HST E/PO Team, Space Telescope Science Institute, Baltimore, MD 21218

\section{Imagine the Universel CD (version 4)}

$\begin{array}{ll}\text { Subject(s): } & \text { Physical Science, Space Science } \\ \text { Format(s): } & \text { CO } \\ \text { Audience: } & \text { Grades K-12, Community College, General Public, } \\ & \text { Higher Education } \\ \text { Msn/Prg: } & \text { HEASARC } \\ \text { Theme(s): } & \text { SEU }\end{array}$

Description: This CD contains a capture of the three Web sites as they existed on January 1, 2000: Imagine the Universe!, StarChild, and the 1999 Astronomy Picture of the Day. Together, they offer information and teaching resources on astronomy and space science for all grade levels and ages. Each site contains its own learning adventure full of facts, fun, music, beautiful images, and movies.

Lead: $\quad$ HEASARC E/PO Team, NASA Goddard Space Flight Center, Greenbelt, MD 20771

\section{Imagine the Universe! Web Site}

$\begin{array}{ll}\text { Subject(s): } & \text { Mathematics, Physical Science, Space Science } \\ \text { Format(s): } & \text { Web Site } \\ \text { Audience: } & \text { Grades 9-12, Adult/Continuing Education, Community } \\ & \text { College, General Public, Higher Education } \\ \text { Msn/Prg: } & \text { HEASARC } \\ \text { Theme(s): } & \text { SEU }\end{array}$

Description: This Web site is a collection of articles, activities, and lesson plans that describe the nature of highly energetic objects and events in our universe, as well as the structure and evolution of the universe. The site discusses what we know, how we know it, and what mysteries remain. It also features the latest news in this field, and profiles scientists working on this science.

Lead: 


\author{
Introduction to Cosmology \\ Subject(s): $\quad$ Space Science \\ Format(s): Web Site \\ Audience: Grades 9-12, Adult/Continuing Education, Community \\ College, General Public, Higher Education \\ Msn/Prg: MAP \\ Theme(s): $\quad$ SEU
}

Description: Cosmology is the study of the origin and evolution of the Universe. This Web site introduces basic concepts in modern cosmology and describes the Microwave Anisotropy Probe (MAP) mission at a general level.

Lead: $\quad$ MAP ESO Team, Adler Planetarium and Astronomy Museum, Chicago, IL 60605

\section{Is There Water on Mars? An Educators Guide with Actlvities for Physical, Earth, and Space Science}

$\begin{array}{ll}\text { Subject(s): } & \begin{array}{l}\text { Earth Science, Physical Science, Space Science, } \\ \text { Technology }\end{array} \\ \text { Format(s): } & \text { Book, PDF, Web Site } \\ \text { Audience: } & \text { Grades } 9-12 \\ \text { Msn/Prg: } & \text { Mars } \\ \text { Theme(s): } & \text { SSE }\end{array}$

Description: By experimenting with water as it changes state and investigating some effects of air pressure on water's boiling temperature, students not only learn core ideas in physical science but can deduce the water simulation on Mars by applying those concepts. They use evidence from their work as well as data and images from NASA's missions to Mars to take a position on whether there was ever water on Mars.

Lead: $\quad$ Mars E/PO Team, NASA Jet Propulsion Laboratory, Pasadena, CA 91109

\section{Jovlan Planots}

$\begin{array}{ll}\text { Subject(s): } & \text { Space Science } \\ \text { Format(s): } & \text { Lithograph, PDF } \\ \text { Audience: } & \text { Grades K-12, Adult/Continuing Education, General } \\ & \text { Public, Preschool Education } \\ \text { Msn/Prg: } & \text { HST } \\ \text { Theme(s): } & \text { SSE }\end{array}$

Description: Pictures, diagrams, and brief details about the four outer giant planets.

Lead: $\quad$ HST E/PO Team, Space Telescope Science Institute, Baltimore, MD 21218

\section{Light Tour}

$\begin{array}{ll}\text { Subject(s): } & \text { Mathematics, Physical Science, Space Science } \\ \text { Format(s): } & \text { Web Site } \\ \text { Audience: } & \text { Grades 8-12, Community College, General Public } \\ \text { Msn/Prg: } & \text { EUVE } \\ \text { Theme(s): } & \text { SEU }\end{array}$

Description: A self-tutorial that introduces the electromagnetic spectrum through the concept of wavelength. Students learn to associate various wavelength ranges with different spectral bands, and can explore images from space astronomy missions in each band.

Lead: EUVE E/PO Team, University of California, Berkeley, CA 94720

\section{Uve from the Sun MultiMedia Kit}

$\begin{array}{ll}\text { Subject(s): } & \text { Earth Science, Physical Science, Space Science } \\ \text { Format(s): } & \text { Book, CD, Kit, Pamphlet, Poster/Wallsheet, VideoNHS } \\ \text { Audience: } & \text { Grades 5-10 } \\ \text { Msn/Prg: } & \text { OSS } \\ \text { Theme(s): } & \text { SEC }\end{array}$

Description: The Multimedia Kit contains the Live from the Sun teacher's guide, a factbook, teacher resource video, student worksheets, an oversized color poster, sample hands-on materials for the activities, and additional materials for background information to use during the project.

Lead: Passport to Knowledge, Geoff Haines-Stiles Productions, Inc., Morristown, NJ 07960

\section{Live from the Sun, Program 1}

$\begin{array}{ll}\text { Subject(s): } & \text { Earth Science, Physical Science, Space Science } \\ \text { Format(s): } & \text { Video } N H S \\ \text { Audience: } & \text { Grades } 5-10 \\ \text { Msn/Prg: } & \text { OSS } \\ \text { Theme(s): } & \text { SEC }\end{array}$

Description: Without the Sun, there would be no life on the surface of Earth. This program provides a comprehensive update on the amazing discoveries of the past decade, during which NASA spacecraft have retumed astonishingly detailed views of the only star we can see... "in close up." But our Sun helps us understand all the other stars out there in the universe beyond our solar system. In addition to seeing the Sun in close-up, viewers will go behind the scenes at NASA Goddard Space Flight Center, Greenbelt, Maryland-Sun Central/Mission Control, for many of America's solar spacecraft, and Lockheed Martin Solar and Astrophysics Laboratory, Palo Alto, California, where some of the most powerful telescopes onboard recent spacecraft have been built and tested.

Lead: $\quad$ Passport to Knowledge, Geoff Haines-Stiles Productions, Inc., Morristown, NJ 07960 


\section{Uve from the Sun, Program 2: Solar Studies and Sunny Interactions}

$\begin{array}{ll}\text { Subject(s): } & \text { Earth Science, Physical Science, Space Science } \\ \text { Format(s): } & \text { VideoNHS } \\ \text { Audience: } & \text { Grades 5-10 } \\ \text { Msn/Prg: } & \text { OSS } \\ \text { Theme(s): } & \text { SEC }\end{array}$

Description: Originally broadcast live from NASA Goddard Space Flight Center, solar researchers explain the "colors" of the Sun and how the Doppler effect reveals the Sun's internal structure, and much more! See how a blowtorch can make a household tile glow orange, and how color is a clue to temperature. Goddard astrophysicists join in a tuneful and scientifically accurate a cappella tribute to our Sun. See how and why solar science is so exciting for the men and women who study our star with spacecraft and telescopes.

Lead: $\quad$ Passport to Knowledge, Geoff Haines-Stiles Productions, Inc., Morristown, NJ 07960

\section{Live from the Sun, Program 3: To the Max}

Subject(s): $\quad$ Earth Science, Physical Science, Space Science

Format(s): $\quad$ VideoNHS

Audience: $\quad$ Grades 6-10

Msn/Prg: $\quad$ OSS

Theme(s): $\quad$ SEC

Description: "To the Max" visits NASA Goddard Space Flight Center (Greenbelt, Maryland) and NASA Marshall Space Flight Center (Huntsville, Alabama) to update viewers on changes in solar behavior as Solar Maximum approaches. Find out how to "follow the Sun" throughout the coming year via the Internet and also via hands-on activities such as building horizon calendars and special "noon shadow" projects, and also.

Lead:

Passport to Knowledge, Geoff Haines-Stiles

Productions, Inc., Morristown, NJ 07960

\section{MAP Fact Sheet}

$\begin{array}{ll}\text { Subject(s): } & \text { Space Science } \\ \text { Format(s): } & \text { PDF, Web Site } \\ \text { Audience: } & \text { Grades 9-12, Adult/Continuing Education, Community } \\ & \text { College, General Public, Higher Education } \\ \text { Msn/Prg: } & \text { MAP } \\ \text { Theme(s): } & \text { SEU }\end{array}$

Description: What questions does MAP seek to answer? What is Cosmic Background radiation? All this and a diagram of the MAP satellite!

Lead: $\quad$ MAP E/PO Team, Adler Planetarium and Astronomy Museum, Chicago, IL 60605

\section{MAP Homepage}

$\begin{array}{ll}\text { Subject(s): } & \text { Space Science } \\ \text { Format(s): } & \text { Web Site } \\ \text { Audience: } & \text { Grades 9-12, Adult/Continuing Education, Community } \\ & \text { College, General Public, Higher Education } \\ \text { Msn/Prg: } & \text { MAP } \\ \text { Theme(s): } & \text { SEU }\end{array}$

Description: The Microwave Anisotropy Probe (MAP) is part of NASA's Explorers program to probe conditions in the early universe. MAP measures temperature differences ("anisotropy") in the cosmic microwave background radiation.

Lead: $\quad$ MAP E/PO Team, Adler Planetarium and Astronomy Museum, Chicago, IL 60605

\section{Mars}

$\begin{array}{ll}\text { Subject(s): } & \text { Earth Science, Space Science } \\ \text { Format(s): } & \text { Lithograph, PDF } \\ \text { Audience: } & \text { Grades K-12, Adult/Continuing Education, General } \\ & \text { Public, Preschool Education } \\ \text { Msn/Prg: } & \text { HST } \\ \text { Theme(s): } & \text { SSE }\end{array}$

Description: A picture and brief description of specific Martian features.

Lead: $\quad$ HST E/PO Team, Space Telescope Science Institute, Baltimore, MD 21218

\section{Mars Navigator CD}

$\begin{array}{ll}\text { Subject(s): } & \text { Earth Science, Physical Science, Space Science } \\ \text { Format(s): } & \text { CD } \\ \text { Audience: } & \text { Grades K-12, General Public } \\ \text { Msn/Prg: } & \text { Mars } \\ \text { Theme(s): } & \text { SSE }\end{array}$

Description: This Mars Navigator CD introduces basic astronomy and aerospace engineering by examining JPL's Mars Pathfinder and Mars Global Surveyor missions to Mars. The content is not tied to any curriculum or lesson plan, but is intended to be an exploratory learning experience.

Lead:

Mars E/PO Team, NASA Jet Propulsion Laboratory, Pasadena, CA 91109

\section{Measuring Solar Activity}

$\begin{array}{ll}\text { Subject(s): } & \text { Earth Science, Physical Science, Space Science } \\ \text { Format(s): } & \text { Web Site } \\ \text { Audience: } & \text { Grades } 6-9 \\ \text { Msn/Prg: } & \text { Yohkoh } \\ \text { Theme(s): } & \text { SEC }\end{array}$


Description: Investigate the cycles of the Sun with 250 years of data! Learn to recognize common features and match $x$-ray images of the Sun with visible light images from the same day.

Lead:

Yohkoh E/PO Team, Lockheed Martin Solar and Astrophysics Lab, Palo Alto, CA 94304

\section{Measuring the Distance to the Sun}

$\begin{array}{ll}\text { Subject(s): } & \text { Physical Science, Space Science } \\ \text { Format(s): } & \text { Web Site } \\ \text { Audience: } & \text { Grades 9-12 } \\ \text { Msn/Prg: } & \text { Yohkoh } \\ \text { Theme(s): } & \text { SEC }\end{array}$

Description: Investigate the shape of Earth's orbit based on the apparent changing size of the Sun. Is the orbit elliptical? Is it circular? Compare the difference in the Sun's diameter as measured from two points in the Earth's orbit and see what you discover!

Lead: $\quad$ Yohkoh E/PO Team, Lockheed Martin Solar and Astrophysics Lab, Palo Alto, CA 94304

\section{Mission to Geospace}

Subject(s): $\quad$ Earth Science, Physical Science, Space Science Format(s): $\quad$ Web Site

Audience: Grades 6-12, Adult/Continuing Education, Community College, General Public, Higher Education

Msn/Prg: $\quad$ ISTP

Theme(s): $\quad$ SEC

Description: Designed as a clearinghouse and window to news and background information about the physics of the Sun-Earth Connection. Most of the emphasis is placed on science news (releases, media coverage), background material and primers, links to key missions, image galleries, and some educator resources. The site is designed to provide one-stop shopping for the best available resources in SEC science, as well as the most complete library collection of news and images.

Lead: ISTP E/PO Team, NASA Goddard Space Flight Center, Greenbelt, MD 20771

\section{Multiwavelength Milky Way}

$\begin{array}{ll}\text { Subject(s): } & \text { Physical Science, Space Science } \\ \text { Format(s): } & \text { Web Site } \\ \text { Audience: } & \text { Grades 9-12, Adult/Continuing Education, Community } \\ & \text { College, General Public, Higher Education } \\ \text { Msn/Prg: } & \text { HEASARC } \\ \text { Theme(s): } & \text { SEU }\end{array}$

Description: This Web site is intended to be both educational and useful to the scientific community. Each window of the electromagnetic spectrum gives us a new view of the universe. You'll find images, a poster, or $35 \mathrm{~mm}$ slides of NASA's multiwavelength satellite data.
Lead:

HEASARC E/PO Team, NASA Goddard Space Flight Center, Greenbelt, MD 20771

\section{Nature's Kaleidoscope}

$\begin{array}{ll}\text { Subject(s): } & \text { Space Science } \\ \text { Format(s): } & \text { PDF, Poster/Wallsheet } \\ \text { Audience: } & \text { Grades K-12, Adult/Continuing Education } \\ \text { Msn/Prg: } & \text { HST } \\ \text { Theme(s): } & \text { ASO }\end{array}$

Description: This is a poster which presents the current Amazing Space Web-based activities in an interesting method. The charts contain relevant details about the modules and accessing information.

Lead: $\quad$ HST E/PO Team, Space Telescope Science Institute, Baltimore, MD 21218

\section{No Escape: The Truth About Black Holes Poster}

$\begin{array}{ll}\text { Subject(s): } & \text { Space Science } \\ \text { Format(s): } & \text { PDF, Poster/Wallsheet } \\ \text { Audience: } & \text { Grades 8-12, General Public } \\ \text { Msn/Prg: } & \text { HST } \\ \text { Theme(s): } & \text { AS0 }\end{array}$

Description: This poster challenges the student to think about an important question. What do you get when you cram $14,400,000,000,000,000,000,000,000$ teachers into a Volkswagen Beetle? Would you believe a Black Hole?

Lead: $\quad$ Amazing Space Team, Space Telescope Science Institute, Baltimore, MD 21218

\section{No Escape: The Truth About Black Holes Web SHe}

$\begin{array}{ll}\text { Subject(s): } & \text { Space Science } \\ \text { Format(s): } & \text { Web Site } \\ \text { Audience: } & \text { Grades 8-12, General Public } \\ \text { Msn/Prg: } & \text { HST } \\ \text { Theme(s): } & \text { ASO }\end{array}$

Description: No Escape: The Truth About Black Holes provides an opportunity for students to research the fascinating topic of black holes and to examine the concepts of escape velocity, gravity, mass, and the speed of light as it applies to the creation of a black hole. Spectacular images provided by the Hubble Space Telescope illustrate the lesson and provide data that the students will use to hunt for black holes in the centers of galaxies.

Lead: $\quad$ Amazing Space Team, Space Telescope Science Institute, Baltimore, MD 21218 


\section{Northern Lights and Solar SprltesI}

Subject(s): $\quad$ Earth Science, Physical Science, Space Science, Technology

Format(s): $\quad$ PDF

Audience: $\quad$ Grades 1-6

Msn/Prg: IMAGE

Theme(s): $\quad$ SEC

Description: Fifty classroom activities designed for $k-6$ students. Topics include magnetism, solar activity, stars, and satellite design.

Lead:

IMAGE E/PO Team, NASA Goddard Space Flight

Center, Greenbelt, MD 20771

\section{Orion Nebula}

$\begin{array}{ll}\text { Subject(s): } & \text { Space Science } \\ \text { Format(s): } & \text { Lithograph, PDF } \\ \text { Audience: } & \text { Grades K-12, Adult/Continuing Education, General } \\ & \text { Public, Preschool Education } \\ \text { Msn/Prg: } & \text { HST } \\ \text { Theme(s): } & \text { ASO } \\ \text { Description: A picture and brief description of the Orion Nebula. } & \\ \text { Lead: } & \quad \text { HST E/PO Team, Space Telescope Science Institute, } \\ & \text { Baltimore, MD 21218 } \\ \text { Passage to a Ringed World } & \\ \text { Subject(s): } & \text { Earth Science, Physical Science, Space Science } \\ \text { Format(s): } & \text { Book, PDF } \\ \text { Audience: } & \text { Grades 8-12, Adult/Continuing Education, Community } \\ & \text { College, General Public, Higher Education, Vocational } \\ & \text { Education }\end{array}$
$\begin{array}{ll}\text { Msn/Prg: } & \text { Cassini/Huygens Probe } \\ \text { Theme(s): } & \text { SSE }\end{array}$

Description: This is a NASA Special Publication. It is an overview of the Saturn system, and the continued exploration by the Cassini spacecraft and the Huygens probe.

Lead: $\quad$ Cassini E/PO Team, NASA Jet Propulsion Laboratory, Pasadena, CA 91109

\section{Picture an Astronomer Activity}

\section{Subject(s):}

Format(s):

Earth Science, Physical Science

Audience:

Web Site

Msn/Prg:

Grades K-12, Community College

Theme(s):

OSS

SSE

Description: In this activity, which is a good introduction to an astronomy unit or to a classroom visit by an astronomer or space scientist, students are asked to imagine an astronomer and then draw a picture. In the instructions, no clues are given about the astronomer's race, sex, or age. Students discuss why they drew the pictures they drew and why they have the mental images of scientists that they have.

Lead: $\quad$ Project Astro, Astronomical Society of the Pacific, San Francisco, CA 94112

\section{Pistol Star}

$\begin{array}{ll}\text { Subject(s): } & \text { Space Science } \\ \text { Format(s): } & \text { Lithograph, PDF } \\ \text { Audience: } & \text { Grades K-12, Adult/Continuing Education, General } \\ & \text { Public, Preschool Education } \\ \text { Msn/Prg: } & \text { HST } \\ \text { Theme(s): } & \text { SEU }\end{array}$

Description: Picture, overlay, and brief description of the most luminous star known to astronomers.

Lead: $\quad$ HST E/PO Team, Space Telescope Science Institute, Baltimore, MD 21218

\section{Remember the Egg Activity}

$\begin{array}{ll}\text { Subject(s): } & \text { Space Science } \\ \text { Format(s): } & \text { Web Site } \\ \text { Audience: } & \text { Grades K-12, Adult/Continuing Education, Community } \\ & \text { College, General Public } \\ \text { Msn/Prg: } & \text { OSS } \\ \text { Theme(s): } & \text { SSE }\end{array}$

Description: This simple but subtle activity helps students train their ability to look for subtle features on worlds they observe through small telescopes or rough images. Students examine a carton of eggs and try to distinguish among the eggs with drawings good enough so another group of students can then tell which egg is which. (Developed by a staff member at NASA Ames Research Center while he was serving as a volunteer astronomer on Project ASTRO.)

Lead: $\quad$ Project Astro, Astronomical Society of the Pacific, San Francisco, CA 94112

\section{Rocks from Space: Meteorites in the Classroom}

$\begin{array}{ll}\text { Subject(s): } & \text { Space Science } \\ \text { Format(s): } & \text { Web Site } \\ \text { Audience: } & \text { Grades 1-5, General Public } \\ \text { Msn/Prg: } & \text { IDEAS } \\ \text { Theme(s): } & \text { ASO }\end{array}$

Description: The Rocks from Space: Meteorites in the Classroom program is a K-5 educational outreach initiative with the Austin Independent $S c h o o l$ District. The goal of the program is to enhance elementary science education by bringing outer space closer using real meteorites in the classroom and by making rocks from space accessible to elementary school classes. Future kits will include real meteorite fragments of sub- 
stantial size from the Odessa, Texas, crater with curriculum units and activities that support space and earth science elements.

Lead: $\quad$ Dr. Dan Lester, University of Texas, Austin, TX 78712

\section{Saturn Educator Guide}

Subject(s): $\quad$ Earth Science, Physical Science, Space Science

Format(s): $\quad$ Book, PDF

Audience: $\quad$ Grades 5-8

Msn/Prg: Cassini/Huygens Probe

Theme(s): SSE

Description: This educator guide consists of lessons, enrichment, and appendices. Includes six standards-based lessons all grounded in constructivist learning theory

Lead: $\quad$ Cassini E/PO Team, NASA Jet Propulsion Laboratory, Pasadena, CA 91109

\section{Soda Bottle Magnetometer}

Subject(s): $\quad$ Earth Science, Physical Science, Space Science

Format(s): Web Site

Audience: $\quad$ Grades 4-12, Community College, General Public

Msn/Prg: IMAGE

Theme(s): $\quad$ SEC

Description: Build a magnetometer for under $\$ 5$ to monitor changes in the Earth's magnetic field inside your classroom. Some of these changes can be due to magnetic storms in space caused by space weather changes and solar storms. Join the Student Magnetometer Network (MagNet) and share your measurements. Detailed instructions, sample data, and tips are provided.

\section{Lead: $\quad$ IMAGE EPO Team, NASA Goddard Space Flight Center, Greenbelt, MD 20771}

\section{Solar Storms and You! Exploring Sunspots and Solar Activity Cycles}

$\begin{array}{ll}\text { Subject(s): } & \text { Earth Science, Space Science } \\ \text { Format(s): } & \text { PDF } \\ \text { Audience: } & \text { Grades 5-8 } \\ \text { Msn/Prg: } & \text { IMAGE } \\ \text { Theme(s): } & \text { SEC }\end{array}$

Description: Three lessons and classroom activities about solar activity: The Sunspot Cycle; Sunspot Activity and Ocean Temperature; Sunspot Activity and Other Stars. Available as a PDF file for downloading.

Lead: $\quad$ IMAGE E/PO Team, NASA Goddard Space Flight Center, Greenbelt, MD 20771

\section{Solar Storms and Youf Exploring Magnetic Storms}

$\begin{array}{ll}\text { Subject(s): } & \text { Earth Science, Physical Science, Space Science } \\ \text { Format(s): } & \text { PDF } \\ \text { Audience: } & \text { Grades 5-8 } \\ \text { Msn/Prg: } & \text { IMAGE } \\ \text { Theme(s): } & \text { SEC }\end{array}$

Description: Three lessons and classroom activities about how solar activity affects Earth's magnetosphere: Magnetic Storms from the Ground; The Motion of the Magnetic Pole; and A Soda Bottle Magnetometer.

Lead:

$$
\begin{aligned}
& \text { IMAGE E/PO Team, NASA Goddard Space Flight } \\
& \text { Center, Greenbelt, MD } 20771
\end{aligned}
$$

\section{Solar Storms and You! Exploring Satelite Design}

$\begin{array}{ll}\text { Subject(s): } & \text { Space Science } \\ \text { Format(s): } & \text { PDF } \\ \text { Audience: } & \text { Grades 5-8 } \\ \text { Msn/Prg: } & \text { IMAGE } \\ \text { Theme(s): } & \text { SEC }\end{array}$

Description: Four lessons and classroom activities about how satellites are designed and built: IMAGE Satellite Scaling; IMAGE Satellite scale model; IMAGE satellite 1/4 scale model; and Pie Charts in Science.

Lead: IMAGE E/PO Team, NASA Goddard Space Flight Center, Greenbelt, MD 20771

\section{Solar Storms and Youl Exploring the Aurora and the lonosphere}

$\begin{array}{ll}\text { Subject(s): } & \text { Earth Science, Physical Science, Space Science } \\ \text { Format(s): } & \text { PDF } \\ \text { Audience: } & \text { Grades 5-8 } \\ \text { Msn/Prg: } & \text { IMAGE } \\ \text { Theme(s): } & \text { SEC }\end{array}$

Description: Three lessons and classroom activities about how solar activity affects Earth's ionosphere: A Simple AM Radio lonosphere Station; Radio Waves and the lonosphere; and The Aurora.

Lead: $\quad$ IMAGE E/PO Team, NASA Goddard Space Flight Center, Greenbelt, MD 20771

\section{Solar Storms and Youl Exploring the Human Impacts of Solar Activity}

$\begin{array}{ll}\text { Subject(s): } & \text { Physical Science, Space Science } \\ \text { Format(s): } & \text { PDF } \\ \text { Audience: } & \text { Grades 5-8 } \\ \text { Msn/Prg: } & \text { IMAGE } \\ \text { Theme(s): } & \text { SEC }\end{array}$

Description: Five lessons about how solar activity affects human health and technology: Solar Storms and Satellites; Cosmic Radiation Creates 
Unfriendly Skies; Satellite Glitches and Cosmic Rays; Planning a Trip to Mars; and Cosmic Rays and Sunspot Number.

Lead: IMAGE E/PO Team, NASA Goddard Space Flight Center, Greenbelt, MD 20771

Solar Storms and Youl Exploring the Wind From the Sun

$\begin{array}{ll}\text { Subject(s): } & \text { Earth Science, Physical Science, Space Science } \\ \text { Format(s): } & \text { PDF } \\ \text { Audience: } & \text { Grades 5-8 } \\ \text { Msn/Prg: } & \text { IMAGE } \\ \text { Theme(s): } & \text { SEC }\end{array}$

Description: Three lessons and classroom activities about the solar wind and how coronal mass ejections affect the Earth: CME Plotting Activity, Solar Activity and CME's, and Anatomy of a CME. Available as a PDF file for downloading.

Lead: $\quad$ IMAGE EPO Team, NASA Goddard Space Flight
Center, Greenbelt, MD 20771

\section{Solar System Trading Cards}

$\begin{array}{ll}\text { Subject(s): } & \text { Space Science } \\ \text { Format(s): } & \text { Web Site } \\ \text { Audience: } & \text { Grades } 3-6 \text {, General Public } \\ \text { Msn/Prg: } & \text { HST } \\ \text { Theme(s): } & \text { ASO }\end{array}$

Description: The students will collect solar system trading cards by playing an interactive card game. They will identify the sun, planets, comets, and asteroids by answering questions about them.

Lead: $\quad$ Amazing Space Team, Space Telescope Science Institute, Baltimore, MD 21218

\section{Stanford Solar Center}

Subject(s): $\quad$ Space Science

Format(s): Web Site

Audience: $\quad$ Grades 2-12, Community College, General Public

Msn/Prg: $\quad$ SOHO

Theme(s): $\quad$ SEC

Description: This Web site presents a collection of fun educational activities based on Solar Oscillations Investigation (SOl) and Solar and Heliospheric Observatory ( $\mathrm{SOHO}$ ) data. Students can explore the Sun's tangled magnetic field, its turbulent surface motions, the dramatic sunspot cycle, and what magic happens in the solar interior where instrumental eyes cannot penetrate.

Lead:

SOHO E/PO Team, NASA Goddard Space Flight Center, Greenbelt, MD 20771

\section{Star Light, Star Bright}

$\begin{array}{ll}\text { Subject(s): } & \text { Physical Science, Space Science } \\ \text { Format(s): } & \text { Web Site } \\ \text { Audience: } & \text { Grades 6-9, General Public } \\ \text { Msn/Prg: } & \text { HST } \\ \text { Theme(s): } & \text { ASO }\end{array}$

Description: Star Light, Star Bright explores the nature of the electromagnetic spectrum. In this lesson, students will identify the different properties of waves and the relationship that exists between energy, wavelength, and frequency. Students will correlate images taken by the Hubble Space Telescope and other astronomical instruments to the wavelength, color, and temperature information that can be found in the spectrum.

Lead: $\quad$ Amazing Space Team, Space Telescope Science Institute, Baltimore, MD 21218

\section{STARBIRTH in the Eagle Nebula \\ Subject(s): $\quad$ Space Science \\ Format(s): Poster/Wallsheet \\ Audience: $\quad$ Grades K-12, Adult/Continuing Education, General \\ Public \\ Theme(s): $\quad$ ASO}

Description: This poster contains images from the Hubble Space Telescope with background material relating to star birth in general and the Eagle Nebula in particular.

Lead: HST E/PO Team, Space Telescope Science Institute, Baltimore, MD 21218

\section{StarChild}

Subject(s): $\quad$ Mathematics, Physical Science, Space Science

Format(s): Web Site

Audience: $\quad$ Grades 1-8

Msn/Prg: HEASARC

Theme(s): $\quad$ SEU

Description: The StarChild Web site provides information and activities on the solar system, space travel, and the universe.

Lead: HEASARC E/PO Team, NASA Goddard Space Flight Center, Greenbelt, MD 20771

\section{Stardust Mission Brochure}

$\begin{array}{ll}\text { Subject(s): } & \text { Space Science } \\ \text { Format(s): } & \text { Pamphlet, PDF } \\ \text { Audience: } & \text { General Public } \\ \text { Msn/Prg: } & \text { Stardust } \\ \text { Theme(s): } & \text { SSE }\end{array}$


Description: This resource was developed for the general public. It is a top-level overview of the Stardust Mission.

Lead: $\quad$ Stardust E/PO Team, NASA Jet Propulsion Laboratory, Pasadena, CA 91109

\section{Stardust Mewsletter}

$\begin{array}{ll}\text { Subject(s): } & \text { Space Science } \\ \text { Format(s): } & \text { Pamphlet, PDF } \\ \text { Audience: } & \text { General Public } \\ \text { Msn/Prg: } & \text { Stardust } \\ \text { Theme(s): } & \text { SSE }\end{array}$

Description: Developed for the general public, this product is a quarterly newsletter designed to give insight into the Stardust Mission. This is issue number one. Lead: $\quad$ Stardust E/PO Team, NASA Jet Propulsion Laboratory,
Pasadena, CA 91109

\section{Stars and Slopes}

\section{Subject(s):}

Mathematics, Physical Science, Space Science

Format(s):

Web Site

Audience:

Grades 9-12

Msn/Prg:

HEASARC

Theme(s):

SEU

Description: This lesson plan uses logarithmic plotting to show the power of a straight line in mathematics, science, and engineering. Students will use the slopes of various curves plotted on $\log$-log graph paper to classify stellar objects as binary stars, supernovae, or active galaxies. The data used in this lesson were obtained from $x$-ray astronomy satellites.

\section{Lead: $\quad$ HEASARC E/PO Team, NASA Goddard Space Flight Center, Greenbelt, MD 20771}

\section{Storms from the Sun-Coronal Mass Ejections \\ Subject(s): $\quad$ Earth Science, Space Science \\ Format(s): PosterWallsheet, Web Site \\ Audience: $\quad$ Grades 8-12, General Public \\ Msn/Prg: ISTP \\ Theme(s): $\quad$ SEC}

Description: This 22 -inch by 34 -inch poster describes coronal mass ejections and how they affect life on Earth. The authors related CMEs to terrestrial weather while describing (qualitatively) the physical processes that bring plasma and energy from the interior of the Sun to the surface and atmosphere of Earth. Designed for a broad public audience, the poster is perhaps most accessible to high school and bright middle school students. Several teachers and outreach professionals were consulted during development, and the poster includes resources and an activity for classroom use. Back of poster is laid out in panels that are easy to photocopy.
Lead:

ISTP E/PO Team, NASA Goddard Space Flight Center, Greenbelt, MD 20771

\section{Sunshine In Your Pockett Making a Sundial for the Northern Hemisphere}

\author{
Subject(S): $\quad$ Physical Science, Space Science \\ Format(s): Web Site \\ Audience: Grades 4-12 \\ Msn/Prg: Yohkoh \\ Theme(s): $\quad$ SEC
}

Description: Learn how to make a portable, inexpensive sundial of your own. Wear it as a necklace or make a keychain! Novice, Intermediate, and Expert instructions are provided.

Lead: $\quad$ Yohkoh E/PO Team, Lockheed Martin Solar and Astrophysics Lab, Palo Alto, CA 94304

\section{Sunspots}

$\begin{array}{ll}\text { Subject(s): } & \text { Space Science } \\ \text { Format(s): } & \text { Web Site } \\ \text { Audience: } & \text { Grades 8-11, Community College, General Public } \\ \text { Msn/Prg: } & \text { HESSI, Information Systems } \\ \text { Theme(s): } & \text { SEC }\end{array}$

Description: Introduction to solar science and solar activity, including history, modern research, and an interactive research quest. Focus on the origin and physics of sunspots, their relation to other forms of solar activity and the impact on life on Earth.

Lead: $\quad$ SEGway Space Sciences Laboratory, University of California, Berkeley, CA 94720

\section{Supernova Chemistry}

$\begin{array}{ll}\text { Subject(s): } & \text { Mathematics, Physical Science, Space Science } \\ \text { Format(s): } & \text { Web Site } \\ \text { Audience: } & \text { Grades } 9-12 \\ \text { Msn/Prg: } & \text { HEASARC } \\ \text { Theme(s): } & \text { SEU }\end{array}$

Description: This lesson gives the student an opportunity to identify elements by using spectroscopy and to relate this activity to elements observed in astronomical settings such as the sun and supernova remnants.

Lead: HEASARC E/PO Team, NASA Goddard Space Flight Center, Greenbelt, MD 20771 
Telescopes in Education User Gulde and Workbook

Subject(s): Mathematics, Physical Science, Space Science, Technology

Format(s): $\quad$ Book, Web Site

Audience: Grades 3-12

Msn/Prg: OSS, OHRE

Theme(s): $\quad$ SEC, SEU, SSE

Description: User guide and sample educator activities for the Telescopes In Education (TIE) program. TIE enables educators and students around the world to remotely control research-quality telescopes and CCD cameras from any computer in their classroom. In three to five minutes, celestial objects (galaxies, nebulae, star clusters, comets, the Moon, the Sun, etc.) can be downloaded to the classroom for photo processing and research projects.

Lead: $\quad$ Telescopes in Education, NASA Jet Propulsion Laboratory, Pasadena, CA 91109

\section{Testing Astrology}

$\begin{array}{ll}\text { Subject(s): } & \text { Earth Science, Physical Science, Space Science } \\ \text { Format(s): } & \text { Web Site } \\ \text { Audience: } & \text { Grades 7-12, Adult/Continuing Education, Community } \\ & \text { College, General Public, Higher Education } \\ \text { Msn/Prg: } & \text { OSS } \\ \text { Theme(s): } & \text { SEC, SEU, SSE }\end{array}$

Description: This suite of activities helps teachers and students to evaluate astrological claims. It includes charting the birthdays of U.S. presidents, comparing horoscopes in different newspapers, and a mixedup horoscope activity. Also included on the site is a skeptical article about astrology and a bibliography of resources. This site is part of Project ASTRO, partially funded by NASA's Office of Space Science, which links astronomers and teachers in ongoing partnerships in 11 regional sites around the country.

Lead: Project Astro, Astronomical Society of the Pacific, San Francisco, CA 94112

\section{The Anatomy of Black Holes}

$\begin{array}{ll}\text { Subject(s): } & \text { Physical Science, Space Science } \\ \text { Format(s): } & \text { Pamphlet, PDF, Poster/Wallsheet, Web Site } \\ \text { Audience: } & \text { Grades 9-12, Adult/Continuing Education, Community } \\ & \text { College, General Public, Higher Education } \\ \text { Msn/Prg: } & \text { HEASARC } \\ \text { Theme(s): } & \text { SEU }\end{array}$

Description: A poster which illustrates the different parts of a black hole as revealed by observations at different wavelengths, with a accompanying information and activity booklet. The booklet provides an introduction to black holes, including historical background, their formation, evidence for their existence, and the electromagnetic spectrum as a probe of black holes. The booklet also includes activities and problems for high school students.

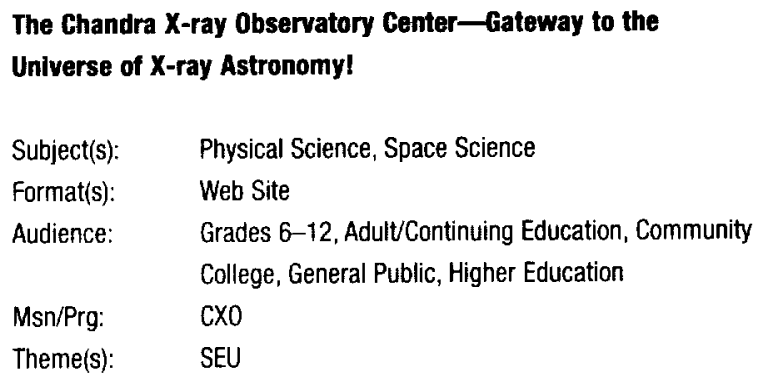

Description: Comprehensive site with a collection of Public Information and Education activities: Chandra Chronicles, Chandra Launch, and Scientific User Support. Site includes a field guide to $x$-ray astronomy, classroom activities with interactive games, and resources for teachers, students, and parents. Spectacular images, handouts, and a photo album!

Lead: $\quad$ CXO E/PO Team, Harvard-Smithsanian Center for Astrophysics, Cambridge, MA 02138

\section{The Dynamic Sun CD}

$\begin{array}{ll}\text { Subject(s): } & \text { Space Science } \\ \text { Format(s): } & \text { CD, PDF } \\ \text { Audience: } & \text { Grades K-12, Adult/Continuing Education, Community } \\ & \text { College, General Public, Higher Education } \\ \text { Msn/Prg: } & \text { SOHO } \\ \text { Theme(s): } & \text { SEC }\end{array}$

Description: A multimedia educational $C D$ on the Sun and its effects on Earth with a collection of presentations and resources for elementary. middle, and high school levels. Includes teachers guides for each. Also provides image sets, interactive poster, FAQs, and a glossary.

Lead: $\quad$ SOHO E/PO Team, NASA Goddard Space Flight Center, Greenbelt, MD 20771

\section{The Experts Speak Out: Europa: Another Water World?}

$\begin{array}{ll}\text { Subject(s): } & \text { Earth Science, Space Science } \\ \text { Format(s): } & \text { Video/NHS } \\ \text { Audience: } & \text { Grades K-12, Adult/Continuing Education, Community } \\ & \text { College, General Public, Higher Education, Vocational } \\ & \text { Education } \\ \text { Msn/Prg: } & \text { Galileo } \\ \text { Theme(s): } & \text { SSE }\end{array}$

Description: A 25-minute video about Europa, one of Jupiter's moons. To order you will need the number AVC 98-167.

Lead: Galileo E/PO Team, NASA Jet Propulsion Laboratory, Pasadena, CA 91109 
The Forecast: Look for Storms, Galo-Force Winds, and Plasma Blobs

$\begin{array}{ll}\text { Subject(s): } & \text { Earth Science, Space Science } \\ \text { Format(s): } & \text { Pamphlet } \\ \text { Audience: } & \text { Grades 7-12, Adult/Continuing Education, Community } \\ & \text { College, General Public, Higher Education, Vocational } \\ & \text { Education } \\ \text { Msn/Prg: } & \text { ISTP } \\ \text { Theme(s): } & \text { SEC }\end{array}$

Description: Four-color foldout brochure that conveys the wonder and excitement of space weather, and why this science is relevant to the nonscientist. The full title is "The Forecast: Look for Storms, Gale-Force Winds, and Plasma Blobs." Conceived, written, and printed as a partnership between the Space Science institute and the International Solar-Terrestrial Physics program.

Lead: $\quad$ SSI, Space Science Institute, Boulder, CO 80303

The Life Cycles of Stars Booklet

$\begin{array}{ll}\text { Subject(s): } & \text { Mathematics, Physical Science, Space Science } \\ \text { Format(s): } & \text { Pamphlet, PDF, Web Site } \\ \text { Audience: } & \text { Grades 9-12 } \\ \text { Msn/Prg: } & \text { HEASARC } \\ \text { Theme(s): } & \text { SEU }\end{array}$

Description: An information/activity booklet which accompanies the Life Cycles of Stars poster. This booklet contains information about the birth, life, and death of stars, and how their mass determines their life cycle. The booklet also discusses the use of the electromagnetic spectrum to understand objects in the universe. The booklet contains seven activities.

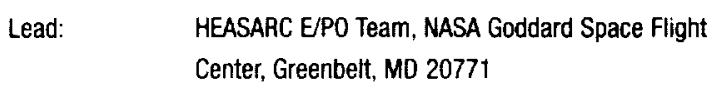

\section{The Ltfe Cycles of Stars Poster}

$\begin{array}{ll}\text { Subject(s): } & \text { Space Science } \\ \text { Format(s): } & \text { Poster/Wallsheet } \\ \text { Audience: } & \text { Grades 9-12, Adult/Continuing Education, Community } \\ & \text { College, General Public, Higher Education } \\ \text { Msn/Prg: } & \text { HEASARC } \\ \text { Theme(s): } & \text { SEU }\end{array}$

Description: This poster illustrates the birth, life, and death of high-mass and low-mass stars.

Lead: HEASARC E/PO Team, NASA Goddard Space Flight Center, Greenbelt, MD 20771

\section{The Million Degree Solar Corona}

$\begin{array}{cl}\text { Subject(s): } & \begin{array}{l}\text { Earth Science, Physical Science, Space Science, } \\ \text { Technology }\end{array} \\ \text { Format(s): } & \begin{array}{l}\text { Poster/Wallsheet } \\ \text { Adult/Continuing Education, Community College, } \\ \text { Gudience: }\end{array} \\ & \begin{array}{l}\text { General Public, Higher Education, Vocational } \\ \text { Education }\end{array} \\ \text { Msn/Prg: } & \text { TRACE } \\ \text { Theme(s): } & \text { SEC }\end{array}$

Description: A 24 inch $\times 28$ inch poster showing the full disk of the Sun as seen in extreme ultraviolet light by the Transition Region And Coronal Explorer (TRACE) satellite. Accompanying text on the back of the poster explains the science behind the image as well as the TRACE mission in general.

Lead:

TRACE E/PO Team, Lockheed Martin Solar and Astrophysics Lab, Palo Alto, CA 94304

\section{The Sun In Time Experiments}

$\begin{array}{ll}\text { Subject(s): } & \text { Physical Science, Space Science } \\ \text { Format(s): } & \text { PDF, Web Site } \\ \text { Audience: } & \text { Grades 5-8 } \\ \text { Msn/Prg: } & \text { IDEAS } \\ \text { Theme(s): } & \text { SEC }\end{array}$

Description: In order to get a feel for how astronomers might measure the altitude of a star or any object, students build a simple sextant. Students can also build a sundial (using a project developed by Marshall's Space Academy).

Lead: $\quad$ Mitzi Adams, NASA Marshall Space Flight Center, Marshall Space Flight Center, AL 35812

\section{The Sun in Time Sllde Show}

$\begin{array}{ll}\text { Subject(s): } & \text { Space Science } \\ \text { Format(s): } & \text { Web Site } \\ \text { Audience: } & \text { Grades 6-8 } \\ \text { Msn/Prg: } & \text { IDEAS } \\ \text { Theme(s): } & \text { SEC }\end{array}$

Description: An online slide show illustrating observations of the sun, its position in the sky, and its motions from ancient times to modern solar observatories.

Lead:
Mitzi Adams, NASA Marshall Space Flight Center, Marshall Space Flight Center, AL 35812 


\section{The Sun in Time Web Site}

$\begin{array}{ll}\text { Subject(s): } & \text { Physical Science, Space Science } \\ \text { Format(s): } & \text { Web Site } \\ \text { Audience: } & \text { Grades 5-8 } \\ \text { Msn/Prg: } & \text { IDEAS } \\ \text { Theme(s): } & \text { SEC }\end{array}$

Description: A program designed to integrate science and social studies curricula through a study of Solar Science and Archaeoastronomy. Through this set of lessons, students will have a better understanding of the motions of the Earth around the Sun, how these motions appear to us here on the Earth, and how ancient cultures observed and interpreted these motions. Includes slide show, script for planetarium program, and experiments for building a sundial and a sextant.

Lead: Mitzi Adams, NASA Marshall Space Flight Center, Marshall Space Flight Center, AL 35812

\section{The X-ray Astronomy Fleld Guide}

$\begin{array}{ll}\text { Subject(s): } & \text { Space Science } \\ \text { Format(s): } & \text { Web Site } \\ \text { Audience: } & \text { Grades 6-12, Adult/Continuing Education, Community } \\ & \text { College, General Public, Higher Education } \\ \text { Msn/Prg: } & \text { CX0 } \\ \text { Theme(s): } & \text { SEU }\end{array}$

Description: An overview to $x$-ray astronomy and $x$-ray sources: from black holes to galaxy clusters. A brief review of the history of $x$-ray astronomy, what $x$-rays are, how they are produced in the cosmos, why $x$-ray telescopes must be in space, and why $x$-ray astronomy is such a "hot" field. An explanation of different types of cosmic $x$-ray sources and detailed descriptions of some of the individual sources observed by the Chandra $X$-ray Observatory.

Lead: $\quad$ CXO E/PO Team, Harvard-Smithsonian Center for Astrophysics, Cambridge, MA 02138

\section{Think SMALL in a BIG Way-Stardust Activity Guide}

$\begin{array}{ll}\text { Subject(s): } & \text { Earth Science, Mathematics, Physical Science, Space } \\ & \text { Science, Life Science } \\ \text { Format(s): } & \text { Book, PDF } \\ \text { Audience: } & \text { Grades 5-8 } \\ \text { Msn/Prg: } & \text { Stardust } \\ \text { Theme(s): } & \text { SSE }\end{array}$

Description: This Stardust guide focuses on activities relating to small bodies of our Solar System, such as asteroids, meteorites, and comets.

Lead: $\quad$ Stardust E/P0 Team, NASA Jet Propulsion Laboratory, Pasadena, CA 91109
Third from the Sun

$\begin{array}{ll}\text { Subject(s): } & \text { Space Science, Technology } \\ \text { Format(s): } & \text { Web Site } \\ \text { Audience: } & \text { Grades 3-4 } \\ \text { Msn/Prg; } & \text { Information Systems } \\ \text { Theme(s): } & \text { SSE }\end{array}$

Description: Students learn about the history of Earth imaging and the Landsat satellite program. They develop interpretation skills as they play a game of inferring the subjects of various Landsat images.
Lead: $\quad$ Center for Science Education, Space Sciences Laboratory, University of California, Berkeley, CA 94720

\section{Time That Period!}

Subject(s): Mathematics, Physical Science, Space Science

Format(s): Web Site

Audience: Grades 7-12

Msn/Prg: HEASARC

Theme(s): SEU

Description: This lesson examines the idea of periodic behavior and how it is determined from a set of data. The students will examine this concept through a hands-on lab that involves a simple, student-made pendulum which is followed up with critical thinking and performance assessment style questions. Students will also analyze data received from high-energy satellites of various binary star systems' orbital periods or stellar rotation periods.

\section{Lead: $\quad$ HEASARC E/PO Team, NASA Goddard Space Flight Center, Greenbelt, MD 20771}

\section{Volcanoes on Another World: Jupiter's Moon lo}

$\begin{array}{ll}\text { Subject(s): } & \text { Earth Science, Space Science } \\ \text { Format(s): } & \text { PDF } \\ \text { Audience: } & \text { Grades 6-12, Community College, General Public, } \\ & \text { Higher Education } \\ \text { Msn/Prg: } & \text { Galileo } \\ \text { Theme(s): } & \text { SSE }\end{array}$

Description: Volcanoes on Another World: Jupiter's moon lo is display artwork (Duratrans with Velcro) in seven art pieces, including a four-foot-diameter enlargement of lo, suitable for posting on an eight-foot by ten-foot carpeted display. Comparing lo to Earth's size and volcanic activity, it also tells the story of the Galileo spacecraft's daring exploration of 10 in late 1999 and early 2000 and highlights the major discoveries. Five pieces of the display have been converted to PDF format for use as teaching content. It can be downloaded from the Resource Directory.

Lead: Galileo E/PO Team, NASA Jet Propulsion Laboratory, Pasadena, CA 91109 


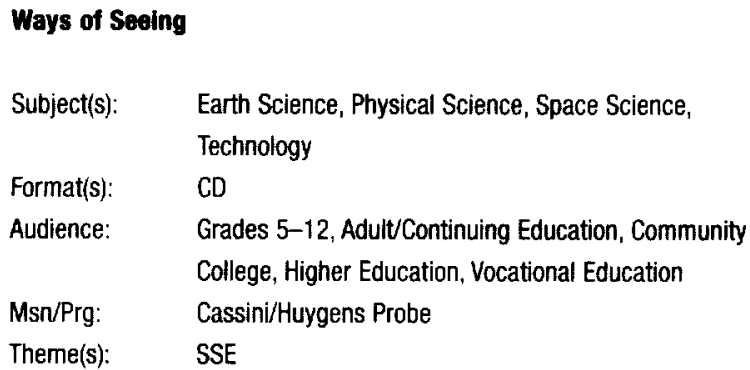

Description: This is a small subsection of the overall Windaws to the Universe Web site. This section provides detailed information about the variety of effects space weather can have.

Lead: $\quad$ Windows on the Universe, Michigan Space Grant Consortium, University of Michigan, Ann Arbor, MI 48109

\section{Yohkoh Public Outreach Project}

Subject(s): $\quad$ Physical Science, Space Science

Format(s): Web Site

Audience: $\quad$ Grades 4-12, General Public

Msn/Prg: Yohkoh

Theme(s): $\quad$ SEC
Description: The Yohkoh Movie Theater (YPOP) is designed to bring you images and movies depicting our nearest star, the Sun, as seen by an $x$ ray telescope on board the Yohkoh satellite. The YPOP site showcases a collection of resources which include a range of activities for youngsters, parents, teachers, and anyone interested in learning more about the Sun. You can make your own movies, see the latest solar images, take a tour of the Sun, and much more. This is a public domain site.

Lead: $\quad$ Yohkoh E/PO Team, Lockheed Martin Solar and Astrophysics Lab, Palo Alto, CA 94304

\section{Educational Programs/Events}

\section{Classroom Education \\ Systemic Improvement}

\section{Chicago Clty-Wide Conferences}

Msn/Prg: DePaul B/F

Description: DePaul presents information about space science in two annual city-wide conferences for Chicago public school science teachers.

Lead: DePaul Broker/Facilitator, DePaul University, Chicago,

Partner(s): $\quad$ Chicago Public School System, Chicago, IL 60608

Venue(s): $\quad$ Chicago Public Schools, Chicago, IL 60608

(Participants: 2000 local)

\section{Chicago Teachers' Advisory}

Msn/Prg: $\quad$ SEC Forum, DePaul B/F

Description: Through the Chicago Teachers' Advisory, DePaul is creating partnerships to develop ways to bring space science to the school children of Chicago. Advisory meetings occur quarterly and attract a broad group of teachers representative of the Chicago Public School System. Sessions are a mixture of space science presentations and discussions in areas such as curriculum and professional development, NASA resources, and communication.

Lead: DePaul Broker/Facilitator, DePaul University, Chicago, IL 60614

Venue(s): $\quad$ DePaul University, Chicago, IL 60614 (Participants: 320 local) 
Meetings with Chicago Public School Principals

Msn/Prg: DePaul B/F

Description: DePaul has participated in six meetings with Principals of Chicago Elementary and Middle Schools to inform them about opportunities in space science education.

Lead: DePaul Broker/Facilitator, DePaul University, Chicago, IL 60614

Partner(s): $\quad$ Walter Payton high School, Chicago, IL 60610

Venue(s): $\quad$ Walter Payton High School, Chicago, IL 60610 (Participants: 30 local)

\section{NASA/llinois/Chicago Partnerships In Development}

Msn/Prg: DePaul B/F

Description: DePaul arranged a meeting of NASA personnel from Education, Space Science, and Earth Science, with key people from the Chicago Public Schools, Chicago museums, and the Illinois State Board of Education. The purpose of the meeting was to make connections, share information, and establish a regular channel of communication.

Lead: DePaul Broker/Facilitator, DePaul University, Chicago, IL 60614

Venue(s): $\quad$ DePaul University, Chicago, IL 60614 (Participants: 26 local)

Near and Far Science for Ilinnois (NFSI)

Msn/Prg: DePaul B/F

Description: NFSI is a professional development program for Illinois teachers funded by the Illinois State Board of Education. DePaul gives presentations at the orientation session each year, provides server space for listserves, and serves as the fiscal agency for parts of the program.

Lead: DePaul Broker/Facilitator, DePaul University, Chicago, IL 60614

Partner(s): $\quad$ Illinois State Board of Education, Springfield, IL 62701 Venue(s): DePaul University, Chicago, IL 60614 (Participants: 100 local)

\section{Space Sclence Charrette}

Msn/Prg: DePaul B/F

Description: This strategic planning meeting for participants from Illinois and Wisconsin included teachers, scientists, and NASA education personnel from each State, and the two State science supervisors. The meeting was a marathon of brainstorming sessions on the state of space science education in the midwest, and events motivating reflections about the nature of science.

Lead:

DePaul Broker/Facilitator, DePaul University, Chicago, IL 60614
Partner(s):

Ilinois State Board of Education, Springfield, IL 62701 Wisconsin Department of Public Instruction, Madison, W| 53707

Venue(s): $\quad$ Yerkes Observatory, Williams Bay, WI 53191

(Participants: 42 local)

\section{Space Sclence for IIIInois Teachers (SSIT)}

Msn/Prg: DePaul B/F

Description: SSIT is an intensive professional development program for teachers from the Chicago Teachers' Advisory and NFSI. The summer component featured a one-week trip to Goddard Space Flight Center and one week at DePaul, and was funded partially by the lllinois Board of Higher Education. Teachers in the program are developing instructional strategies for integrating content from Goddard into their classrooms, and service components for sharing with other teachers. They are also planning state-wide activities related to solar activity.

$\begin{array}{ll}\text { Lead: } & \text { DePaul Broker/Facilitator, DePaul University, Chicago, } \\ & \text { IL } 60614 \\ \text { Partner(s): } & \text { Illinois Board of Higher Education, Springfield, IL } \\ & 62701 \\ \text { Venue(s): } & \text { NASA Goddard Space Flight Center, Greenbelt, MD } \\ & 20771 \text { (Participants: } 30 \text { local) }\end{array}$

Superintendents Seminar 2000

Msn/Prg: $\quad$ CXO

Theme(s): $\quad$ SEU

Description: Chandra briefing presented to Harvard Graduate School of Education "Superintendents Seminar 2000." One hundred school superintendents from around the country. Chandra $X$-Ray Center Director Dr. Harvey Tanabaum gave Chandra briefing, CXC E/PO Coordinator $K$. Lestition discussed use of space science in education. Chandra materials handed out.

Lead: $\quad$ SEU Forum, Smithsonian Astrophysical Observatory, Cambridge, MA 02138

Venue(s): $\quad$ Harvard University, Cambridge, MA 02138

(Participants: 100 local)

\section{Teacher Consultants}

Msn/Prg: $\quad$ DePaul B/F

Description: The Chicago Connection Consultants are a small group of teachers who meet with us monthly. They have defined their roles as (1) providing vision, (2) organizing events, and (3) doing and promulgating activities in the Chicago area. They have taken the leadership in planning the Advisory meetings.

Lead: DePaul Broker/Facilitator, DePaul University, Chicago, IL 60614

Venue(s): $\quad$ DePaul University, Chicago, IL 60614 (Participants: 15 local) 


\section{Teacher Preparation/Enhancement}

Amazing Space Presentation

Msn/Prg: DePaul B/F, HST

Theme(s): $\quad$ ASO, SEU, SSE

Description: Presentations were made on the Amazing Space activities to major partners, including the Maryland schools' Science Supervisors, elementary and secondary teachers from Prince Georges and Anne Arundel Counties in Maryland, Chicago area teachers (as part of a collaboration between HST, Chicago Public Schools, and the Chicago Internet Project), the DePaul Broker/Facilitator workshop "Astronomy Symposium for High School and Middle School Teachers," a committee of teachers and supervisors from Pennsylvania searching for resources related to middle school science on the theme of forces and motion, and the NASA GSFC AESP resource teachers. An HST 10 Year Anniversary Presentation was made over close circuit, interactive video network to teachers across Maryland.

Lead: $\quad$ Amazing Space Office of Public Outreach, Space Telescope Science Institute, Baltimore, MD 21218

Venue(s): AESP Presentation, MD (Participants: 8 local) Astronomy Symposium, Chicago, IL

Penn. State Resource, PA

STSci-Chicago Project, Chicago, IL (Participants: 22 local)

Towson State University, Baltimore, MD 21204

(Participants: 5 local, 25 remote)

\section{Aurora in the Solar System}

Msn/Prg: $\quad$ Solar Probe, Ulysses, Galileo, Genesis

Theme(s): $\quad$ SSE

Description: Aurora in the Solar System is a one-day long workshop aimed at educators in grades 7-12. Scientists present talks on the basic physics behind what causes aurora, where aurora are found (emphasizing Jupiter and Earth), the interaction between the sun and planets, and a supplement on the Solar Maximum. Related classroom activities are presented.

Lead: Galileo E/PO Team, NASA Jet Propulsion Laboratory, Pasadena, CA 91109

\section{Carnegie Academy for Science Education}

Msn/Prg: NAl

Theme(s): $\quad$ ASO

Description: The Academy is an education and public outreach program at the $K-6$ level which includes professional education for practicing teachers. Teachers are involved in a six week summer institute in which astrobiology is the over-arching theme.
Lead:

Office of Public Outreach, Space Telescope Science Institute, Baltimore, MD 21218

\section{Cassinl Exhibit}

Msn/Prg: Cassini/Huygens Probe

Theme(s): $\quad$ SSE

Description: 10 foot $\times 10$ foot booth with "expose" backdrop. Images of Cassini, Saturn, and the Saturn System were presented. Hand out materials included Cassini product information sheets, list of educational materials, and a one-page visual fact sheet on Cassini (copies in both English and Spanish).

Lead: $\quad$ Cassini E/PO Team, NASA Jet Propulsion Laboratory, Pasadena, CA 91109

Venue(s): $\quad$ San Diego Science Educator's Association, San Diego, CA 92101

\section{Cassinl Mission to Satum Teacher Presentations}

Msn/Prg: Cassini/Huygens Probe

Theme(s): SSE

Description: Lecture on the Cassini Mission to Saturn and demonstrations of hands-on activities.

Lead: $\quad$ Cassini E/PO Team, NASA Jet Propulsion Laboratory,

Venue(s): $\quad$ Kentucky State Science Teachers, Lexington, $K Y$ 40507 (Participants: 60 local)

North Carolina State Science Teachers, Durham, NC (Participants: 50 local)

TechEd2000, Palm Springs, CA 92262

Washington State Science Teachers Conference, Spokane, WA (Participants: 45 local)

\section{Destination Moon and Mars}

$\begin{array}{ll}\text { Msn/Prg: } & \text { SERCH B/F, NAI, Mars, Sample Curation, Lunar } \\ & \text { Prospector } \\ \text { Theme(s): } & \text { SSE }\end{array}$

Description: This workshop combined the efforts of Astromaterials group with those of the Lunar Prospector mission and Mars Exploration program to present a broad view of the rocks and geology of the Moon and Mars. Both science content and numerous hands-on activities were presented. JSC also participated in the Astrobiology workshop, the ASU Mars workshop, the Exploring the Solar System short course, and HMNS science and magic workshop.

Lead: $\quad$ Sample Curation E/PO Team, NASA Johnson Space Center, Houston, TX 77058

Venue(s): $\quad$ National Science Teachers Association (NSTA), April 2000, Orlando, FL 32819 (Participants: 500 local) 


\section{Europa: Another Water World?}

Msn/Prg: Galileo, Europa Orbiter

Theme(s): $\quad$ SSE

Description: Educators' Workshop: Join NASA team members in exploring Jupiter's intriguing moon Europa, which may have an ocean of water underneath its surface, and participate in activities designed for your classroom. The first hour of the session will be devoted to learning about Europa and the NASA space missions that explore it. The next hour will be devoted to a demonstration of two classroom activities, and we'll wrap it up with feedback on the activities and discuss further applications of this topic for the classroom.

Lead:

Galileo E/PO Team, NASA Jet Propulsion Laboratory, Pasadena, CA 91109

Venue(s)

California Science Teachers Association, October

1999, Long Beach, CA 90802 (Participants: 12 local)

\section{Exploring the Solar System for Special Needs Students}

Msn/Prg: $\quad$ Sample Curation

Theme(s): $\quad$ SSE

Description: This workshop is part of a series of annual solar system workshops sponsored by GSA Planetary Geology Division. They are six hour intensive workshops for 25-30 teachers. This year's workshop featured special needs, with the Braille solar system and Music of the planets units.

Lead: $\quad$ Sample Curation E/PO Team, NASA Johnson Space Center, Houston, TX 77058

Venue(s): $\quad$ Geological Society of America, Denver, $C 0$

(Participants: 30 local)

\section{From the Ground Upl}

Msn/Prg: $\quad$ SEU Forum

Theme(s): $\quad$ SEU

Description: From the Ground Up, a micro-observatory project brought 13 teachers from all over the country together at the Harvard-Smithsonian Center for Astrophysics to develop curriculum using online telescopes. Sponsored in part by the SEU forum.

Lead: $\quad$ SEU Forum, Smithsonian Astrophysical Observatory, Cambridge, MA 02138

Venue(s): $\quad$ Harvard-Smithsonian Center for Astrophysics, Cambridge, MA 02138 (Participants: 13 local)

\section{Galileo Europa Mission Educator Fellows}

Msn/Prg: Galileo

Theme(s): $\quad$ SSE

Description: The Galileo Europa Mission Educator Fellows program is funded by the Galileo Project at JPL and run by the Challenger Center for
Space Science Education. The goal of the program is to increase the number of teachers across the country who are trained on Galileo related activities during the Galileo Europa Mission phase and to provide a diverse national distribution of Galileo materials and information to the $\mathrm{K}-12$ community. To support this goal, 16 highly motivated GEM Fellows having a diverse background of educational specialties have been recruited and trained.

Lead: Galileo E/PO Team, NASA Jet Propulsion Laboratory, Pasadena, CA 91109

\section{GAVRT Exhlbit}

Msn/Prg: $\quad$ DSMS

Theme(s): $\quad$ SSE

Description: The Goldstone Apple Valley Radio Telescope (GAVRT) Project, an educational program of the Deep Space Network, took a 10-foot by 10-foot booth at the San Diego Science Educator's Association Conference in San Diego, California, on March 9-11, 2000. The new GAVRT pop-up exhibit was displayed; the GAVRT 4-min. video showed continuously on a monitor, and the booth was staffed by JPL and Lewis Center for Educational Research (the JPL GAVRT partner). Brochures were distributed.

Lead: $\quad$ DSMS E/PO Team, NASA Jet Propulsion Laboratory, Pasadena, CA 91109

Venue(s): San Diego Science Educator's Association, San Diego, CA 92101

\section{Genesis Inservice Training}

Msn/Prg: Genesis

Theme(s): $\quad$ SEC

Description: Worked with a group of teachers to prepare them to work with students on special projects within the curriculum and to advance teacher knowledge. The programs are standards-based and connected to national and state benchmarks to provide easy connection to classroom requirements.

Lead: Genesis E/PO Team, NASA Jet Propulsion Laboratory, Pasadena, CA 91109

Venue(s): $\quad$ California State University, Pasadena, CA 91109 (Participants: 75 local) Convention Center, Orlando, FL 32801 (Participants: 70 local; 2 events) Jefferson Elementary School, Pasadena, CA 91050 (Participants: 18 local; 2 events) NASA Jet Propulsion Laboratory, Pasadena, CA 91109 (Participants: 25 local) San Diego School System, San Diego, CA 92101 (Participants: 54 local) University of Wisconsin at Milwaukee, Milwaukee, W| 53201 (Participants: 100 local; 2 events) 


\section{Genesis School Enrichment}

Msn/Prg: Genesis

Theme(s): $\quad$ SEC

Description: Scientists present the content to educators to enhance their background knowledge. The educators work with the scientist to put the activities into a classroom to enable students to gain insight in the new science discoveries.

Lead: Genesis E/PO Team, NASA Jet Propulsion Laboratory, Pasadena, CA 91109

Venue(s): $\quad$ Alchesay High School, Pasadena, CA 91109

(Participants: 155 local)

Blue Ridge High School, Pasadena, CA 91109

(Participants: 160 local)

Community Park Elementary School, Pasadena, CA 91109 (Participants: 200 local)

Sierra Vista Elementary School, Brea, CA 92821

Whitney Young High School, Pasadena, CA 90501

(Participants: 125 local)

Genesis Workshop

Msn/Prg: Genesis

Theme(s): $\quad$ SEC

Description: Educator's workshop at a conference for the chemistry teacher. Materials and workshops are available for high school teachers interested in finding resources for the classroom and learning about educational opportunities in their specific subject area. A day-and-a-half workshop based on the materials developed and posted on the Genesis home page.

Lead: Genesis E/PO Team, NASA Jet Propulsion Laboratory, Pasadena, CA 91109

Venue(s): $\quad$ ChemEd 99 Convention, Pasadena, CA 91109

(Participants: 45 local)

Genesis/Calffornia State University at Morthridge (CSUM) Exhiblt

Msn/Prg: Genesis

Theme(s): $\quad$ SEC

Description: The AAIE is the organizing group of American internationa schools all over the world. It is supported, in part, by the U.S. State Department. This meeting brings together the key educators from the large groups of American-based schools from all over the world. NASA was shown as a partnership with the booth of CSUN, who are very active in this group.

Lead: Genesis E/PO Team, NASA Jet Propulsion Laboratory, Pasadena, CA 91109

Partner(s): California State University, Northridge, CA 91330

Venue(s): $\quad$ Association for the Advancement of internationa Education (AAIE) Annual Conference, San Franciso, CA
Imagine the Unlversel Presentation

$\begin{array}{ll}\text { Msn/Prg: } & \text { SEU Forum, HEASARC } \\ \text { Theme(s): } & \text { SEU }\end{array}$

Description: Dr. James Lochner presented Imagine the Universe!, exploring the universe with Starchild at the Aerospace Conference for Educators, put on by the Alabama Aerospace Teachers Association.

Lead SEU Forum, Smithsonian Astrophysical Observatory, Cambridge, MA 02138

Venue(s): $\quad$ Aerospace Conference for Educators (ACE) 2000 Auburn, AL 36830

Integrating Hubble Space Telescope and other NASA Resources in the Curriculum

Msn/Prg: $\quad$ HST

Theme(s): $\quad$ ASO

Description: Educators' Workshop

Lead: $\quad$ HST E/PO Team, Space Telescope Science Institute, Baltimore, MD 21218

Venue(s): $\quad$ National Science Teachers Association (NSTA), April 2000, Orlando, FL 32819

It's All In Motionl: A Workshop for Teachers

Msn/Prg: $\quad$ IDEAS

Description: Our objectives were to provide astronomy content and hands-on activities to the teachers so that they would be able to use the same approach in their classrooms. Specific objectives were written and discussed at the start of each day, and revisited at the end of the day.

Lead: $\quad$ Dr. Mary West, Montclair State University, Upper Montclair, NJ 07043

Venue(s): $\quad$ Dreyfus Planetarium, Newark, NJ 07101 (Participants: 37 local)

JASON Foundation Summer Instltute Workshop and Training

$\begin{array}{ll}\text { Msn/Prg: } & \text { Stardust } \\ \text { Theme(s): } & \text { SSE }\end{array}$

Description: JASON Foundation: Summer Institute Workshop and Training, Peru. One hundred twenty-five educators in attendance. Topic Crater Impacts on Earth and the Evolution of the Solar System. JASON Foundation is one of three educational Stardust partners.

Lead: Stardust E/PO Team, NASA Jet Propulsion Laboratory, Pasadena, CA 91109 
Partner(s): JASON Foundation for Education, Needham Heights, MA 02494-0005

Venue(s): $\quad$ Amazon Center for Environmental Education and Research (ACEER), Tropical Rainforest Site, Peru (Participants: 125 local)

\section{Join NASA for the Jupiter Flyby}

Msn/Prg: Cassini/Huygens Probe, Galileo, DSMS

Theme(s): SSE

Description: A joint workshop focused on the Cassini Millennium Flyby on December 30,2000 , when Cassini and Galileo will be in close range of Jupiter at the same time. The workshop featured 15-minute presentations by the Cassini and Galileo Missions, the Goldstone Apple Valley Radio Telescope (GAVRT) Project, and Radio JOVE from GSFC.

Lead: DSMS E/PO Team, NASA Jet Propulsion Laboratory, Pasadena, CA 91109

Venue(s): $\quad$ National Science Teachers Association (NSTA), April 2000, Orlando, FL 32819

Jupiter Quest: Listening to Jupiter with a Real Radio Telescope

Msn/Prg: $\quad$ DSMS

Theme(s): $\quad$ SSE

Description: Educators' Workshop: Jupiter Quest, a GAVRT Project curriculum module, is a hands-on, student-driven, standards-based radio astronomy project that used a real 34-meter antenna via the internet. See a simulation and pickup a sample lesson. Presenters included Dr. Michael Klein, Deep Space Network Science Manager, JPL, and Jim Roller, Manager; Kelly Bollman, Curriculum Specialist; and Pat Reader, Teacher Trainer; from the Lewis Center for Educational Research in Apple Valley.

Lead: $\quad$ DSMS E/PO Team, NASA Jet Propulsion Laboratory, Pasadena, CA 91109

Venue(s): National Science Teachers Association (NSTA), April 2000, Orlando, FL 32819

Kinesthetic Astronomy Curriculum Development and Workshops

Msn/Prg: $\quad$ SSI B/F

Theme(s): $\quad$ ASO, SEC, SEU, SSE

Description: Kinesthetic Astronomy is an experiential approach to learning basic astronomical concepts that is in development at the Space Science Institute (SSI) by Dr. Cherilynn Morrow and her collaborator Mike Zawaski, an Outward Bound instructor. This innovative approach teaches basic astronomy through choreagraphed bodily movements and positions that provide educational sensory experiences. "Kinesthetic Astronomy for At-Risk Students" is funded with support from NASA's Office of Space Science/IDEAS grant program. This work is experimenting with the effectiveness of kinesthetic astronomy techniques with at-risk high school students who attend the Eagle Rock School in Estes Park, Colorado. The lesson plans created will be disseminated to JPL Solar System Educators and NASA Aerospace Education Specialists. In general, kinesthetic astronomy lessons are science-rich and fun. They are intended for sixth graders up through adult learners in both formal and informal educational settings. They emphasize astronomical concepts and phenomenon that people can readily encounter in their everyday lives such as time, seasons, and sky motions of the Sun, stars, and planets. Kinesthetic astronomy lesson plans are fully aligned with national science education standards, both in content and instructional practice. In the first lesson, called "Sky Time," students experience a series of simple body movements (e.g. rotating, revolving, tilting, bending, twisting) that give them insight into the relationship between time and astronomical motions of Earth, (rotation about its axis and orbit around the Sun), and also about how these motions influence what we see in the sky at various times of the day and year. Other lessons are devoted to lunar motion, meteor showers, and the sky motions of the planets. Field testing with non-science undergraduates, secondary science teachers, Junior girl scouts, and outdoor educators suggests that kinesthetic astronomy techniques allow learners to achieve a good intuitive grasp of concepts that are much more difficult to learn in more conventional ways such as via textbooks or even computer animation. For the latest on the development of kinesthetic astronomy lessons, please go to: http://www.spacescience.org; click on K-12 Curriculum, and look for the kinesthetic astronomy icon.

Lead: $\quad$ SSI Broker/Facilitator, Space Science Institute, Boulder, CO 80303

Venue(s): $\quad$ American Astronomical Society (AAS), January 2000 , Atlanta, GA 30303 (Participants: 30 local) Astronomical Society of the Pacific (ASP), July 2000, Pasadena, CA 91101 (Participants: 50 local) Colorado Science Convention, September 2000 , Colorado Springs, CO 80907 (Participants: 20 local) Denver Museum and Arvada Center for the Arts, Arvada, CO 80004 (Participants: 20 local) National Science Teachers Association (NSTA) Regional Conference, October 2000, Boise, ID 83701 (Participants: 50 local)

\section{Life in the Solar System Educator Workshop}

$\begin{array}{ll}\text { Msn/Prg: } & \text { NAl, Cassini/Huygens Probe, Galileo, Mars, Europa } \\ & \text { Orbiter } \\ \text { Theme(s): } & \text { SSE }\end{array}$

Description: "Life in the Solar System" is a day-long educator workshop aimed at educators in grades 5-12. It combines hands-on activities for the classroom with lectures by researchers in the field of astrobiology on space missions studying bodies in the Solar System where life might exist or conditions may have supported life. Tours of the facility holding the event are also included.

Lead: Galileo E/PO Team, NASA Jet Propulsion Laboratory, Pasadena, CA 91109

\section{Liftoff Educator Workshop}

Msn/Prg: LPI B/F

Theme(s): SSE 


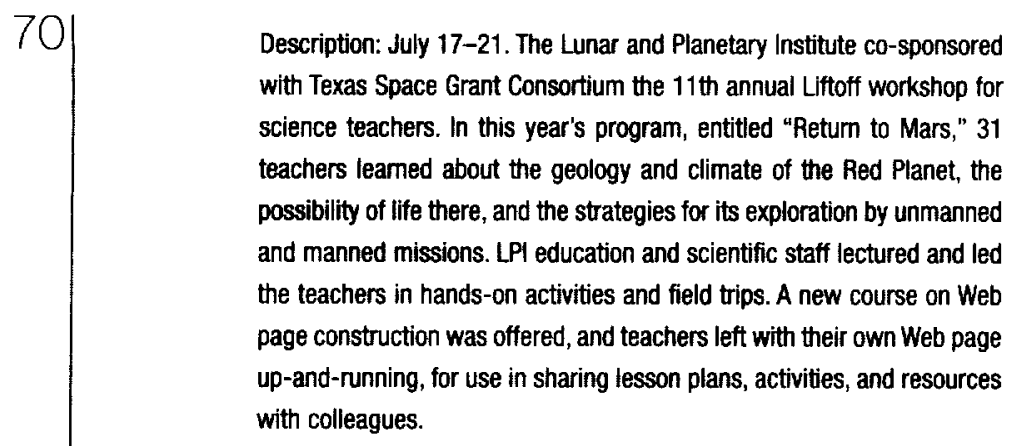

Lead: $\quad$ LPI Broker/Facilitator, Lunar and Planetary Institute, Houston, TX 77058

Venue(s): $\quad$ Lunar and Planetary Institute, Houston, TX 77058

(Participants: 32 local)

\section{Ught, Waves, and Interference}

$$
\begin{array}{ll}
\text { Msn/Prg: } & \text { SIM } \\
\text { Theme(s): } & \text { ASO }
\end{array}
$$

Description: Educators' workshop: Join us as we explore the fascinating world of light, waves, and interference. See and hear how different NASA.JPL flight projects are taking advantage of the wave nature of light and radio waves for extremely accurate measurements. We will engage our teachers by exploring the world of interferometry. They will learn how light can interfere to create darkness. They will examine how we are surrounded by waves and discover that waves can act in surprising ways.

$$
\begin{array}{ll}
\text { Lead: } & \text { SIM E/P0 Team, NASA Jet Propulsion Laboratory, } \\
\text { Venue(s): } & \text { Pasadena, CA 91109 } \\
& \text { Astronomical Society of the Pacific (ASP), July 2000, } \\
& \text { Pasadena, CA 91101 } \\
& \text { San Diego Science Educator's Association, San Diego, } \\
& \text { CA 92101 (Participants: } 1000 \text { local) }
\end{array}
$$

\section{Maine Math and Sclence Alliance}

$\begin{array}{ll}\text { Msn/Prg: } & \text { SEU Forum, CXO } \\ \text { Theme(s): } & \text { SEU }\end{array}$

Description: Ongoing series of teachers workshops for seven (7) master teachers and a curriculum facilitator in conjunction with the Maine Math and Science Alliance. Chandra science topics were presented to the participants for the purpose of developing curricular and content fits. Seven preliminary education exercises were scoped out for further development.

Lead: $\quad$ SEU Forum, Smithsonian Astrophysical Observatory, Cambridge, MA 02138

Venue(s): Havvard-Smithsonian Center for Astrophysics, Cambridge, MA 02138 (Participants: 8 local)

\section{Mars Exploration}

Msn/Prg: IDEAS

Description: The program objectives are to assist teachers from inner-city schools in utilizing technology for student inquiry; provide $\mathrm{K}-12$ workshops for teachers in South Central Los Angeles that will strengthen their understanding of astronomy concepts, provide models of conceptual lessons, and utilize telecommunications; offer Mars Family Science to parents and students in South Central, Downtown, and East Los Angeles; and provide students with direct contact with scientists through classroom visitations.

$\begin{array}{ll}\text { Lead: } & \text { Dr. John Callas, NASA Jet Propulsion Laboratory, } \\ & \text { Pasadena, CA } 91109 \\ \text { Venue(s): } & \text { Los Angeles Unified School District, Los Angeles, CA } \\ & 90051 \text { (Participants: } 3900 \text { local) }\end{array}$

\section{MarsQuest Workshop}

$\begin{array}{ll}\text { Msn/Prg: } & \text { SSI B/F } \\ \text { Theme(s): } & \text { SSE }\end{array}$

Description: MarsQuest Educator Workshop: The MarsQuest Education Program is helping teachers and museum staff share the excitement of Mars exploration with students and the public through full-day teacher workshops held in conjunction with the opening of SSI's MarsQuest traveling exhibit at host sites around the country. The first of these workshops was held at the McWane Center in Birmingham, Alabama, in conjunction with the premier opening of the exhibit. Twelve local educators and six museum staff directly benefited from the workshops. Future workshops will be designed to accommodate 30-40 educators. The workshops are conducted by Dr. Cheri Morrow of the Space Science Institute (Boulder, Colorado), Sheri Klug of Mars K-12 Education Program at Arizona State University, and Dr. Steve Lee of the University of Colorado's Laboratory for Atmospheric and Space Physics. These workshops will broker increasing connections between NASA's master educators (e.g., JPL Solar System Educators/Ambassadors, NASA Aerospace Education Specialists) and science museums.
Lead: $\quad$ SSI Broker/Facilitator, Space Science Institute, Boulder, CO 80303
Venue(s): $\quad$ McWane Center, Birmingham, AL 35203 (Participants: 20 local)

\section{Maryland Sclence Center Teacher Thursday}

$$
\begin{array}{ll}
\text { Msn/Prg: } & \text { IMAGE } \\
\text { Theme(s): } & \text { SEC }
\end{array}
$$

Description: This program brings scientists into a two-hour workshop setting for Baltimore teachers. Scientists present new findings and provide hands-on activities to share with the teachers.

$\begin{array}{ll}\text { Lead: } & \text { IMAGE E/PO Team, NASA Goddard Space Flight } \\ & \text { Center, Greenbelt, MD 20771 } \\ \text { Venue(s): } & \text { Maryland Science Center, Baltimore, MD 21230 }\end{array}$


Mathematics In the Solar System

$$
\begin{array}{ll}
\text { Msn/Prg: } & \text { Sample Curation } \\
\text { Theme(s): } & \text { SSE }
\end{array}
$$

Description: Educators' Workshop: two activities (triangulation to find a meteorite and clouds of Jupiter) were presented. Teachers were asked to critique them and suggest ways to improve NASA's activities for mathematics. Several more activities and handouts were given out after the discussion.

Lead:

Sample Curation E/P0 Team, NASA Johnson Space Center, Houston, TX 77058

Venue(s):

National Council of Teachers of Mathematics (NCTM), April 2000, Chicago, IL 60616 (Participants: 50 local)

\section{MASA Astroblology Institute Outreach and Education Project- The Carnegie Instltution of Washington}

Msn/Prg: $\quad$ NAI

Description: Program of education and public outreach at the $\mathrm{K}-12$ level including inservice training for teachers. The emphasis of the project will be to enhance opportunities for broadly integrated science learning about NASA Astrobiology Institute themes, in the context of rich, interactive experiences. Communication with teachers, the general public and youngsters will be carried out in three ways: 1 . The creation of an interactive Web site featuring content, activities, and inquiry-based projects for students, teachers, and the general public. 2. A comprehensive, weeklong seminar of content instruction and instructional opportunities for teachers. 3. Comprehensive print material for educational settings.

Lead: $\quad$ Astrobiology Institute E/PO Team, NASA Ames Research Center, Moffett Field, CA 94035

Partner(s): Carnegie Institution of Washington, Washington, DC

\section{MASA JSC Astrobiology Instltute Educator Workshops}

Msn/Prg: NAl

Theme(s): $\quad$ ASO

Description: Each year we present numerous teacher workshops on Moon, Mars, and Meteorites. Each consists of about one-third background information and two-thirds hands-on classroom activities. Our goal is to provide teachers with the experience necessary to allow them to use NASA Astrobiology and Astromaterials activity materials in their classes.

Lead: $\quad$ Astrobiology Institute E/PO Team, NASA Ames Research Center, Moffett Field, CA 94035

\section{MASA JSC Astromaterlals Teacher Interns}

Msn/Prg: NAI, Sample Curation

Theme(s): $\quad$ SSE
Description: JSC Astromaterials and Astrobiology science teams mentored eight middle and high school teachers during summer 1999, bringing them into research labs for two months to see how science is done. Then the teachers and E/PO team began to develop curriculum to take our research to the classroom. The resultant "Martian Meteorite Mysteries" has strands in physics, chemistry, geology, and biology, and will be accompanied by virtual lab tours and scientist interviews. The hands-on activities are nearing test stage but visual product is still in the planning stage. Teachers are continuing to return to JSC for monthly team meetings.

Lead:

Sample Curation E/PO Team, NASA Johnson Space Center, Houston, TX 77058

Venue(s): NASA Johnson Space Center, Houston, TX 77058 (Participants: 10 local)

\section{NASA JSC Astromaterials Teacher Workshops}

$\begin{array}{ll}\text { Msn/Prg: } & \text { NAl, Sample Curation } \\ \text { Theme(s): } & \text { SSE }\end{array}$

Description: The JSC Astromaterials and Astrobiology E/PO teams have conducted numerous teacher workshops which include five extended 1-2 day workshops on "Exploring the Solar System" and 24 short 1-2 hour workshops on "Rocks from Space" or "Mars Geology and Life?" as part of a JSC workshop or science (DPS, GSA, NSS) or education (NSTA, CAST, TMSA) conference. We focused on girls in science with Girl Scouts and Expanding Your Horizons, and on minorities at an urban school district (58 percent Hispanic).

Lead: $\quad$ Sample Curation E/PO Team, NASA Johnson Space Center, Houston, TX 77058

Venue(s): $\quad$ NASA Johnson Space Center, Houston, TX 77058 (Participants: 250 local)

\section{MASA Sun-Earth Connection Resources for Your Mathematics Classroom}
Msn/Prg:
SEC Forum, HESSI, IMAGE

Theme(s):

SEC

Description: We will present innovative classroom activities that combine mathematics and space science curriculum elements, which have been developed through partnerships between NASA scientists and educators for grades 8-12. We will focus on two resources: "Solar Storms and You: The Soda Bottle Magnetometer," and "Sunspots." Solar storms can affect the Earth's magnetic field causing small changes in its direction. A magnetometer operates like a sensitive compass and senses these slight changes. The soda bottle magnetometer has been built by students for under $\$ 5$. Students can also compare their results with other schools in the Magnetometer Network (MagNet). "Sunspots" covers solar science (ancient and modem) and features an interactive research exercise where students attempt to correlate the areas of sunspots with those of active regions as seen in satellite $x$-ray imagery.

Lead:

SEC Forum, University of California, Berkeley, CA 94720 


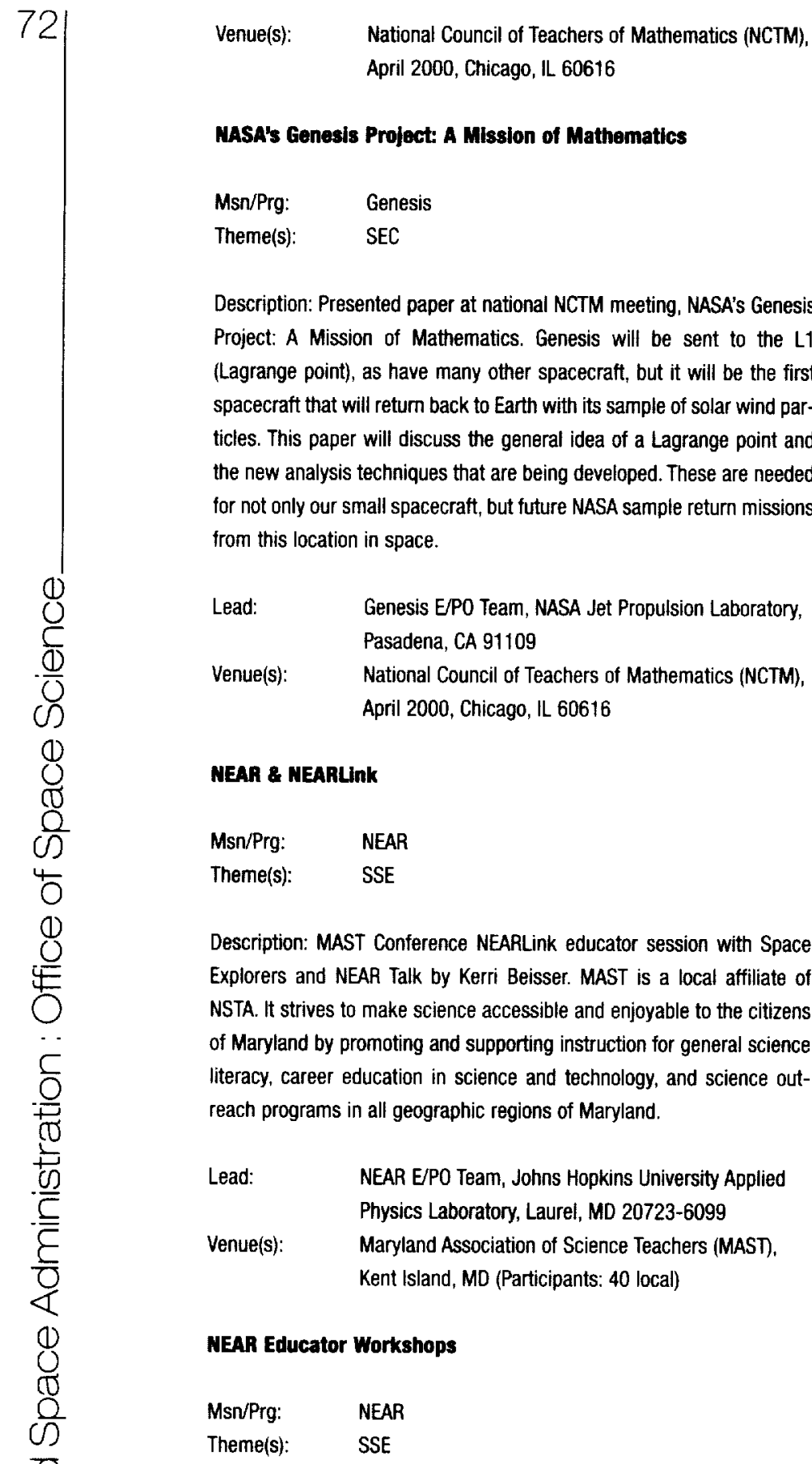

Description: Talks and classroom activities on the NEAR Mission, NearEarth Asteroids, and related subjects presented to teachers by NEAR project staff during educator workshops.

$\begin{array}{ll}\text { Lead: } & \text { NEAR E/PO Team, Johns Hopkins University Applied } \\ & \text { Physics Laboratory, Laurel, MD 20723-6099 } \\ \text { Venue(s): } & \text { Applied Physics Laboratory, Laurel, MD } 20723 \\ & \text { (Participants: } 25 \text { local) } \\ & \text { Lake County Reg. Off, Grayslake, IL 60030 } \\ & \text { (Participants: } 60 \text { local) } \\ & \text { NASA Goddard Space Flight Center, Greenbelt, MD } \\ & \text { 20771 (Participants: } 72 \text { local; } 3 \text { events) }\end{array}$

NASA Jet Propulsion Laboratory, Pasadena, CA 91109 (Participants: 90 local; 2 events)

\section{OSS Exhibit at Calfornia Science Teachers Association (CSTA)}

Msn/Prg:

SSE Forum, VSOP, Solar Probe, Ulysses, Cassini/Huygens Probe, Galileo, Voyager, Stardust, Mars, Europa Orbiter, Pluto/Kuiper Express, DSMS, OSS

Theme(s): $\quad$ SEC, SEU, SSE

Description: In a 40 -foot by 10-foot integrated space at CSTA, 0SS had two separate exhibits, coordinated by the SSE Forum and JPL. US Space VLBI (SEU Forum) occupied a 10 foot $x 10$ foot space, and the remainder was a segment of the OSS exhibit featuring the SSE and SEC themes. A series of 12 OSS workshops ran continuously throughout the convention in a "Space and Earth Showcase": JPL, Earth Science, Cassini, Mars Surveyor, Solar Missions, TIE, SIRTF, Astrobiology (ARC), Volcanoes in Our Solar System, GAVRT/DSN, TOPEX, and Stardust. A series of six 3-hour short-courses were presented: Saturn, Earth Science, Pluto, Europa, Kinesthesizing Space Science, and Life in the Solar System. A tour of JPL was given on Saturday.

$\begin{array}{ll}\text { Lead: } & \text { OSS, NASA Headquarters, Washington, DC } 20546 \\ \text { Partner(s): } & \text { Telescopes in Education, NASA Jet Propulsion } \\ & \text { Laboratory, Pasadena, CA } 91109 \\ \text { Venue(s): } & \text { California Science Teachers Association, October } \\ & 1999, \text { Long Beach, CA } 90802\end{array}$

\section{OSS Exhibit at National Council of Teachers of Mathematics (NCTM)}

$\begin{array}{ll}\text { Msn/Prg: } & \text { SIM, SIRTF, SOFIA, NAI, Sample Curation, OSS } \\ \text { Theme(s): } & \text { SSE }\end{array}$

Description: NCTM provides the opportunity for thousands of math teachers to come together and learn more about the new and various ways to teach math. OSS attends the conference to highlight how math is used to conduct space science through the provision of various education and outreach materials to the teachers.

Lead: $\quad$ OSS, NASA Headquarters, Washington, DC 20546

Partner(s): $\quad$ Maryland Science Center, Baltimore, MD 21230

Venue(s): National Council of Teachers of Mathematics (NCTM), April 2000, Chicago, IL 60616

\section{OSS Exhlbit at National Science Teachers Association (NSTA)}

$\begin{array}{ll}\text { Msn/Prg: } & \text { HST, CGRO, Cassini/Huygens Probe, Galileo, Deep } \\ & \text { Impact, Genesis, NEAR, Stardust, Mars, DSMS, } \\ & \text { Sample Curation, OSS, Lunar Prospector } \\ \text { Theme(s): } & \text { ASO, SEU, SSE }\end{array}$

Description: NSTA provides the opportunity for thousands of science teachers to come together to learn about the latest discoveries in science. OSS attends the conference to provide the teachers information about space science via posters, education briefs, hands-on activity 
packets, lithographs, CD's, brochures, and other educational material. The conference also provided a venue for field-testing the Space Science Education Directory on teachers.

Lead: $\quad$ OSS, NASA Headquarters, Washington, DC 20546

Venue(s): $\quad$ National Science Teachers Association (NSTA), April 2000, Orlando, FL 32819

\section{Duter Planets/Solar Probe Project: Educator Workshops}

Msn/Prg: $\quad$ SIRTF, NAI, Keck, Solar Probe, Ulysses, Cassini/Huygens Probe, Galileo, Voyager, Deep Impact, Stardust, Mars, OP/SP, Europa Orbiter, Pluto/Kuiper Express, DS-1, DSMS

Theme(s): SSE

Description: Outer Planets/Solar Probe Project has designed several thematic components for participation in collaborative educator workshops that focus on teaching for Conceptual Change. Pluto, Ninth Planet or Not! Nine Lessons: Nine Models of Teaching features Pluto as a unifying strand in an interdisciplinary approach to teaching about the Solar System. LabVIEW and Computer Science Lessons is an introduction to systems integration and prepares the middle school/high school student for participation in school-to-work programs. Space Science Mimediately! features kinesthetic approaches to the teaching of space science and technology. Culturally-relevant lessons present space science in a context of non-Western traditions.

Lead: $\quad$ OP/SP E/PO Team, NASA Jet Propulsion Laboratory, Pasadena, CA 91109

\section{Outer Planets/Solar Probe Project: From the Outer Planets to the Inner City}

Msn/Prg: $\quad$ SIRTF, NAl, Keck, Solar Probe, Ulysses, Cassini/Huygens Probe, Galileo, Voyager, Deep Impact, Stardust, Mars, OP/SP, Europa Orbiter, Pluto/Kuiper Express, DS-1, DSMS

Theme(s): $\quad$ SSE

Description: Urban Education Initiative, From the Outer Planets to the Inner City. This model features liaison work between JPL, inner-city schools, and community organizations that provide informal science learning opportunities. We assess needs, conduct teacher enhancement workshops, and elicit proposals from participating teachers that lead to direct involvement of scientists and engineers both at JPL and in the classroom. This model also encourages direct student involvement by hiring qualified students from inner city settings to work within the outreach program. The effort encourages interdepartmental and interdisciplinary collaboration district-wide and at the school site. The Outreach office facilitates learning experiences, school-to-work internships, and Web-based instruction, and cultivates an ongoing relationship with educators and teachers. We provide special opportunities for students and parents to experience space exploration knowledge together.
Venue(s):

Alta Loma Elementary School, Los Angeles, CA 90019 (Participants: 250 local)

California Science Center, Los Angeles, CA 90037

Hillside Elementary School, Los Angeles, CA 90031

(Participants: 50 local)

Murchison Elementary School, Los Angeles, CA 90033

(Participants: 40 local)

Natural History Museum, Los Angeles, CA 90037

\section{Radio Astronomy at Jupiter}

Msn/Prg: $\quad$ Cassini/Huygens Probe, DSMS

Theme(s): $\quad$ SSE

Description: Educator workshop for teachers throughout Southern California. Workshop is co-sponsored by the Cassini Program and GAVRT Project.

Lead: Cassini E/PO Team, NASA Jet Propulsion Laboratory, Pasadena, CA 91109

Partner(s): $\quad$ GAVRT, Jet Propulsion Laboratory, Pasadena, CA 91109

\section{Radio Astronomy from the Classroom}

Msn/Prg: $\quad$ DSMS

Theme(s): SSE

Description: Educator's Workshop: A description of the Goldstone Apple Valley Radio Telescope (GAVRT) Project in which teachers are trained to calibrate and control a 34-meter radio telescope and students connect through the internet to use the telescope to gather data on the magnetosphere and atmospheric temperatures of Jupiter. The data is analyzed by the students and submitted to JPL for inclusion in the science database.

Lead: $\quad$ DSMS E/PO Team, NASA Jet Propulsion Laboratory, Pasadena, CA 91109

Venue(s): $\quad$ California Science Teachers Association, October 1999, Long Beach, CA 90802

\section{Saturn in Your Kitchen and Backyard}

Msn/Prg: $\quad$ Cassini/Huygens Probe

Theme(s): $\quad$ SSE

Description: Educators' Workshop: Explore the high-technology world of space exploration using everyday materials.

Lead: $\quad$ Cassini E/PO Team, NASA Jet Propulsion Laboratory, Pasadena, CA 91109

Venue(s): $\quad$ California Science Teachers Association, October 1999, Long Beach, CA 90802 (Participants: 40 local) San Diego Science Educator's Association, San Diego, CA 92101 (Participants: 15 local) TechEd2000, Palm Springs, CA 92262 (Participants: 15 local) 
SIRTF Educator Workshop

Msn/Prg:

SIRTF, SOFIA

Theme(s):

ASO

Description: Fitty teachers came to JPL for a day of infrared education, lectures, demonstrations, and discussions. Several products were handed out, including slide sets, videos, posters, and classroom activities.

$\begin{array}{ll}\text { Lead: } & \text { SIRTF E/PO Team, California Institute of Technology, } \\ & \text { Pasadena, CA } 91125 \\ \text { Venue(s): } & \text { NASA Jet Propulsion Laboratory, Pasadena, CA } 91109\end{array}$

\section{SOFIA Education Partners Propram}

Msn/Prg: $\quad$ SOFIA

Theme(s): $\quad$ ASO

Description: SOFIA Education Partners Program (EPP) develops partnerships between teachers and scientists, graduate students, engineers, and others in the SOFIA program. Training for the partners is provided through Project ASTRO, the nationally recognized educational program developed by the Astronomical Society of the Pacific. The partners work together on at least four activities each school year. EPP will continue to grow as the instrument development teams are invited to participate.

Lead: $\quad$ SOFIA E/PO Team, NASA Ames Research Center Moffett Field, CA 94035

Venue(s): $\quad$ Cupertino Elementary School, Cupertino, CA NASA Ames Research Center, Moffett Field, CA 94035-1000 (2 events) Project ASTRO Training, San Mateo, CA (Participants: 65 local)

\section{SOFIA/Raytheon Alrcraft Integration Systems Tour}

Msn/Prg: $\quad$ SOFIA

Theme(s): $\quad$ ASO

Description: A group of teachers and students affiliated with the EXES instrument E/PO program at the University of Texas, Austin attended a tour of the Raytheon Aircraft Integration Systems (RAIS) in Waco, Texas. The attendees were teachers working with Dr. Mary Kay Hemenway at UT Austin, and select students. The tour was conducted with RAIS staff and Michael Bennett, SOFIA E/PO Lead. Highlights included a walk-through of the systems integration lab and the aircraft fuselage, and IR demonstrations.

Lead: SOFIA E/PO Team, NASA Ames Research Center, Moffett Field, CA 94035

Venue(s): $\quad$ Raytheon AIS, Waco, TX 76705

SOFIA-Explering the Intrared Universe From 41,000 Feet

Msn/Prg: $\quad$ SOFIA

Theme(s): $\quad$ ASO
Description: Educators' workshop: SOFIA, the Stratospheric Observatory for Infrared Astronomy, will be the world's largest airborne observatory; it will see first light in 2002. SOFIA is a joint U.S.-German project, funded by NASA and DLR. SOFIA will carry a 2.5 meter telescope in a $747-$ SP to the stratosphere to observe the infrared universe invisible to groundbased telescopes. In the United States, Universities Space Research Association (USRA) is teamed with Raytheon Systems Corporation and United Airlines to build and operate the observatory with scientific support from the University of California. The SETI Institute and Astronomical Society of the Pacific are developing the education and public outreach program for the observatory. DLR is funding the telescope. SOFIA will fly for 20 years and will involve educators at all levels in research missions. Learn how you can join a research mission on board SOFIA and bring space down to Earth.

Lead:

SOFIA E/PO Team, NASA Ames Research Center, Moffett Field, CA 94035

Venue(s): $\quad$ American Astronomical Society (AAS), January 2000 Atlanta, GA 30303 ASTROCON 2000 Conference, Ventura, CA 93001 (Participants: 40 local) Idaho Science Teachers Association, Coeur d'Alene, ID 83815 (Participants: 40 local) International Planetarium Society Meeting, Montreal, Quebec

National Science Teachers Association (NSTA)

Midwestern Area, October 1999, Detroit, MI National Science Teachers Association (NSTA) Southern Area, November 1999, Tulsa, OK National Science Teachers Association (NSTA) Western Area, December 1999, Reno, NV 89509 National Science Teachers Association (NSTA), April 2000, Orlando, FL 32819 (Participants: 50 local)

\section{Solar System Educators Program (SSEP)}

Msn/Prg:

Cassini/Huygens Probe, Galileo, Deep Impact, Stardust, Mars, Europa Orbiter, Pluto/Kuiper Express, DSMS

Theme(s): $\quad$ SSE

Description: Solar System Educators Program (SSEP) is a program designed to bring the excitement of space exploration to students across the Nation. SSEP has recruited 77 volunteer educators who are trained at JPL during a 4-day institute. Educators meet scientists, project managers, and other mission personnel, and are provided with hands-on demonstrations, lectures, tours, and many opportunities to immerse themselves in JPL's robotic missions to the solar system. Each educator retums to his or her home town and holds a minimum of three workshops, reaching a total of 100 teachers, who are able to pass this information along to their students in grades $\mathrm{K}-12$. The program is managed, under contract to JPL, by Space Explorers, Inc. in partnership with the Virginia Space Grant Consortium.

Lead: 
Partner(s): $\quad$ Space Explarers, Inc., De Pere, WI 54115

Virginia Space Grant Consortium, Norfolk, VA 23529

Venue(s):

Coeur d' Alene, ID 83814

Worthington, MN

Gloucester, MA 01930

American Association of University Women

Brownell-Talbat School, NE

Buhl Planetarium \& Observatory, Pittsburgh, PA

15212

Decorah High School, Decorah, IA

Earth/Space Center, River Grove, IL 60143 (3 events)

Embassy Suites, Alexandria, VA

Glen Eyrie Center, Colorado Springs, CO

Idaho State University, Pocatello, ID

Idaho Technical College, Idaho Falls, ID

Inn at Grand Glaize, Osage Beach, M0 65065 (2

events)

Marriott Hotel, Des Moines, IA

Northwood Junior High School, Highland Park, IL

University of Northern lowa, Cedar Falls, IA 50613

University of Wisconsin at Milwaukee, Milwaukee, WI

53201

Volcano National Park, Volcano, HI

Windward Community College, Kaneohe, HI 96744 (2

events)

Wings over Rockies, Denver, C0 80205 (4 events)

\section{Space Science and the Texas Essential Knowledge and Skills} (TEKS)

Msn/Prg: LPI B/F

Theme(s): $\quad$ SSE

Description: Personnel from the Lunar and Planetary Institute Broker/Facilitator team, Johnson Space Center, and Space Center Houston conducted a 1-day workshop on Space Science and the TEKS standards on February 17, 2000, at Space Center Houston. Twenty-five teachers from the region attended the day of presentations and hands-on activities designed to help teachers of grades 6 and 8 who are now required to teach units on space science as outlined in the TEKS State standards.

Lead: $\quad$ LPI Broker/Facilitator, Lunar and Planetary Institute, Houston, TX 77058

Venue(s): $\quad$ Space Center Houston, Houston, TX 77258-0653

(Participants: 25 local)

\section{Space Science XV Teacher's Workshop}

Msn/Prg: $\quad$ CXO

Theme(s): $\quad$ SEU

Description: Co-sponsored Space Science XV teachers workshop, July 20-23, with the Wright Center for Innovative Science Education at Turts University. The workshop theme was "Chandra and the X-ray Universe." Twenty-six teacher-participants were selected nationwide. Nine members of the Chandra team-seven scientists, one engineer, and the
Chandra X-ray Center (CXC) E/PO coordinator-presented Chandra-related briefings. Chandra-related curricular materials and educational exercises, that had been developed by the CXC E/PO team working with teachers during the year, were presented and reviewed. Revisions are being incorporated prior to the material's release on the CXC Web site.

Lead: $\quad$ SEU Forum, Smithsonian Astrophysical Observatory, Cambridge, MA 02138

Partner(s): Wright Center for Innovative Science Education, Medford, MA 02155

Venue(s): $\quad$ Tufts University, Medford, MA 02155

\section{Space Weather Workshops}

Msn/Prg: $\quad$ SSI B/F

Theme(s): $\quad$ SEC

Description: Space Weather Workshop: This workshop introduces teachers of grades 7-10 to the exciting world of Space Weather-disturbances in the Sun's atmosphere that aftect the Earth environment. The workshop uses the context of Space Weather to support teachers in meeting their standards-based needs in Earth and Space Science, Physical Science, and Mathematics. The topic of Space Weather is timely because the Sun is entering into a period of maximum activity. Workshop content includes hands-on experience with NSF-supported, inquiry-based lesson plans about the Sun and interaction with the Space Weather Center exhibit. The first of these workshops was held at the Denver Museum of Nature and Science in conjunction with the premier opening of the exhibit. Twelve Denver-area educators attended. The workshop was conducted by Dr. Paul Dusenbery and Dr. Cheri Morrow, both of the Space Science Institute.

Lead: $\quad$ SSI Broker/Facilitator, Space Science Institute, Boulder, CO 80303

Venue(s): $\quad$ American Association of Physics Teachers (AAPT), July 2000, Guelph, Ontario, Canada (Participants: 70 local) Astronomical Society of the Pacific (ASP), July 2000, Pasadena, CA 91101 (Participants: 100 local) Denver Museum of Nature and Science, Denver, $\mathrm{CO}$ 80205 (Participants: 12 local)

\section{STELAR/Astroblology Program}

$\begin{array}{ll}\text { Msn/Prg: } & \text { NAl } \\ \text { Theme(s): } & \text { ASO }\end{array}$

Description: STELAR, which stands for Science Training for Enhancing Leadership and Learning Through Accomplishments in Research, provides teachers of grades $\mathrm{K}-14$ an opportunity to acquire a realistic working view of the conduct of science. Through collaboration with NASA Ames Research Center scientists and engineers, teachers are given the opportunity to learn about cutting-edge science that will be used in developing science curriculum. As a means to accomplish this objective, teachers work alongside NASA/Ames research scientists using stateof-the-art equipment and research to improve their knowledge and skills in science, math, and technology. The teacher's objective will be to tie the 
research and the classroom activities into an exciting topic of life science space science, and astrobiology.

Lead: $\quad$ Astrobiology Institute E/PO Team, NASA Ames Research Center, Moffett Field, CA 94035

Venue(s): $\quad$ NASA Ames Research Center, Moffett Field, CA 94035-1000

\section{Sun-Earth Connection Content Workshops}

Msn/Prg: HESSI, IMAGE, TRACE, ISTP, Polar, SOHO, Wind, Yohkoh, Genesis

Theme(s): $\quad$ SEC

Description: Scientists and Educators train persons in the Sun-Earth Connection Science. The scientists share the content and new discoveries, while the educators enhance the presentations with hands-on activities.

Lead: $\quad$ SEC Forum, NASA Goddard Space Flight Center, Greenbelt, MD 20771

Venue(s): $\quad$ NASA Goddard Space Flight Center, Greenbelt, MO 20771 (Participants: 25 local)

Sunspots, UV, and Me: A Student-based Solar Research Project

Msn/Prg: Genesis

Theme(s): $\quad$ SEC

Description: Eastchester Middle School has incorporated the Genesis Project SUN into their program called Project Sunshine. This presentation discussed their overall project (It has won national awards totaling over $\$ 20,000$ ). Genesis (Dr. Yanow) presented a portion of this workshop explaining Project SUN and comparing the data fram Eastchester to other schools around the world.

Lead: Genesis E/PO Team, NASA Jet Propulsion Laboratory, Pasadena, CA 91109

Venue(s): National Science Teachers Association (NSTA), April 2000 , Orlando, FL 32819

Sunspots: Introducing the Active Sun

Msn/Prg: HESSI

Theme(s): $\quad$ SEC

Description: We attended to the 14th Annual Center for Education and Equity in Mathematics Science and Technology (CEEMaST) Conference on April 29 in Pomona, California. A workshop with a title Sunspots: Introducing the Active Sun was given. Using text, science images, diagrams, and RealMedia scientist interviews, the Web-based lesson gives a qualitative introduction to concepts of modern solar physics, then guides students through a research activity that helps develop abilities of measurement, mathematical modeling, and critical interpretation. The material is supported by teacher-friendly background material, lesson plans, discussion questions, and student worksheets.
Lead:

Venue(s):

HESSI EPPO Team, NASA Goddard Space Flight Center, Greenbelt, MD 20771

Center for Education and Equity in Mathematics,

Science, and Technology (CEEMaST) Conference,

Pomona, CA 91768

\section{Teaching the National Standards Content: The History and Nature of Science Using NASA/JPL Materials}

$\begin{array}{ll}\text { Msn/Prg: } & \text { Genesis } \\ \text { Theme(s): } & \text { SEC }\end{array}$

Description: This workshop examined the historical development of different aspects of science and the people who were the leaders. After examining their stories, we had to decide if they were "HIP"-i.e., did they demonstrate in their lives and work that they were honest, had integrity, and passion.

Lead: Genesis E/PO Team, NASA Jet Propulsion Laboratory, Pasadena, CA 91109

Venue(s): $\quad$ National Science Teachers Association (NSTA), April 2000, Orlando, FL 32819 (Participants: 5 local)

\section{TIMED Onsite Educational Experience}

$\begin{array}{ll}\text { Msn/Prg: } & \text { SEC Forum, TIMED } \\ \text { Theme(s): } & \text { SEC }\end{array}$

Description: Educators learn about SEC science and the partnerships between NASA centers and other science facilities as they visit JHU APL. The experiences are varied-from internships to tours.

Lead: SEC Forum, NASA Goddard Space Flight Center, $\begin{array}{ll} & \text { Greenbelt, MD } 20771 \\ \text { Venue(s): } & \text { Applied Physics Laboratory, Laurel, MD } 20723\end{array}$

Tour the X-ray Sky with NASA

Msn/Prg: HEASARC

Theme(s): $\quad$ SEU

Description: Educators' workshop: Dr. James Lochner and Ms. Maggie Masetti taught participants how they can use data from an active NASA mission, the Rossi $X$-ray Timing Explorer, in their classrooms. Participants saw the dynamic ways this data, from sources such as black holes, neutron stars, and active galaxies, can be used as part of their activities and lessons and for student projects in math or science.
Lead:
HEASARC E/P0 Team, NASA Goddard Space Flight Center, Greenbelt, MD 20771
Venue(s): $\quad$ National Science Teachers Association (NSTA). April

\section{Toward Other Planetary Systems (TOPS)}

$\begin{array}{ll}\text { Msn/Prg: } & \text { ASO Forum, NAl, Deep Impact } \\ \text { Theme(s): } & \text { ASO, SSE }\end{array}$


Description: Toward Other Planetary Systems (TOPS) is an annual 3-week workshop organized by Karen Meech, a member of the Deep Impact Science team. Deep Impact is now participating by providing manpower for the workshop as well as materials as they are developed. The workshop is sponsored by the University of Hawaii, the Institute for Astronomy, Montana State University at Bozeman, and NSF and serves 30 Pacific Island instructors and 30 students. Training takes place in astronomy, telescope observation, Hawailan history of comet observation, and space missions. Gretchen Walker represented Deep Impact from the University of Maryland and will return next year. Each attendee will in turn spend 60 workshop hours training other Pacific Island instructors in their community.

$\begin{array}{ll}\text { Lead: } & \text { Deep Impact E/PO Team, University of Maryland, } \\ & \text { College Park, MD 20742 } \\ \text { Partner(s): } & \text { Montana State University, Bozeman, MT } 59717 \\ & \text { National Science Foundation, Arlington, VA 22230 } \\ & \text { University of Hawaii, Institute for Astronomy, Honolulu, } \\ & \text { HI } 96822 \\ \text { Venue(s): } & \text { Hawaii Preparatory Academy, Kamuela, HI } 96743\end{array}$

\section{Universe Education forum: Space Science Resources on Cosmic Structure and Evolution}

Msn/Prg: $\quad$ SEC Forum, MAP

Theme(s): $\quad$ SEU

Description: Educators' Workshop: From the Big Bang to black holes, current NASA research on deep space can make important science concepts come alive in the classroom.

Lead:

SEC Forum, NASA Goddard Space Flight Center, Greenbelt, MD 20771

Venue(s): $\quad$ National Science Teachers Association (NSTA), April 2000, Orlando, FL 32819

Using a NASA Mission to Focus Attention on Astronomy and
Physics
Msn/Prg: $\quad$ IDEAS
Theme(s): SSE

Description: The workshops were geared for teachers of grades 6-12 and emphasizes a hands-on approach to communicating the basic concepts underlying the goals and objectives of the Near-Earth Asteroid Rendezvous (NEAR) mission.

Lead: $\quad$ Dr. Beth Clark, Cornell University, Ithica, NY 14853

Venue(s): $\quad$ Secondary School, Ithica, NY 14853 (Participants: 10 local)

Secondary School, Corning, NY 14830

Secondary School, Cortland, NY 13077

Secondary School, Homer, NY 14853

Secondary School, Mantgomery, NY 12549

Secondary School, Odessa, NY 14869

Secondary School, Westminster, MD 21158 Using a Web-based "Sunspots" Resource—Results from a
Student Summer Outreach Program

Msn/Prg: $\quad$ SEC Forum

Theme(s): $\quad$ SEC

Description: Educators' Workshop: Al the San Francisco Unified School District (SFUSD), all students entering high school attend a "Summer Step-Up" program which emphasizes the use of technology and projectbased learning. The SEGway (Science Education Gateway) program at UC Berkeley partnered with SFUSD curriculum specialists and teachers to offer a week-long curriculum featuring a Web-based "Sunspots" resource. "Sunspots" incorporates background information, including the importance of the Sun in ancient cultures, a historical account of sunspots observations, and current NASA research. In addition, the resource contains guidance for safe sunspots viewing and a Java interactive research tool that allows students to analyze possible correlations between sunspots and $x$-ray active regions from satellite images of the Sun. I will discuss lessons learned from this pilot program which served 600 students during the Summer of 1999.

\section{Lead: $\quad$ SEGway Space Sciences Laboratory, University of California, Berkeley, CA 94720 \\ Venue(s): American Association of Physics Teachers (AAPT), January 2000, Orlando, FL 34747 (Participants: 100 local)}

\section{VITS Presentations for Educational Purposes}

$\begin{array}{ll}\text { Msn/Prg: } & \text { SEC Forum, IMAGE, SOHO } \\ \text { Theme(s): } & \text { SEC }\end{array}$

Description: Scientists or engineers participate in a distance learning opportunity for teachers and students not local to the NASA Center.

Lead: SEC Forum, NASA Goddard Space Flight Center, Greenbelt, MD 20771

Venue(s): $\quad$ NASA Goddard Space Flight Center, Greenbelt, MD 20771 (Participants: 80 local, 80 remote)

\section{Volcanoes in Our Solar System Workshop}

$\begin{array}{ll}\text { Msn/Prg: } & \text { Galileo } \\ \text { Theme(s): } & \text { SSE }\end{array}$

Description: Educators' Workshop: Explore the volcanic regions of our solar system, where fiery explosions and vents spray icy particles, from Earth to the remote moons of Jupiter and Neptune. Focused around the flyby this fall by the Galileo spacecraft of volcanoes on Jupiter's fiery moon lo, we'll demonstrate hands-on classroom activities that investigate volcanism, and we'll make connections to NASA's current space exploration.

Lead: Galileo E/PO Team, NASA Jet Propulsion Laboratory, Pasadena, CA 91109

Venue(s): $\quad$ California Science Teachers Association, October 1999, Long Beach, CA 90802 (Participants: 30 local) 
Volcanoes in the Solar System Educator's Workshop

Msn/Prg: Galileo, Mars

Theme(s): $\quad$ SSE

Description: Volcanoes in the Solar System is a 1-day workshop aimed at educators in grades 5-12. Scientists present talks on what is known about volcanoes and volcanism on Earth, Mars, Jupiter's moon lo, and the icy satellites of the outer planets. Activities from the USGS "Volcanoes!" educator guide, from NASA's "Planetary Geology" educator guide, and a newly developed activity on to's volcanoes are presented to teachers to compliment the scientific information presented.

Lead: Galileo E/PO Team, NASA Jet Propulsion Laboratory, Pasadena, CA 91109

Venue(s): $\quad$ NASA Jet Propulsion Laboratory, Pasadena, CA 91109 (Participants: 185 local)

Water in the Solar System Educator Workshop

Msn/Prg: $\quad$ Galileo, Mars, Lunar Prospector

Theme(s): $\quad$ SSE

Description: "Water in the Solar System" is a 1-day educator workshop aimed at educators of grades 5-12. It combines lectures by scientists working on space missions studying bodies in the solar system where water is known to exist and hands-on activities for the classroom. Tours of the facility holding the event are also included.

\section{Lead: Galileo E/PO Team, NASA Jet Propulsion Laboratory, Pasadena, CA 91109}

\section{What Do Sclentists Do? A Short Workshop for Teachers}

Msn/Prg: IDEAS

Description: The primary objective of the project was to give science teachers a feel for what practicing research scientists do for a living through 1-day workshops. Each workshop centered around a case study of an active research topic in planetary science. The workshop covered some fundamental principles of planetary science that would be useful to the teachers as well as where to go for quality educational materials on the planets.
Lead:
Dr. Robert Herrick, Lunar and Planetary Institute, Houston, TX 77058
Venue(s):
Houston Independent School District, Houston, TX 77001 (Participants: 120 local)

\section{What is Astrobiology?}

Msn/Prg: NAl

Theme(s): $\quad$ ASO

Description: Dr. Jakosky presented a teacher and student astrobiology workshop that introduced the concept of astrobiology. $\begin{array}{ll}\text { Lead: } & \text { Astrobiology Institute E/PO Team, NASA Ames } \\ & \text { Research Center, Moffett Field, CA 94035 } \\ \text { Venue(s): } & \text { Astrobiology Science Conference, Boulder, C0 } 80309\end{array}$

\section{Workshop for Challenger Center Presenters}

Msn/Prg: $\quad$ CXO

Theme(s): $\quad$ SEU

Description: Chandra briefing presented to curriculum workshop for Challenger Center presenters and coordinators. Thirty-five participants represented Challenger Centers from around the country (and Hawaii). Chandra X-ray Center (CXC) Director Dr. Harvey Tanabaum gave a Chandra briefing and $\mathrm{CXC}$ E/PO Coordinator $\mathrm{K}$. Lestition discussed incorporation of materials into curricular activities. Chandra materials were handed out. Follow-on contacts have been initiated.

\section{Lead: $\quad$ SEU Forum, Smithsonian Astrophysical Observatory, Cambridge, MA 02138 \\ Venue(s): Harvard-Smithsonian Center for Astrophysics, Cambridge, MA 02138 (Participants: 35 local)}

\section{Zooming in on Black Holes}

Msn/Prg: $\quad$ SIM

Description: Zooming in On Black Holes exhibit was taken to the 1999 CSTA Meeting in Long Beach, California.

Lead: $\quad$ SIM E/PO Team, NASA Jet Propulsion Laboratory,

Venue(s): California Science Teachers Association, October 1999, Long Beach, CA 90802

Curriculum Development/Dissemination

\section{Astrobialogy: The Search for Life on Other Worlds}

Msn/Prg: NAl

Theme(s): $\quad$ ASO

Description: With a major grant from the National Science Foundation, TERC's Center for Earth and Space Science Education, NASA Ames Research Center, and NASA Jet Propulsion Laboratory have developed an innovative, inquiry-based high-school course on "Astrobiology-the Search for Life on Other Worlds." Through a series of focal topics and inquiry-based investigations, students will learn the fundamental scientific concepts in a cross-disciplinary context and develop research skills including modeling, laboratory experiments, field observations, and image and data analysis.
Lead:
Astrobiology Institute E/PO Team, NASA Ames Research Center, Moffett Field, CA 94035
Partner(s)
TERC, Cambridge, MA 02140 


\section{HST Amazing Space}

Msn/Prg: $\quad$ HST

Theme(s): $\quad$ ASO

Description: The Hubble Space Telescope Amazing Space Workshop is a 5-week session geared at developing interactive online modules using Hubble data and images.

Lead

Amazing Space Office of Public Outreach, Space

Telescope Science Institute, Baltimore, MO 21218

Improving Sth Grade Untfied Science Curricula via the Inclusion of MASA Space Science Data

Msn/Prg: IDEAS

Description: The primary objective of this project was to redesign a 9th grade unified science lesson to incorporate current NASA space science data into an interdisciplinary activity. The project was designed not only to improve the quality of information conveyed by the lesson, but also served to train the teacher in how to access such data via Internet resources.

Lead:

Dr. Michael Carini, NASA Goddard Space Flight Center Greenbelt, MD 20771

Venue(s):

Severn Junior High School, Amold, MD 21012

SEGway Resource Development with San Francisco Unified School District Teachers

Msn/Prg: Information Systems

Theme(s): $\quad$ ASO

Description: Tapping the rich assortment of online, inquiry-based digital science curriculum materials for grades 6-9, we work with middle and high school science teachers to support the newly adopted science standards of the San Francisco Unified School District. Our goals are to develop materials and support science teachers in content knowledge, pedagogy, and the use of technology. Our goal is also to disseminate technology-based science curriculum beyond our immediate partners. We work with 4 teachers teaching grades $6,8,9$, and 10 . We have 1 -day meetings every other month, either at our lab site or in their school.

Lead: $\quad$ SEGway Space Sciences Laboratory, University of California, Berkeley, CA 94720

Partner(s): San Francisco Unified School District, San Francisco, CA 94102

Venue(s): San Francisco Unified School District, San Francisco, CA 94102
Student Support

Astrobiology Lecture Series

Msn/Prg: NAl

Theme(s): $\quad$ ASO

Description: 0ver 40 lectures were given in the past year by researchers, educators, and engineers on topics in astrobiology and its research and technologies. Venues included universities, conferences, corporations, classrooms, NASA centers and community colleges.

Lead:

Astrobiology Institute E/PO Team, NASA Ames

Research Center, Moffett Field, CA 94035

\section{Astrobiology Option in WISE Week at Pennsylvania State University}

Msn/Prg: $\quad$ NAl

Description: PSARC is participating in WISE Week, a 1-week residential science and engineering career exploration program for young women in the 11th grade. WISE Week is organized by Penn State's WISE Institute. It is specifically designed for young women with an aptitude in science and math who would like to learn about careers in science, health, and engineering. The basic program consists of 10 hands-on workshops and a week-long science or engineering design project. About 20 students who select the astrobiology option learn about various theories concerning the origin of life and the evolution of environments and life on early Earth.

Lead: $\quad$ Astrobiology Institute E/PO Team, NASA Ames

Research Center, Moffett Field, CA 94035

\section{Books Are Rockets to Knowledge}

$\begin{array}{ll}\text { Msn/Prg: } & \text { LPI B/F } \\ \text { Theme(s): } & \text { SSE }\end{array}$

Description: Lunar and Planetary Institute Education staff gave a brief presentation on the history of rocketry and Newton's Laws to 250 students in grades 1-5 at an end-of-the-year library event at Austin Elementary in Baytown, Texas. These students had read from a selection of books on rocketry and space travel, and were responsible library patrons during the entire course of the school year. We demonstrated pop rockets, gave pencil rockets to everyone, and donated space science materials for teacher classrooms and a raffle.

Lead: $\quad$ LPI Broker/Facilitator, Lunar and Planetary Institute, Houston, TX 77058

Venue(s): $\quad$ Austin Elementary School, Baytown, TX 77521

(Participants: 270 local) 


\section{Cassini Educator Fellow Speaker}

Msn/Prg: Cassini/Huygens Probe

Theme(s): $\quad$ SSE

Description: Talk on the Cassini mission to Saturn given by a member of the Solar System Educators/Cassini Fellows Program.

Lead: $\quad$ Cassini E/PO Team, NASA Jet Propulsion Laboratory, Pasadena, CA 91109

Venue(s): $\quad$ Burlington Community College, Burlington, VT 05401 (Participants: 10 local)

Central High School, Cheyenne, WY 82003

(Participants: 140 local; 2 events)

Cheyenne Community College, Cheyenne, wY 82001

(Participants: 35 local)

COBO Convention Center, Detroit, Ml 48226

(Participants: 27 local; 2 events)

East Valley School District, Spokane, WA 99216

(Participants: 187 local; 3 events)

Fairfield School District, Fairfield, $0 \mathrm{H}$ (Participants: 25

local)

Greenfield High School, Greenfield, MA 01301

(Participants: 72 local; 3 events)

Grosse Pointe N. High School, Grosse Pointe, MI

48236 (Participants: 43 local)

JFK Middle School, Northampton, MA 01062

(Participants: 72 local; 3 events)

Kentucky Department of Education, Morehead, $K Y$

40351 (Participants: 5 local)

Lexington Center, Lexington, KY 40507 (Participants:

42 local; 2 events)

Linn Benton Callege, Albany, OR 97321 (Participants:

25 local)

Murray State University, Murray, KY 42071

(Participants: 45 local)

Presntonsburg School, Prestonsburg, KY (Participants:

40 local)

Region 6 MS Science, Lexington, KY (Participants: 30 local)

Rochester Community College, Rochester, MN 55904

(Participants: 28 local)

Spokane Center, Spokane, WA 99201 (Participants: 22 local; 2 events)

Talcott Mountain SC, Avon, CT 06001 (Participants: 50 local)

Tulsa Community College, Tulsa, OK 74103

(Participants: $\mathbf{4 0}$ local)

Weaver High School, Hartford, CT 06112 (Participants: 20 local)

WISTEC Planetarium, Eugene, OR 97401 (Participants:

61 local; 2 events)

\section{Cassinl Flight Team Speaker}

Msn/Prg: Cassini/Huygens Probe

Theme(s):
SSE
Description: Talk on the Cassini mission to Saturn given by a member of the Cassini Flight Team.

Lead: $\quad$ Cassini E/PO Team, NASA Jet Propulsion Laboratory, Pasadena, CA 91109

Venue(s): $\quad$ Arizona State University, Tempe, AZ 85287

(Participants: 150 local)

Bemidji State University, Bemidji, MN 56601

Boy Scout Council, Upland, CA 91784 (Participants:

41 local)

California State Polytechnic University, Pomona, CA 91768 (Participants: 30 local)

eHobbies.com, Santa Monica, CA 90404 (Participants: 100 local)

El Camino College, Torrance, CA 90506 (Participants: 75 local)

Estrada Courts, Los Angeies, CA (Participants: 1000

local)

Humboldt Elementary School, Portland, OR 97217

(Participants: 75 local)

Huppert Elementary, San Antonio, TX 78228

(Participants: 65 local)

Incarnation School, Glendale, CA 91202 (Participants:

200 local)

lowa City Library, lowa City, IA 52240 (Participants:

2650 local)

JFK High School, San Antonio, TX 78226 (Participants: 150 local)

Loma Park Elementary, San Antonio, TX 78228

(Participants: 145 local)

NASA Jet Propulsion Laboratory, Pasadena, CA 91109

(Participants: 303 local, 50 remote; 5 events)

Odyssey School, Pasadena, CA 91106 (Participants:

250 local)

Painter Ave School, Whittier, CA 90601 (Participants:

100 local)

Pasadena City Hall, Pasadena, CA 91101

(Participants: 1000 local)

Pinecrest School, Valencia, CA 91355 (Participants: 20 local)

Roosevelt High School, Portland, OR 97203

(Participants: 50 local)

University of California, Los Angeles, CA 90024

(Participants: $\mathbf{4 0}$ local)

University of Idaho, Moscow, ID 83844 (Participants:

45 local)

Upland Community School, Upland, CA 91786

(Participants: 50 local)

\section{Cassini Mlssion to Saturn Classroom Presentations}

Msn/Prg: $\quad$ Cassini/Huygens Probe

Theme(s): $\quad$ SSE

Description: Presentations to students and/or teachers of Cassini mission summary and/or classroom activities and demonstrations. 
Lead:

Cassini E/PO Team, NASA Jet Propulsion Laboratory, Pasadena, CA 91109

Venue(s):

Alvord Middle School, Riverside, CA 92503

(Participants: 8 local)

Brookings High School, Brookings, SD 57006

(Participants: 50 local)

Edberg residence, La Cañada, CA 91011

Educator Resource Center, Pomona, CA

Granby Memorial Middle School, Granby, CT 06035

Kearns Primary School, Granby, CT 06035

Long Beach Convention Center, Long Beach, CA

(Participants: 25 local)

NASA Jet Propulsion Laboratory, Pasadena, CA 91109

(Participants: 175 local; 2 events)

NGC Observatory-EMA0, Frazier Park, CA

(Participants: 14 remote)

Paradise Canyon School, La Cañada, CA 91011 (3

events)

Pasadena Convention Center, Pasadena, CA 91101

Pasadena Main Library, Pasadena, CA

TechEd2000, Palm Springs, CA 92262 (Participants:

12 local)

Traweek Middle School, Covina, CA 91723

University of Minnesota, Minneapolis, MN 55455

(Participants: 100 local)

Chandra Operations Control Center Tours

Msn/Prg: $\quad$ SEU Forum, CXO

Theme(s): $\quad$ SEU

Description: The Chandra Operations Control Center is located in Cambridge, Massachusetts, and was the host location for several tour groups, including minority student coordinators, students from gifted junior high group, a high school SWAS student learning program, MIT students, and a Boy Scout troop.

Lead: $\quad$ CXO E/PO Team, Harvard-Smithsonian Center for Astrophysics, Cambridge, MA 02138

Venue(s): $\quad$ Chandra OCC, Cambridge, MA 02139 (Participants: 85 local; 5 events)

\section{Clear Creek Independent School Distrlct (Texas) Alpha Program}

\section{Msn/Prg: $\quad$ LPI B/F}

Theme(s): $\quad$ SSE

Description: The Lunar and Planetary Institute teaches the course "Exploring the Solar System" to 5th graders in the Clear Creek Independent School District (Texas) Alpha Program for gifted and talented students. Students from across the district attend the 12-week course for a 3 1/2-hour block ance a week during the regular school semester. In 2000, the 17th class was taught by scientists and staff, emphasizing "what we know and how we know" about the solar system.

Lead: LPI Broker/Facilitator, Lunar and Planetary Institute, Houston, TX 77058
Partner(s): Clear Creek Independent School District, League City, TX 77574

Venue(s): $\quad$ Lunar and Planetary Institute, Houston, TX 77058

\section{Comcast/Discovery Metworks Event}

Msn/Prg: NEAR

Theme(s): $\quad$ SSE

Description: Comcast/Discovery Mission 2000: Operation NEAR. As a prelude to National Space Day 2000, the Johns Hopkins University Applied Physics Laboratory teamed up with Comcast, Discovery Networks, and the Maryland State Department of Education to give more than 100 Maryland middle school students a true outer space experience. The students moved from behind their desks to behind the scenes of a deep-space mission during Comcast-Discovery Mission 2000: Operation NEAR. The students heard a briefing on the NEAR mission-the first to orbit an asteroid-and took part in a special student press conference with NEAR team members Andy Cheng, Rob Gold, Scott Murchie, and Andy Santo. The students then donned clean-room suits and toured the Lab's space facilities, including the NEAR Mission Operations Center, the space environment simulation lab, the vibration test lab, and the satellite communications facility.

Lead: $\quad$ NEAR E/PO Team, Johns Hopkins University Applied Physics Laboratory, Laurel, MD 20723-6099

Venue(s): $\quad$ Applied Physics Laboratory, Laurel, MD 20723

\section{CONTOUR School Visits}

Msn/Prg: CONTOUR

Theme(s): $\quad$ SSE

Description: Talks, videos, and classroom activities on the CONTOUR Mission, Near-Earth Asteroids, and related subjects, presented to students by CONTOUR project staff during school visits.

Lead:

CONTOUR E/PO Team, Space Telescope Science Institute, Baltimore, MD 21218

Venue(s):

Applied Physics Laboratory, Laurel, MD 20723

(Participants: 50 local; 2 events)

California State University, Los Angeles, CA 90032

(Participants: 35 local)

Longfellow Elementary, Columbia, MD

NASA Jet Propulsion Laboratory, Pasadena, CA 91109

(Participants: 45 local)

University of Virginia, Charlottesville, VA 22903

(Participants: 20 local)

\section{Cooperative Satellite Leaming Program Student Conference}

Msn/Prg: $\quad$ ACE

Theme(s): $\quad$ SEU

Description: A business, government, and educational partnership, focusing on space sciences and engineering. Sponsars are NASA and Honeywell Technology Solutions Inc. Students at participating high 


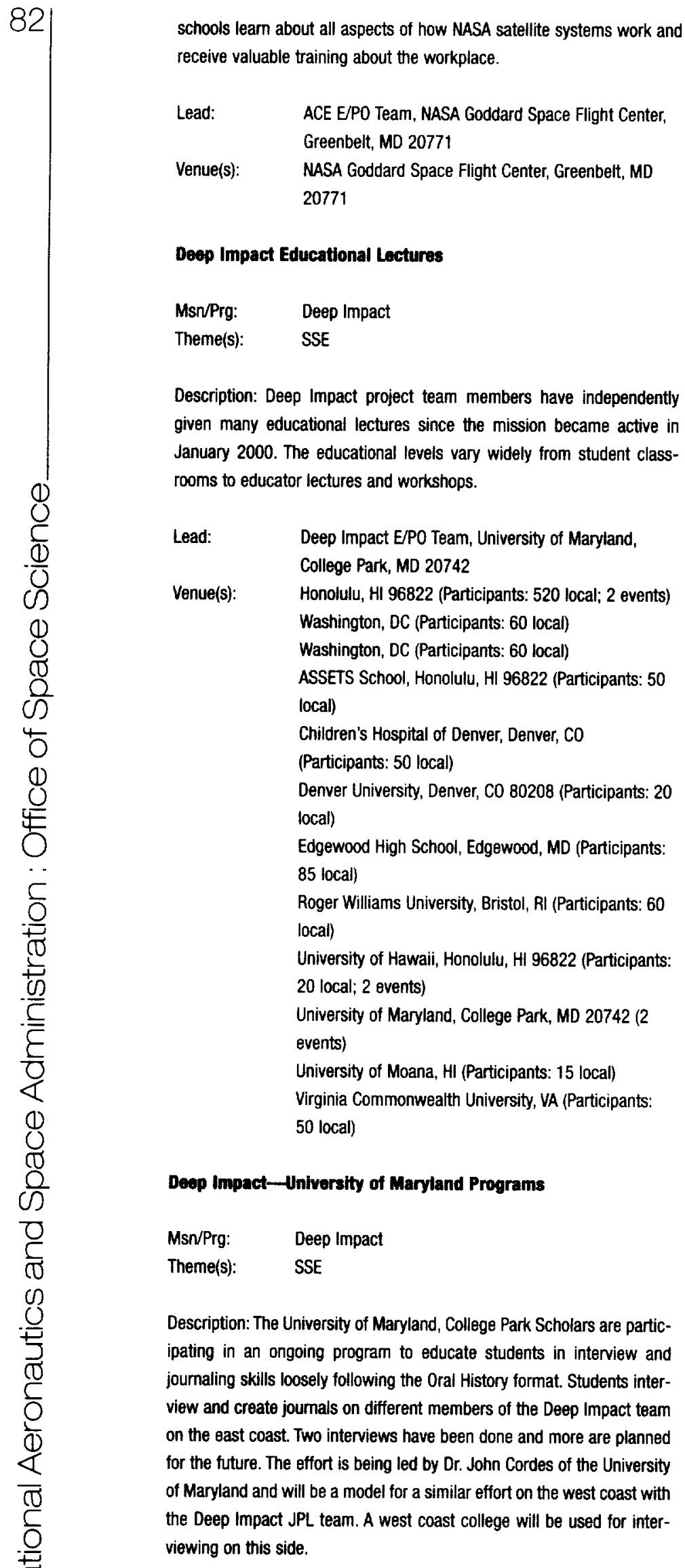

Lead:

Venue(s):

Deep Impact E/PO Team, University of Maryland, College Park, MD 20742

\section{Goldstone Apple Valley Radio Telescope (GAVRT) Project}

Msn/Prg: $\quad$ DSMS

Theme(s): $\quad$ SSE

Description: JPL is partnering with the Lewis Center for Educational Research in Apple Valley, California, to offer students in grades 6-12 a unique opportunity to perform real science from their classrooms. Connecting through the internet, students assume command of a decommissioned 34-meter NASA antenna from the Deep Space Network, Goldstone. Observations are made using radio astronomy. Students collect data, analyze data, and learn that science isn't a set of facts but an ongoing process of research and discovery. They also learn team building, problem-solving, and Internet and software skills. Data is submitted to JPL for inclusion in a database. GAVRT is a curriculum-based project designed to align with State science standards and providing extensive teacher training and interactive support.

Lead: $\quad$ DSMS E/PO Team, NASA Jet Propulsion Laboratory,

Venue(s): $\quad$ Auburn University, Auburn, AL 36849 (Participants: 7 local)

Berry Middle School, Hoover, AL 35216 (Participants:

12 local, 12 remote)

Brewton Middle School, Brewton, AL 36426

(Participants: 225 local, 225 remote)

Cedar Fidge Middle School, Decatur, AL 36503

(Participants: 20 local, 20 remote)

Chelsea Middle School, Chelsea, AL 35043

(Participants: 185 local, 195 remote)

Cherokee County High School, AL35960 (Participants:

5 local, 5 remote)

East High School, Erie, PA 16503 (Participants: 74

remote; 2 events)

Fort Payne Middle School, Fort Payne, AL 35967

(Participants: 150 local, 150 remote)

Glendora High School, Glendora, CA 91740

(Participants: 170 remote)

Harborside School, San Diego, CA 92106-2299

(Participants: 160 local)

Homewood Middle School, Homewood, AL 35209

(Participants: 225 local, 225 remote)

Lakes Middle School, Couer d'Alene, ID 83814

(Participants: 6 remote)

Lewis Center for Educational Research, Apple Valley,

CA 92307 (Participants: 6 local)

Dak Mountain MS, Birmingham, AL 35242

(Participants: 190 local, 190 remote)

Oak Park Middle School, Decatur, AL 36503

(Participants: 15 local, 15 remote)

Opelika Middle School, Opelika, AL 36801

(Participants: 350 remote) 
Pacelli High School, Columbus, GA 31906

(Participants: 11 local, 15 remote; 2 events)

Russell Co. Jr. High, Seale, AL 36875 (Participants:

332 local, 332 remote)

Sanford Middle School, Opelika, AL 36804

(Participants: 170 remote)

St. Mary's School, Medford, OR 97504 (Participants:

115 remote)

Strong Vincent High School, Erie, PA 16502

(Participants: 82 remote)

University Public School, Detroit, Ml 48201

(Participants: 145 remote)

Vista Compana School, Apple Valley, CA 92307

(Participants: 80 remote)

Westlawn Middle School, Hunstville, AL 35805

(Participants: 15 remote)

\section{HESSI at Solar Camp}

Msn/Prg: HESSI

Theme(s): $\quad$ SEC

Description: HESSI at Solar Camp, UC Berkeley Space Sciences Laboratory, Grizzly Peak Road (2) Centennial Blvd., MC 7450, Berkeley, CA. $94720-7450$, July 26th, 2000. The HESSI at Solar Camp program involved 15 middle school students from the Bay Area, three scientists/professionals from the UC Berkeley Space Sciences Lab, and a teacher. Highlights of the Solar Camp tour of the Lab included seeing the Mission Operations Control room, viewing the HESSI spacecraft from outside the clean room, watching the 10-meter communications dish track a passing satellite overhead, and a wrap-up discussion with an astronomer. Each student received a HESSI poster, HESSI paper model booklet, and other similar materials.

Lead: $\quad$ SEGway Space Sciences Laboratory, University of California, Berkeley, CA 94720

Venue(s): $\quad$ Solar Camp, Berkeley, CA 94720-7450 (Participants: 19 local)

\section{Institute for the Academic Advancement of Youth}

Msn/Prg: Cassini/Huygens Probe

Theme(s): $\quad$ SSE

Description: This Institute is funded through Johns Hopkins University in Baltimore, Maryland, for the purpose of inspiring highly gifted students.

Lead: $\quad$ Cassini E/PO Team, NASA Jet Propulsion Laboratory, Pasadena, CA 91109

Partner(s): Johns Hopkins University, Baltimore, MD 21218-2695

Venue(s): Loyola Marymount University, Marina del Rey, CA 90292 (Participants: 30 local)

\section{Los Angeles County Science Fair}

Msn/Prg: Cassini/Huygens Probe

Theme(s): $\quad$ SSE
Description: Over 1,000 middle and high school students participated in this event. Two members of the Cassini Project served as judges for the physics and astronomy category.

Lead: $\quad$ Cassini E/PO Team, NASA Jet Propulsion Laboratory, Pasadena, CA 91109

Venue(s): $\quad$ Los Angeles County Science Fair, Los Angeles, CA 90015 (Participants: 1000 local)

\section{Mars Education and Public Outreach (E/PO)}

Msn/Prg: NAI, SOHO, Cassini/Huygens Probe, Galileo, Stardust, Mars, DSMS

Theme(s): $\quad$ SSE

Description: Mars E/PO includes classroom visits/presentations by Mars Exploration Team members, national/regional//ocal teacher workshops, national teacher field trips, Mars Global Surveyor Space Flight Facility laboratory tours, Mars-related curriculum development, and other leveraged/partnership activities related to Mars exploration.

Lead: $\quad$ Mars E/PO Team, NASA Jet Propulsion Laboratory

Venue(s): $\quad$ Aprende Middle School, Chandler, AZ 85226

(Participants: 150 local)

Arizona State University, Tempe, AZ 85287

(Participants: 2025 local; 6 events)

Blue Sky Elementary School, Santa Clarita, CA 91351

(Participants: 84 local)

Boise State University, Boise, ID 83725 (Participants:

50 local)

California Science Teachers Association, October 1999, Long Beach, CA 90802 (Participants: 55 local) Cartthorp School, Santa Monica, CA 90402

(Participants: 20 local)

CASA Retired Teacher, Rancho Bernardo, CA

(Participants: 80 local)

Chadwick School, Palos Verdes, CA (Participants: 40

local)

Chautaqua NSF, Kailua-Kona, HI 96740 (Participants:

\section{8 local)}

Cub Scout Pack, Norwalk, CA 90650 (Participants: 60 local)

Cub Scout Pack 312, Littlerock, CA (Participants: 41 local)

Culver Christian School, Los Angeles, CA 90066

(Participants: 74 local)

Death Valley/Mono Lk, Death Valley, CA $9232 B$

(Participants: 60 local; 2 events)

Desert Vista Elementary School, Apache Junction, AZ 85219 (Participants: 605 local)

Dope Christian Academy, Long Beach, CA 90808

(Participants: 20 local)

Esperanza Elementary School, Phoenix, AZ 85027

(Participants: 60 local)

Fees Middle School, Tempe, AZ 85283 (Participants: 320 local) 
Garden Lakes School, Phoenix, AZ 85039

(Participants: 150 local)

Grant \& Edison Elementary School, Santa Monica, CA

90404 (Participants: 240 local)

Greenfield Elementary School, Phoenix, AZ 85040-

1193 (Participants: 59 local)

Horace Mann Elementary School, Beverly Hills, CA

90211 (Participants: 19 local)

LA County Courts, Los Angeles, CA 90012

(Participants: 60 local)

Luther Burbank Elementary School, Altadena, CA

91001 (Participants: 50 local)

Moorpark High School, Moorpark, CA 93021

(Participants: 155 local)

NASA Jet Propulsion Laboratory, Pasadena, CA 91109

(Participants: 25 local; 2 events)

North Hollywood High School, North Hollywood, CA

91607 (Participants: 52 local)

Onizuka Space Center, Kailua-Kona, HI 96745

(Participants: 21 local)

Orlando Civic Plaza, Orlando, FL 32800 (Participants:

256 local)

Palm Crest School, La Cañada, CA 91011

(Participants: 27 local)

Pasadena Convention Center, Pasadena, CA 91101

(Participants: 50 local)

Phoenix Civic Plaza, Phoenix, AZ 85004 (Participants:

85 local)

Prescott Pines, Prescott, AZ 86301 (Participants: 216

local)

Prescott Pines Camp, Prescott, AZ 86303

(Participants: 216 local)

Ralph Dunlap School, Santa Maria, CA 93455

(Participants: 70 local)

SBRS-Raytheon, Goleta, CA 93117 (Participants: 30

local)

Scottsdale Community College, Scottsdale, AZ 85251

(Participants: 60 local)

Spectrolab, Sylmar, CA 91342 (Participants: 50 local)

St. John of God, Norwalk, CA 90650 (Participants: 140

local)

Sunrise Mountain High School, Peoria, AZ 85382

(Participants: 56 local)

Tappan Middle School, Ann Arbor, Ml 48104

(Participants: 36 local)

University of Hawaii, Honolulu, HI 96822 (Participants:

85 local)

University of Houston, Houston, TX 77058

(Participants: 250 local)

Verba Buena Elementary School, Agoura Hills, CA

(Participants: 36 local)

Verba Buena Elementary School, Las Virgenes, CA

(Participants: 36 local)

Villa Corta Elementary, La Puente, CA 91744

(Participants: 30 local)

Village Christian Academy, Sun Valley, CA 91352

(Participants: 31 local)
Washington Elementary School, Norco, CA 91760

(Participants: $\mathbf{3 7 0}$ local)

Waverley School, Pasadena, CA (Participants: 51 local) Williams School, Glendora, CA 91741 (Participants: 54 local)

Willow Elementary School, Agoura Hills, CA 91301

(Participants: 31 local)

\section{Maryland Summer Center for Space Sclence for 6th and 7th Graders}

Msn/Prg: TIMED, CONTOUR, NEAR

Theme(s): $\quad$ SEC

Description: JHU/APL hosted the Maryland Summer Center for Space Science Program for 6th and 7th graders. Students learned to harness the power of technology and keep pace with the expanding knowledge of space science. Students experienced the process involved in planning/launching a simulated space mission, including design/fabrication of instrumentation for a spacecraft. They were part of a Mission Team that built a spacecraft scale model complete with instrumentation as a NASA Discovery Program mission. Students also created mission logos poster sessions, budgets, E/PO plans, and even gave a full mission overview oral presentation to their peers. JHU/APL offered an exciting environment for this study of applications in space. Students interacted with scientists, engineers, and program management. They examined instruments, visited test facilities, NEAR mission operations, and clean room facilities to view the TIMED spacecraft. TIMED, CONTOUR, and NEAR were NASA Discovery programs highlighted during the two weeks.

Lead: Physics Laboratory, Laurel, MD 20723-6099

Venue(s): $\quad$ Applied Physics Laboratory, Laurel, MO 20723 (Participants: 32 local)

\section{MESSENGER School Vlsit}

$\begin{array}{ll}\text { Msn/Prg: } & \text { MESSENGER } \\ \text { Theme(s): } & \text { SSE }\end{array}$

Description: Shirley Rabenau, JHU/APL, distributed MESSENGER Mission materials to a group of middle school students from the Woodbourne Center (for students with behavioral and emotional problems) in Baltimore, Maryland at JHU/APL/BSA Day of Caring Picnic and Game Day on September 1, 2000

Lead: $\quad$ MESSENGER E/P0 Team, American Association for the Advancement of Science (AAAS), Washington, DC 20005

Venue(s): $\quad$ Applied Physics Laboratory, Laurel, MD 20723 (Participants: 16 local)

\section{MESSEMGER TalK}

Msn/Prg: MESSENGER

Theme(s): SSE 
Description: On MArch 1, 2000, Tom Strikwerda, JHU/APL, gave a talk on "Current Space Missions" to the University Seminar class Space Exploration, and discussed MESSENGER.

$\begin{array}{ll}\text { Lead: } & \text { MESSENGER E/PO Team, American Association for the } \\ & \text { Advancement of Science (AAAS), Washington, DC } \\ & 20005 \\ \text { Venue(s): } & \text { University of Virginia, Charlottesville, VA 22903 } \\ & \text { (Participants: } 20 \text { local) }\end{array}$

\section{MASA JSC Astromaterials Distribution}

Msn/Prg: $\quad$ Sample Curation

Theme(s): $\quad$ SSE

Description: JSC Astromaterials Curation team makes samples of Rocks from Space available for formal and informal education. These include display samples for museums, lunar and meteorite thin sections for colleges, lunar and meteorite disks for pre-college, and lunar and martian soil simulants for all groups. These samples are accompanied with educational materials and visuals. We also helped KSC prepare a Mars touchstone and leant a Mars meteorite to several NASA centers. We also examined 65 meteorwrongs for the public.

Lead: $\quad$ Sample Curation E/PO Team, NASA Johnson Space Center, Houston, TX 77058

\section{MASA JSC Astromaterials Student Workshops}

\section{Msn/Prg: NAl, Sample Curation}

Theme(s): $\quad$ SSE

Description: JSC Astromaterials and Astrobiology team presented many workshops to HS students at JSC. These included Jason argonauts, two presentations per week for Texas Aerospace Scholars, and the International Space School. It also included school visits for career day.

Lead: $\quad$ Sample Curation E/PO Team, NASA Johnson Space Center, Houston, TX 77058

Venue(s): $\quad$ NASA Johnson Space Center, Houston, TX 77058 (Participants: 2000 local)

\section{NEAR School Visits}

$\begin{array}{ll}\text { Msn/Prg: } & \text { NEAR } \\ \text { Theme(s): } & \text { SSE }\end{array}$

Description: Talks, videos, and classroom activities on the NEAR Mission, Near-Earth Asteroids, and related subjects, presented to students by NEAR project staff during school visits.
Lead: NEAR E/PO Team, Johns Hopkins University Applied Physics Laboratory, Laurel, MD 20723-6099
Venue(s): $\quad$ Applied Physics Laboratory, Laurel, MD 20723 (Participants: 20 local) California State University, Long Beach, CA 90840 (Participants: 45 local)

California State University, Los Angeles, CA 90032 (Participants: 35 local)

Clarksville Elementary School, Clarksville, MD 21029

(Participants: 180 local)

Elkridge Landing Middle School, Elkridge, MD

(Participants: 120 local)

Forcey School, Silver Spring, MD 20904 (Participants:

60 local)

Friendship School, West Friendship, MD 21104

(Participants: 20 local)

Ft. Garrison Elementary School, Baltimore, MD 21208

(Participants: 73 local)

Home-schooled students, Westminster, MD 21157

(Participants: 30 local)

NASA Goddard Space Flight Center, Greenbelt, MD

20771 (Participants: 40 local)

Riderwood Elementary, Towson, MD 21204

(Participants: 27 local)

Scotchtown Hills Elementary, Laurel, MD 20723

(Participants: 60 local)

St. Catherine Labour, Wheaton, MD 20902

(Participants: 105 local; 2 events)

St. Johns Lane Elementary, Ellicott City, MD 21042

(Participants: 25 local)

University of Virginia, Charlottesville, VA 22903

(Participants: 70 local; 2 events)

Wilde Lake High School, Columbia, MD 21044

(Participants: 30 local)

\section{MEAR Student Press Conference}

$\begin{array}{ll}\text { Msn/Prg: } & \text { NEAR } \\ \text { Theme(s): } & \text { SSE }\end{array}$

Description: JHU/APL hosted a student press conference (C0-sponsored by the Planetary Society) for students from area schools on NEAR \& the general topic of exploration. Each participating school sent two students and one mentor. Mainstream media was also invited. However, only student questions were addressed. The mainstream media was there to cover the event at large. The speakers were Dr. Noam izenberg, JHU/APL NEAR Team, Dr. Rob Gold, JHU/APL NEAR Team, Dr. Roald Sagdeev, Professor University of Maryland and former Director of the Institute for Space Research, Russian Academy of Sciences. Students came prepared to discuss NEAR and had completed classroom activities prior to this event. After a NEAR introduction with video, each panelist spoke for 10 minutes with slides and/or video and the rest of the time was used to answer the students' prepared questions. A tour of JHU/APL followed after the press conference.
Lead:
NEAR E/PO Team, Johns Hopkins University Applied
Physics Laboratory, Laurel, MD 20723-6099
Venue(s):
Applied Physics Laboratory, Laurel, MD 20723
(Participants: 50 local) 


\section{SCES Astronomy Club}

Msn/Prg: $\quad$ SEC Forum

Theme(s): $\quad$ SEC

Description: Scientists work with local elementary school students and share backyard astronomy with them. This happens in the school as an enrichment program.

Lead:

SEC Forum, NASA Goddard Space Flight Center, Greenbelt, MD 20771

Sclence in Outer Space_freshman Sominar

Msn/Prg: HESSI

Theme(s): $\quad$ SEC

Description: The HESSI Principal Investigator and E/PO lead at UC Berkeley supported 14 one-and-a half-hour seminars on research in space science, followed by an informal discussion. Topics covered included: the active Sun and space weather, Earth's magnetosphere and auroras, Mars and the Moon, space dust and Space Shuttle experiments, the nearby interstellar medium, extra-solar planets, cosmic gamma ray bursts, the search for extraterrestrial intelligence, and space science and education in our schools. In addition, there was a field trip to the Space Sciences Laboratory to see how space experiments are made, to view UC Berkeley's own solar satellite HESSI, and to visit the spacecraft Mission and Science Operations Center and tracking antenna. Twenty-five freshmen who were NOT majoring and would otherwise not be involved in science/engineering took the class from January 25-May 2, 2000. A trip to HESSI Ground station and Science and Operation Center was the highlight.

$\begin{array}{ll}\text { Lead: } & \text { Center for Science Education, Space Sciences } \\ & \text { Laboratory, University of California, Berkeley, CA } \\ & 94720 \\ \text { Venue(s): } & \text { University of California, Berkeley, CA 94720-7450 } \\ & \text { (Participants: } 25 \text { local) }\end{array}$

Sclentists In the Classroom

Msn/Prg: $\quad$ SEC Forum, HST, SOHO, Yohkoh, Cassini/Huygens Probe, Galileo, Voyager

Theme(s): SEC

Description: Scientists visit classrooms to share the work that they do and the science of the Sun. Visits vary from grade to grade, but requests for elementary through high school are often met. Scientists hope to motivate students to go into a field of science. They are helping to stimulate the minds of students in hopes of initiating interest that will lead them into becoming scientists.

Lead: $\quad$ SEC Forum, NASA Goddard Space Flight Center, Greenbelt, MD 20771

\section{SIM Educational Lectures}

Msn/Prg: $\quad$ SIM

Theme(s): $\quad$ ASO

Description: SIM scientist and outreach specialist do a variety of classroom and community college lectures throughout any given school year.

Lead: $\quad$ SIM E/PO Team, NASA Jet Propulsion Laboratory, Pasadena, CA 91109

Venue(s): $\quad$ Cresenta High School, La Cresenta, CA (Participants: 35 local)

NASA Jet Propulsion Laboratory, Pasadena, CA 91109 (Participants: 100 local)

Newcomb Elementary, Long Beach, CA (Participants: 50 local)

\section{Space Explorers, Inc., NEARilnk Program}

Msn/Prg: NEAR

Theme(s): $\quad$ SSE

Description: The Space Explorers, Inc., NEARlink Program focuses on math, science, and technology in the classroom. Designed for a handson/minds-on environment, students participating in the program will be involved in teamwork, communication, research, and computer-based skilts preparing them to meet the challenges of the global marketplace. The programs are divided into three phases. Phase I is designed to prepare the class for a NEARlink mission. It provides the necessary classroom materials and resources to make the project a valuable leaming experience for the students. It also provides the teacher with the support necessary to used the program with confidence. This phase of the program consists of two parts: the curriculum and mission team selection. The curriculum has been developed by classroom teachers and is modular in nature.

Lead: $\quad$ NEAR E/PO Team, Johns Hopkins University Applied

Partner(s): Physics Laboratory, Laurel, MD 20723-6099

Venue(s): $\quad$ Atlanta, GA 30308 (Participants: 26 local)

Akron City School District, Akron, $\mathrm{OH} 44308$

(Participants: 25 local)

Alexander Hamilton High School, Los Angeles, CA

90034 (Participants: 22 local)

Alexis | Dupont High School, Wilmington, DE 19807

(Participants: 25 local)

Anna Joyce Elementary, Detroit, MI 48214

(Participants: 23 local)

Antonia Pantoja High School, Chicago, IL 60647

(Participants: 27 local)

Apollo Senior High School, St. Cloud, MN 56303

(Participants: 23 local)

Archmere Academy, Claymont, DE 19703

(Participants: 24 local)

Artington High School, St. Paul, MN 55117

(Participants: 23 local) 
Arthur Hill High School, Saginaw, MI 48602

(Participants: 27 local)

Austin Baltz Elementary, Wilmington, DE 19805

(Participants: 21 local)

Avon Elementary, Lake Villa, IL 60030 (Participants:

47 local)

Axtel Park Middle School, Sioux Falls, SD 57104

(Participants: 25 local)

Ayersville High School, Defiance, $\mathrm{OH} 43512$

(Participants: 20 local)

B.Mahlon Brown Jr. High School, Henderson, NV

89015 (Participants: 26 local)

Ballou High School, Washington, DC 20032

(Participants: 27 local)

Barberton High School, Barberton, $\mathrm{OH} 44203$

(Participants: 25 local)

Battle Mountain Jr. High School, Battle Mountain, NV

89820 (Participants: 22 local)

Belmont Elementary School, West Babylon, NY 11704

(Participants: 25 local)

Benjamin Banneker Elementary, Milford, DE 19963

(Participants: 29 local)

Berrien County Math, Berrien Springs, Ml 49103

(Participants: 25 local)

Biltmore Altemative School, Las Vegas, NV 89101

(Participants: 22 local)

Bishop Manogue High School, Reno, NV 89512

(Participants: 26 local)

Boulder City High School, Boulder City, NV 89005

(Participants: 24 local)

Brownsburg Jr. High School, Brownsburg, IN 46112

(Participants: 34 local)

Burkholder Middle School, Henderson, NV 89015

(Participants: 32 local)

Calvary Church Christian School, Las Vegas, NV

89101 (Participants: 26 local)

Cape Henlopen High School, Defiance, OH 43512

(Participants: 24 local)

Caravel Academy, Bear, DE 19701 (Participants: 30

local)

Carrie Downie Elementary, New Castle, DE 19720

(Participants: 28 local)

Casimir Pulaski Intermediate School, Wilmington, DE

19805 (Participants: 29 local)

Cedar Lane Elementary, Middletown, DE 19709

(Participants: 23 local)

Centennial High School, Columbus, $\mathrm{OH} \mathbf{4 3 2 2 0}$

(Participants: 27 local)

Central Baldwin Middle School, Robertsdale, AL

36567 (Participants: 28 local)

Chaparral High School, Las Vegas, NV 89121

(Participants: 34 local)

Charleston Middle School, Charleston, IL 61920

(Participants: 24 local)

Charter School of Wilmington, Wilmington, DE 19807

(Participants: 27 local)
Chorpus Christi School, Wilmington, DE 19805

(Participants: 22 local)

Church Street School, Plains, NY 10603 (Participants:

46 local; 2 events)

Churchill County Jr. School, Fallon, NV 89406

(Participants: 28 local)

Clague Middle School, Ann Arbor, MI 48105

(Participants: 27 local)

Clark High School, Las Vegas, NV 89102 (Participants:

23 local)

Clayton Elementary, Clayton, DE 19938 (Participants:

22 local)

Colbert Heights High School, Tuscumbia, AL 35674

(Participants: 32 local)

Colwyck Elementary, New Castle, DE 19720

(Participants: 23 local)

Commodore MacDonough, Saint Georges, DE 19733

(Participants: 24 local)

Concord High School, Wilmington, DE 19801

(Participants: 26 local)

Cony Hill School, Augusta, ME 04330 (Participants: 24

local)

Coolidge Middle School, Ferndale, Ml 48220

(Participants: 23 local)

Crestwood Elementary, Madison, W/ $\mathbf{5 3 7 0 1}$

(Participants: 23 local)

CW Woodbury Jr. High School, Las Vegas, NV 89121

(Participants: 26 local)

Danville Bate Middle School, Danville, KY 40422

(Participants: 25 local)

Darrell Swope Middle School, Reno, NV 89509

(Participants: 24 local)

Delaware City Elementary, Delaware City, DE 19706

(Participants: 23 local)

Dell Robinson Middle School, Las Vegas, NV 89110

(Participants: 28 local)

Desert Pines High School, Las Vegas, NV 89110

(Participants: 23 local)

Dodgeville Middle School, Dodgeville, WI 53533

(Participants: 101 local)

Dover AFB Middle School, Dover, DE 19901

(Participants: 28 local)

Dover Central Middle School, Dover, DE 19901

(Participants: 22 local)

Drew Academy, Houston, TX 77091 (Participants: 24

local)

Drew-Pyle Intermediate School, Wilmington, DE

19801 (Participants: 23 local)

Eagle Valley Middle School, Carson City, NV 89702

(Participants: 26 local)

Earl Wooster High School, Reno, NV 89502

(Participants: 27 local)

East Lawrence High School, Trinity, AL 35673

(Participants: 20 local)

East Millsboro Elementary, Millsboro, DE 19966

(Participants: 21 local) 
Eastern Illinois University, Charleston, IL 61920

(Participants: 35 local)

Edison Middle School, Huntington Beach, CA 92646

(Participants: 28 local)

Edison Middle School, South Bend, IN 46615

(Participants: 26 local)

Edison Middle School, Green Bay, WI 54302

(Participants: 25 local)

Edward Miller High School, Auburn, ME 04210

(Participants: 29 local)

Eldorado High School, Las Vegas, NV 89110

(Participants: 24 local)

Elko Jr. High School, Elko, NV 89801 (Participants: 23 local)

Ensweiller Academy, Gary, IN 46408 (Participants: 26 local)

Episcopal High School, Jacksonville, FL 32207

(Participants: 24 local)

Epworth Christian School, Laurel, DE 19956

(Participants: 30 local)

Erie Middle School, Erie, C0 80516 (Participants: 27 local)

F. D. Roosevelt Middle School, Cleveland, $\mathrm{OH} 44108$

(Participants: 27 local)

Fairview Elementary, Dover, DE 19904 (Participants:

25 local)

Fayetteville High School, Fayetteville, AR 72701

(Participants: 29 local)

Fegeley Middle School, Portage, iN 46368

(Participants: 24 local)

Fifer Middle School, Camden Wyoming, DE 19934

(Participants: 23 local)

Forest Oak Elementary, Newark, DE 19711

(Participants: 21 local)

Franke Park Elementary, Fort Wayne, IN 46808

(Participants: 25 local)

Frankford Elementary, Frankford, DE 19945

(Participants: 24 local)

Franklin Elementary, Appleton, WI 54911 (Participants: 32 local)

Franklin High School, Livonia, MI 48150 (Participants:

40 local)

Frankton Jr./Sr. High School, Frankton, IN 46044

(Participants: 30 local)

Garrett Morgan Middle School, Cleveland, $\mathrm{OH} 44113$

(Participants: 25 local)

Garside Middle School, Las Vegas, NV 89107

(Participants: 26 local)

Gen. Arnold Primary School, Dover, DE 19901

(Participants: 23 local)

George Read Middle School, New Castle, DE 19720

(Participants: 24 local)

Georgetown Elementary, Georgetown, DE 19947

(Participants: 22 local)

Georgian Heights Elementary School, Columbus, $\mathrm{OH}$

43228 (Participants: 26 local)
Glasgow High School, Newark, DE 19702

(Participants: 29 local)

Glencoe Elementary, Gadsden, AL 35905

(Participants: 30 local)

Grant Sawyer Middle School, Las Vegas, NV 89118

(Participants: 25 local)

Green Bay East High School, Green Bay, WI 54301

(Participants: 26 local)

Greenspun Jr. High School, Henderson, NV 89014

(Participants: 23 local)

Gunning Bedford Middle School, Delaware City, DE

19706 (Participants: 28 local)

Hairy Davis School, Cleveland, OH 44102

(Participants: 20 local)

Hanby Middle School, Wilmington, DE 19801

(Participants: 27 local)

Harold Brinley Middle School, Las Vegas, NV B9108

(Participants: 30 local)

Harris-Lake Park Com, Lake Park, IA 51347

(Participants: 23 local)

Harshman Middle School, Indianapolis, IN 46201

(Participants: 28 local)

Hawthorne Elementary, Hawthorne, NV 89415

(Participants: 26 local)

Helena Elementary, Helena, AL 35080 (Participants:

24 local)

Holy Cross School, Dover, DE 19901 (Participants: 62 local)

Hook Elementary School, West Troy, $\mathrm{OH} 45373$

(Participants: 25 local)

Hyde Park Jr. High School, Las Vegas, NV 89107

(Participants: 24 local)

Illinois Math \& Science, Aurora, IL 60506

(Participants: 16 local)

Immaculate Heart of Mary, Wilmington, DE 19803

(Participants: 29 local)

Indian River Senior High, Frankford, DE 19945

(Participants: 35 local)

Infant Jesus of Prag, Flossmoor, IL 60422

(Participants: 16 local)

Isle High School, South Isle, MN 56342 (Participants: 22 local)

J. Cashman Jr. High School, Las Vegas, NV 89102

(Participants: 21 local)

J. Ralph Mcllaine Elementary, Magnolia, DE 19962

(Participants: 45 local)

Jane Addams School, Palatine, IL 60067 (Participants: 12 local)

Jasper Elementary School, Jasper, TN 37347

(Participants: 36 local)

Jefferson Elementary, Kenosha, WI 53140

(Participants: 21 local)

John Bassett Moore School, Smyrna, DE 19977

(Participants: 56 local)

John Laidlaw Elementary, Westem Springs, IL 60558

(Participants: 24 local) 
Kenny Guinn Jr. High Schaol, Las Vegas, NV 89103 (Participants: 36 local)

KO Knudson Jr. High School, Las Vegas, NV 89104 (Participants: 12 local)

Lake Waco Mantessori School, Waco, TX 76708

(Participants: 36 local)

Las Vegas Academy, Las Vegas, NV 89101

(Participants: 30 local)

Las Vegas High School, Las Vegas, NV 89122

(Participants: 32 local)

Laurel Intermediate, Laurel, DE 19956 (Participants:

25 local)

LBJ Middle School, Johnson City, TX 78636

(Participants: 30 local)

Lewes Middle School, Lewes, DE 19958 (Participants:

32 local)

Lincoln Park Elementary, Duluth, MN 55807

(Participants: 31 local)

Lincoln West High School, Cleveland, $\mathrm{OH} 44109$

(Participants: 15 local)

Litchfield High School, Litchfield, IL 62056

(Participants: 16 local)

Little Chute Elementary, Little Chute, WI 54140

(Participants: 19 local)

Little Oak Middle School, Slidell, LA 70461

(Participants: 20 local)

Longfellow Middle School, Wauwatosa, WI 53213

(Participants: 34 local)

Lord Botetourt High School, Dalville, VA 24083

(Participants: 26 local)

Lulu Ross Elementary, Milford, DE 19963

(Participants: 27 local)

Luverne High School, Luverne, AL 36049

(Participants: 10 local)

Lynch Elementary School, Lapeer, MI 48446

(Participants: 19 local)

Manning Elementary School, Jamaica Plain, MA

02130 (Participants: 24 local)

Marbrook Elementary, Wilmington, DE 19808

(Participants: 16 local)

Marguerite Burnett Elementary, Wilmington, DE 19802

(Participants: 18 local)

Math \& Science Academy, San Antonio, TX

(Participants: 35 local)

McAuley High School, Portland, ME 04103

(Participants: 20 local)

McCall Elementary School, McCall, ID 83638

(Participants: 29 local)

McCollough Elementary, New Castle, DE 19720

(Participants: 43 local)

McKinley Elementary School, Norman, OK 73069

(Participants: 24 local)

McLenegan Elementary, Beloit, WI 53511

(Participants: 26 local)

McMichael Middle School, Detroit, MI 48208

(Participants: 21 local)
Milford Middle School, Milford, DE 19963

(Participants: 90 local)

Mineral County High School, Hawthorne, NV 89415

(Participants: 16 local)

Monticello High School, Monticello, IL 61856

(Participants: 30 local)

Montwood Middle School, El Paso, TX 77936

(Participants: 48 local; 2 events)

N. College Hill High School, Cincinnati, OH 45224

(Participants: 6 local)

New Castle Baptist Academy, New Castle, DE 19720

(Participants: 26 local)

New Country School, Henderson, MN (Participants: 24

local)

Newark High School, Newark, DE 19711 (Participants:

18 local)

North East High School, North East, MD 21901

(Participants: 50 local)

North High School, Des Moines, IA 50313

(Participants: 32 local)

North High School, Waukesha, WI 53188 (Participants

39 local)

North Medford High School, Medford, OR 97504

(Participants: 19 local)

O'Callahan Middle School, Las Vegas, NV 89113

(Participants: 12 local)

Oakdale Elementary School, Toledo, OH 43605

(Participants: 32 local)

Our Lady of the Assumption, Beloit, WI 53511

(Participants: 34 local)

Padua Academy, Wilmington, DE 19806 (Participants:

29 local)

Page Elementary School, Middleville, Ml 49333

(Participants: 28 local)

Park Street Middle School, Grove City, OH 43123

(Participants: 15 local)

Pederson Elementary, Altoona, WI 54720 (Participants:

19 local)

Perry Meridian Middle School, Indianapolis, IN 46217

(Participants: 32 local)

Pickaway Elementary School, Circleville, OH 43113

(Participants: 31 local)

Pierce School, Grosse Pointe, Ml 48230 (Participants:

30 local)

Pike Central Middle School, Petersburg, IN 47567

(Participants: 32 local)

Platteville Public School, Platteville, WI 53818

(Participants: 29 local)

Pleasant Hill School, Peoria, IL 61605 (Participants: 53 local; 2 events)

Plover-Whiting School, Plover, WI 54467 (Participants:

26 local)

Portland High School, Portland, ME 04101

(Participants: 24 local)

Pyle Intermediate School, Wilmington, DE 19801

(Participants: 15 local) 
Quincy Middle School, Quincy, MI 49082 (Participants:

32 local)

Raymer Elementary School, Toledo, OH 43605

(Participants: 31 local)

Redding Middle School, Middletown, DE 19709

(Participants: 12 local)

Redondo Beach Unified School District, Redondo

Beach, CA 90278 (Participants: 160 local)

Rehoboth Elementary, Rehoboth Beach, DE 19971

(Participants: 12 local)

Reno High School, Reno, NV 89509 (Participants: 18

local)

Richardson Park Elementary, Wilmington, DE 19804

(Participants: 16 local)

River Valley Middle School, Jeffersonville, IN 47130

(Participants: 51 local)

Riverbend Elementary, Chesterfield, M0 63017

(Participants: 56 local)

Riverview Elementary School, Silver Lake, WI 53170

(Participants: 18 local)

Riverview Middle School, Silver Lake, WI 53170

(Participants: 35 local)

Roosevelt Jr. High School, Springfield, OH 45505

(Participants: 32 local)

Roslyn Middle School, Rostyn Heights, NY 11577

(Participants: 26 local)

Saint Andrews School, Middletown, DE 19709

(Participants: 24 local)

Saint Elizabeth High, Wilmington, DE 19805

(Participants: 89 local)

Saint John The Beloved, Wilmington, DE 19808

(Participants: 16 local)

Saint Marks High School, Wilmington, DE 19808

(Participants: 13 local)

Saint Matthew Elementary, Wilmington, DE 19804

(Participants: 25 local)

San Lorenzo High School, San Lorenzo, CA 94580

(Participants: 16 local)

Sandusky County, Fremont, OH 43420 (Participants:

68 local)

Saturn River Front Academy, St. Paul, MN 55101

(Participants: 25 local)

School, Wilmington, DE 19810 (Participants: 28 local)

Scott Elementary School, Merrill, WI 54452

(Participants: 30 local)

Seaford High School, Seaford, DE 19973 (Participants:

25 local)

Seeger High School, West Lebenon, IN 47991

(Participants: 24 local)

Shad Bush Education, Shelby Township, Ml 48317

(Participants: 21 local)

Shades Mountain Elementary, Hoover, AL 35226

(Participants: 39 local)

Sheboygan South High School, Sheboygan, WI 53081

(Participants: 24 local)

Silver Lake Elementary, Middletown, DE 19709

(Participants: 15 local)
Skyway Middle School, Presque Isle, ME 04769

(Participants: 19 local)

Sonora Elementary, Sonora, CA 95370 (Participants:

22 local)

Sparks High School, Sparks, NV 89431 (Participants:

17 local)

Sparta Middle School, Sparta, WI 54656 (Participants:

18 local)

St. Ignace Middle School, Ignace, Ml $\mathbf{4 9 7 8 1}$

(Participants: 15 local)

St. James Catholic School, Gadsden, AL 35901

(Participants: 24 local)

St. John Vianney School, Janesville, WI 53545

(Participants: 26 local)

St. John's Jesuit High School, Toledo, $\mathrm{OH} 43615$

(Participants: 29 local)

St. Mark's Lutheran School, Watertown, WI 53094

(Participants: 34 local)

St. Vincent, River Forest, IL 60305 (Participants: 31 local)

Sterling Elementary, Sterling, AK 99672 (Participants: 25 local)

Stillwater Area High School, North Stillwater, MN 55082 (Participants: 22 local)

Stranton Middle School, Wilmington, DE 19804

(Participants: 36 local)

Stratford Road Elementary School, Plainview, NY

11803 (Participants: 23 local)

Stubbs Intermediate School, Wilmington, DE 19801

(Participants: 24 local)

Summit Country Day School, Cincinnati, OH 45420

(Participants: 24 local)

Sussex Central High, Georgetown, DE 19947

(Participants: 35 local)

Taylor Middle School, Kokomo, IN 46902 (Participants:

24 local)

Terry Parker High School, Jacksonville, FL 32211

(Participants: 18 local)

Thomas Bayard Elementary, Wilmington, DE 19805

(Participants: 16 local)

Thomas Jefferson School, Hoffman Estates, IL 60195

(Participants: 25 local)

Thurman White Middle School, Henderson, NV 89014

(Participants: 22 local)

Tower Hill School, Wilmington, DE 19806

(Participants: 30 local)

Traner Middle School, Reno, NV 89512 (Participants:

12 local)

United High School, Laredo, TX 78045 (Participants:

28 local)

University School, Shaker Heights, $\mathrm{OH} 44122$

(Participants: 15 local)

Usher Middle School, Atlanta, GA 30318 (Participants:

24 local)

Valley High School, Flint, MI 48503 (Participants: 22

local) 
Vaughn Middle School, Reno, NV 89512 (Participants: 32 local)

Vickers Elementary School, Victoria, TX 77904

(Participants: 15 local)

Virginia CUSD \#64, Virginia, IL 62691 (Participants: 12

local)

Wainwright Middle School, Lafayette, IN 47905

(Participants: 65 local)

Walter Johnson Jr. High School, Las Vegas, NV 89128

(Participants: 30 local)

Warner Elementary School, Wilmington, DE 19802

(Participants: 22 local)

Washoe High School, Reno, NV 89512 (Participants:

68 local)

Waterville High School, Waterville, ME 04901

(Participants: 35 local)

Waterville Jr. High School, Waterville, ME 04901

(Participants: 48 local)

Waunakee High School, Waunakee, WI 53597

(Participants: 24 local)

West Seaford Elementary, Seaford, DE 19973

(Participants: 29 local)

West Side Elementary, Marshall, MN 56258

(Participants: 24 local)

Western Senior High School, Las Vegas, NV 89107

(Participants: 30 local)

Westview Elementary, Wood Dale, IL 60191

(Participants: 22 local)

William Penn High School, New Castle, DE 19720

(Participants: 23 local)

Wilmington Montessori School, Wilmington, DE 19810

(Participants: 23 local)

Winnemucca Jr. High School, Winnemucca, NV 89445

(Participants: 25 local)

Woodward School, Kalamazoo, MI 49007

(Participants: 26 local)

\section{Speakers Bureau @ STScl}

Msn/Prg: $\quad$ HST

Theme(s): $\quad$ ASO

Description: The Institute receives requests from schools and organizations to have scientists do talks about the Hubble Space Telescope and its discoveries. Scientist from the Institute participate on a voluntary basis, and will normally distribute education materials at the talk.

Lead: $\quad$ Office of Public Outreach, Space Telescope Science Institute, Baltimore, MD 21218

\section{STARBASE Network}

Msn/Prg: $\quad$ OSS

Description: STARBASE--Students Training for Achievement in Research Based on Analytic Space-science Experiences-is a combination of dedicated hardware, professional astronomers, teachers, and students working together in scientific investigations and education. The purpose is to involve motivated high school and college students as direct and integral participants in the research of space scientists, including as the ultimate goal, involvement in a space-based astrophysics mission. The initial efforts are centered on developing a network of three, longitudinally-spaced, meter-class, CCD-imaging telescopes that can be operated remotely or robotically over the Internet, or operated locally for training and research. A 0.6 meter telescope at Western Kentucky University and the 1.3 meter Remotely Controlled Telescope (RCT) at Kitt Peak National Observatory are being refurbished and automated, and non-Federal funding is being sought for placing a robotic 0.6 meter telescope at the Wise Observatory in Israel. A network of universities that share common research and educational interests is being developed, and over a dozen undergraduate students are involved in developing various aspects of STARBASE.

Lead: $\quad$ Dr. Charles McGruder, Western Kentucky University, Bowling Green, KY 42101

Partner(s): $\quad$ Boston University, Boston, MA 02215

EOS Technologies, Inc., Tucson, AZ 85705

Georgia State University, Atlanta, GA 30303-3083

Lawrence Hall of Science, Berkeley, CA 94720-5200

Planetary Science Institute, Tucson, AZ 85705

Wise Observatory, Tel Aviv University, Tel Aviv, Israel

Venue(s):

Western Kentucky University, Bowling Green, KY 42101

\section{Stardust Uve Interactive Programs}

Msn/Prg: Stardust

Theme(s): $\quad$ SSE

Description: Five live interactive programs completed by Educational Management Group (EMG), an educational arm of Simon and Shuster. Included: "Encounter with a Comet," "Designing a Spacecraft," "Think Small in a Big Way," "Aerogel," and a 30-minute live broadcast from Cape Canaveral for Stardust launch. Over 1.2 million students and educators were reached throughout the U.S., Canada, Japan, and Mexico during all presentations. Zero-dollar contract agreement with company. Stardust Outreach Office provided content only. In return EMG provided master of all productions and duplicated materials (factsheets, curriculum) at their expense.

Lead: $\quad$ Stardust E/PO Team, NASA Jet Propulsion Laboratory, Pasadena, CA 91109

Partner(s): $\quad$ Simon and Shuster, Educational Managment Group, Venue(s): Kennedy Space Center, Kennedy Space Center, FL 32899

\section{STEREO/MPACT at Solar Camp}

Msn/Prg: STEREO

Theme(s): $\quad$ SEC

Description: STEREO/IMPACT Solar Camp@Lawrence Hall of Science, UC Berkeley Space Sciences Laboratory, Grizzly Peak Road @ Centennial Blvd., MC 7450, Berkeley, CA 94720-7450, August 23, 2000. The 
STEREO/MPACT at Solar Camp program involved 18 middle school students from the Bay Area, three scientists/professionals from the UC Berkeley Space Sciences Lab, and a teacher. Highlights of the Solar Camp tour of the Lab included seeing the Mission Operations Control room, viewing a satellite from outside the clean room, watching the 10-meter communications dish track a passing satellite overhead, and a wrap-up discussion with a STEREO/IMPACT scientist. Each student received a STEREO/MPACT 3-D poster and glasses, a satellite paper model booklet, and other similar materials.

$\begin{array}{ll}\text { Lead: } & \text { SEGway Space Sciences Laboratory, University of } \\ & \text { California, Berkeley, CA } 94720 \\ \text { Venue(s): } & \text { Lawrence Hall of Science, Berkeley, CA 94720-7450 } \\ & \text { (Participants: } 22 \text { local) }\end{array}$

Sunspots-San Francisco Unified School District (SFUSD) STEPUP Summer School

Msn/Prg: $\quad$ SEC Forum, HESSI

Theme(s): $\quad$ SEC

Description: One of the Web-based SEGway lessons, "Sunspots," was taught to the incoming 9th graders during summer school 2000, for the San Francisco Unified School District's STEP-UP program. Five high schools participated. An estimated 500 students took the class. The curricula lasted about 2 weeks, as part of their daily physical sciences and technology curricula.
Lead: $\quad$ SEGway Space Sciences Laboratory, University of California, Berkeley, CA 94720
Venue(s): $\quad$ Five High Schools in San Francisco, San Francisco, CA (Participants: 500 local)

\section{SWAS Student Learning Group}

Msn/Prg: $\quad$ SWAS

Theme(s): $\quad$ SEU

Description: During the 1999/2000 school year, scientist Dr. Rene Plume worked with students at the Keystone Oaks High School in Pittsburgh, PA. Using SWAS data, students analyzed data in a southern hemisphere dark cloud. The students then traveled to Boston to the Harvard-Smithsonian Center for Astrophysics to present their results. This coming year, a new batch of students will be analyzing SWAS water maps of the molecular cloud DR21.

$\begin{array}{ll}\text { Lead: } & \text { SEU Forum, Smithsonian Astrophysical Observatory, } \\ & \text { Cambridge, MA } 02138 \\ \text { Venue(s): } & \text { Harvard-Smithsonian Center for Astrophysics, } \\ & \text { Cambridge, MA } 02138 \text { (Participants: } 35 \text { local) }\end{array}$

Telescopes in Education Program

Msn/Prg: $\quad$ OSS, OHRE

Description: The Telescopes in Education (TIE) program brings the opportunity to use a remotely controlled telescope and charge-coupled device
(CCD) camera in a real-time, hands-on, interactive environment to students around the world. TIE enables students to increase their knowledge of astronomy, astrophysics, and mathematics; improve their computer literacy; and strengthen their critical thinking skills. The TIE program currently utilizes a science-grade 24 -inch reflecting telescope located at the Mount Wilson Observatory, high above the Los Angeles basin in the San Gabriel Mountains of Southern California. The telescope has been used by students in grades K-12 to observe galaxies, nebulae, variable stars, eclipsing binaries, and other ambitious projects and experiments. Hundreds of schools in the United States and around the world (including Australia, Canada, England, and Japan) have successfully used the prototype telescope on Mount Wilson. Through TIE, students have rediscovered and cataloged a variable star and assisted the Pluto Express project at NASA Jet Propulsion Laboratory to revise the ephemeris (orbital location) for the planet Pluto.
Lead:
Telescopes in Education, NASA Jet Propulsion
Laboratory, Pasadena, CA 91109
Partner(s):
Mt. Wilson Institute, Mt. Wilson, CA 91023

\section{Voyager/Ulysses High School Interview Program}

$\begin{array}{ll}\text { Msn/Prg: } & \text { Ulysses, Voyager } \\ \text { Theme(s): } & \text { SEC }\end{array}$

Description: Students from Los Angeles County compete for an interview opportunity with team members on Space Science, Spacecraft Design, Spacecraft Operations, and Project Management. Students' interests are matched with team member volunteers. Students do the research, professional interview, and professional presentation at end of project. The pilot program began in 1999. A team member attends all presentations for evaluation. The schools that participated were Palm Desert High, Rancho Cucamonga High, Newport Harbor High, Jurupa Valley High, and Barstow High Schools.

Lead:

Ulysses E/PO Team, NASA Jet Propulsion Laboratory, Pasadena, CA 91109

Venue(s): $\quad$ Barstow High School, Barstow, CA Jurupa Valley High School, CA Newport Harbor High School, CA Paim Desert High School, CA Rancho Cucamonga High School, CA

\section{Public Outreach}

\section{A Child's Universe}

$\begin{array}{ll}\text { Msn/Prg: } & \text { Stardust, Mars } \\ \text { Theme(s): } & \text { SSE }\end{array}$

Description: The ASU Mars K-12 Education Program co-facilitated "A Child's Universe" and recruited all of the teacher facilitators for this 3day, hands-on activity event. 
Lead:

Mars E/PO Team, NASA Jet Propulsion Laboratory, Pasadena, CA 91109

Partner(s): $\quad$ Arizona State University, Tempe, AZ 85287

Venue(s):

PlanetFest '99, Pasadena, CA 91101 (Participants: 185 local)

\section{ACE Exhibit}

Msn/Prg: $\quad$ ACE

Theme(s): $\quad$ SEC

Description: Temporary display on ACE at the University of Delaware

Lead: $\quad$ ACE E/PO Team, NASA Goddard Space Flight Center, Greenbelt, MD 2077

Venue(s): $\quad$ University of Delaware, Newark, DE 19716

\section{Arizona State University Geoscience Open House}

Msn/Prg: $\quad$ CONTOUR, Deep Impact, NEAR, Stardust, Mars, MUSES-CN, Rosetta, NEAT

Theme(s): $\quad$ SSE

Description: Aimee Whalen and Cheryn Roff from the Stardust Project attended the Arizona State University Geoscience Department Open House on October 16, 1999. Stardust, NEAR, NEAT, Deep Impact, RosettaMIR0, MUSES-CN, and Contour were represented. Stardust and MUSES-CN Nanorover models were on hand. Approximately 2,000 (general public) were in attendance. Arizona State University Geoscience Open House included the ASU Mars K-12 Education Program and Thermal Emission Spectrometer Program materials and event support.

Lead: $\quad$ Stardust E/PO Team, NASA Jet Propulsion Laboratory, Pasadena, CA 91109

Venue(s): $\quad$ Arizona State University, Tempe, AZ 85287

(Participants: 1200 local)

Astromaterials/Astrobiology JSC Open House

Msn/Prg: $\quad$ NAl, Sample Curation

Theme(s): $\quad$ SSE

Description: The JSC Open House brought more than 100,000 people to tour JSC on August 26, 2000. The JSC Astromaterials/Astrobiology science and E/PO teams presented eight exhibits: Astromaterials, Astrobiology, Lunar Sample Lab, Genesis Lab, Microprobe Lab, Mars Exploration, Planetary Astronomy, and Planetary Science Education.

Lead: $\quad$ Sample Curation E/PO Team, NASA Johnson Space Center, Houston, TX 77058

Venue(s): $\quad$ NASA Johnson Space Center, Houston, TX 77058

\section{Australlan Science Festival}

Msn/Prg: $\quad$ DPS0, CONTOUR, Deep Impact, Genesis, MESSENGER, NEAR, Stardust, Lunar Prospector

Theme(s):
Description: The Australian Science Festival promotes science and technology in society, particularly to young people, and aims to raise awareness and understanding of scientific discovery and research. Since the first festival in 1993, the event has grown to attract over 150,000 visitors. The Discovery Program supplied posters, bookmarks, and other materials from all the Discovery missions, as the highlight of the Canberra Deep Space Communication Complex exhibit.

$\begin{array}{ll}\text { Lead: } & \text { Discovery E/P0 Team, NASA Jet Propulsion } \\ & \text { Laboratory, Pasadena, CA } 91109 \\ \text { Venue(s): } & \text { Canberra, Australia }\end{array}$

\section{Brain Thrust}

Msn/Prg: $\quad$ ACE

Theme(s): $\quad$ SEU

Description: "1999, A Space Odyssey: Exploring the Universe Today and in the New Millennium"-invited session entitled "Brain Thrust" presented by Or. Robert Gabrys, Chief, Education Office, NASA GSFC. Includes "Exploring the Extreme Universe!" CD.

Lead: ACE E/PO Team, NASA Goddard Space Flight Center Greenbelt, MD 20771

Partner(s): $\quad$ NASA GSFC Office of Education, Greenbelt, MD 20771 Venue(s): $\quad$ 1999, A Space Odyssey, Brookłandville, MD 21022

\section{CAL_DAY}

Msn/Prg: HESS

Theme(s): $\quad$ SEC

Description: Students, faculty, and staff are pleased to be the hosts for a day of discovery, learning, and fun on the Berkeley campus. Our schools, colleges, departments, museums, athletic facilities, lawns, and libraries are open and waiting for you.

Lead: $\quad$ Center for Science Education Space Sciences Laboratory, University of California, Berkeley, CA 94720

Venue(s): $\quad$ Space Science Lab, Berkeley, CA 94720 (Participants 150 local)

\section{Cassini Mlliennium Flyby}

Msn/Prg: $\quad$ Cassini/Huygens Probe, Galileo

Theme(s): $\quad$ SSE

Description: Cassini will fly by Jupiter on December 30,2000 . In support of this opportunity, the Program is sponsoring events including a flyby Web site, three educator conferences, a friends \& family celebration, a public event, and many individual presentations to schools and the public throughout the United States.

Lead Cassini E/PO Team, NASA Jet Propulsion Laboratory. Pasadena, CA 91109

Venue(s): 


\section{Cassini Mlssion to Saturn Public Loctures}

Msn/Prg: Cassini/Huygens Probe

Theme(s): SSE

Description: Public lecture on the science, engineering, and technology involved in the Cassini Mission to Saturn.

Lead: $\quad$ Cassini E/PO Team, NASA Jet Propulsion Laboratory, Pasadena, CA 91109

Venue(s): $\quad$ Azusa City Library, Azusa, CA 91702 (Participants: 250 local; 4 events) Girl Scouts National Convention, Kansas City, MO (Participants: 10000 local) Hansen Planetarium, Salt Lake City, UT 84111-1590 (Participants: 150 local) Holiday Inn, Ventura, CA 93001 (Participants: 100 local; 2 events) March Air Force Base, Riverside, CA (Participants: 85 local)

NASA Jet Propulsion Laboratory, Pasadena, CA 91109 (Participants: 70 local; 4 events)

San Dimas High School, San Dimas, CA 91773

(Participants: 200 local; 2 events)

Wahib's Restaurant, Alhambra, CA 91801

(Participants: 40 local; 2 events)

\section{Challenger Center Enrichment Conference}

Msn/Prg: LPI B/F

Theme(s): $\quad$ SSE

Description: The Lunar and Planetary Institute supported the Challenger Center Enrichment Conference, which was held in two overlapping sessions, August 6-9 and 9-12, 2000. The goal was to saturate attendees with the latest in space science and NASA projects. Thirty-four attendees from three countries and 17 U.S. states were representatives of the Challenger Learning Center and Educator Networks, and included Cassini, STARDUST, and GEM Fellows and two Teacher-in-Space finalists. LPI education staff presented a short lecture on the structure of the OSS Ecosystem and role of the Broker/Facilitator, distributed materials, and explored with the audience possibilities for collaborations and partnerships.

Lead:

LPI Broker/Facilitator, Lunar and Planetary Institute, Houston, TX 77058

Venue(s): $\quad$ Space Center Houston, Houston, TX 77258-0653

\section{Chandra Team Public Appearances}

Msr/Prg: $\quad$ SEU Forum, CXO

Theme(s): $\quad$ SEU

Description: Members of the Chandra science and engineering teams speak to a wide variety of audiences about the mission. Amateur and professional groups were reached, including the Amateur Telescope Makers of Boston, the Cape Ann Amateur Radio Association, the North Shore
Amateur Astronomy Club, the University of Arizona Astronomy Summer Camp, the Canadian Astronomical Society, and the Aspen Center for Physics. Senior citizens' groups, Boy Scouts, the Massachusetts Audubon Society also learned about Chandra. Several talks were given at professional facilities, including TRW, the McDonald Observatory, the University of Wisconsin at White Water, and the University of California at San Diego.

Lead: $\quad$ CXO E/PO Team, Harvard-Smithsonian Center for

Venue(s): Astrophysics, Cambridge, MA 02138

Gloucester, MA 01930 (Participants: 20 local) Groveland, MA 01834 (Participants: 45 local) Harvard, MA (Participants: 32 local) Aspen Center for Physics, Aspen, C0 81611 Boston Museum of Science, Boston, MA 02114-1099 (Participants: 480 local; 3 events) Canadian Astronomical Society, Vancouver, BC Congressional reception, Washington, DC Epcot, FL (Participants: 1500 local) Harvard-Smithsonian Center for Astrophysics, Cambridge, MA 02138 (Participants: 10 local) Ipswich River, Ipswich, MA 01938 (Participants: 50 local)

McDonald Observatory, Austin, TX 78712

New Hampshire Boy Scouts, Concord, NH 03301 (Participants: 30 local) TRW, Redondo Beach, CA 90277 (Participants: 400 local)

University of Arizona, Tucson, AZ 85721

University of California - San Diego, La Jolla, CA 92093-0424 (Participants: 100 local) University of Wisconsin at White Water, White Water, WI 53190 (Participants: 200 local)

\section{CONTOUR Talk}

$\begin{array}{ll}\text { Msn/Prg: } & \text { CONTOUR } \\ \text { Theme(s): } & \text { SSE }\end{array}$

Description: Don Yeomans made a presentation "Exploring Near-Earth Objects to the general public at Glendale Community College on January 21,2000 .
Lead:
CONTOUR E/PO Team, Space Telescope Science Institute, Baltimore, MO 21218
Venue(s): Glendale Community College, Glendale, CA 91208 (Participants: 150 local)

\section{Deep Impact Exhibits}

$\begin{array}{ll}\text { Msn/Prg: } & \text { Deep Impact } \\ \text { Theme(s): } & \text { SSE }\end{array}$

Description: The Deep Impact Mission is featured through some shortterm exhibits. These exhibits generally run in a public area for no more than three months and will be replaced by formal Deep Impact exhibits when they are available. 
Lead: Deep Impact E/PO Team, University of Maryland, College Park, MD 20742

Venue(s): Anne Arundel Community College, Arnold, MD 21012

\section{Deep Impact Team Speaking Engagements}

Msn/Prg: Deep Impact

Theme(s): $\quad$ SSE

Description: Project team members from the University of Maryland, NASA JPL, and extended locations have given several lectures, visits, demonstrations, or workshops during the year 2000 .

Lead: $\quad$ Deep Impact E/PO Team, University of Maryland, College Park, MD 20742

Venue(s): $\quad$ Ala Moana Hotel, Honolulu, HI 96822 (Participants: 200 local)

Astronomy Camp, Council Blufts, IA 50513

(Participants: 20 local)

Boulder Lion's Club, Boulder, CO (Participants: 12 local)

Denver Lion's Club, Denver, CO

Metro Rotary Club, Honolulu, HI 96822 (Participants:

75 local)

Museum of Natural History and Cormack Planetarium, Providence, RI 02905 (Participants: 75 local) NASA Jet Propulsion Laboratory, Pasadena, CA 91109 (Participants: 100 local)

University of Hawaii, Honolulu, HI 96822

Wheatland Elementary School, Wheatland, Wy

(Participants: 50 local)

\section{Deep Space Metwork Team Publlc Appearances}

\section{Msn/Prg: DSMS}

Theme(s): $\quad$ SSE

Description: Deep Space Network Managers gave presentations on this spacecraft communications network to Earth-based communicators, including the Corona-Norco (CA) Amateur Radio Club, the Riverside (CA) Amateur Radio Association, and the Quarter Century Wireless Association in Riverside.

Lead: $\quad$ DSMS E/PO Team, NASA Jet Propulsion Laboratory, Pasadena, CA 91109

Venue(s): $\quad$ Riverside, CA 92501 (Participants: 200 local)

Corona Senior Center, Corona, CA 92882

(Participants: 150 local)

LaSierra University Church, Riverside, CA 92503

(Participants: 120 local)

\section{Discovery Channel Store Star Party}

Msn/Prg: $\quad$ Cassini/Huygens Probe, Deep Impact

Theme(s): $\quad$ SSE
Description: This event included a lecture/slide presentation on astronomy and telescopic viewing of Jupiter and Saturn on the Promenade in Santa Monica, California.

Lead: $\quad$ Cassini E/PO Team, NASA Jet Propulsion Laboratory, Pasadena, CA 91109

Partner(s): Discovery Channel,

Venue(s): Discovery Channel Star Party, Santa Monica, CA

\section{Earth and Sky Radio Programs}

Msn/Prg: $\quad$ SSE Forum

Theme(s): $\quad$ SSE

Description: Twelve 90-second radio interviews on planetary science topics from JPL were prepared and are airing on "Earth and Sky," an award-winning daily science radio series heard by millions of listeners on over 950 commercial and public stations and their translators throughout the United States. Titles include "Return from Mars," "Red Scare?," "Ice Dwarves," "Europan Soup du Jour," "Geology Report," "View from a Comet," "Stardust," "A Ghostly Thing," "Avoiding Asteroids," "Mining Asteroids," "Building Blocks," and "Ra-Shalom." Eleven shows on Earth topics from NASA JPL were also prepared.

Lead: SSE Forum, NASA Jet Propulsion Laboratory, Pasadena, CA 91109

\section{Eclipse '99 and '01}

Msn/Prg: $\quad$ SEC Forum, HESSI, SOHO

Theme(s): $\quad$ SEC

Description: A total solar eclipse occurred in Europe and Asia on August 11,1999 . We used this event as a "hook" to introduce large numbers of the American public to NASA Sun-Earth Connection research. Museum events were held at eight museums around the country, including the Expłoratorium, LHS, National Air and Space Museum, and Denver Museum of Science. The events attracted up to 5,000 members of the general public, including $\mathbf{5 0 0}$ girl scouts who participated in overnight camp-in events and learned about space science, eclipses, and the Sun. Remotely over the Internet, 300,000 people enjoyed the eclipse Web cast from their home computers. During the two days surrounding the eclipse event, $10,000,000$ hits were received on the Eclipse Web site. Plans are being made for similar events connected with the total solar eclipse in southern Africa on June 21, 2001.

Lead: $\quad$ SEC Forum Space Sciences Laboratory, University of California, Berkeley, CA 94720

Venue(s): Denver Museum of Nature and Science, Denver, CO 80205

Exploratorium, San Francisco, CA 94123 (Participants: 2500 local, 300000 remote)

Lawrence Hall of Science, Berkeley, CA 94720

(Participants: $\mathbf{4 0 0}$ local)

National Air and Space Museum, Washington, DC 20560-0321 (Participants: 100 local) 


\section{Engaging Challenger Center's Space Science Researchers in Highly Leveraged National Education and Public Outreach}

Msn/Prg: $\quad$ OSS

Description: In order to ensure that all of its E/PO initiatives include a strong space science component, reflect the experience of researchers, and are scientifically accurate, the Challenger Center has established an in-house Space Science Research (SSR) department. Within this department, the staff splits its time between research supported by various sources and E/PO activities supported by NASA's Office of Space Science. A major component of these activities is "Window on the Universe," an initiative to build a network of 15 underserved communities committed to sustained, community-wide science, math, and technology education. "Window" communities are visited by a national team of researchers and educators for a week of activities that include educator training, family science nights, and researcher visits to classrooms. The core goal is to provide an entire community with a window on the research experience, the process of science, and the lives of researchers.

$\begin{array}{ll}\text { Lead: } & \text { Or. Jeff Goldstein, Challenger Center for Space } \\ & \text { Science Education, Alexandria, VA 22314 } \\ \text { Venue(s): } & \text { Challenger Center for Space Science Education, } \\ & \text { Alexandria, VA 22314 }\end{array}$

\section{Explorel}

Msn/Prg: LPI B/F

Theme(s): $\quad$ SSE

Description: The "Explore!" program was developed to facilitate distribution of basic space science information and related NASA materials, utilizing the highly leveraged public library systems. Libraries have long provided essential learning resources that strengthen and perpetuate formal and informal education. NASA materials can be utilized, organized, and distributed nationwide to a broad spectrum of the populace. "Fun with Science" was developed as a new and exciting way to team public libraries, community sponsors, and scientists to bring space science to the community. Targeted to preteen youth, Fun with Science explores scientific concepts through directed experiments in an inquiry-based approach.

Lead: $\quad$ LPI Broker/Facilitator, Lunar and Planetary Institute, Houston, TX 77058

Venue(s): $\quad$ Alexandria Convention Center, Alexandria, LA 71301 (Participants: 600 local)

Brown Convention Center, Houston, TX 77010

(Participants: 8000 local)

East Baton Rouge Library, East Baton Rouge, LA

70812 (Participants: 27 local)

Houston Public Library, Houston, TX 77002-2534

(Participants: 18 local)

Lunar and Planetary Institute, Houston, TX 77058

(Participants: 22 local)

\section{Genesis Family Night}

Msn/Prg: Genesis

Theme(s): $\quad$ SEC

Description: The family night with Genesis is meant to inform the parents about NASA space science and to encourage partnerships within NASA and schools.

$\begin{array}{ll}\text { Lead: } & \text { Genesis E/PO Team, NASA Jet Propulsion Laboratory, } \\ & \text { Pasadena, CA } 91109 \\ \text { Venue(s): } & \text { Jefferson Elementary School, Pasadena, CA } 91050 \\ & \text { (Participants: } 300 \text { local) }\end{array}$

\section{Interviow for Future Watch}

Msn/Prg: NAI

Theme(s): $\quad$ ASO

Description: Dr. Gene McDonald gave an interview for Future Watch radio/TV program at Cal Poly Pomona in which he discussed astrobiology and future space exploration.

Lead: $\quad$ Astrobiology Institute E/PO Team, NASA Ames Research Center, Moffett Field, CA 94035

Venue(s): $\quad$ California State Polytechnic University, Pomona, CA 91768

\section{Johns Hopkins University Applled Physics Laboratory Open House}

Msn/Prg: CONTOUR, MESSENGER, NEAR

Theme(s): $\quad$ SSE

Description: JHU/APL Family Day 0pen House on May 2, 2000. Space Department Exhibits focused on NEAR, MESSENGER, and CONTOUR. Kerri Beisser, JHU/APL E/PO, was the deputy Space Department Organizer.

Lead: $\quad$ CONTOUR E/PO Team, Space Telescope Science Institute, Baltimore, MD 21218

Venue(s): $\quad$ Applied Physics Laboratory, Laurel, MD 20723 (Participants: 2000 local)

MAP Team Public Appearances

Msn/Prg: MAP

Theme(s): $\quad$ SEU

Description: MAP team members gave talks on the mission, the cosmic microwave background, and cosmology.

Lead: $\quad$ MAP E/PO Team, Adler Planetarium and Astronomy Museum, Chicago, IL 60605

Venue(s): $\quad$ Montgomery College, Germantown, MD 20876 Montgomery High School, Germantown, MD Old Bridge High School, Old Bridge, NJ 08857 (2 events) 
SAS, Providence, Rl 02901

Skyscrapers Astronomical Society, Providence, Rl

\section{Mars Girl Scouts}

Msn/Prg: $\quad$ IDEAS

Description: The team conducted one of many short courses being offered as a part of a Saturday devoted to professional development of Mile-Hi troop leaders. In the troop leader workshop, an alpha version of an astronomy resource guide for troop leaders was distributed to support their efforts in conducting activities with their girls that would lead to earning the junior astronomy badge called Sky Search.

Lead: Dr. Cherilynn Morrow, Space Science Institute, Boulder, CO 80303

Venue(s): $\quad$ Space Science Institute, Boulder, CO 80303-1058 (Participants: 45 local)

\section{NASA Goddard Community Day}

$\begin{array}{ll}\text { Msn/Prg: } & \text { SEC Forum } \\ \text { Theme(s): } & \text { SEC }\end{array}$

Description: Supported SECEF/SEC booth for Goddard Community Day 2000.

Lead: $\quad$ SEC Forum, NASA Goddard Space Flight Center, Greenbelt, MD 20771

Venue(s): $\quad$ NASA Goddard Space Flight Center, Greenbelt, MD 20771

\section{MASA JPL Open House}

Msn/Prg:

SIM, SIRTF, Ulysses, Voyager, CONTOUR, Deep Impact, NEAR, Stardust, DS-1, DSMS, MUSES-CN, Rosetta

Theme(s): ASO, SEC, SSE

Description: The Annual NASA JPL Open House for the community ran for two days (June 3-4, 2000), and approximately 45,000 people attended the event. The Deep Space Network had two booths. SIM field-tested new hands on activities with 300 participants at our booth. SIRTF had an interactive booth about infrared astronomy, using the color infrared camera and new infrared video.

Lead: $\quad$ SSE Forum, NASA Jet Propulsion Laboratory Pasadena, CA 91109

Venue(s): $\quad$ NASA Jet Propulsion Laboratory, Pasadena, CA 91109 (Participants: 40000 local)

MASA JSC Astromaterlals Medla and Tours

Msn/Prg: NAI, Sample Curation

Theme(s): $\quad$ SSE

Description: NASA JSC Astromaterials curation, E/PO, and Astrobiology teams provided numerous tours of the lunar and meteorite curation facil- ity for the following E/PO groups: 16 film crews preparing educational TV (like NOVA, Discovery Channel, BBC, NHK); 86 VIPS; 24 teachers; 37 researchers; 103 college students; and 42 pre-college students. We hosted an artist preparing a space drama. The Lunar Lab Visitor Viewing Area was open to the public for the NASA JSC Open House and Inspection.

Lead: $\quad$ Sample Curation E/PO Team, NASA Johnson Space Center, Houston, TX 77058

Venue(s): $\quad$ NASA Johnson Space Center, Houston, TX 77058

\section{NEAR Exhlbit at Anne Arundel Community College}

Msn/Prg: $\quad$ NEAR

Theme(s): $\quad$ SSE

Description: NEAR Exhibit by Beth Huffnagel, Anne Arundel Community College, Arnold, Maryland.

Lead: $\quad$ NEAR E/PO Team, Johns Hopkins University Applied Physics Laboratory, Laurel, MD 20723-6099

Venue(s): $\quad$ Anne Arundel Community College, Arnold, MD 21012

\section{MEAR Shoemaker Facllity Tours}

Msn/Prg: NEAR

Theme(s): $\quad$ SSE

Description: Visitors to JHU/APL learned about the NEAR mission from the scientists and engineers charged with carrying out the mission and visited the cleanroom and mission operations. The individual tour groups included Rotary International, Society of Women Engineers, Hagerstown Community College, Technical University of Munich, and the Oil City (PA) Young Astronauts group.

$\begin{array}{ll}\text { Lead: } & \text { NEAR E/PO Team, Johns Hopkins University Applied } \\ & \text { Physics Laboratory, Laurel, MD 20723-6099 } \\ \text { Venue(s): } & \text { Applied Physics Laboratory, Laurel, MD } 20723 \\ & \text { (Participants: } 136 \text { local; } 5 \text { events) }\end{array}$

\section{NEAR Shoemaker Public Team Appearances}

Msn/Prg: NEAR

Description: Scientists and engineers from the NEAR Shoemaker Team imparted their knowledge to a variety of public audiences. Youth groups were reached through several talks with Cub Scouts, Boy Scouts, Girl Scout Brownies, and older Girl Scouts. Adult special interest groups reached included the Portland (ME) Rotary Club, the men's club of the Evangelical Lutheran Church (MD), a professional journalist group from the PEW Fellowship in International Journalism, the Washington (DC) Area Astronomers, and Planetary Society (MD) members and general public, and attendees at a Glendale (CA) Community College lecture. Materials were sent in support of the Challenger Center for Space Science "Window on the Universe" program, and the AIAA Paper Airplane Contest at the Baltimore Museum of Industry. 
Lead: $\quad$ NEAR E/PO Team, Johns Hopkins University Applied Physics Laboratory, Laurel, MD 20723-6099

Venue(s): $\quad$ Applied Physics Laboratory, Laurel, MD 20723 (Participants: 110 local; 3 events)

Baltimore Museum of Industry, Baltimore, MO 21230

(Participants: 100 local)

Boy Scouts (School), Ellicott City, MD 21043

(Participants: 15 local)

Brownie Scouts, Laurel, MD 20723 (Participants: 14 local)

Clarksville Elementary School, Clarksville, MD 21029

(Participants: 60 local)

Evangelical Lutheran, Frederick, MD 21701

(Participants: 10 local)

Glendale Community College, Glendale, CA 91208

(Participants: 10 local)

Rotary Club, Portland, ME (Participants: 135 local)

U.S. Naval Observatory, Washington, DC 20392

(Participants: 100 local)

\section{MEAR/CONTOUR Exhibit}

$\begin{array}{ll}\text { Msn/Prg: } & \text { CONTOUR, NEAR } \\ \text { Theme(s): } & \text { SSE }\end{array}$

Description: Kerri Beisser E/PO, JHU/APL had an exhibit set up at the Maryland Excellence Conference on NEAR and CONTOUR. This included U.S. Senate Productivity awards by Senator Mikulski and Senator Sarbanes. This event was "A Collaborative Celebration of Organizational Excellence," recognizing the achievements of exemplary organizations in Maryland. This Maryland Excellence Conference was held at JHU/APL.

Lead: $\quad$ NEAR E/PO Team, Johns Hopkins University Applied Physics Laboratory, Laurel, MD 20723-6099

Venue(s): $\quad$ Maryland Excellence Conference, Laurel, MD 20723

\section{Open Might at the Space Telescope Science Insthtute}

Msn/Prg: $\quad$ HST

Theme(s): $\quad$ ASO

Description: Free public lectures at the Space Telescope Science Institute (STScl). Each month a noted scientist discusses a different cosmic topic.

Lead: $\quad$ Office of Public Outreach, Space Telescope Science Institute, Baltimore, MD 21218

Venue(s): $\quad$ Space Telescope Science Institute, Baltimore, MD 21218

\section{Origins Publlc Outreach Exhiblt}

Msn/Prg: $\quad$ ASO Forum, HST

Theme(s): $\quad$ ASO

Description: "AARP Celebrates 2000" was the biennial convention for the American Association of Retired Persons. The Origins booth was present. Origins staff distributed materials and discussed the Origins Program and the Origins Education Forum with convention attendees. Origins/HST staff included Terry Teays, Bonnie Eisenhamer, Denise Smith, Dan McCallister, Heather Bradbury, and Robert Staley.

Lead: $\quad$ ASO Forum, Space Telescope Science Institute, Baltimore, MD 21218

Venue(s): $\quad$ American Association of Retired Persons (AARP), May 2000, Orlando, FL 32819

OSS Exhibit at American Association of Retired Persons (AARP)

Msn/Prg: Cassini/Huygens Probe, 0SS

Theme(s): $\quad$ SSE

Description: AARP is the Nation's leading organization for people $\mathbf{5 0}$ and older. NASA has a major presence as an exhibitor at this biannual convention. Along with the Code $S$ exhibit, Cassini had a hologram displayed on the exhibit floor.

Lead: $\quad$ OSS, NASA Headquarters, Washington, DC 20546

Venue(s): $\quad$ American Association of Retired Persons (AARP), May 2000, Orlando, FL 32819

\section{Passport to Knowledge}

Msn/Prg: $\quad$ OSS

Theme(s): $\quad$ SEC

Description: During the second year of a continuing grant, PASSPORT TO KNOWLEDGE (P2K) produced and distributed three new hour-long videos: "LIVE FROM THE SUN 2000: To The Max," focusing on the science of the solar cycle, and two "LIVE FROM THE STORM" programs, featuring NASA researchers associated with the TRMM spacecraft as well as other NASA satellite imagery. The programs aired over participating PBS stations and NASA-TV and were supported by both real-time and asynchronous interaction via the Internet with NASA and other researchers. The two "STORM" programs are part of "PASSPORT TO WEATHER AND CLIMATE," a new multiple-media educational actlvity which debuted in this grant period and which also includes a printed Teacher's Guide and full-featured Web site, with video, print, and online components. All P2K materials provide correlation between the videos, hands-on, and online activities and resources and the National Science Education Standards/AAAS "Benchmarks."

Lead: Geoff Haines-Stiles, Geoff Haines-Stiles Productions,

Inc., Morristown, NJ 07960

Venue(s): $\quad$ Public Broadcasting System

\section{PlanetFest'9g}
Msn/Prg: Cassini/Huygens Probe, Galileo, Voyager, Stardust, Mars, DS-1, DSMS, MUSES-CN
Theme(s): $\quad$ SSE

Description: On December 3-5, 1999, PlanetFest '99 was held in the Pasadena Convention Center. NASA JPL had an entire section reserved. 
PlanetFest was held in conjunction with the Mars Polar Lander and DS-2 missions' final approach to Mars.

$\begin{array}{ll}\text { Lead: } & \text { New Millenium E/P0 Team, NASA Jet Propulsion } \\ & \text { Laboratory, Pasadena, CA } 91109 \\ \text { Venue(s): } & \text { PlanetFest '99, Pasadena, CA } 91101 \text { (Participants: } \\ & 4000 \text { local) }\end{array}$

\section{Quest Web Cast}

Msn/Prg: $\quad$ SOFIA

Theme(s): $\quad$ ASO

Description: The Quest program at NASA Ames Research Center conducts Web casts with scientists and engineers. Participants include schools and the public.

Lead:

SOFIA E/PO Team, NASA Ames Research Center, Moffett Field, CA 94035

\section{Royal Astronomical Soclety of Canada General Assembly}

Msn/Prg: Cassini/Huygens Probe

Theme(s): $\quad$ SSE

Description: The first event was an invited presentation on the developments in cometary astronomy since Comet Halley's return in 1986. The second event was a performance by the Cassini Virtual Singers (one member, drafting RASC participants). The regular singers are a group of Cassini Program scientists, engineers, technicians, and support staff who enjoy modifying the lyrics of familiar songs into lyrics apropos to Cassini and planetary exploration. This was a public performance (as opposed to in-house), with suitable introductions and explanations made to the audience.

Lead: $\quad$ Cassini E/PO Team, NASA Jet Propulsion Laboratory, Pasadena, CA 91109

Venue(s): Royal Astronomical Society of Canada General Assembly, Winnipeg, Canada

\section{Sample Curation Exhibit at Planetfest 'g9}

$\begin{array}{ll}\text { Msn/Prg: } & \text { NAl, Sample Curation } \\ \text { Theme(s): } & \text { SSE }\end{array}$

Description: Our exhibit focused on NASA JSC's contributions to curation and studies of rocks from space, especially from Mars. A Mars meteorite was displayed, and four scientists supported the exhibit, including Dave McKay and Everett Gibson, who were also keynote speakers at the conference.

$\begin{array}{ll}\text { Lead: } & \text { Sample Curation E/P0 Team, NASA Johnson Space } \\ & \text { Center, Houston, TX 77058 } \\ \text { Venue(s): } & \text { PlanetFest '99, Pasadena, CA } 91101\end{array}$

San Mateo Astronomical Society

$\begin{array}{ll}\text { Msn/Prg: } & \text { Yohkoh } \\ \text { Theme(s): } & \text { SEC }\end{array}$

Description: Presentation about the use of the Sun as a topic within a classroom setting.

Lead: $\quad$ Yokoh E/P0 Team, Lockheed Martin Solar and

Venue(s): $\quad$ Astronomical Society, San Mateo, CA 94304

(Participants: 100 local)

\section{Science Education Web Stte Developers Conference}

Msn/Prg: $\quad$ HST

Theme(s): $\quad$ ASO

Description: This was the first conference of this sort. Funded by $D O E$, it brought together a representative from 25 of the top science education Web sites (as selected by the Local Organizing Committee) in the country. HST's "Amazing Space" was one of the selected sites. Teays was invited to give two presentations. This was very much a "nuts and bolts" practitioners' meeting, with a lot of practical discussion of how to develop and operate a science education Web site.

$\begin{array}{ll}\text { Lead: } & \text { HST E/PO Team, Space Telescope Science Institute, } \\ & \text { Baltimore, MD } 21218 \\ \text { Venue(s): } & \text { Eccles Institute, Salt Lake City, UT 84112-5330 }\end{array}$

SOFIA Open House at Raytheon, Waco, TX

Msn/Prg: $\quad$ SOFIA

Theme(s): $\quad$ ASO

Description: Raytheon Aircraft Integration Systems (RAIS) of Waco, TX, hosted a community open house for SOFIA. RAIS is modifying the Boeing $747 \mathrm{SP}$ that will be SOFIA, and the open house was held in conjunction with an on site briefing tour for NASA headquarters staff. Dr. Ed Weiler participated in the public events, and was very well received by the Waco community.

$\begin{array}{ll}\text { Lead: } & \text { SOFIA E/PO Team, NASA Ames Research Center, } \\ & \text { Moffett Field, CA } 94035 \\ \text { Venue(s): } & \text { Raytheon AIS, Waco, TX } 76705\end{array}$

Solar System Ambassadors

Msn/Prg: $\quad$ SIRTF, NAl, Keck, Solar Probe, Ulysses, Cassini/Huygens Probe, Galileo, Voyager, Deep Impact, Stardust, Mars, OP/SP, Pluto/Kuiper Express, DS-1, DSMS, Lunar Prospector

Description: The Solar System Ambassadors Program is a public outreach program designed to work with motivated volunteers across the Nation. Those volunteers organize and conduct public events that communicate exciting discoveries and plans in Solar System research, exploration, and 
technology through non-traditional forums, e.g., community service clubs, libraries, museums, planetariums, star parties, and mall displays. Ambassadors are space enthusiasts, $\mathrm{K}-12$ in-service educators, retirees, community college teachers, and other members of the general public interested in providing greater service and inspiration to the community at large. During 2000, Ambassadors conducted approximately 600 events that directly reached more than one-half million people in communities across the United States.

Lead: $\quad$ Solar System Ambassadars, NASA Jet Propulsion Laboratory, Pasadena, CA 91109

Venue(s): $\quad$ Bridgewater, NJ 08807

Sutherlin, OR 97479 (10 events)

Gloucester, MA 01930 (2 events)

Bridgewater, NJ 08807 (Participants: 50 local; 3

events)

Gloucester, MA 01930 (3 events)

"Astronomical Moments" cable TV program, Hastings,

MN 55033 (Participants: 2000 local, 1000 remote; 2

events)

Adler Planetarium and Astronomy Museum, Chicago,

IL 60605 (3 events)

Ahwatukee Community Center, Phoenix, AZ 85044

Alabama Math/Science/Technology/Education

Coalition, Huntsville, AL 35810

Altamont Tri County Fair, Altamont, NY 12009

(Participants: 350 local)

Ambassador Resource Web Site, Ypsilanti, Ml 48197

(Participants: 375 remote)

American Institute of Petroleum Geologists, Casper, Wr 82609 (2 events)

Anderson College, Anderson, SC 29721

Andrews ISD Planetarium, Andrews, TX 79714

Andrews Middle School, Andrews, TX 79714 (3

events)

Animas Public Schools, Animas, NM 88311

Arizona State University, Tempe, AZ 85287 (5 events)

Armadillocon 22 Science Fiction Convention, Austin,

TX 78741

Association of Physics Teachers-New York

University, New York, NY 10012

Astronauts Memorial Foundation, Cocoa Beach, FL

32931

Astronomical Society of the Palm Beaches, West Palm

Beach, FL 33408 (2 events)

Astronomy Camp, Council Bluffs, IA 50513 (2 events)

Astronomy Club, Grand Junction, C0 81501

Aurora University, Aurora, IL 60504

Aviation Club, Council Bluffs, IA 50513

Aviva Hills School Science Day, San Marcos, CA

92069

Barnes and Noble, Jenkintown, PA 19046

BayCon Science Fiction Convention, San Francisco,

CA 94101

Belevedere School, Council Bluffs, IA 50513

Berne-Knox-Westerlo Middle School, Berne, NY

12023
Blair School, Council Bluffs, IA 50513

Blue Hills School, Ft. Osage, MO 64088

Borders Books, Niles, $0 \mathrm{OH} 44446$ (Participants: 50

local; 2 events)

Boston Museum of Science, Boston, MA 02114-1099

Boy Scout Troop 820, Caldwell, NC 27278

Boy Scouts and 4-H Club, Leonardtown, MD 20650

Breisenmeister Intermediate School Science Club,

Seguin, TX 78155 ( 3 events)

Brownsville Public Library, Brownsville, TX 78520

BSA National Camp (Western Region), Camp Lost

Valley, CA 92060

Bushnell Company Astronomy Night, Overland Park, KS 66214

Camden County Library, Voornees, NJ 08043

Camp Twin Echo, Greater Pittsburgh Council, BSA,

Pittsburgh, PA 15944

Camp Wildwood Family Camp, Independence, M0

64055

Canton Lions Club, Canton, NY 13617

Capricon Science, Arlington Park, IL 61312

Carrboro Public Library, Carrboro, NC 27510

Casper Planetarium, Casper, WY 82601 (7 events)

Casper Planetarium, Ethete, WY 82520

Casper Planetarium, Ft. Washakie, Wr 82514

Centerplace Restoration, Independence, M0 64050

Central High School, Council Bluffs, IA 50513

Channel 2 Morning Show (WB2day), Denver, CO

80205 (Participants: 20000 remote)

Chicon 2000: The World Science Fiction Convention,

Chicago, IL 60601 (5 events)

Children's World Learning Center, Phoenix, AZ 85044

Christian Academy, Council Bluffs, IA 50513

Cincinnati Observatory Center, Cincinnati, OH 45201

( 3 events)

Civil Air Patrol, Grand Junction, CO 81501 (2 events)

Civil Air Patrol Cadets Encampment, French Camp, CA 95231

Civil Air Patrol Squad, Stockton, CA 95206 (2 events)

Clackamas Community College, Oregon City, $\mathrm{OR}$

97045 (2 events)

Clackamas Town Center Mall, Portland, OR 97266 (3

events)

Club Shoshone, Granada Hills, CA 91344 (2 events)

Coatesville Cub Scouts, Coatesville, PA 19358

Colorado Scientific Society, Denver, C0 80014

Conclave Science, Lansing, M| 48901

Corning Community College, Corning, NY 14830

Council Bluffs School, Council Bluffs, IA 50513

Coyote Valley Elementary Schoot Girl Scouts,

Middletown, CA 9546

Creighton University Seminar, Creighton, NE 68729

Crossroads Astronomy Club, Victoria, TX 77901 (7)

events)

Da Vinci Society Night, Albuquerque, NM 87104

Del Amo Mall, Torrance, CA 90501

Delaura Middle School, Satellite Beach, FL 32901 
Denver Museum of Nature and Science, Denver, CO

80205 (7 events)

Desert Pacific Council's Boy Scout Camp (Mataguay

Scout Res), Santa Ysabel, CA 92070

Drake Planetarium, Cincinnati, OH 41001 (2 events)

Drake Planetarium, Cincinnati, $\mathrm{OH} 41042$ (2 events)

Drake Planetarium, Cincinnati, $\mathrm{OH} 45212$ (4 events)

Dreyfus Planetarium, Newark, NJ 07101

Dundee School, Council Bluffs, IA 50513

Eagle Optics Star Party, Madison, WI 53562

East Valley Astronomy Club, Scottsdale, AZ 85256 (6

events)

Educator Conference, Houston, TX 77058

El Camino College Planetarium, Torrance, CA 90504

Elmira-Corning Astronomical Society-Corning

Community College, Corning, NY 14830 (2 events)

Emergency Operations Center, Laurens, SC 29360

Empire State Aerosciences Museum, Glenville, NY

12302

Ethical Society, Philadelphia, PA 19101 (2 events)

Exchange Club Meeting, Houston, MS 38851

Flandrau Science Center, Tucson, AZ 85721 (2 events)

Fleming Middle School, Grants Pass, OR 97526

Florida Fish and Wildlife Conservation Commission,

West Palm Beach, FL 33416

Florida Institute of Technology, Melbourne, FL 32901

(3 events)

Fort Calhoun School, Council Blufts, IA 50513

Fort Vannoy Elementary School, Grants Pass, OR

97526

Franklin Institute Science Museum, Philadelphia, PA

19103 (12 events)

Fullerton College, Fullerton, CA 92832 (4 events)

Garfield School, Casper, WY 82609

GATE Class, Middleton, CA 94561

Geological Society of the Oregon Country Portland

State University, Portland, OR 97207-0751

Georgia Southern University, Statesboro, GA 30460 (4

events)

Georgia State University, Statesboro, GA 30460 (6

events)

Girl Scout House, Voorheesville, NY 12186

Glendale Community College, Glendale, AZ 85302

Glenview Public Access TV, Glenview, IL 60025

Glenview Public Library, Glenview, IL 60025

Goose Creek State Park, Washington, NC 27889

Grand Canyon Star Party, Grand Canyon, AZ 86023

Greenville Public Library, Greenville, SC 29601

Greenville Public Library, Greenville, SC 29601

Guest Lecture to Freshman Seminar, Melbourne, FL 32901

Gulf Coast Council Boy Scout Winter Camp, Mathis, TX 79368

Hamburg State Park, Mitchell, GA 30820

Hayes Middle School, Albuquerque, NM 87110

Helix High Astronomy Club, La Mesa, CA 91941

Highland Park High School, Highland Park, NJ 08904
Hillsborough Elementary School, Hillsborough, NJ 08876 (Participants: 120 local) Home School Group, Council Bluffs, IA 50513 (2 events)

Home School Science Fair/Science Day, Ontario, CA 91758 Homeschooler Parents, Stockton, CA 95206 Hudson Elementary, Hudson, WY 82515 IMAX Theatre, Tempe, AZ 85282 Immanual Baptist Church, Independence, M0 64052 Indian Prairie School District 204 Science Fair Day, Aurora, IL 60504

Interested Students and Parents, East Machias, ME 04630

International Association, Denver, CO 80126

(Participants: 3000 remote)

Jetty Park, Cocoa Beach, FL 32931

Jewish Community Day School, Durham, NC 27705

Johns Hopkins Univ CTY program at UC Santa Cruz,

Santa Cruz, CA 95060

Juan de Fuca Festival, Port Angeles, WA 98362

Kamahameha Elementary School, Honolulu, HI 96819 Kansas Astronomical Observers, Wichita, KS 67201

Kilohana Elementary School, Island of Molokai,

Kilohana, HI 96749

Kiwanis Central, Council Bluffs, IA 50513

Kiwanis Club, Wichita, KS 67201

Kiwanis South, Council Bluffs, IA 50513

Kiwanis West, Council Bluffs, IA 50513

Kopernik Space Education Center, Vestal, NY 13850 (4

\section{events)}

Lake Afton Public Observatory, Wichita, KS 67201 (11

events)

Lake Erie Nature and Science Center, Bay Village, $\mathrm{OH}$

\section{0}

Lake Kissimmee State Park's 7th Annual Star Party, Lake Wales, FL 33853

Lake Texana State Park, Edna, TX 77957 (2 events)

Lakeland College, Howards Grove, WI 53083

Lakeviw Community Library, Random Lake, WI

53075-1708

Laramie County Public Library, Laramie, WY 82001

Laurens Amateur Radio Club, Laurens, SC 29360

Lawrence Livermore National Laboratory, Berkeley,

CA 94701

Liberal Arts, Science and Engineering Research

(LASER) Day, Melbourne, FL 32901

Lincolnwood Public Library, Lincolnwood, IL 60007

Lion Country Safari, West Palm Beach, FL 33415

Lions Central, Council Bluffs, IA 50513

Lions West, Council Bluffs, IA 50513

Loblolly Observatory, Nursery, TX 77976 (2 events)

Lockheed Martin Space Voyage Camp, Denver, CO

80236

Lothrup School, Council Bluffs, IA 50513

Luff Elementary School, Independence, M0 64055

Lyme School, Lyme, NH 03768 
Mahoning County Fair, Canfield, $\mathrm{OH} 44406$

(Participants: 200 local)

Mahoning Valley Parent Kidzette Section-Around the

Universe, Boardman, OH 44512 (Participants: 3000

local; 7 events)

Maine Math and Science Alliance, Brunswick, ME

04011

Manzanita Elementary School, Grants Pass, OR 97526

Mark Sylvestre Planetarium, Plymouth State College,

Plymouth, NH 03264 (5 events)

Mars Fest at Los Alamos, Los Alamos, NM 87111

Massena Library, Massena, NY 13662

Maywood Environmental Center, Sheboygan, WI

53081

McMann School, Council Bluffs, IA 50513

Meridian Community College, Meridian, MS 39301

Mesa County Public Library, Grand Junction, CO

81501

Mid-South Star Astronomy Conference 2000, French

Camp, MS 39745 (3 events)

Middlesex High School, Middlesex, NJ 08846

Middletown Times Star, Middletown, CA 95461

Middletown Unified School District Teachers,

Middleton, CA 95461

Midlands Astronomy Club, Columbia, SC 29201

Mill Creek Elementary School, Independence, M0

64050

Millennium Women in Science- Math and

Engineering Day, Anchorage, AK 99501

Minicon Science, Minneapolis, MN 55401

Minnesota Public Radio, St. Paul, MN 55101

(Participants: 25000 local, 25000 remote)

Mitchell Elementary School, Albuquerque, NM 87111

(2 events)

Mokena Public Library, Mokena, IL 60448

Moreland Public Library, Philadelphia, PA 19090

Morrow Observatory, Bedford, IN 47421 (18 events)

Morton Grove Public Library, Morton Grove, IL 60053

Mount Hood Community College Planetarium,

Gresham, OR 97030 ( 3 events)

MST 2000 Conference, Binghamton, NY 13901

Mt. Tabor Middle School, Portland, OR 97215

Museum of Science and History, Jacksonville, FL 32207 (Participants: 2000 local; 7 events)

Museum of Science and Industry, Chicago, IL 60637

(2 events)

Naperville Astronomical Society, Naperville, IL 60540

NASA Jet Propulsion Laboratory, Pasadena, CA 91109

(4 events)

National Academy of Science, Philadelphia, PA 19103

National Atomic Museum, Albuquerque, NM 87185 (3

events)

National Science Teachers Association (NSTA)

Western Area, December 1999, Reno, NV 89509

National Science Teachers Association (NSTA), April

2000, Orlando, FL 32819 (2 events)
National Severe Storms Laboratory, Norman, OK 73071 ( 3 events)

National Space Society/Mars Society Wichita Chapter, Wichita, KS 67201

Navy League Armed Forces Day Observance at the

Del Amo Mall, Torrance, CA 90503 (2 events)

New Jersey State Museum \& Planetarium, Trenton, NJ 08625

New Mexico Museum of Natural History and Science, Albuquerque, NM 87104

New Mexico Space Society General Meeting,

Albuquerque, NM 87109 ( 3 events)

North Carolina A\&T University, Greensboro, NC 27401

North Georgia College and State University,

Dahlonega, GA 30597 (2 events)

North High School, Council Bluffs, IA 50513

North Hills High School Planetarium, Pittsburgh, PA

15229 (3 events)

North Pennsylvania Senior Center, Philadelphia, PA

19103

Olympic National Park, Port Angeles, WA 98362 (3

events)

Omaha Symphony, Omaha, NE 68101

Orange County Science Education Association 1999

Fall, Orange, CA 92866

Oregon Museum of Science and Industry, Portland,

OR 97214-3354 (2 events)

Oregon Science Teachers Association, Hood River, OR 97031

Ott Staff Development Center, Akron, $\mathrm{OH} 44301$ (3 events)

Palatine School, Palatine, IL 60067

Palm Glades Girt Scout Council Camp Welaka, Hobe

Sound, FL 33455

Palo Verde Middle School Community Science Night, Phoenix, AZ 85052

Parnell Elementary School, Parnell, W1 53073

Paulucci Planetarium, University of Minnesota at

Duluth, Duluth, MN 55810 (2 events)

PENC North Piedmont Chapter, Greensboro, NC 27401

Peoria Country Club, Peoria, AZ 85381

Pima Air and Space Museum, Tucson, AZ 85719

Pines of North Carolina Girl Scout Camp, Selma, NC 27576 (2 events)

Planetarium-Uno, Council Bluffs, IA 50513 (4 events) Portable Drake Planetarium-Outreach, Cincinnati, OH 45227 (2 events)

Portable Drake Planetarium-Outreach, Cincinnati, $\mathrm{OH} 41042$

Preceptor Delta lota, Lawson, M0 64062

Professional Engineers of NC, PENC 2000

Professional Dev Con, Greensboro, NC 27401

Professional Engineers of North Carolina, Greenville,

NC 27833

Rainwater Planetarium and Observatory, French

Camp, MS 39745 (5 events) 
Raritan Valley Community College, Somerville, $\mathrm{NJ}$

08876

Regional Alabama Science Teacher Convention,

Birmingham, AL 35210

Reynolds School, Tucson, AZ 85730

Rittenhouse City Institute Library, Philadelphia, PA

19101

Ritter Planetarium, Toledo, OH 43606

Riverside City Park, Victoria, TX 77901

Riverside Military Academy, Gainesville, GA 30310 (2

events)

Rolling Meadows School, Rolling Meadows, IL 60008

Rotary Club North, Council Bluffs, IA 50513

Rotary Club South, Council Bluffs, IA 50513 (2 events)

Rotary Main, Council Bluffs, IA 50513

Rotary SAC, Council Bluffs, IA 50513

Russell C. Davis Planetarium, Jackson, MS 39201 -

4115

Rutland Intermediate School, Rutland, VT 05701

Ryan's Restaurant, Laurens, SC 29360

San Diego Astronomy Association, San Diego, CA

92191 (2 events)

San Diego State University, San Diego, CA 92182

School, Tamarac, FL 33319 (3 events)

Sci-Quest Open House, Huntsville, AL 35810

Science Fiction Convention, Fairfield, CA 94533

Science PLUS Institute Teachers/Roper Mountain

Science, Greenville, SC 29601 (2 events)

Science Teachers Association of New York, Ellenville,

NY 12428

SciTech interactive, Aurora, IL 60504

Scobee Planetarium, San Antonio, TX 78212

Seipelt Elementary School, Milford, $\mathrm{OH} \mathbf{4 5 1 5 0}$

Sheboygan Memorial Mall National Astronomy Day,

Sheboygan, WI 53081

Shrine Luncheon, Tucson, AZ 85719

Sociedad Astronomica de Baja Califomia Cultural

Center, Tijuana, Mexico

Society of Women Engineers, Glendale, AZ 85052

Somerset County 4-H Fair, Bridgewater, NJ 08807

South Carlsbad State Beach Park, South Carlsbad, CA 92009

South Florida Science Museum, West Palm Beach, FL 33405 ( 3 events)

Space Center, Alamagordo, NM 88311 (10 events)

Space Center, San Antonio, TX 78248

Space Shuttle Launch, Titusville, FL 32780

St. Ann's Catholic Church, Wichita, KS 67201

St. Cecelia School, Council Bluffs, IA 50513

St. George School, Council Bluffs, IA 50513

St. James School, Council Bluffs, IA 50513

Stardust/Seminole Star Party, Tamarac, FL 33319

Stargazers Rambles, USAF Academy, CO 80901

(Participants: 250 local; 5 events)

State University NY at Albany, Albany, NY 12110

STEP Technology, Porttand, OR 97219 (2 events)

Success by Six, Columbus, GA 31829
Sunriver Nature Center Observatory, Sunriver, OR 97707 (19 events)

Sunset Astronomical Society Star Party, Saginaw

Township, Ml 48601

Super Science Weekend, Trenton, NJ 08625 (2

events)

Taylor Elementary School, Cincinnati, OH 45251

Taylor Observatory, Kelseyville, CA 95451

Teacher Workshop, Aroostock County, ME 04769

Temple University Ambler Campus, Philadelphia, PA

19002

Texas Education Agency Technology Conference, San

Antonio, TX 78248

The Albuquerque Astronomical Society, Albuquerque,

NM 87131

The Constellation Newsletter, Huntsville, AL 35810

The Hurricane Ridge Star Party, Port Angeles, WA

98362

The Mars Polar Lander Landing Party, Tamarac, FL

33319

The Mars Society, Tamarac, FL 33319

The Norwich Free Academy and Adelphia Cable

Television, Nonwich, CT 06360 (Participants: 12000

local, 12175 remote; 4 events)

Three Rivers School District, Grants Pass, OR 97526

(2 events)

Toastmasters Area 5 Contest, Moorestown, NJ 08057

Torrance Air Fair Association, Torrance, CA 90505 (2

events)

Tree Tops Park, Tamarac, FL 33319

Trinity Lutheran Church, Abington, PA 19001

United Artists Theatre, Tamarac, FL 33319

University of Chicago Laboratory Middle School

Assembly, Chicago, IL 60037

University of Cincinnati, Raymond Walters Campus,

Cincinnati, $\mathrm{OH} 45201$

University of Connecticut Math and Science Day,

Mansfield, CT 06250

University of Florida, Bradenton, FL 34201

University of Mississippi, Oxford, MS 38866

University of New Mexico, Albuquerque, NM 87131

University of Wisconsin at Marathon, Wausau, WI

54401 (2 events)

University of Wisconsin at Sheboygan, Sheboygan, WI

53081 (3 events)

USAF Academy, USAF Academy, C0 80901

(Participants: 150 local; 7 events)

Ventura County Astronomical Society, Ojai, CA 93023

Vermont Aviation Advisory Council Day Camp.

Rutland, VT 05701

Visitation School, Kansas City, MO 64101

Walmart Parking Lot, Victoria, TX 77901

Ward Beecher Planetarium, Youngstown, $\mathrm{OH} 44555$ (2

events)

Wausau District Schools, Wausau, WI 54401

(Participants: 1200 local; 4 events)

Weigel Elementary School, Cincinnati, OH 45239 
West Elementary, Lander, WY 82520

Western Colorado Museum, Grand Junction, C0

81501 (2 events)

Western Sky Planetarium, Grand Junction, WY 80501

Windward Community College, Kaneohe, HI 96744 (4

events)

Windycon Science, Schaumburg, IL 60159

Winterhaven Mobile Home Park, Brownsville, TX

78521

Woods Learning Center, Casper, Wr 82609 (2 events)

World Science Fiction, Chicago, IL 60601

Wyoming State Science Fair, Laramie, WY 82501 (2

events)

Xavier University, Cincinnati, $0 \mathrm{H} 45207$

Young Astronauts, Riverton, WY 82501

Youngstown Vindicator "The Cosmos" (weekly astronomy column), Youngstown, OH 44503 (Participants

24000 local; 25 events)

\section{Space Place Access for Community Education-A WWW Lnk}

Msn/Prg: IDEAS

Description: The goal of this program is to publish a selection of astronomical activities, information, and events associated with the University of Wisconsin's Space Place on the WWW for educators, teacher workshop participants, and the general public.

Lead: $\quad$ Dr. Karen Bjorkman, University of Wisconsin, Madison, WI 53715

Venue(s): University of Wisconsin, Madison, WI 53715

Total Solar Eellpse Wob Casts as Tools for Public Outreach

Msn/Prg: $\quad$ SEC Forum

Theme(s): $\quad$ SEC

Description: Educators' Workshop: Total solar eclipses-unique natural events - serve as a "hook" to engage the public in discussions about solar research, NASA's Sun-Earth Connection theme, and general astronomy. The Sun-Earth Connection Education Forum (SECEF), one of four national centers of space science education and outreach funded by the NASA Office of Space Science, is partnering with science museums to support total solar eclipse Web casts. SECEF is using high-visibility public events, such as the 1998 and 1999 eclipse events, to highlight NASA research and the people responsible for the science discoveries. I will discuss the outcomes of Eclipse ' 98 and Eclipse '99, produced by Live@The Exploratorium, present lessons learned, and show a video of the Eclipse ' 99 which involved the participation of several museums nationwide.

\footnotetext{
Lead: $\quad$ SEC Forum, NASA Goddard Space Flight Center, Greenbelt, MD 20771

Venue(s): $\quad$ American Association of Physics Teachers (AAPT), January 2000, Orlando, FL 34747 (Participants: 100 local)
}

\section{Universe in the Park}

Msn/Prg: $\quad$ IDEAS

Description: The primary objective of Universe in the Park was to establish a public outreach program of hands-on astronomy during summer months in State parks of Wisconsin. Each session would consist of a short, informal talk and presentation showcasing recent discoveries from NASA missions, followed by viewing of astronomical objects through binoculars and a moderate aperture telescope.

Lead: Dr. Eric Wilcots, University of Wisconsin, Madison, WI 53715

Venue(s): $\quad$ State Parks, WI (Participants: 1280 local)

University of Maryland Observatory Open House

Msn/Prg: NEAR

Theme(s): $\quad$ SSE

Description: Lucy McFadden was guest speaker at the University of Maryland Observatory Open House on September 5, 2000.

Lead: $\quad$ NEAR E/PO Team, Johns Hopkins University Applied Physics Laboratory, Laurel, MD 20723-6099

Venue(s): $\quad$ University of Maryland, College Park, MD 20742 (Participants: 100 local)

\section{Windows to the Universe Program}

Msn/Prg: Information Systems

Description: Windows to the Universe is a user-friendly learning system on the Earth and Space sciences for use by the general public. The objective of this project, funded by NASA, is to develop an innovative and engaging Web site that spans the Earth and space sciences. Our goal is to build a site that includes a rich array of documents, including images, movies, animations, and data sets, that explore the Earth and space sciences and the historical and cultural ties between science, exploration, and the human experience. Our site is being developed with the goal of being appropriate for use in museums and libraries, and to be a resource for students in their studies of the Earth and space sciences.

Lead: $\quad$ Michigan Space Grant Consortium, University of Michigan, Ann Arbor, MI 48109 


\section{Scientist Involvement}

\section{Astrobiology Outreach}

Msn/Prg: NAl, Sample Curation

Theme(s): $\quad$ SSE

Description: Presented and attended a four-and-a-half-day conference that was organized by topical symposia and problem-oriented sessions. Special sessions were scheduled with two evenings of poster sessions at the University of Clear Lake, Houston, TX. The NAl Outreach office submitted an abstract for presentation and a poster was created to highlight the NASA Astrobiology Institute's outreach program. An educator workshop was held one day prior to the science conference which included a tour of the Museum of Science in Houston. Sessions were held with scientists and outreach leads from all over the country. Informal education was the topic, which included a viewing of the planetarium exhibit that Johnson Space Center collaborated on. The museum directors and staff presented to the group.

Lead: $\quad$ Astrobiology Institute E/PO Team, NASA Ames

Venue(s): Lunar and Planetary Science Conference (LPSC), March 2000, Houston, TX 77058

\section{Astromaterials Posters}

Msn/Prg: Sample Curation

Theme(s): $\quad$ SSE

Description: We presented two posters to the science/education community: JSC Astromaterials-Astrobiology Teacher Intern Program and Destination Moon Planetarium Show.

Lead: $\quad$ Sample Curation E/P0 Team, NASA Johnson Space Center, Houston, TX 77058

Venue(s): Lunar and Planetary Science Conference (LPSC) March 2000, Houston, TX 77058

\section{Chandra Exhlbit}

Msn/Prg: $\quad$ CXO

Theme(s): $\quad$ SEU

Description: The Chandra $X$-ray Observatory booth features a (plastic) representation of the smallest mirror shell, a small spacecraft model, a light table image, and a plasma screen for display of Chandra images and to use in demonstrations of Chandra analysis software. Staffing includes Chandra X-ray Center (CXC) E/PO coordinator and Webmaster, CXC science spokesperson, data systems staff, and CXC scientists. Materials such as lithos, posters, postcards, and bookmarks are distributed, and requests for larger quantities of materials from university teachers, amateur astronomers, and $\mathrm{K}-12$ teachers are taken.

Lead:
Venue(s):

American Astronomical Society (AAS), January 2000,

Atlanta, GA 30303

American Astronomical Society (AAS), June 2000,

Rochester, NY 14601

\section{Collaborations Between Scientists and Museums and Planetariums}

Msn/Prg: $\quad$ LPI B/F

Theme(s): $\quad$ SSE

Description: NASA JSC, the LPI Broker/Facilitator, and the Houston Museum of Natural Science hosted this day-long workshop to bring together scientists and representatives of museums and planetariums to discuss goals and means of collaboration. Several examples of collaborations were used to illustrate the process and not just the result. Houston, TX 77058

Partner(s): $\quad$ Houston Museum of Natural Science, Houston, TX 77030

Venue(s): Lunar and Planetary Science Conference (LPSC), March 2000, Houston, TX 77058 (Participants: 60 local)

\section{Deep Impact Outreach at the Astronomical Society of the Pactic (ASP)}

$\begin{array}{ll}\text { Msn/Prg: } & \text { Deep Impact, Stardust } \\ \text { Theme(s): } & \text { SSE }\end{array}$

Description: Deep Impact participated in the ASP conference through the distribution of fact sheets and staffing. The conference took place in Pasadena, California, on July 15-18, 2000. Aimee Whalen staffed as a representative of STARDUST and Deep Impact.

Lead: $\quad$ Deep Impact E/PO Team, University of Maryland, College Park, MD 20742

Venue(s): Astronomical Society of the Pacific (ASP), July 2000, Pasadena, CA 91101

Deep Impact Poster at American Astronomical Society (AAS)

Msn/Prg: Deep Impact

Theme(s): $\quad$ SSE

Description: Deep Impact outreach team member Stephanie McLaughlin gave a poster talk at the AAS June meeting in Rochester, New York. Several hundred attended the conference and approximately 25 listened to the poster talk about the STSP amateur astronomy Web site hosted by the Deep impact mission.

Lead: Deep Impact E/PO Team, University of Maryland, College Park, MD 20742

Venue(s): $\quad$ American Astronomical Society (AAS), June 2000, Rochester, NY 14601 


\section{Deop Space Network Exhiblt at Astronomical Soclety of the Pacific (ASP)}

Msn/Prg: Cassini/Huygens Probe, Galileo, Stardust, Mars, DSMS

Theme(s): SSE

Description: The Deep Space Network exhibit was part of a larger JPL exhibit at the Astronomical Saclety of the Pacific Annual Conference in Pasadena, California, on July 13-18, 2000. The DSN booth featured radio astronomy and radar astronomy science results, as well as the Goldstone Apple Valley Radio Telescope (GAVRT) Project. One day was set aside for educators and 90 attended. Overall conference attendance was lower than anticipated.

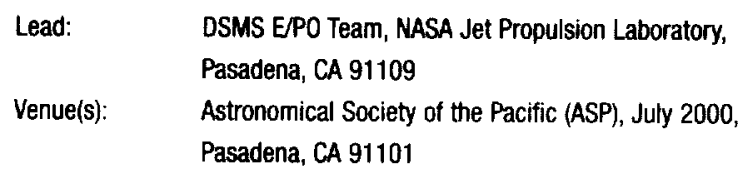

Description: Dr. Cherilynn Morrow worked with Dr. Roberta Johnson to convene the session "Education and Outreach Activities in the Space Physics and Aeronomy, Planetary Sciences, and Atmospheric Sciences."

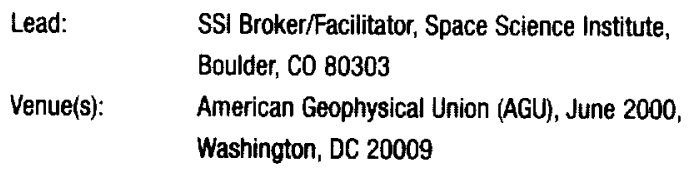

Helpful Hints on Working Eflectively with Sclence Conters, Museums, and Planotariums

Msn/Prg: $\quad$ LPI B/F

Theme(s): $\quad$ SSE

Description: The LPI Broker/Facilitator developed and sponsored this workshop for interested space scientists prior to the 31st Lunar and Planetary Science Conference. Speakers from a variety of public venues described their experiences with this kind of public outreach. Cross-cutting issues were discussed by the whole group. The topics included "Roles and Resources" and "The Lurid versus the Staid" as they impact scientist/museum collaborations. Fifty-two attended.

Lead: $\quad$ LPI Broker/Facilitator, Lunar and Planetary Institute, Houston, TX 77058

Partner(s): $\quad$ Houston Museum of Natural Science, Houston, TX 77030

Venue(s): Lunar and Planetary Science Conference (LPSC), March 2000, Houston, TX 77058

\section{IDEAS Poster}

Msn/Prg: HST

Theme(s): $\quad$ ASO

Description: There was a poster presentation for the IDEAS program at the meeting.

Lead: $\quad$ HST E/PO Team, Space Telescope Science Institute, Baltimore, MD 21218

Venue(s): $\quad$ American Astronomical Society (AAS), June 2000, Rochester, NY 14601

\section{Mars Global Surveyor SIldes}

Msn/Prg: $\quad$ SSE Forum

Theme(s): $\quad$ SSE

Description: AAS/DPS is the primary professional conference for planetary scientists. JPL provided 900 sets of Mars Global Surveyor slides for conference participants to use in their classes and public talks.
Lead:
SSE Forum, NASA Jet Propulsion Laboratory,
Venue(s): $\quad$ Coeur d' Alene, ID 83814
Pasadena, CA 91109

\section{Mlsconceptions Scientists Often Have About the National Sclence Education Standards}
Msn/Prg:
$\mathrm{SSI} B / \mathrm{F}$
Theme(s):
ASO, SEC, SEU, SSE

Description: Cheri Morrow presented the paper "Misconceptions Scientists Often Have About The National Science Education Standards," and participated in the poster session with a poster on the Space Weather Mini-exhibit, a partnership with GSFC/SEC.
Lead:
SSI Broker/Facilitator, Space Science Institute, Boulder, $\mathrm{CO} 80303$
Venue(s):

$$
\begin{aligned}
& \text { American Astronomical Society (AAS), January 2000, } \\
& \text { Atlanta, GA } 30303 \text { (Participants: } 500 \text { local) } \\
& \text { American Geophysical Union (AGU), December 1999, } \\
& \text { San Francisco, CA } 94103
\end{aligned}
$$

\section{MEAR Education and Publlc Outreach Program}

$\begin{array}{ll}\text { Msn/Prg: } & \text { NEAR } \\ \text { Theme(s): } & \text { SSE }\end{array}$

Description: AGU E/PO invited talk by Andy Cheng. "The NEAR Earth Asteroid Rendezvous (NEAR) Education and Public Outreach Program."

$\begin{array}{ll}\text { Lead: } & \text { NEAR E/PO Team, Johns Hopkins University Applied } \\ & \text { Physics Laboratory, Laurel, MD 20723-6099 } \\ \text { Venue(s): } & \text { American Geophysical Union (AGU), June 2000, } \\ & \text { Washington, DC 20009 }\end{array}$


Origins E/PO Exhlbit at American Astronomical Society (AAS)

Msn/Prg:

ASO Forum, HST, Deep Impact

Theme(s):

ASO

Description: The Origins E/PO exhibit booth at AAS meetings provides opportunities for discussions with visitors about NASA space science E/PO activities and how they might become involved; introductions to other attendees in order to foster collaborations; and demonstrations of the online Space Science Education Resource Directory.

Lead: $\quad$ ASO Forum, Space Telescope Science Institute, Baltimore, MD 21218

Venue(s): $\quad$ American Astronomical Society (AAS), January 2000, Attanta, GA 30303

American Astronomical Society (AAS), June 2000 ,

Rochester, NY 14601

\section{OSS ExhibH at American Assoclation for the Advancement of Science (AAAS)}

Msn/Prg: $\quad$ SEC Forum, OSS

Theme(s): $\quad$ SEC

Description: NASA Enterprises participated in the 2000 conference in Washington, DC. OSS organized a 30-foot exhibit, and SECEF helped recruit GSFC colleagues to staff the booth. Besides many local teachers, there were also some serious researchers and reporters.

Lead: $\quad$ OSS, NASA Headquarters, Washington, DC 20546

Venue(s): $\quad$ American Association for the Advancement of Science, February 2000, Washington, DC 20008

\section{SIRTF Exhlbh}

Msn/Prg: $\quad$ SIRTF

Theme(s): $\quad$ ASO

Description: Interactive booth using infrared camera and infrared video.

Lead: $\quad$ SIRTF E/PO Team, Califomia Institute of Technology, Pasadena, CA 91125

Venue(s): $\quad$ Astronomical Society of the Pacific (ASP), July 2000, Pasadena, CA 91101

\section{Space Place Poster}

Msn/Prg: DS-1

Theme(s): $\quad$ SSE

Description: During the week of May 1-5, Nancy Leon and Diane Fisher had a Space Place poster session at the Fourth International Academy of Astronautics (IAA) International Conference on Low-Cost Planetary Missions. The exhibit was viewed by approximately 200 people. It presented ways a low-cost mission could get a lot of publicity by just hiring the outreach team at JPL to create an activity involving their mission. That one activity may be printed or displayed in numerous avenues.
Lead:

New Millenium E/PO Team, NASA Jet Propulsion

Laboratory, Pasadena, CA 91109

Venue(s): $\quad$ IAA International Conference on Low-Cost Planetary Missions, May 2000, Laurel, MD 20723

Space Science Institute Seminar Series

Msn/Prg: $\quad$ SSI B/F

Theme(s): $\quad$ ASO, SEC, SEU, SSE

Description: The Space Science Institute (Boulder, Colorado) has launched a local Seminar Series in Earth and Space Science Education to promote collegiality, communication, and collaboration. The seminars are intended primarily to serve as a professional development and networking opportunity for 1) education and public outreach professionals who work in local scientific research institutions; 2) scientists interested or involved in education and public outreach; and 3) educators interested in working with the scientific community. Seminar leaders are invited from the local area with occasional visits from special guests. The format will allow time for discussion among the seminar participants. Ideas for seminar topics include (but are not limited to) 1) updates on the EPO programs in local research institutions; 2) reports on innovative EPO projects or programs; 3) and creating successful partnerships between scientists and educators. The first seminar was held on October 31,2000 , and attended by over 20 scientists and educators representing institutions such as the University of Colorado's Laboratory for Atmospheric and Space Physics and the Center for Integrated Research in the Earth Sciences, the NOAA Space Environment Center, the National Center for Atmospheric Research, and the Denver Museum of Nature and Science.

$\begin{array}{ll}\text { Lead: } & \text { SSI Broker/Facilitator, Space Science Institute, } \\ & \text { Boulder, CO } 80303 \\ \text { Venue(s): } & \text { Area research institutions, Boulder, CO } 80303\end{array}$

\section{Sunspots from Anclent Cultures to Modem Research}

Msn/Prg: HESSI

Theme(s): $\quad$ SEC

Description: This was a special session entitled "Highlights of Education and Public Outreach Activities Undenway in the Space Physics and Aeronomy, Planetary Sciences, and Atmospheric Sciences Section." A poster was presented on behalf of HESSI and SEGway. Sunspots from Ancient Cultures to Modern Research

Lead: $\quad$ HESSI E/PO Team, University of California, Berkeley, CA 94720

Venue(s): $\quad$ American Geophysical Union (AGU), June 2000, Washington, DC 20009

\section{Web Resources for Scientists}

Msn/Prg: $\quad$ SSI B/F

Theme(s): $\quad$ ASO, SEC, SEU, SSE

Description: SSI has created a collection of online resources designed to facilitate and encourage scientist involvement in EPO, and address com- 
mon misconceptions held by many scientists concerning various aspects of EPO. The following papers and presentations can be found by going to http://www.spacescience.org and clicking on the QuickLinks pull-down menu, and choosing EPO papers: 1) So You Want to Make a CD-ROM? by S. Pompea and C. A. Morrow; 2) The Diversity of Roles for Scientists in Education and Public Outreach, by C.A. Morrow; 3) Scientific Elites and Illiterates, by David L. Goodstein; 4) What are the Similarities Between Scientific Research and Science Education Reform? by C.A. Morrow; 5 ) Misconceptions Scientists Often Have about the National Science Education Standards, by C.A. Morrow; 6) A Framework for Planning Education and Public Outreach Programs Associated with Scientific Research Programs, by C.A. Morrow; 7) Scientist Involvement in Education and Public Outreach: Making the Case, presentation by C.A. Morrow; 8) Explanatory Guide to the NASA Office of Space Science Education and Public Outreach Evaluation Criteria.

Lead: SSI Broker/Facilitator, Space Science Institute, Boulder, CO 80303

\section{Workshops for Sclentists}

$\begin{array}{ll}\text { Msn/Prg: } & \text { SSI B/F, OHRE } \\ \text { Theme(s): } & \text { ASO, SEC, SEU, SSE }\end{array}$

Description: For the past six years, the Space Science Institute (SSI) in Boulder, Colorado, has conducted pioneering professional development workshops for space scientists on K-12 education. The workshop has been funded by NASA's Education Division with additional support from the Office of Space Science Broker/Facilitator program. Approximately 250 participants and guest presenters have been served. The goals of the 4-day "Workshop for Scientists, Engineers, and EPO Leads" are 1) to enhance and sustain a national cadre of well-informed NASA scientists, engineers, and EPO managers who can act as advocates and leaders for effective science education and as role models for colleagues engaged in EPO activities; 2) to strengthen and increase the effectiveness of the education activities involving the NASA science and engineering communities that are presently (and soon-to-be) underway; and 3) to provide scientists, engineers, and EPO managers who are active in EPO with focused and ongoing opportunities for showcasing their work and networking with colleagues and education experts. SSI is currently in pursuit of funds from all NASA Enterprises to continue this highly successful work.

Lead: SSI Broker/Facilitator, Space Science Institute, Boulder, CO 80303

Venue(s): $\quad$ Space Science Institute, Boulder, C0 80303-1058 (Participants: 45 local) 


\section{Appendix $B$}

NASA Space Science E/PO Points of Contact

This directory provides contact information for each of the NASA organizations, missions, and programs involved in space science E/PO. 

NASA

http://www.nasa.gov

Office of Space Science (OSS)

Dr. Jeffrey Rosendhal

Assistant Associate Administrator (Education and Outreach)

NASA Headquarters

Code S

Washington, DC 20546

(202) 358-2470

Jeffrey.Rosendhal@hq.nasa.gov

http://spacescience.nasa.gov/education/

Office of Human Resources and Education (OHRE)

Frank Owens

Director, Education Division

NASA Headquarters

Code FE

Washington, DC 20546

(202) 358-1110

fowens@hq.nasa.gov

http://education.nasa.gov/

Office of Equal Opportunity Programs (OEOP)

Bettie White

Director, Minority University Research and Education Division

NASA Headquarters

Code EU

Washington, DC 20546

(202) 358-0970

bwhite@hq.nasa.gov

http://www.hq.nasa.gov/office/codee/mured.htmI

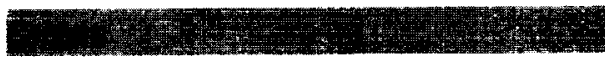

NASA Ames Research Center (ARC)

Donald G. James

Director of Education

NASA Ames Research Center

Code 204-14

Moffett Field, CA 94035

(650) 604-4967

http://education.arc.nasa.gov/
NASA Goddand Space Flight Center (GSFC)

Dr. Robert Gabrys

Director of Education

NASA Goddard Space Flight Center

Code 130.3

Greenbelt, MD 20771

(301) 286-7205

http://education.gsfc.nasa.gov'

NASA Johnson Space Center (JSC)

Mike Kincaid

Chief, Education and Student Programs Branch

NASA Johnson Space Center

Mailcode AH2

2101 NASA Road 1

Houston, TX 77058

(281) 483-6848

http://www.jsc.nasa.gov/pao/educators/

NASA Marshall Space Flight Center (MSFC)

Jim Pruitt

Manager, Education Programs Department

NASA Marshall Space Flight Center

Mail Code CD60

Marshall Space Flight Center, AL 35812

(256) 544-8800

http://www1.msfc.nasa.gov/education/index.htm/

http://eis.jpl.nasa.gov/eao/

Dr. Parvin Kassaie

Director of Education

NASA Jet Propulsion Laboratory

Mailstop 180-109

4800 Oak Grove Drive

Pasadena, CA 91109

(818) 354-8814

Parvin.Kassaie@jpl.nasa.gov

Kimberly Shepard

Manager, Public Engagement Office

NASA Jet Propulsion Laboratory

Mailstop 264-788

4800 Oak Grove Drive

Pasadena, CA 91109

(818) 354-0185

Kimberly.J.Shepard@jpl.nasa.gov 


\section{E/PO Support Network}

http://spacescience.nasa.gov/education/ecosystem.htm

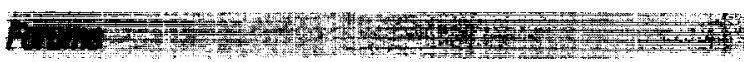

Astronomical Search for Origins Forum (ASO Forum)

Dr. Terry Teays

Space Telescope Science institute

3700 San Martin Drive

Baltimore, MD 21218

(410) 338-4733

teays@stsci.edu

Solar System Exploration Forum (SSE Forum)

Dr. Ellis Miner

NASA Jet Propulsion Laboratory

Mailstop 230-260

4800 0ak Grove Drive

Pasadena, CA 91109

(818) $354-4450$

Ellis.D.Miner@jpl.nasa.gov

Leslie Lowes

NASA Jet Propulsion Laboratory

Mail Stop 264-419

4800 Oak Grove Drive

Pasadena, CA 91109

(818) 393-7734

Leslie.L.Lowes@jpl.nasa.gov

Structure and Evolution of the Earth Forum (SEU Forum)

Dr. Roy Gould

Smithsonian Astrophysical Observatory

60 Garden Street

Cambridge, MA 02138

(617) 496-7689

rgould@cfa.harvard.edu

Sun-Earth Connection Forum (SEC Forum)

Dr. Isabel Hawkins

University of California

Space Sciences Laboratory

Grizzly Peak at Centennial

Berkeley, CA $94720-7450$

(510) 643-5662

isabelh@ssi.berkeley.edu
Dr. Richard Vondrak

NASA Goddard Space Flight Center

Mail Code 690.0

Greenbelt, MO 20771

(301) 286-8112

vondrak@lepvax.gsfc.nasa.gov

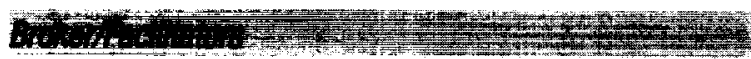

DePaul Broker/Facilitator (DU B/F)

Dr. Lynn Narasimhan

DePaul University

990 W. Fullerton

Chicago, IL 60614

(773) 325-1854

cnarasim@condor.depaul.edu

Lunar and Planetary Institute Broker/Facilitator (LPI B/F)

Kathleen Johnson

Lunar and Planetary Institute

3600 Bay Area Boulevard

Houston, TX 77058

(281) 244-2014

Johnson@|pi.usra.edu

Ohio Aerospace Institute Broker/Facilitator (OA/ B/F)

Dr. Larry Cooper

Ohio Aerospace Institute

7661 Squirrel Creek Drive

Cincinnati, $\mathrm{OH} 45247$

(513) 245-9897

OSSBroker@oai.org

Southeast Regional Clearinghouse Broker/Facilitator (SERCH B/F)

Dr. Cassandra Runyon

Southeast Regional Clearinghouse

66 George Street

Charleston, SC 29424

(843) $953-5437$

cass@cofc.edu

Space Science institute Broker/Facilitator (SSI B/F)

Dr. Cherilynn Morrow

Space Science Institute

1540 30th Street, Suite 10

Boulder, $\mathrm{CO} 80303$

(303) $492-7321$

camorrow@colorado.edu 


\section{Astronomical Search for Origins Missions}

http://spacescience.nasa.gov
http://origins.jpl.nasa.gov/

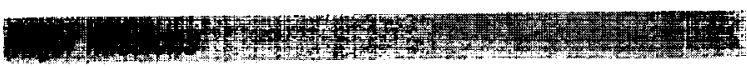

Hubble Space Telescope (HST)

Dr. Peg Stanley

Space Telescope Science Institute

Office of Public Outreach

3700 San Martin Drive

Baltimore, MD 21218

(410) 338-4536

pstanley@stsci.edu

Next Generation Space Telescope (NGST)

Dr. Peg Stanley

Space Telescope Science Institute

Office of Public Outreach

3700 San Martin Drive

Baltimore, MD 21218

(410) 338-4536

pstanley@stsci.edu

Space Infrared Telescope Facility (SIRTF)

\section{Dr. Michael Bicay}

California Institute of Technology

SIRTF Science Center/PAC

Pasadena, CA 91125

(626) 397-9506

mdb@ipac.caltech.edu

Space Interferometry Mission (SIM)

Dr. Rudolf Danner

NASA Jet Propulsion Laboratory

Mailstop 105-24

4800 0ak Grove Drive

Pasadena, CA 91109

(818) 393-4877

rudolf.danner@jpl.nasa.gov

Stratospheric Observatory for Intrared Astronomy (SOFIA)

Michael Bennett

NASA Ames Research Center

Mailstop 144-2

Moffett Field, CA 94035

(650) 604-2128

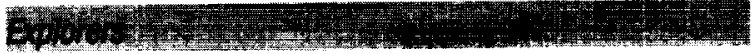

Far-Uitraviolet Spectroscopic Explorer (FUSE)

Dr. Luciana Bianchi

Johns Hopkins University

Center for Astrophysical Sciences

$3400 \mathrm{~N}$. Charles Street

Baltimore, MD 21218-2695

(410) 516-4009

bianchi@stsci.edu

Full-sky Astrometric Mapping Explorer (FAME)

Dr. P. Kenneth Seidelmann

U.S. Naval Observatory

3450 Massachusetts Avenue NW

Washington, OC 20392

(202) 762-1441

pks@spica.usno.navy.mil

http://spacescience.nasa.gov

http://origins.jpl.nasa.gov/

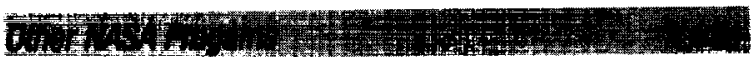

Keck Interferometer (Keck)

Nancy Leon

NASA Jet Propulsion Laboratory

Mailstop 301-235

4800 0ak Grove Drive

Pasadena, CA 91109

(818) 354-1067

nancy.j.leon@jpl.nasa.gov

NASA Astrobiology Institute (NAI)

Krisstina Wilmoth

Ames Research Center

Mailstop 240-1

Moffett Field, CA 94035

(650) 604-6137

kwilmoth@mail.arc.nasa.gov

Space Technology 3 (New Millennium) (ST-3)

Nancy Leon

NASA Jet Propulsion Laboratory

Mailstop 301-235

4800 Oak Grove Drive

Pasadena, CA 91109

(818) 354-1067

nancy.j.leon@jpl.nasa.gov 


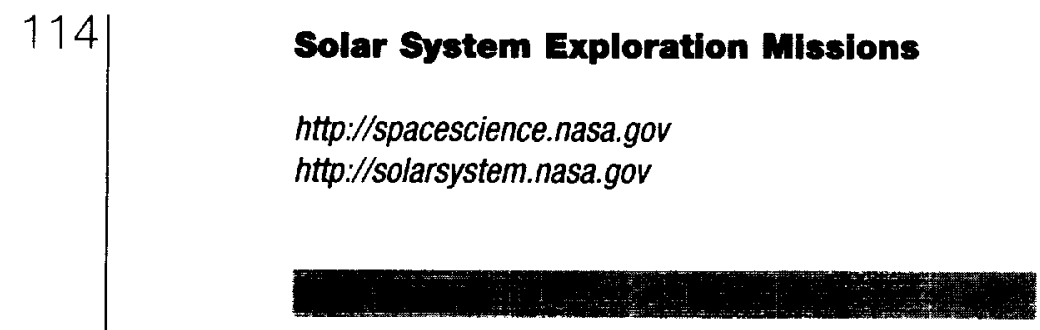

SSE Theme Lead

Anita Sohus

NASA Jet Propulsion Laboratory

Mailstop 264-788

4800 Oak Grove Drive

Pasadena, CA 91109

(818) 354-6613

Anita.M.Sohus@jpi.nasa.gov

Cassini

Stephen Edberg

NASA Jet Propulsion Laboratory

Mailstop 230-205

4800 Oak Grove Drive

Pasadena, CA 91109

(818) 354-6085

Stephen.J.Edberg@jpl.nasa.gov

Galileo

Lesile Lowes

NASA Jet Propulsion Laboratory

Maistop 264-419

4800 0ak Grove Drive

Pasadena, CA 91109

(818) 393-7734

Leslie.L.Lowes@jpl.nasa.gov

Voyager

Andrea Angrum

NASA Jet Propulsion Laboratory

Mailstop 264-801

4800 Oak Grove Drive

Pasadena, CA 91109

(818) 354-6775

andrea.angrum@jpl.nasa.gov
Discovery Program Support Office (DPSO)

Shari Asplund

NASA Jet Propulsion Laboratory

Mailstop 156-223

4800 Oak Grove Drive

Pasadena, CA 91109

(818) 354-7280

Shari.Asplund@jpl.nasa.gov

Comet Nucleus Tour (CONTOUR)

Dr. Robert A. Brown

Space Telescope Science Institute

3700 San Martin Drive

Baltimore, MD 21218

(410) 516-8129

rbrown@stsci.edu

Deep impact

Dr. Lucy McFadden

University of Maryland

Department of Astronomy

College Park, MD 20742

(301) 405-2081

mcfadden@astro.umd.edu

Genesis

Gilbert Yanow

NASA Jet Propulsion Laboratory

Mailstop 264-370

4800 Oak Grove Drive

Pasadena, CA 91109

(818) 354-8060

gilbert.yanow@jpl.nasa.gov

Lunar Prospector

Lisa Chu-Thielbar

NASA Ames Research Center

Mailstop 244-19

Moffett Field, CA 94035

(650) 604-0182

Ichu-thielbar@mail.arc.nasa.gov 
Mercury Surface, Space ENvironment, GEochemistry and Ranging (MESSENGER)

Dr. George "Pinky" Nelson

Project 2061, AAAS

1333 H St., NW, Room 847

Washington, DC 20005

(202) 326-7047

gnelson@aaas.org

Dr. Shirley Malcom

American Association for the Advancement of Science (AAAS)

1200 New York Ave., NW

Washington, DC 20005

(202) $326-6680$

smalcom@aaas.org

Near Earth Asteroid Rendezvous (NEAR)

Kerri Beisser

Applied Physics Laboratory

Space Department Education \& Public Outreach

11100 Johns Hopkins Road

Laurel, MD 20723-6099

(443) $778-6050$

Kerri.Beisser@jhuapl.edu

Stardust

Aimee Whalen

NASA Jet Propulsion Laboratory

Mailstop 301-429

4800 Oak Grove Drive

Pasadena, CA 91109

(818) 354-3245

Aimee.L.Whalen@jpl.nasa.gov

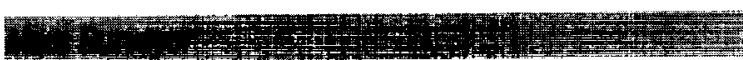

Mars Theme Lead (Mars)

Michelle Viotti

NASA Jet Propulsion Laboratory

Mailstop 264-438

4800 0ak Grove Drive

Pasadena, CA 91109

(818) 354-8774

Michelle.Viotti@jpl.nasa.gov
Mars Global Surveyor (MGS)

See Mars Theme Lead

Mars Odyssey 2001

See Mars Theme Lead

Mars 2003 Rovers

See Mars Theme Lead

Outer Planets/Solar Probe Project (OP/SP)

Richard Shope

NASA Jet Propulsion Laboratory

Mailstop 301-335

4800 0ak Grove Drive

Pasadena, CA 91109

(818) 354-3812

Richard.E.Shope-HI@jpl.nasa.gov

Europa Orbiter

See Outer Planets/Solar Probe

Pluto/Kuiper Express

See Outer Planets/Solar Probe

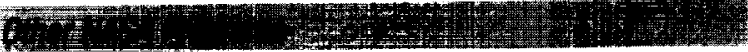

Deep Space 1 (New Millennium) (DS-1)

Nancy Leon

NASA Jet Propulsion Laboratory

Mailstop 301-235

4800 0ak Grove Drive

Pasadena, CA 91109

(818) 354-1067

nancy.j.leon@jp|.nasa.gov

Deep Space Mission Support Office (DSMS)

Shirley Wolff

NASA Jet Propulsion Laboratory

Mailstop 303-401

4800 Oak Grove Drive

Pasadena, CA 91109

(B18) 354-4069

Shirley.E.Wolff@jpl.nasa.gov 
Marilyn Lindstrom

NASA Johnson Space Center

Code SN2

2101 NASA Road 1

Houston, TX 77058

(281) $483-5135$

mlindstr@ems.jsc.nasa.gov

\section{Structure and Evolution of the Universe Mlssions}

http://spacescience.nasa.gov

http://universe.gstc.nasa.gov

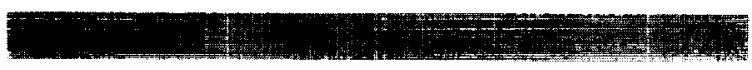

Chandra X-Ray Obsenvatory (CXO)

Kathy Lestition

Harvard-Smithsonian Center for Astrophysics

Mailstop 06

60 Garden Street

Cambridge, MA 02138

(617) 495-7399

klestition@cfa.harvard.edu

Gamma-ray Large Area Space Telescope (GLAST)

Dr. Lynn Corninsky

Sonoma State University

Department of Physics and Astronomy

1801 East Cotati Avenue

Rohnert Park, CA 94928

(707) 664-5655

lynnc@charmian.sonoma.edu

Gravity Probe B Relativity Mission (GP-B)

Jennifer Mullins

Stanford University

MC 4085

W.W. Hansen Experimental Physics Lab

Stanford, CA 94305

(650) 725-6856

mullins@relgyro.stanford.edu
Cosmic Hot Interstellar Plasma Spectrometer (CHIPS)

Dr. Nahide Craig

University of California

Space Sciences Laboratory

Berkeley, CA 94720

(510) 643-7273

ncraig@ssl.berkeley.edu

Galaxy Evolution Explorer (GALEX)

Christopher Martin

California Institute of Technology

Pasadena, CA 91125

cmartin@srl.caltech.edu

Microwave Anisotropy Probe (MAP)

Lindsay Clark

Adler Planetarium \& Astronomy Museum

1300 S. Lake Shore Drive

Chicago, IL 60605

(312) 322-0316

Lindsay_Clark@adlernet.org

Rossi X-ray Timing Explorer (RXTE)

Patricia Boyd

NASA Goddard Space Flight Center

Mailstop 662.0

Greenbelt, MD 20771

(301) 286-2550

padi@hea1.gsfc.nasa.gov

Submillimeter Wave Astronomy Satellite (SWAS)

Dr. Rene Plume

Harvard-Smithsonian Center for Astrophysics

Mailstop 66

60 Garden Street

Cambridge, MA 2138

(617) 496-7830

rplume@cfa.harvard.edu

Swift Gamma Ray Burst MIDEX Mission (SWIFT)

Dr. Laura Whittock

Sonoma State University

Department of Physics and Astronomy

1801 East Cotati Avenue

Rohnert Park, CA 94928

(707) 664-2256

laura.whitlock@sonoma.edu 


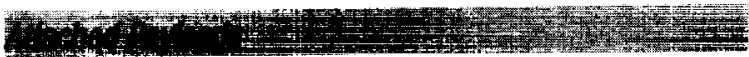

Advanced Calorimeter for Composition of Elements on the Space Station (ACCESS)

Beth Jacob

Goddard Space Flight Center

Mailstop 664.0

Greenbelt, MD 20771

(301) 286-7209

beth@gamma.gsfc.nasa.gov

http://spacescience.nasa.gov

http://universe.gsfc.nasa.gov/

\section{Gotor WASA Progems}

High Energy Astrophysics Science Archive Research Center (HEASARC)

Dr. James Lochner

NASA Goddard Space Flight Center

Mailstop 662.0

Greenbelt, MD 20771

(301) 286-9711

lochner@xeric.gsfc.nasa.gov

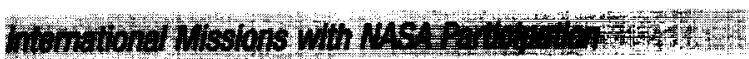

X-Ray Multi-Mirror Satellite (XMM-Newton)

Chris Foster

University of California, Santa Barbara

Coordinator of Academic Outreach

College of Letters and Science

Santa Barbara, CA 93106

(805) 893-7966

cfoster@itsc.ucsb.edu

\section{Sun-Earth Connection Missions}

http://spacescience.nasa.gov

http://sec.gstc.nasa.gov

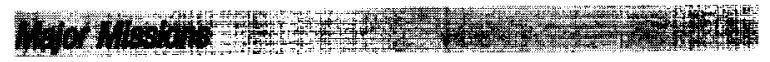

Ulysses

Andrea Angrum

NASA Jet Propulsion Laboratory

Mailstop 264-801

4800 0ak Grove Drive

Pasadena, CA 91109

(818) 354-6775

andrea.angrum@jpl.nasa.gov

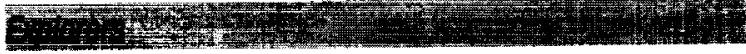

Advanced Composition Explorer (ACE)

Beth Jacob

NASA Goddard Space Flight Center

Mailstop 664.0

Greenbelt, MD 20771

(301) 286-7209

beth@gamma.gsfc.nasa.gov

http://spacescience.nasa.gov

http.//sec.gsfc.nasa.gov/

Fast Auroral Snapshot Explorer (FAST)

Dr. Nahide Craig

University of California, Berkeley

Space Sciences Laboratory

Berkeley, CA 94720

(510) 643-7273

ncraig@ssl.berkeley.edu

High Energy Solar Spectroscopic Imager (HESSI)

Dr. Nahide Craig

University of California

Space Sciences Laboratory

Berkeley, CA 94720

(510) 643-7273

ncraig@ssl.berkeley.edu

Imager for Magnetopause-to-Aurora Global Exploration (IMAGE)

Dr. Sten Odenwald

NASA Goddard Space Flight Center

Mailstop 633.0

Greenbelt, MD 20771

(301) 286-6953

odenwald@bolero.gsfc.nasa.gov

Solar Anomalous and Magnetospheric Particle Explorer (SAMPEX)

Dr. Shrikanth Kanekal

NASA Goddard Space Flight Center

Mailstop 696.0

Greenbelt, MD 20771

(301) 286-6517

kaneka|@lepsam.gsfc.nasa.gov 


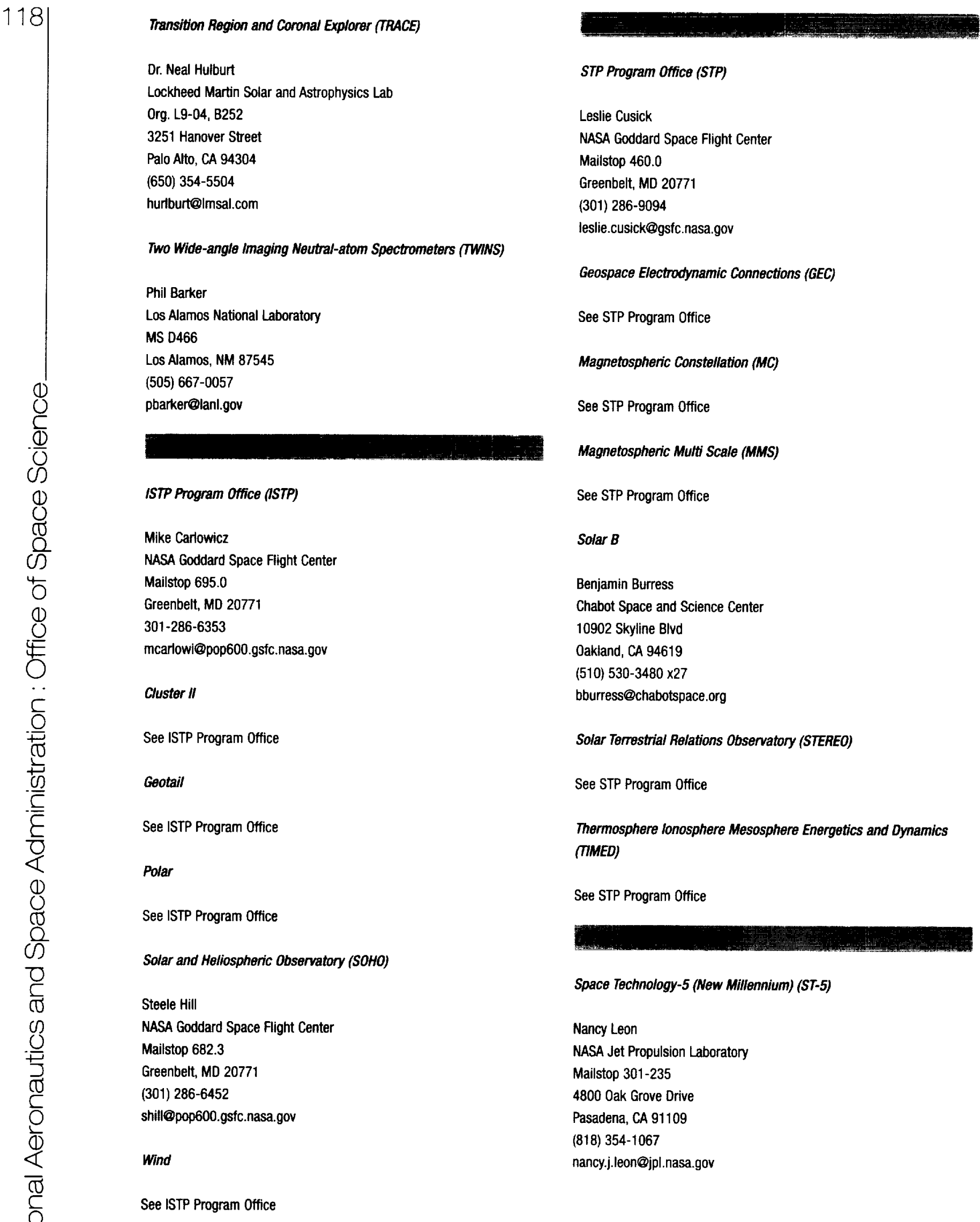




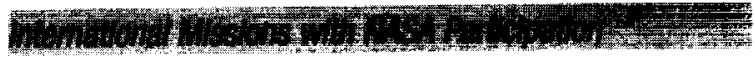

Dr. David Alexander

Lockheed Martin Solar and Astrophysics Lab

Org. L9-41, B252

3251 Hanover Street

Palo Alto, CA 94304

(650) 424-2047

alexander@imsal.com

\section{IDEAS}

http://ideas.stsci.edu/ideas.shtmI

Heather Bradbury

Space Telescope Science Institute

Office of Public Outreach

3700 San Martin Drive

Baltimore, MD 21218

(410) 338-4968

ideas@stsci.edu 
$-$ 


\section{Appendix C} OSS E/PO Partners

Listed here are the institutions and organizations with which OSS had partnerships for carrying out E/PO activities in FY 2000. 

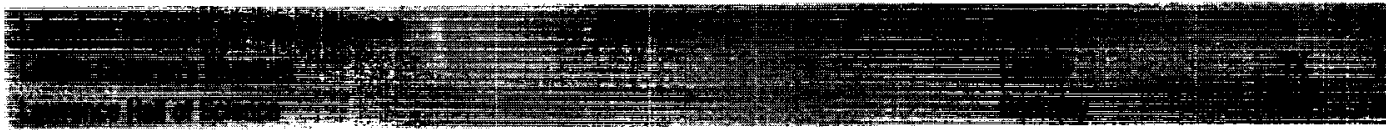

Lida G. Sharpe Planetarium

Memphis

Longway Planetarium

Flint

TN $\quad 38111-3399$

Louisiana Nature Center Planetarium

New Orleans

48503

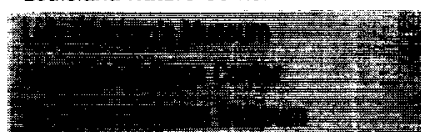

mate

McWane Center

Mid America Air Museum

Museum of Art \& Science

(1)

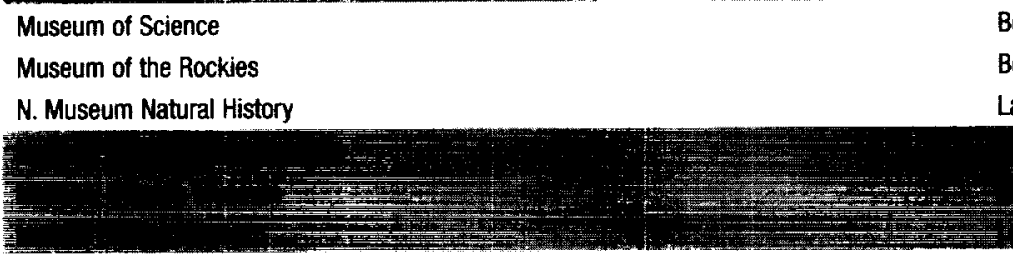

\begin{tabular}{llll}
\hline New England Air Museum & Windsor Locks & CT & 06096 \\
Niagara Aerospace Museum & Niagara Falls & NY & 14304 \\
Northern Stars Planetarium & Fairfield & ME & 04937
\end{tabular}

Northern Stars Planetarium

Boston

MA 02114-1099

Museum of the Rockies

Bozeman

MT 59717

Lancaster

PA 17603

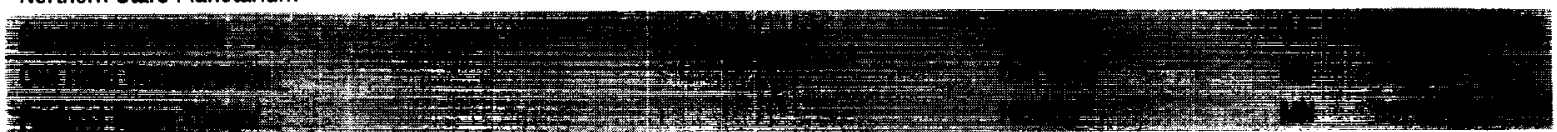

Pima Air \& Space Museum

Rainwater Planetarium and Observatory

Red River Valley Museum

Tucson

French Camp

Vernon
AZ $\quad 85719$

MS 39745

TX 76385-2004

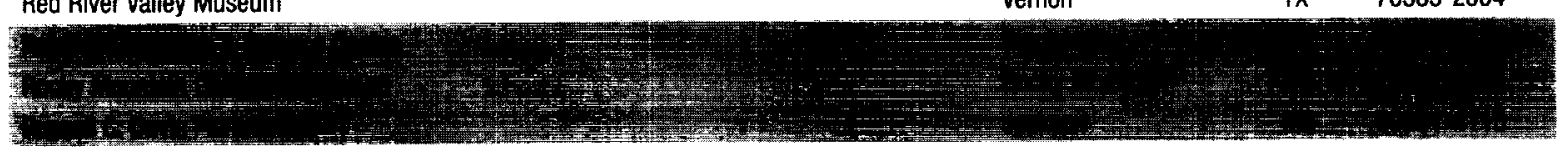

Santa Maria Museum of Flight

Santa Maria $\quad$ CA 93455

Schreder Planetarium \& Science Learning Center

Redding

CA 96001

Science Center of West Virginia

Bluefield

W 24701

$\begin{array}{llll} & & & \\ & & & \\ \end{array}$

$\begin{array}{llll} & & & \\ \end{array}$

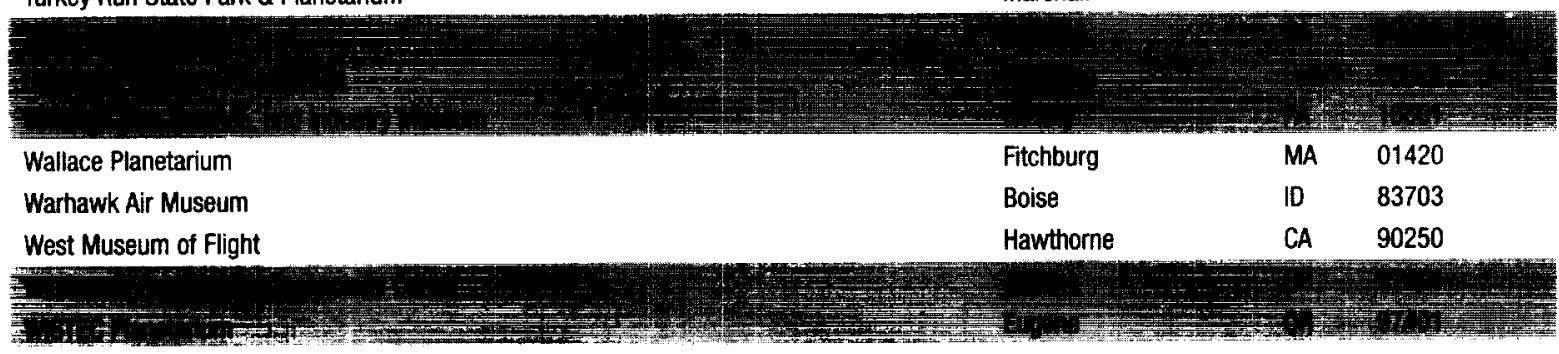


EDUCATIONAL INSTITUTIONS AND ORGANIZATIONS: K-12

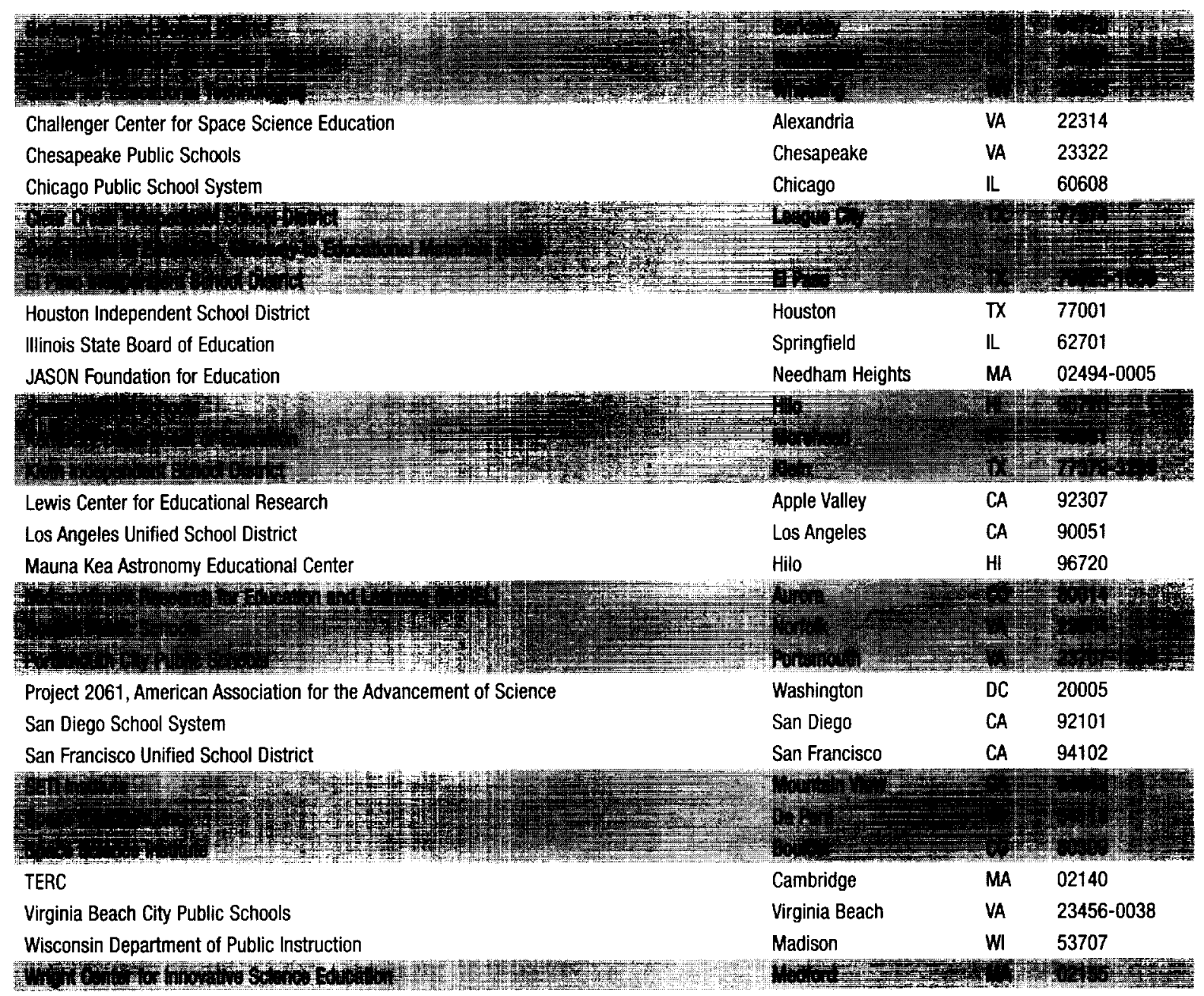




\section{EDUCATIONAL INSTITUTIONS AND ORGANIZATIONS: Higher Education}

("indicates Minority Institution)

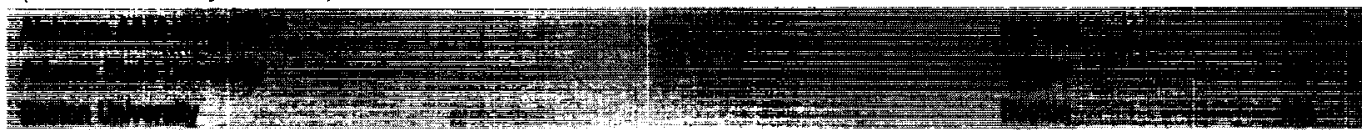

\begin{tabular}{llll}
\hline \hline California Institute of Technology & Pasadena & CA & 91125 \\
California State University* & Northridge & CA & 91330 \\
Case Western Reserve University & Cleveland & $0 H$ & 44106
\end{tabular}

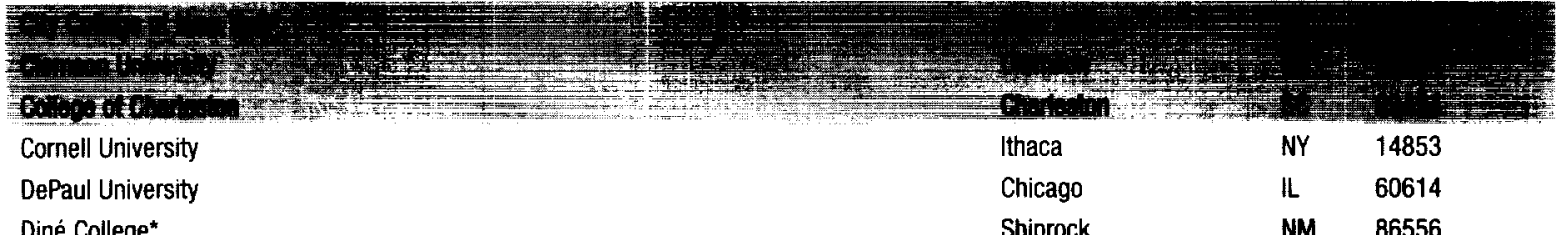
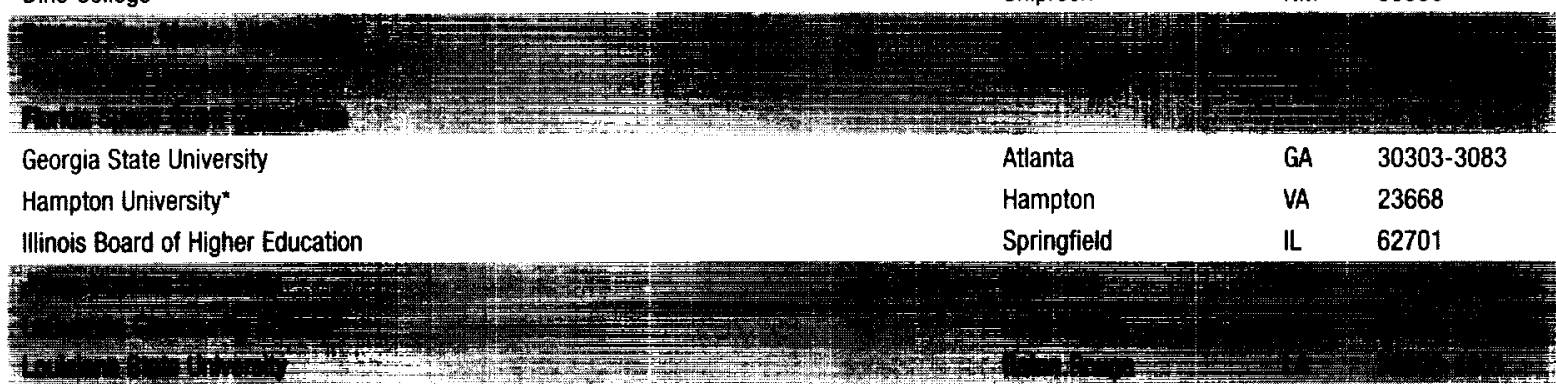
Medgar Evers College*
Brooklyn
NY 11225
Montana State University
Bozeman
MT $\quad 59717$
NJ 07043

Montclair State University

Upper Montclair

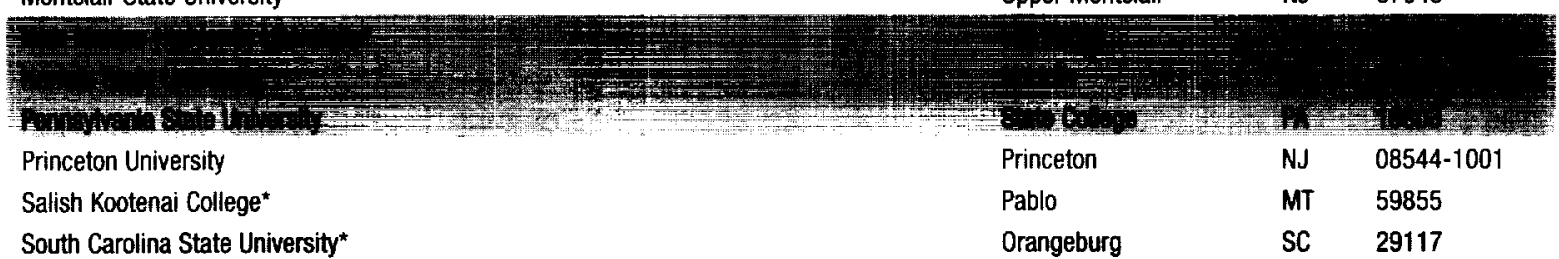

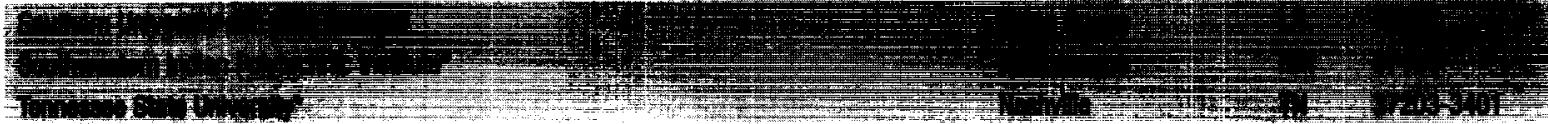

Texas Southern University*

University of Alabama

Houston

TX 77004

University of California

Huntsville

AL $\quad 35899$

Berkeley

CA 94720

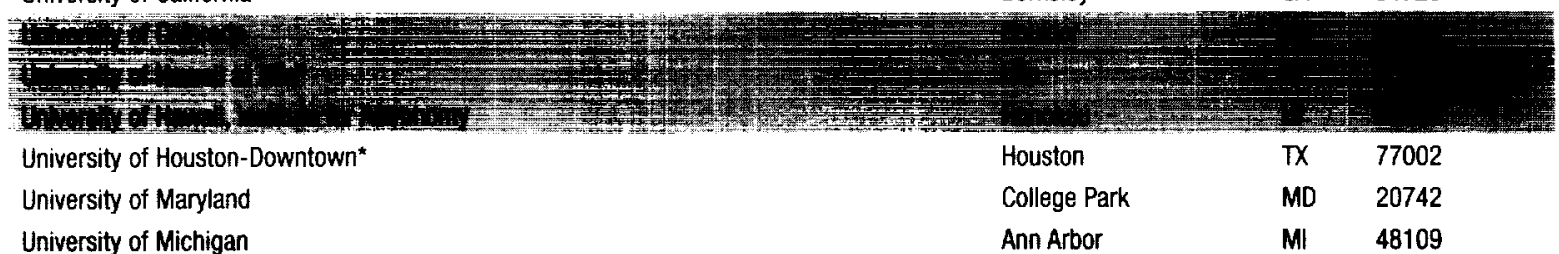

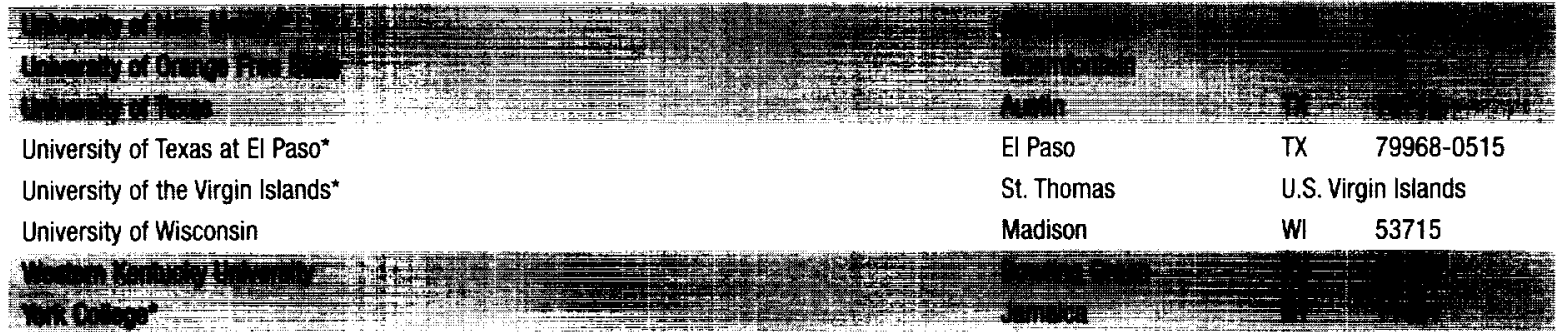




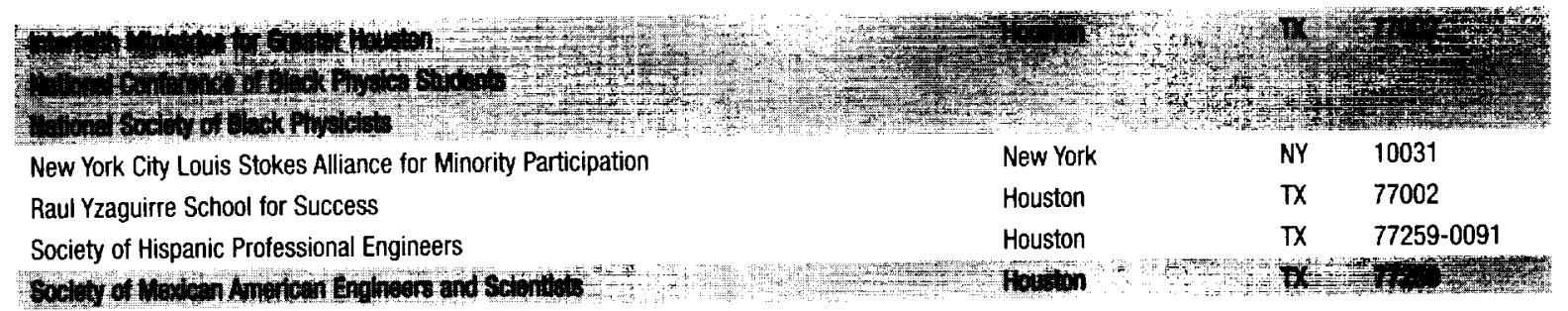

\section{SCIENCE INSTITUTIONS AND ORGANIZATIONS: NASA-Affiliated}

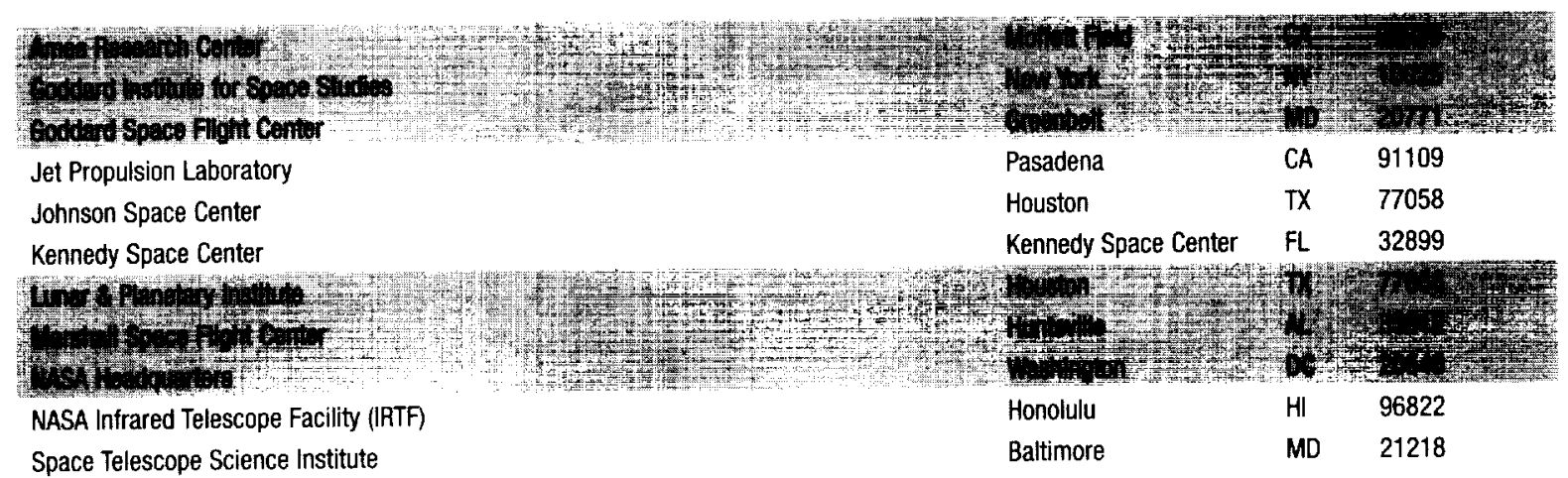

\section{SCIENCE INSTITUTIONS AND ORGANIZATIONS: Non-NASA}

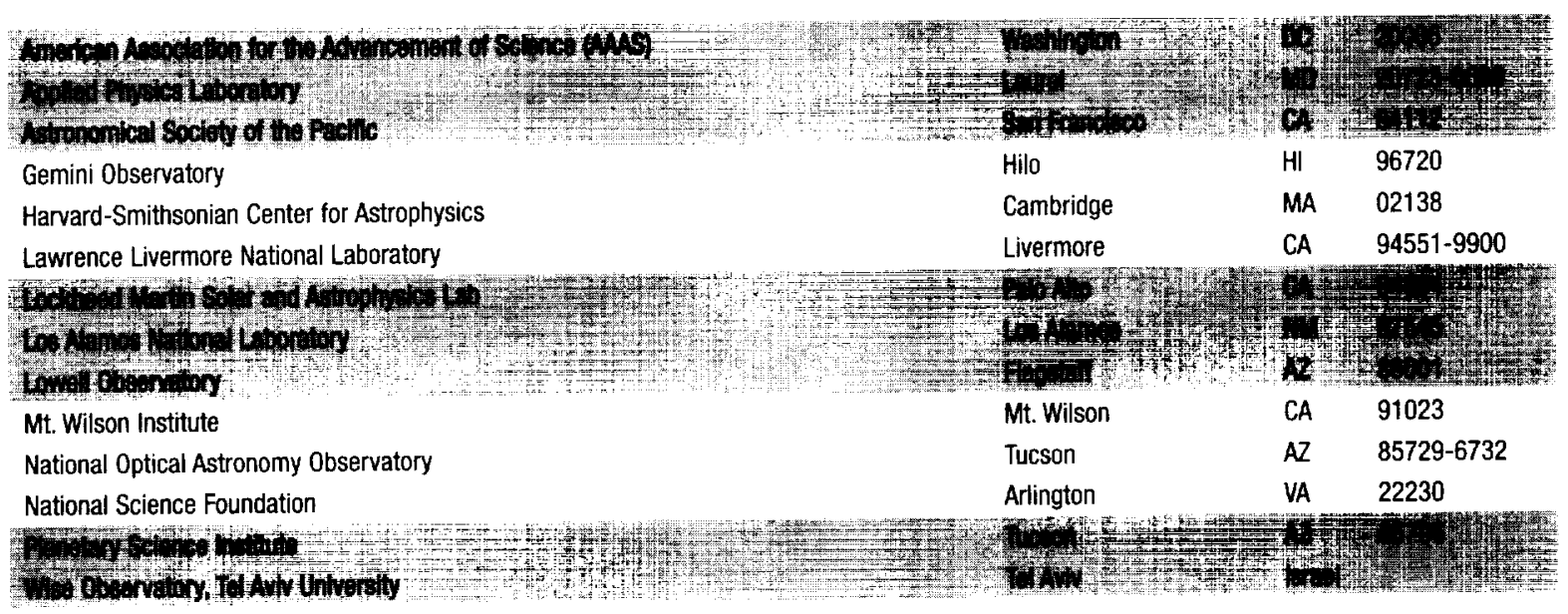

\section{COMMERCIAL, NON-PROFIT, AND MASS MEDIA ORGANIZATIONS}

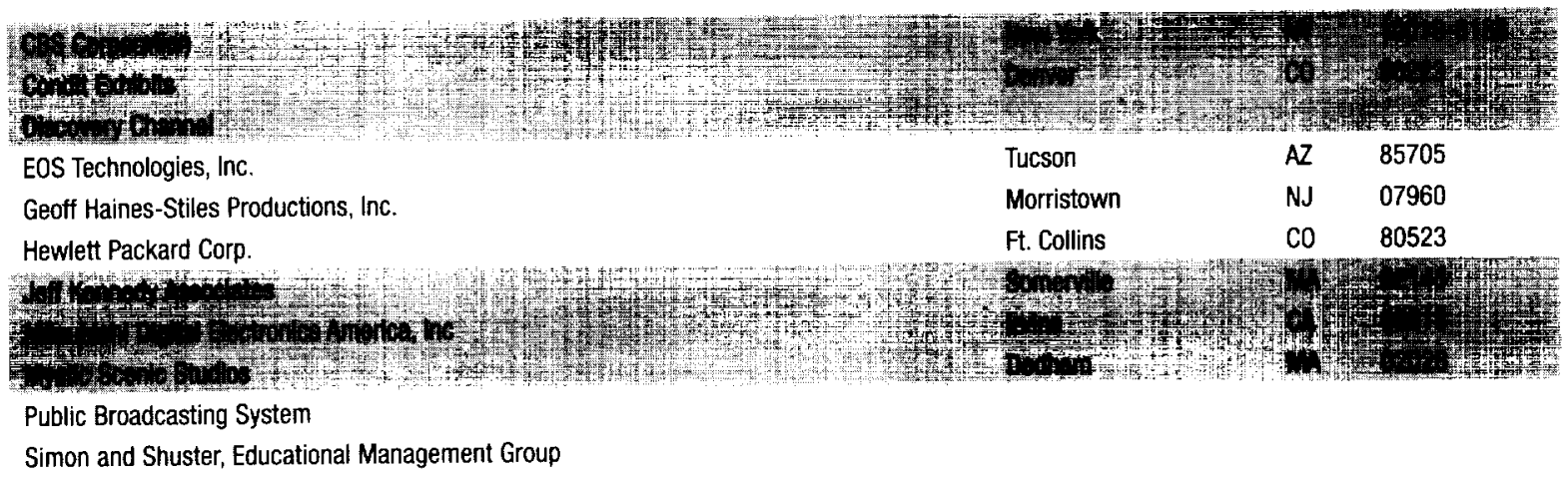




\section{Appendix D}

OSS Conference Support

Listed here are the conferences at which OSS E/PO had a substantial presence in FY 2000. 



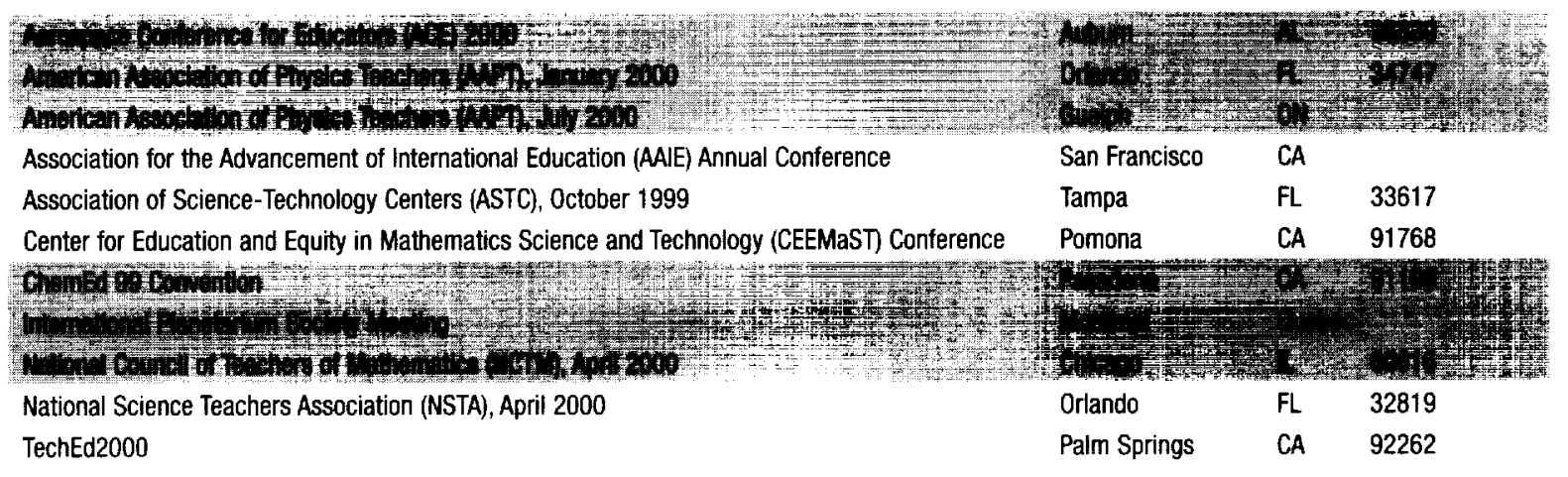

\section{EDUCATION CONFERENCES: Regional}

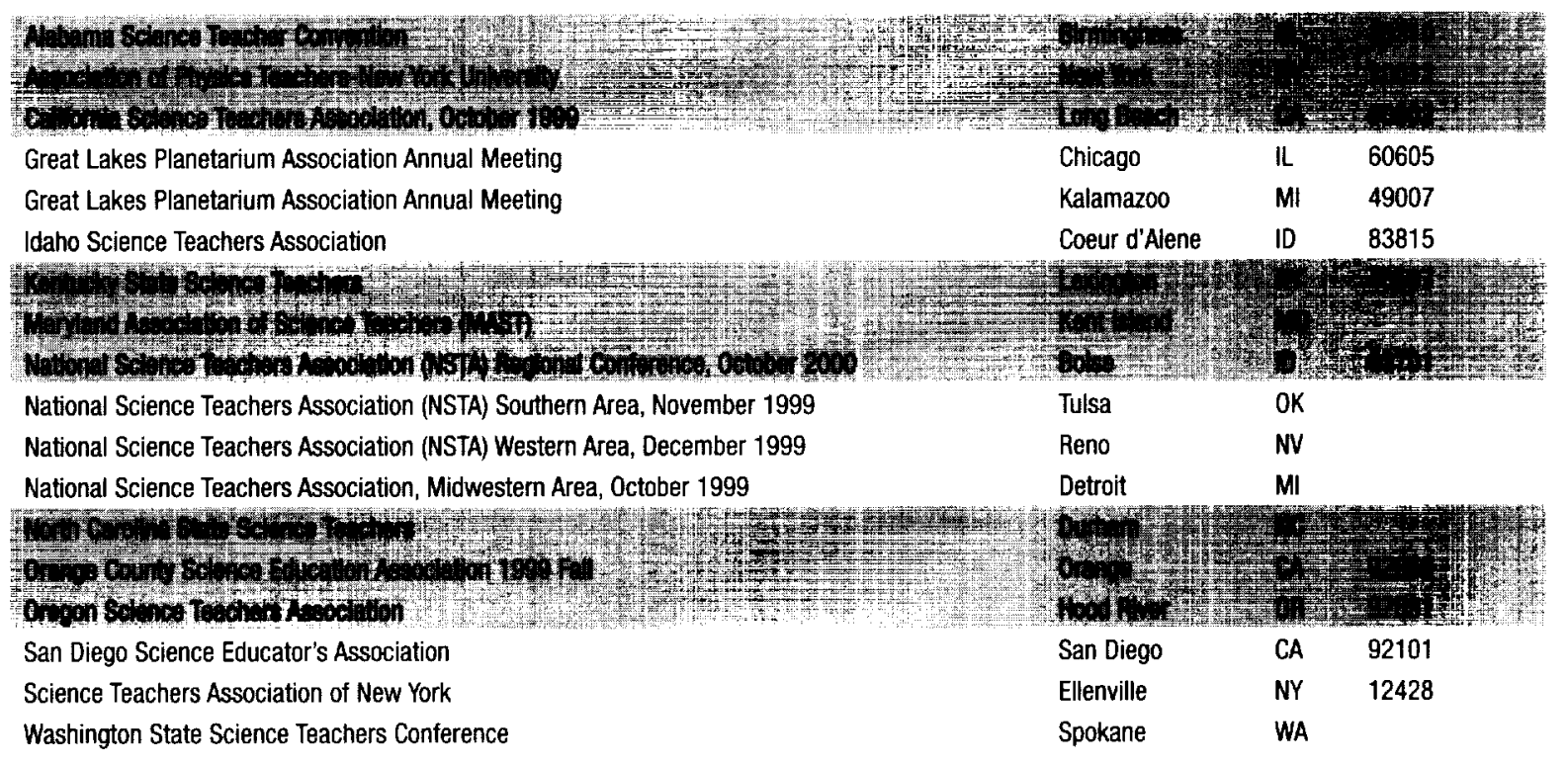

\section{MINORITY CONFERENCES}

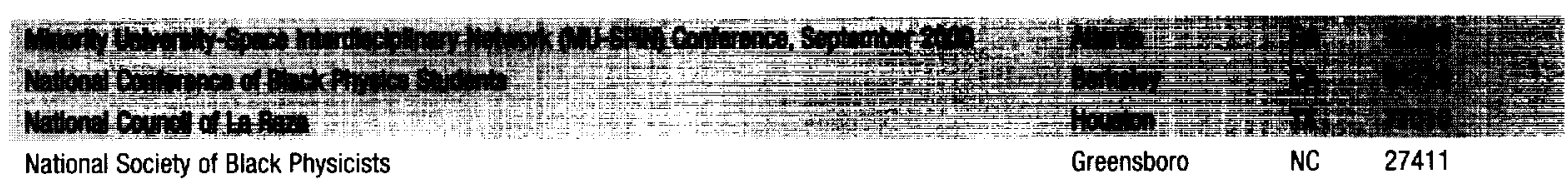

\section{SCIENCE CONFERENCES}

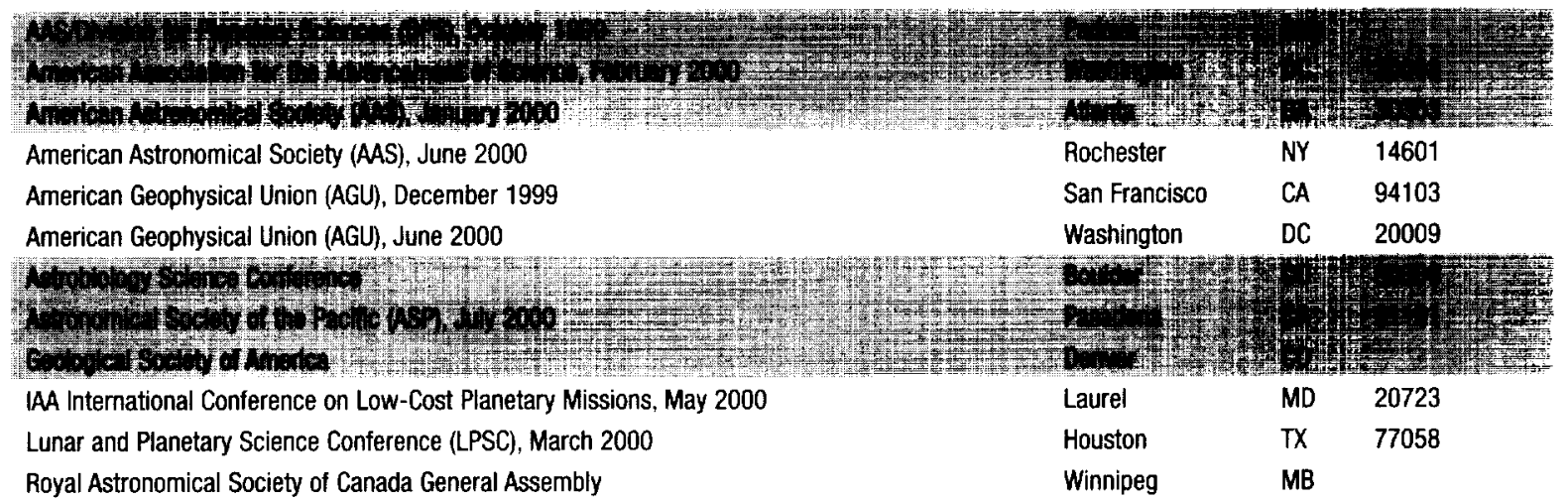




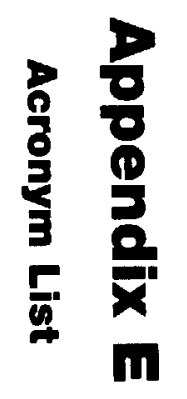





\section{Acronym Description}

\begin{tabular}{|c|c|}
\hline 2MASS & Two Micron All Sky Survey \\
\hline ACCESS & Advanced Calorimeter for Composition of Elements on the Space Station \\
\hline ACE & Advanced Composition Explorer \\
\hline AMS-2 & Alpha Magnetic Spectrometer \\
\hline ARC & Ames Research Center \\
\hline ARISE & Advanced Radio Interferometry between Space and Earth \\
\hline ASCA & Advanced Satellite for Cosmology and Astrophysics \\
\hline ASO & Astronomical Search for Origins \\
\hline ASO Forum & Astronomical Search for Origins Forum \\
\hline ASPERA-3 & Analyzer of Space Plasma and Energetic Atoms (on Mars Express) \\
\hline ASTRO-E & Astro-E \\
\hline BeppoSAX & Satellite per Astronomia X \\
\hline CATSAT & Cooperative Astrophysics and Technology Satellite \\
\hline CGRO & Compton Gamma-Ray Observatory \\
\hline CHIPS & Cosmic Hot Interstellar Plasma Spectrometer \\
\hline CONTOUR & Comet Nucleus Tour \\
\hline $\mathrm{CXO}$ & Chandra X-Ray Observatory \\
\hline DePaul B/F & DePaul Broker/Facilitator \\
\hline DFRC & Dryden Flight Research Center \\
\hline DPSO & Discovery Program Support Office \\
\hline DS-1 & Deep Space 1 (New Millennium) \\
\hline DSMS & Deep Space Mission Support Office \\
\hline EUVE & Extreme Ultraviolet Explorer \\
\hline FAME & Full-sky Astrometric Mapping Explorer \\
\hline FAST & Fast Auroral Snapshot Explorer \\
\hline FIRST & Far Infrared and Submillimeter Telescope \\
\hline FUSE & Far-Ultraviolet Spectroscopic Explorer \\
\hline GALEX & Galaxy Evolution Explorer \\
\hline GEC & Geospace Electrodynamic Connections \\
\hline GLAST & Gamma-ray Large Area Space Telescope \\
\hline GP-B & Gravity Probe B Relativity Mission \\
\hline GRC & Glenn Research Center \\
\hline GSFC & Goddard Space Flight Center \\
\hline HEASARC & High Energy Astrophysics Science Archive Research Center \\
\hline HESSI & High Energy Solar Spectroscopic Imager \\
\hline HETE ॥ & High Energy Transient Explorer II \\
\hline $\mathrm{HQ}$ & NASA Headquarters \\
\hline HST & Hubble Space Telescope \\
\hline IMAGE & Imager for Magnetopause-to-Aurora Global Exploration \\
\hline IMEX & Inner Magnetosphere Explorer \\
\hline IMP-8 & Interplanetary Monitoring Platform \\
\hline INTEGRAL & International Gamma-Ray Astrophysics Laboratory \\
\hline ISTP & ISTP Program Office \\
\hline JPL & Jet Propulsion Laboratory \\
\hline JSC & Johnson Space Center \\
\hline Keck & Keck Interferometer \\
\hline KSC & Kennedy Space Center \\
\hline LaRC & Langley Research Center \\
\hline LISA & Laser Interferometer Space Antenna \\
\hline LPI B/F & Lunar and Planetary Institute Broker/Facilitator \\
\hline MAP & Microwave Anisotropy Probe \\
\hline Mars & Mars Theme Lead \\
\hline MC & Magnetospheric Constellation \\
\hline MESSENGER & Mercury Surface, Space ENvironment, GEochemistry and Ranging \\
\hline MGS & Mars Global Surveyor \\
\hline
\end{tabular}




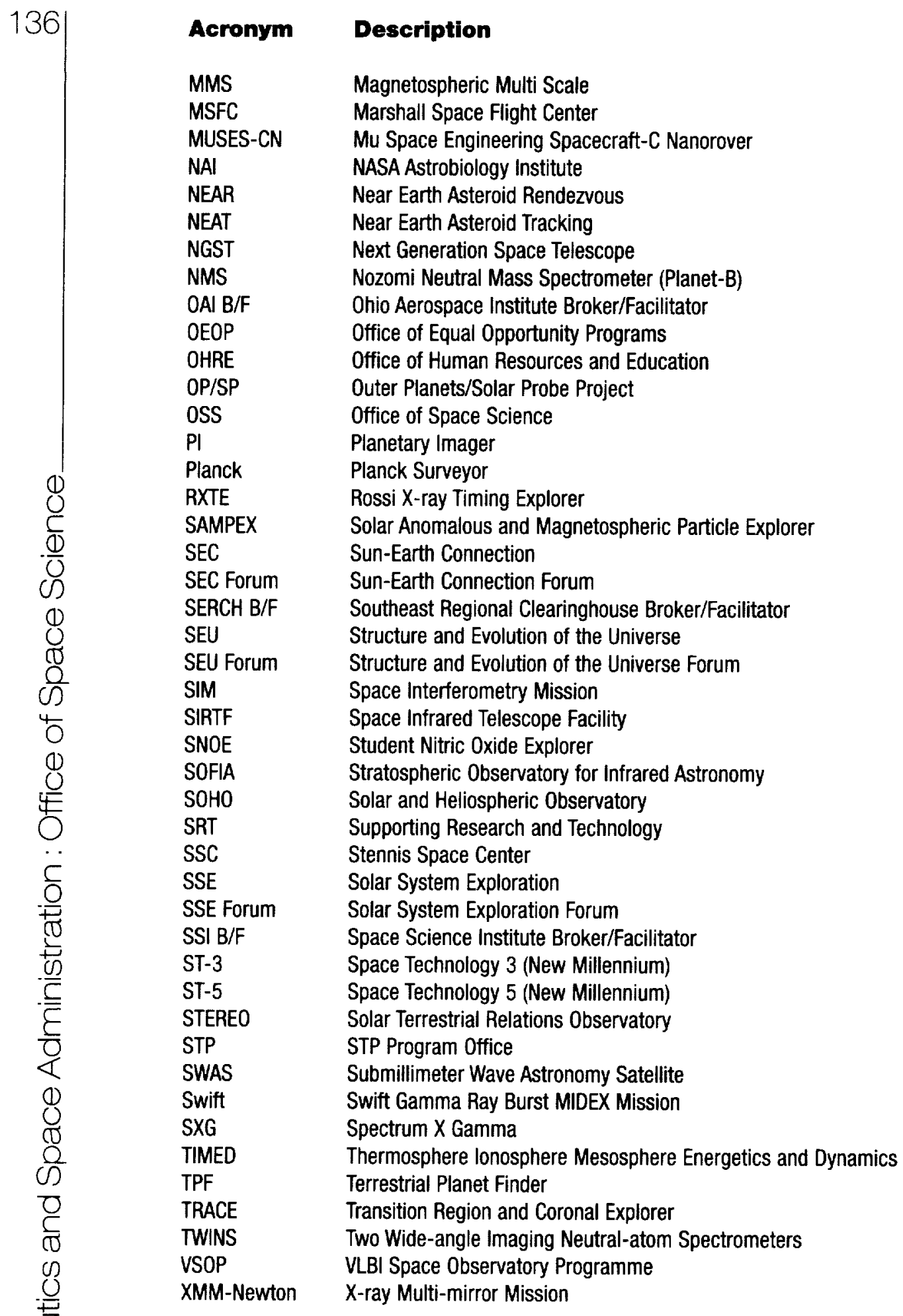


This index lists the FY 2000 OSS E/PO products and programs according to the NASA organizations, programs, or missions that were responsible for producing or carrying out the product or program. The leading numbers indicate the page in Appendix A where a full description of the product or program may be found. 

NASA

NASA Headquarters (HO)

Office of Space Science (OSS)

39. A Space Science Curriculum at Hampton University: Development of a Minor, Faculty Enhancement, and K-14 Outreach

39. An Urban Outreach Program in Space Science

39. Astronomy and Astrophysics Course Development at Salish Kootenai College

46. Build a Dobsonian Telescope Activity

43. Center for Automated Space Science (CASS)

33. Center for Space Science Education at the Adler Planetarium and Astronomy Museum

33. Chabot Space and Science Center

39. Collision Processes in Astrophysical Plasmas

40. Connecting Sun City with Sun-Earth Connections

35. Design a Space Science Mission with Nova Nautics

96. Engaging Challenger Center's Space Science Researchers in Highly Leveraged National Education and Public Outreach

40. Enhancement of Space Science Research at South Carolina State University (SCSU)

40. Internet-Based Education and Research with Robotic Telescopes for Native American and Hispanic Students

54. Live from the Sun MultiMedia Kit

54. Live from the Sun, Program 1

55. Live from the Sun, Program 2: Solar Studies and Sunny Interactions

55. Live from the Sun, Program 3: To the Max

37. NASA Space Science Education Partnership

41. NASA-HBCU Partnership to Enhance Minority Education and Research Participation in the Space Sciences

44. National Conference of Black Physics Students

41. New Mexico Connections: Connecting People, Places, and Research

41. New Opportunities through Minority Initiatives in Space Science

41. New York City Space Science Research Alliance

107. OSS Exhibit at American Association for the Advancement of Science (AAAS)

98. OSS Exhibit at American Association of Retired Persons (AARP)

37. OSS Exhibit at Association of Science-Technology Centers (ASTC)

72. OSS Exhibit at California Science Teachers Association (CSTA)

44. OSS Exhibit at National Council of La Raza

72. OSS Exhibit at National Council of Teachers of Mathematics (NCTM)

72. OSS Exhibit at National Science Teachers Association (NSTA)
44. OSS Outreach at National Society of Black Physicists (NSBP)

42. Partnerships in Astronomy and Astrophysics Education and Research at Southern University

98. Passport to Knowledge

57. Picture an Astronomer Activity

57. Remember the Egg Activity

42. Space Science Education and Sun-Earth Connection

91. STARBASE Network

42. Stars on Earth

92. Telescopes in Education Program

61. Telescopes in Education User Guide and Workbook

61. Testing Astrology

32. Voyage-A Scale Model Solar System for the National Mall

43. York College Observatory Educational Outreach Service to the College and the Public School Community

\section{Office of Human Resources and Education (OHRE)}

33. Bishop Museum/Mauna Kea Education Center

46. Build a Dobsonian Telescope Activity

33. Chabot Space and Science Center

51. Eye on the Sky

35. Franklin Institute

31. MarsQuest Exhibition

92. Telescopes in Education Program

61. Telescopes in Education User Guide and Workbook

108. Workshops for Scientists

\section{Office of Equal Opportunity Programs (OEOP)}

39. A Space Science Curriculum at Hampton University: Development of a Minor, Faculty Enhancement, and K-14 Outreach

39. An Urban Outreach Program in Space Science

39. Astronomy and Astrophysics Course Development at Salish Kootenai College

43. Center for Automated Space Science (CASS)

39. Collision Processes in Astrophysical Plasmas

40. Connecting Sun City with Sun-Earth Connections

40. Enhancement of Space Science Research at South Carolina State University (SCSU)

40. Internet-Based Education and Research with Robotic Telescopes for Native American and Hispanic Students

41. NASA-HBCU Partnership to Enhance Minority Education and Research Participation in the Space Sciences

41. New Mexico Connections: Connecting People, Places, and Research

41. New Opportunities through Minority Initiatives in Space Science

41. New York City Space Science Research Alliance

42. Partnerships in Astronomy and Astrophysics Education and Research at Southern University 
42. Space Science Education and Sun-Earth Connection

43. York College Observatory Educational Outreach Service to the College and the Public School Community

\section{E/PO Support Network}

\section{Fonms}

\section{Astronomical Search for Origins Forum (ASO Forum)}

35. Great Lakes Planetarium Association (GLPA) Space Science Advisory Committee

31. Hubble Space Telescope: New Views of the Universe

107. Origins E/PO Exhibit at American Astronomical Society (AAS)

98. Origins Public Outreach Exhibit

76. Toward Other Planetary Systems (TOPS)

\section{Solar System Exploration Forum (SSE Forum)}

33. Adler Planetarium

95. Earth and Sky Radio Programs

35. Great Lakes Planetarium Association (GLPA) Space Science Advisory Committee

36. International Planetarium Society

106. Mars Global Surveyor Slides

37. National Air and Space Museum

72. OSS Exhibit at California Science Teachers Association (CSTA)

\section{Structure and Evolution of the Universe Forum (SEU Forum)}

81. Chandra Operations Control Center Tours

94. Chandra Team Public Appearances

31. Cosmic Horizons: Our Place in Space and Time

48. Cosmic Survey: What Are Your Ideas About the Universe?

67. From the Ground Up!

35. Great Lakes Planetarium Association (GLPA) Space Science Advisory Committee

68. Imagine the Universe! Presentation

70. Maine Math and Science Alliance

\section{Sun-Earth Connection Forum (SEC Forum)}

64. Chicago Teachers' Advisory

95. Eclipse ' 99 and ' 01

35. Great Lakes Planetarium Association (GLPA) Space Science Advisory Committee

44. Minority University-Space Interdisciplinary Network (MU-SPIN) Workshop

97. NASA Goddard Community Day

71. NASA Sun-Earth Connection Resources for Your Mathematics Classroom
107. OSS Exhibit at American Association for the Advancement of Science (AAAS)

37. OSS Exhibit at Association of Science-Technology Centers (ASTC)

44. OSS Exhibit at National Council of La Raza

44. OSS Outreach at National Society of Black Physicists (NSBP)

86. SCES Astronomy Club

86. Scientists in the Classroom

32. Space Weather Center Exhibit

92. Sunspots-San Francisco Unified School District (SFUSD) STEP-UP Summer School

76. TIMED Onsite Educational Experience

104. Total Solar Eclipse Web Casts as Tools for Public Outreach

77. Universe Education Forum: Space Science Resources on Cosmic Structure and Evolution

77. Using a Web-based "Sunspots" Resource-Results from a Student Summer Outreach Program

77. VITS Presentations for Educational Purposes

Broker-Facilintors

\section{DePaul Broker/Facilitator (DePaul B/F)}

66. Amazing Space Presentation

64. Chicago City-Wide Conferences

64. Chicago Teachers' Advisory

35. Great Lakes Planetarium Association (GLPA) Space Science Advisory Committee

65. Meetings with Chicago Public School Principals

36. NASA Space Science Education and Outreach Resources for Planetariums

65. NASA/llinois/Chicago Partnerships in Development

65. Near and Far Science for Illinois (NFSI)

37. OSS Booth at Great Lakes Planetarium Association (GLPA)

38. Planetarium Learning and Teaching Opportunities (PLATO)

65. Space Science Charrette

65. Space Science for Illinois Teachers (SSIT)

65. Teacher Consultants

Lunar and Planetary Institute Broker/Facilitator (LPI $B / F)$

79. Books Are Rockets to Knowledge

94. Challenger Center Enrichment Conference

81. Clear Creek Independent School District (Texas) Alpha Program

105. Collaborations Between Scientists and Museums and Planetariums

96. Explore!

106. Helpful Hints on Working Effectively with Science Centers, Museums, and Planetariums

69. Liftoff Educator Workshop 
75. Space Science and the Texas Essential Knowledge and Skills (TEKS)

Ohio Aerospace Institute Broker/Facilitator (OAI B/F)

35. Great Lakes Planetarium Association (GLPA) Space Science Advisory Committee

\section{Southeast Regional Clearinghouse Broker/Facilitator (SERCH B/F)}

35. Design a Space Science Mission with Nova Nautics

66. Destination Moon and Mars

37. NASA Space Science Education Partnership

\section{Space Science Institute Broker/Facilitator (SSI B/F)}

106. Education and Outreach Activities in the Space Physics and Aeronomy, Planetary Sciences, and Atmospheric Sciences

69. Kinesthetic Astronomy Curriculum Development and Workshops

31. MarsQuest Exhibition

70. MarsQuest Workshop

106. Misconceptions Scientists Often Have About the National Science Education Standards

107. Space Science Institute Seminar Series

32. Space Weather Center Exhibit

75. Space Weather Workshops

107. Web Resources for Scientists

108. Workshops for Scientists

\section{ASTRONOMICAL SEARCH FOR ORIGINS MISSIONS}

\section{Major Missions}

Hubble Space Telescope (HST)

66. Amazing Space Presentation

45. Amazing Space Web Site

46. Astronaut Challenge

47. Colliding Galaxies

47. Comets

49. Eagle Nebula

51. From Galileo to Hubble: Why a Telescope in Space?

51. Galaxies Galore, Games and More

51. Galaxy Centaurus A

52. Helix Nebula

79. HST Amazing Space

53. Hubble Deep Field Academy

53. Hubble Deep Field Poster

36. Hubble News Early Access Program

53. Hubble Space Telescope

36. Hubble Space Telescope 10th Anniversary Slide Set and Script

36. Hubble Space Telescope 10th Anniversary Video
31. Hubble Space Telescope National Visitor Center

31. Hubble Space Telescope: New Views of the Universe

53. Hubble's Galaxy Gallery

106. IDEAS Poster

68. Integrating Hubble Space Telescope and other NASA Resources in the Curriculum

54. Jovian Planets

55. Mars

56. Nature's Kaleidoscope

56. No Escape: The Truth About Black Holes Poster

56. No Escape: The Truth About Black Holes Web Site

98. Open Night at the Space Telescope Science Institute

107. Origins E/PO Exhibit at American Astronomical Society (AAS)

98. Origins Public Outreach Exhibit

57. Orion Nebula

72. OSS Exhibit at National Science Teachers Association (NSTA)

57. Pistol Star

99. Science Education Web Site Developers Conference

86. Scientists in the Classroom

59. Solar System Trading Cards

91. Speakers Bureau @ STSCl

59. Star Light, Star Bright

59. STARBIRTH in the Eagle Nebula

38. ViewSPACE-Broadband Exhibition Multimedia

Space Infrared Telescope Facility (SIRTF)

97. NASA JPL Open House

72. OSS Exhibit at National Council of Teachers of Mathematics (NCTM)

73. Outer Planets/Solar Probe Project: Educator Workshops

73. Outer Planets/Solar Probe Project: From the Outer Planets to the Inner City

44. Outer Planets/Solar Probe Project: From the Sun to the Star Nations

74. SIRTF Educator Workshop

107. SIRTF Exhibit

99. Solar System Ambassadors

Space Interferometry Mission (SIM)

70. Light, Waves, and Interference

97. NASA JPL Open House

72. OSS Exhibit at National Council of Teachers of Mathematics (NCTM)

86. SIM Educational Lectures

78. Zooming in on Black Holes

Stratospheric Observatory for Infrared Astronomy (SOFIA)

33. Chabot Space and Science Center

37. National Air and Space Museum 
72. OSS Exhibit at National Council of Teachers of Mathematics (NCTM)

99. Quest Web Cast

74. SIRTF Educator Workshop

74. SOFIA Education Partners Program

99. SOFIA Open House at Raytheon, Waco, TX

74. SOFIA/Raytheon Aircraft Integration Systems Tour

74. SOFIA—Exploring the Infrared Universe From 41,000 Feet

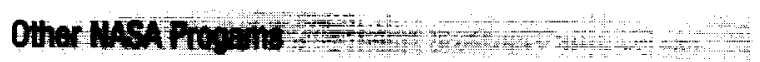

Keck Interferometer (Keck)

34. Club Space Place

73. Outer Planets/Solar Probe Project: Educator Workshops

73. Outer Planets/Solar Probe Project: From the Outer Planets to the Inner City

44. Outer Planets/Solar Probe Project: From the Sun to the Star Nations

99. Solar System Ambassadors

38. ViewSPACE-Broadband Exhibition Multimedia

\section{NASA Astrobiology Institute (NAI)}

79. Astrobiology Lecture Series

79. Astrobiology Option in WISE Week at Pennsylvania State University

105. Astrobiology Outreach

78. Astrobiology: The Search for Life on Other Worlds

93. Astromaterials/Astrobiology JSC Open House

66. Carnegie Academy for Science Education

66. Destination Moon and Mars

96. Interview for Future Watch

69. Life in the Solar System Educator Workshop

83. Mars Education and Public Outreach (E/PO)

71. NASA Astrobiology Institute Outreach and Education Project - The Carnegie Institution of Washington

36. NASA JSC Astrobiology Institute Education and Exhibits

71. NASA JSC Astrobiology Institute Educator Workshops

97. NASA JSC Astromaterials Media and Tours

85. NASA JSC Astromaterials Student Workshops

71. NASA JSC Astromaterials Teacher Interns

71. NASA JSC Astromaterials Teacher Workshops

72. OSS Exhibit at National Council of Teachers of Mathematics (NCTM)

73. Outer Planets/Solar Probe Project: Educator Workshops

73. Outer Planets/Solar Probe Project: From the Outer Planets to the Inner City

44. Outer Planets/Solar Probe Project: From the Sun to the Star Nations

99. Sample Curation Exhibit at Planetfest ' 99

99. Solar System Ambassadors

75. STELLAR/Astrobiology Program
76. Toward Other Planetary Systems (TOPS)

78. What Is Astrobiology?

\section{SOLAR SYSTEM EXPLORATION MISSIONS}

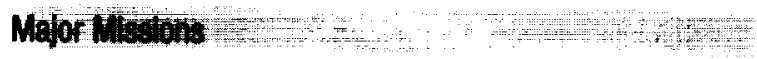

\section{Cassini/Huygens Probe}

80. Cassini Educator Fellow Speaker

66. Cassini Exhibit

80. Cassini Flight Team Speaker

93. Cassini Millennium Flyby

80. Cassini Mission to Saturn Classroom Presentations

46. Cassini Mission to Saturn Color Fact Sheet

94. Cassini Mission to Saturn Public Lectures

46. Cassini Mission to Saturn Spanish Fact Sheet

66. Cassini Mission to Saturn Teacher Presentations

46. Cassini/Huygens Mission to Saturn and Titan

47. Cassini/Huygens Spacecraft 1/37 Scale Model

106. Deep Space Network Exhibit at Astronomical Society of the Pacific (ASP)

95. Discovery Channel Store Star Party

83. Institute for the Academic Advancement of Youth

69. Join NASA for the Jupiter Flyby

69. Life in the Solar System Educator Workshop

83. Los Angeles County Science Fair

83. Mars Education and Public Outreach (E/PO)

98. OSS Exhibit at American Association of Retired Persons (AARP)

72. OSS Exhibit at California Science Teachers Association (CSTA)

72. OSS Exhibit at National Science Teachers Association (NSTA)

73. Outer Planets/Solar Probe Project: Educator Workshops

73. Outer Planets/Solar Probe Project: From the Outer Planets to the Inner City

44. Outer Planets/Solar Probe Project: From the Sun to the Star Nations

57. Passage to a Ringed World

98. PlanetFest ' 99

73. Radio Astronomy at Jupiter

99. Royal Astronomical Society of Canada General Assembly

58. Saturn Educator Guide

73. Saturn in Your Kitchen and Backyard

86. Scientists in the Classroom

99. Solar System Ambassadors

74. Solar System Educators Program (SSEP)

64. Ways of Seeing

Galileo

66. Aurora in the Solar System

93. Cassini Millennium Flyby 
106. Deep Space Network Exhibit at Astronomical Society of the Pacific (ASP)

49. Europa Geology Interactive Jigsaw Puzzle

50. Europa: Another Water World

67. Europa: Another Water World?

50. Europa-Jupiter's Icy Moon

67. Galileo Europa Mission Educator Fellows

51. Galileo Public Web Site

51. Galileo Spacecraft $1 / 45$ Scale Model

69. Join NASA for the Jupiter Flyby

69. Life in the Solar System Educator Workshop

83. Mars Education and Public Outreach (E/PO)

72. OSS Exhibit at California Science Teachers Association (CSTA)

72. OSS Exhibit at National Science Teachers Association (NSTA)

73. Outer Planets/Solar Probe Project: Educator Workshops

73. Outer Planets/Solar Probe Project: From the Outer Planets to the Inner City

44. Outer Planets/Solar Probe Project: From the Sun to the Star Nations

98. PlanetFest ' 99

86. Scientists in the Classroom

99. Solar System Ambassadors

74. Solar System Educators Program (SSEP)

38. Space Place Museum Partners

61. The Experts Speak Out: Europa: Another Water World?

77. Volcanoes in Our Solar System Workshop

78. Volcanoes in the Solar System Educator's Workshop

63. Volcanoes on Another World: Jupiter's Moon 10

78. Water in the Solar System Educator Workshop

\section{Voyager}

44. Minority University-Space Interdisciplinary Network (MU-SPIN) Workshop

97. NASA JPL Open House

72. OSS Exhibit at California Science Teachers Association (CSTA)

73. Outer Planets/Solar Probe Project: Educator Workshops

73. Outer Planets/Solar Probe Project: From the Outer Planets to the Inner City

44. Outer Planets/Solar Probe Project: From the Sun to the Star Nations

98. PlanetFest ' 99

86. Scientists in the Classroom

99. Solar System Ambassadors

92. Voyager/Ulysses High School Interview Program

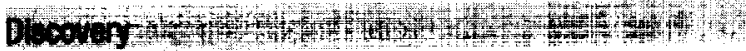

Discovery Program Support Office (DPSO)

93. Australian Science Festival
Comet Nucleus Tour (CONTOUR)

93. Arizona State University Geoscience Open House

93. Australian Science Festival

81. CONTOUR School Visits

94. CONTOUR Talk

96. Johns Hopkins University Applied Physics Laboratory Open House

84. Maryland Summer Center for Space Science for 6th and 7th Graders

97. NASA JPL Open House

98. NEAR/CONTOUR Exhibit

\section{Deep Impact}

93. Arizona State University Geoscience Open House

93. Australian Science Festival

82. Deep Impact Educational Lectures

94. Deep Impact Exhibits

48. Deep Impact Fact Sheet

105. Deep Impact Outreach at the Astronomical Society of the Pacific (ASP)

105. Deep Impact Poster at American Astronomical Society (AAS)

95. Deep Impact Team Speaking Engagements

82. Deep Impact-University of Maryland Programs

95. Discovery Channel Store Star Party

44. Minority University-Space Interdisciplinary Network (MU-SPIN) Workshop

97. NASA JPL Open House

107. Origins E/PO Exhibit at American Astronomical Society (AAS)

72. OSS Exhibit at National Science Teachers Association (NSTA)

73. Outer Planets/Solar Probe Project: Educator Workshops

73. Outer Planets/Solar Probe Project: From the Outer Planets to the Inner City

44. Outer Planets/Solar Probe Project: From the Sun to the Star Nations

99. Solar System Ambassadors

74. Solar System Educators Program (SSEP)

76. Toward Other Planetary Systems (TOPS)

\section{Genesis}

66. Aurora in the Solar System

93. Australian Science Festival

96. Genesis Family Night

67. Genesis Inservice Training

68. Genesis School Enrichment

68. Genesis Workshop

68. Genesis/California State University at Northridge (CSUN) Exhibit

44. Minority University-Space Interdisciplinary Network (MU-SPIN) Workshop

72. NASA's Genesis Project: A Mission of Mathematics 
72. OSS Exhibit at National Science Teachers Association (NSTA)

76. Sun-Earth Connection Content Workshops

76. Sunspots, UV, and Me: A Student-based Solar Research Project

76. Teaching the National Standards Content: The History and Nature of Science Using NASA.JPL Materials

\section{Lunar Prospector}

93. Australian Science Festival

66. Destination Moon and Mars

72. OSS Exhibit at National Science Teachers Association (NSTA)

99. Solar System Ambassadors

78. Water in the Solar System Educator Workshop

Mercury Surface, Space ENvironment, GEochemistry and Ranging (MESSENGER)

93. Australian Science Festival

96. Johns Hopkins University Applied Physics Laboratory Open House

84. MESSENGER School Visit

84. MESSENGER Talk

43. Minority University-Space Interdisciplinary Network (MU-SPIN) Break-Out Session

\section{Near Earth Asteroid Rendezvous (NEAR)}

93. Arizona State University Geoscience Open House

93. Australian Science Festival

81. Comcast/Discovery Networks Event

35. Griffith Observatory

96. Johns Hopkins University Applied Physics Laboratory Open House

36. Louisiana Nature Center Planetarium

84. Maryland Summer Center for Space Science for 6th and 7th Graders

97. NASA JPL Open House

72. NEAR \& NEARLink

32. NEAR Asteroid in the Atrium @ Maryland Science Center

106. NEAR Education and Public Outreach Program

72. NEAR Educator Workshops

97. NEAR Exhibit at Anne Arundel Community College

85. NEAR School Visits

97. NEAR Shoemaker Facility Tours

97. NEAR Shoemaker Public Team Appearances

37. NEAR Show @ Rainwater Planetarium

85. NEAR Student Press Conference

98. NEAR/CONTOUR Exhibit

72. OSS Exhibit at National Science Teachers Association (NSTA)

86. Space Explorers, Inc., NEARlink Program

104. University of Maryland Observatory Open House

\section{Stardust}

92. A Child's Universe

45. Aerogel Brochure

93. Arizona State University Geoscience Open House

93. Australian Science Festival

105. Deep Impact Outreach at the Astronomical Society of the Pacific (ASP)

106. Deep Space Network Exhibit at Astronomical Society of the Pacific (ASP)

68. JASON Foundation Summer Institute Workshop and Training

83. Mars Education and Public Outreach (E/P0)

97. NASA JPL Open House

72. OSS Exhibit at California Science Teachers Association (CSTA)

72. OSS Exhibit at National Science Teachers Association (NSTA)

73. Outer Planets/Solar Probe Project: Educator Workshops

73. Outer Planets/Solar Probe Project: From the Outer Planets to the Inner City

44. Outer Planets/Solar Probe Project: From the Sun to the Star Nations

98. PlanetFest ' 99

99. Solar System Ambassadors

74. Solar System Educators Program (SSEP)

91. Stardust Live Interactive Programs

59. Stardust Mission Brochure

60. Stardust Newsletter

63. Think SMALL in a BIG Way-Stardust Activity Guide

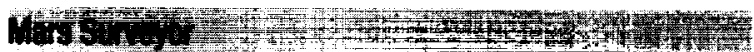

\section{Mars Theme Lead (Mars)}

92. A Child's Universe

93. Arizona State University Geoscience Open House

34. Club Space Place

106. Deep Space Network Exhibit at Astronomical Society of the Pacific (ASP)

66. Destination Moon and Mars

55. Mars

54. Is There Water on Mars? An Educators Guide with Activities for Physical, Earth, and Space Science

69. Life in the Solar System Educator Workshop

83. Mars Education and Public Outreach (E/PO)

55. Mars Navigator $C D$

72. OSS Exhibit at California Science Teachers Association (CSTA)

72. OSS Exhibit at National Science Teachers Association (NSTA)

73. Outer Planets/Solar Probe Project: Educator Workshops

73. Outer Planets/Solar Probe Project: From the Outer Planets to the Inner City 
44. Outer Planets/Solar Probe Project: From the Sun to the Star Nations

98. PlanetFest ' 99

99. Solar System Ambassadors

74. Solar System Educators Program (SSEP)

78. Volcanoes in the Solar System Educator's Workshop

78. Water in the Solar System Educator Workshop

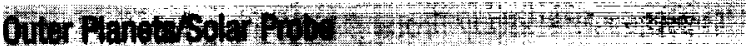

\section{Outer Planets/Solar Probe Project (OP/SP)}

73. Outer Planets/Solar Probe Project: Educator Workshops

73. Outer Planets/Solar Probe Project: From the Outer Planets to the Inner City

44. Outer Planets/Solar Probe Project: From the Sun to the Star Nations

99. Solar System Ambassadors

\section{Europa Orbiter}

67. Europa: Another Water World?

69. Life in the Solar System Educator Workshop

72. OSS Exhibit at California Science Teachers Association (CSTA)

73. Outer Planets/Solar Probe Project: Educator Workshops

73. Outer Planets/Solar Probe Project: From the Outer Planets to the Inner City

44. Outer Planets/Solar Probe Project: From the Sun to the Star Nations

74. Solar System Educators Program (SSEP)

\section{Pluto/Kuiper Express}

72. OSS Exhibit at California Science Teachers Association (CSTA)

73. Outer Planets/Solar Probe Project: Educator Workshops

73. Outer Planets/Solar Probe Project: From the Outer Planets to the Inner City

44. Outer Planets/Solar Probe Project: From the Sun to the Star Nations

99. Solar System Ambassadors

74. Solar System Educators Program (SSEP)

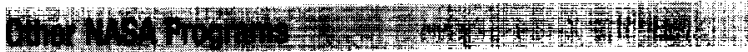

Deep Space 1 (New Millennium) (DS-1)

34. Club Space Place

97. NASA JPL Open House

73. Outer Planets/Solar Probe Project: Educator Workshops

73. Outer Planets/Solar Probe Project: From the Outer Planets to the Inner City
44. Outer Planets/Solar Probe Project: From the Sun to the Star Nations

98. PlanetFest' 99

99. Solar System Ambassadors

38. Space Place Museum Partners

107. Space Place Poster

\section{Deep Space Mission Support Office (DSMS)}

46. Bringing Images from Space to Earth

48. Deep Space Network Brochure

48. Deep Space Network Communications

106. Deep Space Network Exhibit at Astronomical Society of the Pacific (ASP)

95. Deep Space Network Team Public Appearances

49. Deep Space Network—Radio Astronomy

67. GAVRT Exhibit

52. Goldstone Apple Valley Radio Telescope (GAVRT) Pamphlet

82. Goldstone Apple Valley Radio Telescope (GAVRT) Project

69. Join NASA for the Jupiter Flyby

69. Jupiter Quest: Listening to Jupiter with a Real Radio Telescope

83. Mars Education and Public Outreach (E/PO)

97. NASA JPL Open House

72. OSS Exhibit at California Science Teachers Association (CSTA)

72. OSS Exhibit at National Science Teachers Association (NSTA)

73. Outer Planets/Solar Probe Project: Educator Workshops

73. Outer Planets/Solar Probe Project: From the Outer Planets to the Inner City

44. Outer Planets/Solar Probe Project: From the Sun to the Star Nations

98. PlanetFest ' 99

73. Radio Astronomy at Jupiter

73. Radio Astronomy from the Classroom

99. Solar System Ambassadors

74. Solar System Educators Program (SSEP)

Near Earth Asteroid Tracking (NEAT)

93. Arizona State University Geoscience Open House

\section{Sample Curation}

105. Astrobiology Outreach

105. Astromaterials Posters

93. Astromaterials/Astrobiology JSC Open House

49. Destination Mars

33. Destination Moon

66. Destination Moon and Mars

50. Exploring Meteorite Mysteries Teacher's Guide

50. Exploring the Moon Teacher's Guide 
67. Exploring the Solar System for Special Needs Students

71. Mathematics in the Solar System

85. NASA JSC Astromaterials Distribution

97. NASA JSC Astromaterials Media and Tours

85. NASA JSC Astromaterials Student Workshops

71. NASA JSC Astromaterials Teacher Interns

71. NASA JSC Astromaterials Teacher Workshops

72. OSS Exhibit at National Council of Teachers of Mathematics (NCTM)

72. OSS Exhibit at National Science Teachers Association (NSTA)

99. Sample Curation Exhibit at PlanetFest ' 99

\section{Mu Space Engineering Spacecraft-C Nanorover (MUSES-CN)}

93. Arizona State University Geoscience Open House

97. NASA JPL Open House

98. PlanetFest ' 99

\section{Rosetta}

93. Arizona State University Geoscience Open House

97. NASA JPL Open House

\section{STRUCTURE AND EVOLUTION OF THE UNIVERSE MISSIONS}

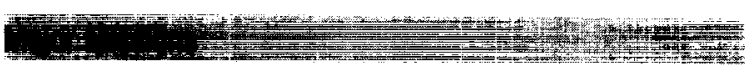

Chandra X-Ray Observatory (CXO)

32. Beyond the Edge of the Universe

47. Chandra 101: Overview for Teachers and Students

47. Chandra Coloring and Activity Book

105. Chandra Exhibit

81. Chandra Operations Control Center Tours

47. Chandra Photo Album

94. Chandra Team Public Appearances

70. Maine Math and Science Alliance

75. Space Science XV Teacher's Workshop

65. Superintendents Seminar 2000

61. The Chandra X-ray Observatory Center-Gateway to the Universe of $X$-ray Astronomy!

63. The $X$-ray Astronomy Field Guide

78. Workshop for Challenger Center Presenters

Compton Gamma-Ray Observatory (CGRO)

32. Beyond the Edge of the Universe

72. OSS Exhibit at National Science Teachers Association (NSTA)
Extreme Ultraviolet Explorer (EUVE)

49. Electromagnetic Radiation on Trial

50. EUVE Satellite Data Flow Demonstration

54. Light Tour

\section{Microwave Anisotropy Probe (MAP)}

45. A Teachers' Guide to the Universe

54. Introduction to Cosmology

55. MAP Fact Sheet

55. MAP Homepage

96. MAP Team Public Appearances

77. Universe Education Forum: Space Science Resources on Cosmic Structure and Evolution

Rossi X-ray Timing Explorer (RXTE)

32. Beyond the Edge of the Universe

Submillimeter Wave Astronomy Satellite (SWAS)

92. SWAS Student Learning Group

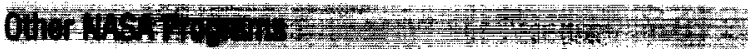

High Energy Astrophysics Science Archive Research Center (HEASARC)

45. AstroCappella

52. Gamma-ray Bursts Booklet

52. Gamma-ray Bursts Poster

52. Get the Picture

52. How Big is That Star?

53. Imagine the Universe! CD (version 4)

68. Imagine the Universe! Presentation

53. Imagine the Universe! Web Site

56. Multiwavelength Milky Way

59. StarChild

60. Stars and Slopes

60. Supernova Chemistry

61. The Anatomy of Black Holes

62. The Life Cycles of Stars Booklet

62. The Life Cycles of Stars Poster

63. Time That Period!

76. Tour the X-ray Sky with NASA

64. What's the Frequency, Roy G. Biv?

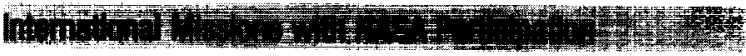

VBI Space Observatory Programme (VSOP)

34. Club Space Place

72. OSS Exhibit at California Science Teachers Association (CSTA) 
SUN-EARTH CONNECTION MISSIONS

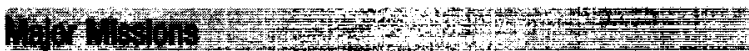

Solar Probe

66. Aurora in the Solar System

72. OSS Exhibit at California Science Teachers Association (CSTA)

73. Outer Planets/Solar Probe Project: Educator Workshops

73. Outer Planets/Solar Probe Project: From the Outer Planets to the Inner City

44. Outer Planets/Solar Probe Project: From the Sun to the Star Nations

99. Solar System Ambassadors

\section{Ulysses}

66. Aurora in the Solar System

44. Minority University-Space Interdisciplinary Network (MU-SPIN) Workshop

97. NASA JPL Open House

72. OSS Exhibit at California Science Teachers Association (CSTA)

73. Outer Planets/Solar Probe Project: Educator Workshops

73. Outer Planets/Solar Probe Project: From the Outer Planets to the Inner City

44. Outer Planets/Solar Probe Project: From the Sun to the Star Nations

99. Solar System Ambassadors

92. Voyager/Ulysses High School Interview Program

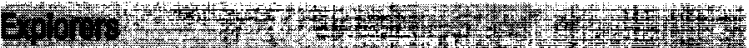

\section{Advanced Composition Explorer (ACE)}

45. ACE Brochure

93. ACE Exhibit

45. ACE Science Fact Sheet

93. Brain Thrust

81. Cooperative Satellite Learning Program Student Conference

48. Cosmic and Heliospheric Learning Center

44. Minority University-Space Interdisciplinary Network (MU-SPIN) Workshop

32. Space Weather Center Exhibit

\section{High Energy Solar Spectroscopic Imager (HESSI)}

93. CAL_DAY

95. Eclipse ' 99 and ' 01

83. HESSI at Solar Camp

44. Minority University-Space Interdisciplinary Network (MU-SPIN) Workshop
71. NASA Sun-Earth Connection Resources for Your Mathematics Classroom

86. Science in Outer Space--Freshman Seminar

32. Space Weather Center Exhibit

76. Sun-Earth Connection Content Workshops

60. Sunspots

107. Sunspots from Ancient Cultures to Modern Research

92. Sunspots-San Francisco Unified School District (SFUSD) STEP-UP Summer School

76. Sunspots: Introducing the Active Sun

Imager for Magnetopause-to-Aurora Global Exploration (IMAGE)

70. Maryland Science Center Teacher Thursday

44. Minority University-Space Interdisciplinary Network (MU-SPIN) Workshop

71. NASA Sun-Earth Connection Resources for Your Mathematics Classroom

57. Northern Lights and Solar Sprites!

58. Soda Bottle Magnetometer

58. Solar Storms and You! Exploring Sunspots and Solar Activity Cycles

58. Solar Storms and You! Exploring Magnetic Storms

58. Solar Storms and You! Exploring Satellite Design

58. Solar Storms and You! Exploring the Aurora and the Ionosphere

58. Solar Storms and You! Exploring the Human Impacts of Solar Activity

59. Solar Storms and You! Exploring the Wind From the Sun

32. Space Weather Center Exhibit

76. Sun-Earth Connection Content Workshops

77. VITS Presentations for Educational Purposes

Transition Region and Coronal Explorer (TRACE)

44. Minority University-Space Interdisciplinary Network (MU-SPIN) Workshop

76. Sun-Earth Connection Content Workshops

62. The Million Degree Solar Corona

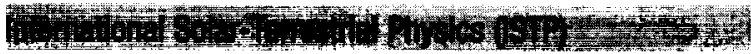

ISTP Program Office (ISTP)

44. Minority University-Space Interdisciplinary Network (MU-SPIN) Workshop

56. Mission to Geospace

32. Space Weather Center Exhibit

60. Storms from the Sun-Coronal Mass Ejections

76. Sun-Earth Connection Content Workshops

62. The Forecast? Look for Storms, Gale-Force Winds, and Plasma Blobs 
68. Genesis School Enrichment

68. Genesis Workshop

68. Genesis/California State University at Northridge (CSUN) Exhibit

52. Goldstone Apple Valley Radio Telescope (GAVRT) Pamphlet

82. Goldstone Apple Valley Radio Telescope (GAVRT) Project

83. Institute for the Academic Advancement of Youth

36. International Planetarium Society

54. Is There Water on Mars? An Educators Guide with Activities for Physical, Earth, and Space Science

68. JASON Foundation Summer Institute Workshop and Training

69. Join NASA for the Jupiter Flyby

69. Jupiter Quest: Listening to Jupiter with a Real Radio Telescope

69. Life in the Solar System Educator Workshop

70. Light, Waves, and Interference

83. Los Angeles County Science Fair

83. Mars Education and Public Outreach (E/PO)

70. Mars Exploration

106. Mars Global Surveyor Slides

55. Mars Navigator CD

97. NASA JPL Open House

72. NASA's Genesis Project: A Mission of Mathematics

37. National Air and Space Museum

73. Outer Planets/Solar Probe Project: Educator Workshops

73. Outer Planets/Solar Probe Project: From the Outer Planets to the Inner City

44. Outer Pianets/Solar Probe Project: From the Sun to the Star Nations

57. Passage to a Ringed World

98. PlanetFest ' 99

73. Radio Astronomy at Jupiter

73. Radio Astronomy from the Classroom

99. Royal Astronomical Society of Canada General Assembly

58. Saturn Educator Guide

73. Saturn in Your Kitchen and Backyard

86. SIM Educational Lectures

99. Solar System Ambassadors

74. Solar System Educators Program (SSEP)

38. Space Place Museum Partners

107. Space Place Poster

Q1 Stardust Live Interactive Proorams.
61. The Experts Speak Out: Europa: Another Water World?

63. Think SMALL in a BIG Way - Stardust Activity Guide

77. Volcanoes in Our Solar System Workshop

78. Volcanoes in the Solar System Educator's Workshop

63. Volcanoes on Another World: Jupiter's Moon lo

92. Voyager/Ulysses High School Interview Program

78. Water in the Solar System Educator Workshop

64. Ways of Seeing

78. Zooming in on Black Holes

University of California

93. CAL_DAY

95. Eclipse ' 99 and ' 01

49. Electromagnetic Radiation on Trial

50. EUVE Satellite Data Flow Demonstration

51. Eye on the Sky

83. HESSI at Solar Camp

54. Light Tour

71. NASA Sun-Earth Connection Resources for Your Mathematics Classroom

86. Science in Outer Space-Freshman Seminar

79. SEGway Resource Development with San Francisco Unified School District Teachers

91. STEREO/IMPACT at Solar Camp

60. Sunspots

107. Sunspots from Ancient Cultures to Modern Research

92. Sunspots-San Francisco Unified School District (SFUSD) STEP-UP Summer School

63. Third from the Sun

77. Using a Web-based "Sunspots" Resource-Results from a Student Summer Outreach Program

\section{Colorado}

\section{Space Science Institute}

106. Education and Outreach Activities in the Space Physics and Aeronomy, Planetary Sciences, and Atmospheric Sciences

69. Kinesthetic Astronomy Curriculum Development and Workshops

97. Mars Girl Scouts

31. MarsQuest Exhibition

70. MarsQuest Workshop

106. Misconceptions Scientists Often Have About the
84. Maryland Summer Center for Space Science for 6th and 7th Graders

72. NEAR \& NEARLink

32. NEAR Asteroids in the Atrium @ Maryland Science
58. Solar Storms and You! Exploring the Human Impacts of Solar Activity

59. Solar Storms and You! Exploring the Wind From the Sun 
University of Colorado

33. Exploring the Solar System at Fiske Planetarium

\section{District Of Columbia}

American Association for the Advancement of Science (AAAS)

\section{MESSENGER School Visit}

84. MESSENGER Talk

\section{NASA Headquarters}

44. National Conference of Black Physics Students

107. OSS Exhibit at American Association for the Advancement of Science (AAAS)

98. OSS Exhibit at American Association of Retired Persons (AARP)

37. OSS Exhibit at Association of Science-Technology Centers (ASTC)

72. OSS Exhibit at California Science Teachers Association (CSTA)

72. OSS Exhibit at National Council of Teachers of Mathematics (NCTM)

72. OSS Exhibit at National Science Teachers Association (NSTA)

44. OSS Outreach at National Society of Black Physicists (NSBP)

\section{Florida}

\section{Florida A\&M University}

39. Collision Processes in Astrophysical Plasmas

\section{Florida Space Grant Consortium}

48. Comets: A Multimedia Presentation for Schools

\section{Museum of Discovery and Science}

37. NASA Space Science Education Partnership

\section{Hawail}

\section{Bishop Museum}

33. Bishop Museum/Mauna Kea Education Center University of Hawaii

50. Exploring the Moon Teacher's Guide
University of Hawaii at Hilo

41. New Opportunities Through Minority Initiatives in Space Science

\section{IIIInois}

\section{Adler Planetarium and Astronomy Museum}

45. A Teachers' Guide to the Universe

33. Center for Space Science Education at the Adler Planetarium and Astronomy Museum

54. Introduction to Cosmology

55. MAP Fact Sheet

55. MAP Homepage

96. MAP Team Public Appearances

\section{DePaul University}

64. Chicago City-Wide Conferences

64. Chicago Teachers' Advisory

35. Great Lakes Planetarium Association (GLPA) Space Science Advisory Committee

65. Meetings with Chicago Public School Principals

36. NASA Space Science Education and Outreach Resources for Planetariums

65. NASA/llinois/Chicago Partnerships in Development

65. Near and Far Science for Illinois (NFSI)

37. OSS Booth at Great Lakes Planetarium Association (GLPA)

38. Planetarium Learning and Teaching Opportunities (PLATO)

65. Space Science Charrette

65. Space Science for Illinois Teachers (SSIT)

65. Teacher Consultants

\section{Kentucky}

Western Kentucky University

91. STARBASE Network

\section{Loulsiana}

\section{Southern University and A\&M College}

42. Partnerships in Astronomy and Astrophysics Education and Research at Southern University

\section{Maryland}

Johns Hopkins University Applied Physics Laboratory

81. Comcast/Discovery Networks Event

35. Griffith Observatory

36. Louisiana Nature Center Planetarium 
84. Maryland Summer Center for Space Science for 6 th and 7 th Graders

72. NEAR \& NEARLink

32. NEAR Asteroids in the Atrium @ Maryland Science Center

106. NEAR Education and Public Outreach Program

72. NEAR Educator Workshops

97. NEAR Exhibit at Anne Arundel Community College

85. NEAR School Visits

97. NEAR Shoemaker Facility Tours

97. NEAR Shoemaker Public Team Appearances

37. NEAR Show @ Rainwater Planetarium

85. NEAR Student Press Conference

98. NEAR/CONTOUR EXhibit

86. Space Explorers, Inc., NEARlink Program

38. STEREO Presentation at Maryland Science Center

104. University of Maryland Observatory Open House

\section{NASA Goddard Space Flight Center}

45. ACE Brochure

93. ACE Exhibit

45. ACE Science Fact Sheet

45. AstroCappella

93. Brain Thrust

81. Cooperative Satellite Learning Program Student Conference

48. Cosmic and Heliospheric Learning Center

49. Differential Rotation of the Sun

52. Gamma-ray Bursts Booklet

52. Gamma-ray Bursts Poster

52. Get the Picture

52. How Big is That Star?

53. Imagine the Universe! CD (version 4)

53. Imagine the Universe! Web Site

79. Improving 9th Grade Unified Science Curricula via the Inclusion of NASA Space Science Data

70. Maryland Science Center Teacher Thursday

43. Minority University-Space Interdisciplinary Network (MU-SPIN) Break-Out Session

44. Minority University-Space Interdisciplinary Network (MU-SPIN) Workshop

56. Mission to Geospace

56. Multiwavelength Milky Way

97. NASA Goddard Community Day

57. Northern Lights and Solar Sprites!

44. OSS Exhibit at National Council of La Raza

86. SCES Astronomy Club

86. Scientists in the Classroom

58. Soda Bottle Magnetometer

58. Solar Storms and You! Exploring Sunspots and Solar Activity Cycles

58. Solar Storms and You! Exploring Magnetic Storms

58. Solar Storms and You! Exploring Satellite Design

58. Solar Storms and You! Exploring the Aurora and the Ionosphere
58. Solar Storms and You! Exploring the Human Impacts of Solar Activity

59. Solar Storms and You! Exploring the Wind From the Sun

59. Stanford Solar Center

59. StarChild

60. Stars and Slopes

60. Storms from the Sun-Coronal Mass Ejections

76. Sun-Earth Connection Content Workshops

76. Sunspots: Introducing the Active Sun

60. Supernova Chemistry

61. The Anatomy of Black Holes

61. The Dynamic Sun CD

62. The Life Cycles of Stars Booklet

62. The Life Cycles of Stars Poster

63. Time That Period!

76. TIMED Onsite Educational Experience

104. Total Solar Eclipse Web Casts as Tools for Public Outreach

76. Tour the X-ray Sky with NASA

77. Universe Education Forum: Space Science Resources on Cosmic Structure and Evolution

77. VITS Presentations for Educational Purposes

64. What's the Frequency, Roy G. Biv?

\section{Space Telescope Science Institute}

66. Amazing Space Presentation

45. Amazing Space Web Site

46. Astronaut Challenge

66. Carnegie Academy for Science Education

47. Colliding Galaxies

47. Comets

81. CONTOUR School Visits

94. CONTOUR Talk

49. Eagle Nebula

51. From Galileo to Hubble: Why a Telescope in Space?

51. Galaxies Galore, Games, and More

51. Galaxy Centaurus A

52. Helix Nebula

79. HST Amazing Space

53. Hubble Deep Field Academy

53. Hubble Deep Field Poster

36. Hubble News Early Access Program

53. Hubble Space Telescope

36. Hubble Space Telescope 10th Anniversary Slide Set and Script

36. Hubble Space Telescope 10th Anniversary Video

31. Hubble Space Telescope National Visitor Center

31. Hubble Space Telescope: New Views of the Universe

53. Hubble's Galaxy Gallery

106. IDEAS Poster

68. Integrating Hubble Space Telescope and other NASA Resources in the Curriculum

96. Johns Hopkins University Applied Physics Laboratory Open House

54. Jovian Planets 
55. Mars

56. Nature's Kaleidoscope

56. No Escape: The Truth About Black Holes Poster

56. No Escape: The Truth About Black Holes Web Site

98. Open Night at the Space Telescope Science Institute

107. Origins E/PO Exhibit at American Astronomical Society (AAS)

98. Origins Public Outreach Exhibit

57. Orion Nebula

57. Pistol Star

99. Science Education Web Site Developers Conference

59. Solar System Trading Cards

91. Speakers Bureau @ STScl

59. Star Light, Star Bright

59. STARBIRTH in the Eagle Nebula

38. ViewSPACE-Broadband Exhibition Multimedia

\section{University of Maryland}

82. Deep Impact Educational Lectures

94. Deep Impact Exhibits

105. Deep Impact Outreach at the Astronomical Society of the Pacific (ASP)

105. Deep Impact Poster at American Astronomical Society (AAS)

95. Deep Impact Team Speaking Engagements

82. Deep Impact-University of Maryland Programs

76. Toward Other Planetary Systems (TOPS)

\section{Massachusetts}

\section{Harvard-Smithsonian Center for Astrophysics}

47. Chandra 101: Overview for Teachers and Students

47. Chandra Coloring and Activity Book

105. Chandra Exhibit

81. Chandra Operations Control Center Tours

47. Chandra Photo Album

94. Chandra Team Public Appearances

61. The Chandra X-ray Observatory Center-Gateway to the Universe of $X$-ray Astronomy!

63. The $X$-ray Astronomy Field Guide

\section{Smithsonian Astrophysical Observatory}

32. Beyond the Edge of the Universe

31. Cosmic Horizons: Our Place in Space and Time

48. Cosmic Survey: What Are Your Ideas About the Universe?

67. From the Ground Up!

68. Imagine the Universe! Presentation

70. Maine Math and Science Alliance

75. Space Science XV Teacher's Workshop

65. Superintendents Seminar 2000

92. SWAS Student Learning Group

78. Workshop for Challenger Center Presenters

\section{Michigan}

University of Michigan

104. Windows to the Universe Program

64. Windows to the Universe: Effects at Earth of Space Weather Events

\section{Montana}

Salish Kootenai College

39. Astronomy and Astrophysics Course Development at Salish Kootenai College

\section{New Jersey}

Geoff Haines-Stiles Productions, Inc.

54. Live from the Sun MultiMedia Kit

54. Live from the Sun, Program 1

55. Live from the Sun, Program 2: Solar Studies and Sunny Interactions

55. Live from the Sun, Program 3: To the Max

98. Passport to Knowledge

Montclair State University

68. It's All in Motion!: A Workshop for Teachers

\section{New Mexico}

Diné College

40. Internet-Based Education and Research with Robotic Telescopes for Native American and Hispanic Students

\section{Eastern New Mexico University}

41. New Mexico Connections: Connecting People, Places, and Research

\section{Southwestern Indian Polytechnic Institute}

42. Stars on Earth

\section{New York}

Cornell University

77. Using a NASA Mission to Focus Attention on Astronomy and Physics

Medgar Evers College

41. New York City Space Science Research Alliance 
York College

43. York College Observatory Educational Outreach Service to the College and the Public School Community

\section{North Carolina}

\section{Discovery Place}

35. Design a Space Science Mission with Nova Nautics

\section{Pennsylvanla}

Franklin Institute Science Museum

35. Franklin Institute

\section{South Carollna}

\section{South Carolina State University}

40. Enhancement of Space Science Research at South Carolina State University (SCSU)

\section{Tennessee}

Tennessee State Universtiy

43. Center for Automated Space Science (CASS)

Texas

\section{Lunar and Planetary Institute}

79. Books Are Rockets to Knowledge

94. Challenger Center Enrichment Conference

81. Clear Creek Independent School District (Texas) Alpha Program

105. Collaborations Between Scientists and Museums and Planetariums

96. Explore!

106. Helpful Hints on Working Effectively with Science Centers, Museums, and Planetariums

69. Liftoff Educator Workshop

75. Space Science and the Texas Essential Knowledge and Skills (TEKS)

78. What Do Scientists Do? A Short Workshop for Teachers

\section{NASA Johnson Space Center}

105. Astromaterials Posters

93. Astromaterials/Astrobiology JSC Open House

49. Destination Mars

33. Destination Moon

66. Destination Moon and Mars
50. Exploring Meteorite Mysteries Teacher's Guide

67. Exploring the Solar System for Special Needs Students

71. Mathematics in the Solar System

85. NASA JSC Astromaterials Distribution

97. NASA JSC Astromaterials Media and Tours

85. NASA JSC Astromaterials Student Workshops

71. NASA JSC Astromaterials Teacher Interns

71. NASA JSC Astromaterials Teacher Workshops

99. Sample Curation Exhibit at Planetfest '99

\section{University of Houston-Downtown}

39. An Urban Outreach Program in Space Science University of Texas

57. Rocks from Space: Meteorites in the Classroom

University of Texas at El Paso

40. Connecting Sun City with Sun-Earth Connections

\section{Virginia}

Challenger Center for Space Science Education

96. Engaging Challenger Center's Space Science Researchers in Highly Leveraged National Education and Public Outreach

32. Voyage-A Scale Model Solar System for the National Mall

\section{Hampton University}

39. A Space Science Curriculum at Hampton University: Development of a Minor, Faculty Enhancement, and K-14 Outreach

Norfolk State University

41. NASA-HBCU Partnership to Enhance Minority Education and Research Participation in the Space Sciences

\section{Wisconsin}

\section{University of Wisconsin}

104. Space Place Access for Community Education-A WWW Link

104. Universe in the Park 

